\title{
Environmental Impacts, Health and Safety Impacts, and Financial Costs of the Front End of the Nuclear Fuel Cycle
}

July 2013

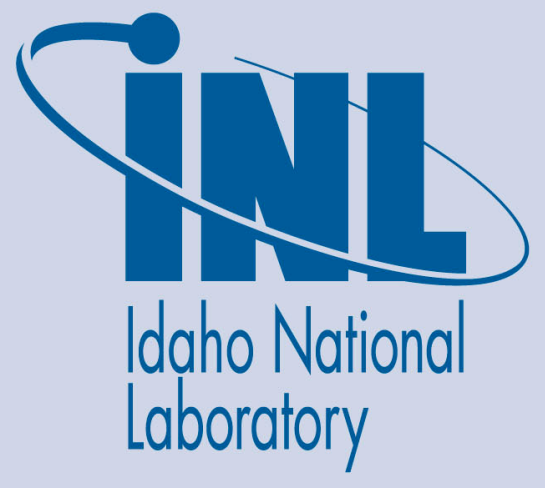

The INL is a U.S. Department of Energy National Laboratory operated by Battelle Energy Alliance 
INL/EXT-14-32302

FCRD-FCO-2012-000124

\section{Environmental Impacts, Health and Safety Impacts, and Financial Costs of the Front End of the Nuclear Fuel Cycle}

\section{Considerations Relevant to Fuel Cycle Technology Evaluation}

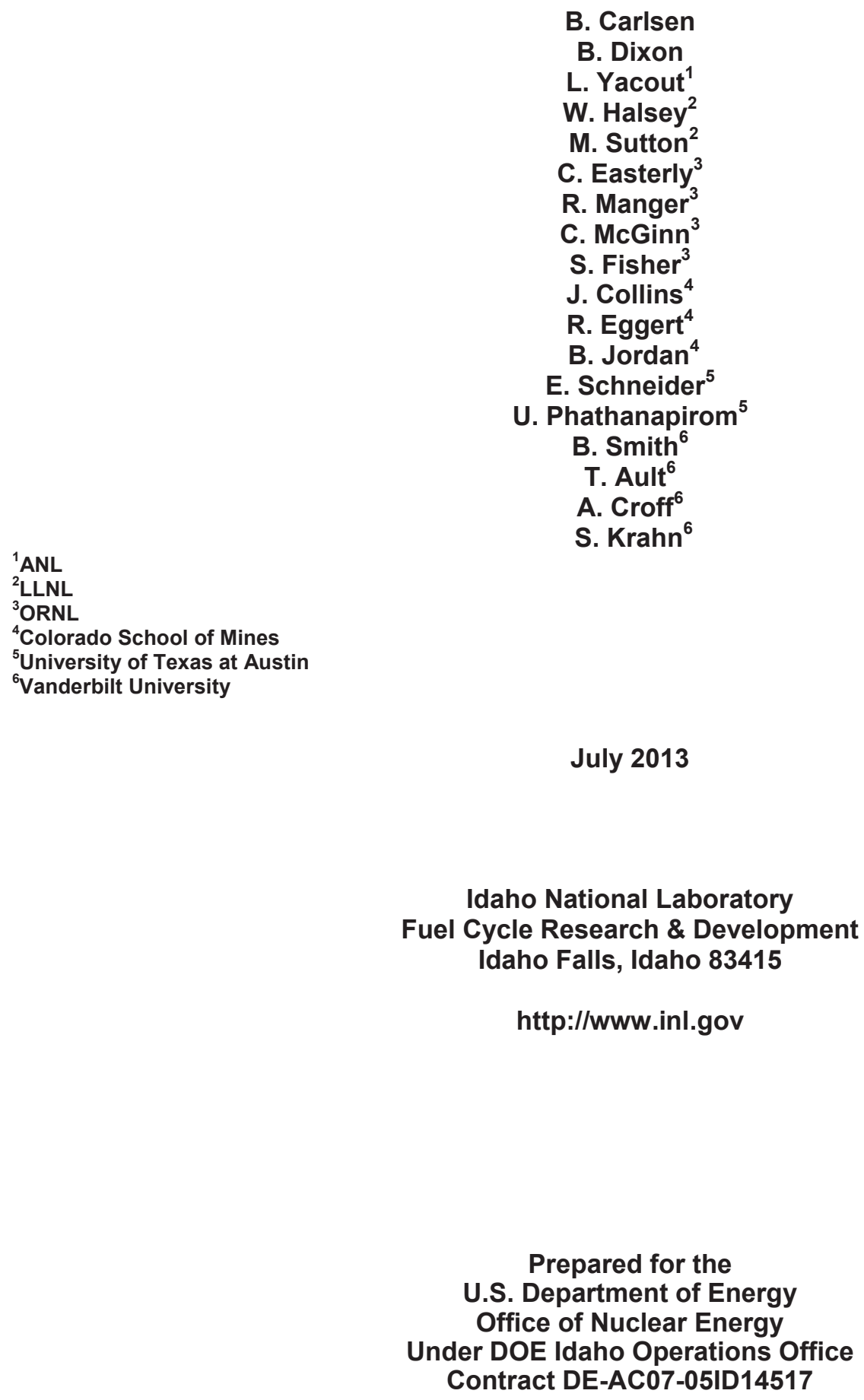





\section{ACKNOWLEDGEMENTS}

We would like to acknowledge the assistance of Brad Van Gosen of the US Geological Survey along with Dr. Sam Romberger and Dr. Linda Figueroa of the Colorado School of Mines, who were very useful providing information about uranium/thorium geology and mining.

DISCLAIMER

This information was prepared as an account of work sponsored by an agency of the U.S. Government. Neither the U.S. Government nor any agency thereof, nor any of their employees, makes any warranty, expressed or implied, or assumes any legal liability or responsibility for the accuracy, completeness, or usefulness, of any information, apparatus, product, or process disclosed, or represents that its use would not infringe privately owned rights. References herein to any specific commercial product, process, or service by trade name, trade mark, manufacturer, or otherwise, does not necessarily constitute or imply its endorsement, recommendation, or favoring by the U.S. Government or any agency thereof. The views and opinions of authors expressed herein do not necessarily state or reflect those of the U.S. Government or any agency thereof. 


\section{EXECUTIVE SUMMARY}

The Department of Energy Office of Nuclear Energy's Fuel Cycle Technologies (FCT) program is preparing to evaluate several proposed nuclear fuel cycle options to help guide and prioritize FCT research and development. Metrics are being developed to assess performance against nine evaluation criteria that will be used to assess relevant impacts resulting from all phases of the fuel cycle. This report addresses the impacts of the front-end of the nuclear fuel cycle (FEFC), including land, water, and energy use; $\mathrm{CO} 2$ emissions; occupational, public, and ecological health and safety; and financial cost impacts.

FEFC processes, unlike many of the proposed fuel cycles and technologies under consideration, involve mature operational processes presently in use at a number of facilities worldwide. This report identifies significant impacts resulting from these current FEFC processes and activities. Impacts considered to be significant are those that may be helpful in differentiating between fuel cycle performance and for which the FEFC impact is not negligible relative to those from the remainder of the full fuel cycle.

This report:

- Defines 'representative' processes that typify impacts associated with each step of the FEFC,

- Establishes a framework and architecture for rolling up impacts into normalized measures that can be scaled to quantify their contribution to the total impacts associated with various fuel cycles, and

- Develops and documents the bases for estimates of the impacts and costs associated with each of the representative FEFC processes.

FEFC processes addressed in this report include all activities from obtaining raw stock of $\mathrm{U}$ or Th and delivering it, in specified form, to the fuel fabrication facility. For uranium, these activities include mining, milling, refining to produce yellowcake $\left(\mathrm{U}_{3} \mathrm{O}_{8}\right)$, conversion of yellowcake to uranium hexafluoride $\left(\mathrm{UF}_{6}\right)$, enrichment to obtain the specified U-235 content for fuel fabrication, and deconversion of depleted $\mathrm{UF}_{6}\left(\mathrm{DUF}_{6}\right)$. For thorium-based fuels, these activities include recovering Th and purifying it to produce thorium oxalate for use in nuclear fuel.

Impacts for each FEFC process are normalized against one of three base units, tonnes of natural uranium or thorium used, tonnes of DU produced, or separative work units used. This normalization scheme enables scaling of FEFC impacts to model a broad range of proposed fuel cycles. Chapter 7 of the report includes a summary of the normalized impacts and an example of how these impacts are scaled for a specified fuel cycle.

This revision is a significant update to the report issued in September 2012. In addition to revising a number of assumptions and calculations, it adds $\mathrm{CO}_{2}$ emission estimates and significantly revises the assumptions and approach relevant to production of thorium. Specifically, it recognizes that by-products from ongoing mining of rare earth elements and titanium-bearing materials produce a thorium-bearing by-product stream sufficient to supply a broad range of future scenarios requiring thorium-based nuclear fuels. 
Environmental Impacts, Health and Safety Impacts, and Financial Costs of the Front-End of the Nuclear Fuel Cycle

July 2013

This Page Intentionally Left Blank 
Environmental Impacts, Health and Safety Impacts, and Financial Costs of the Front-End of the

Nuclear Fuel Cycle

\section{CONTENTS}

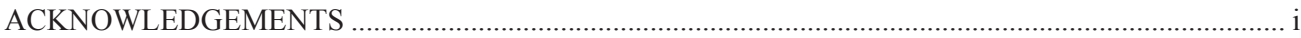

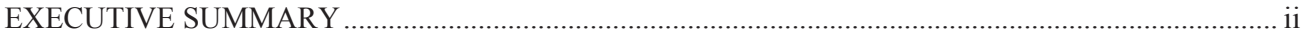

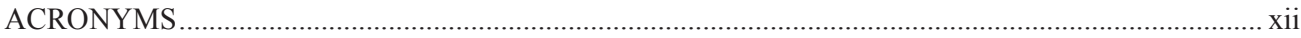

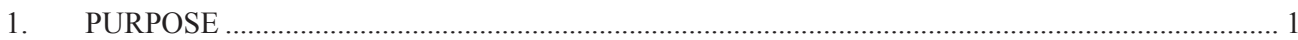

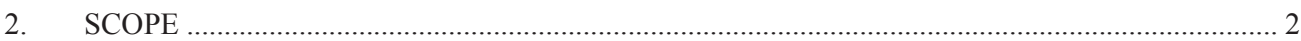

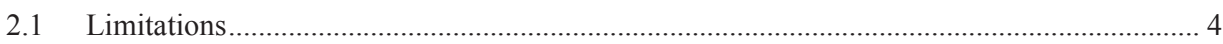

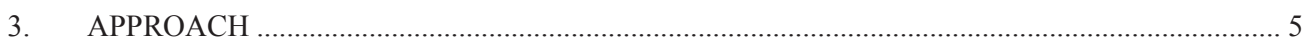

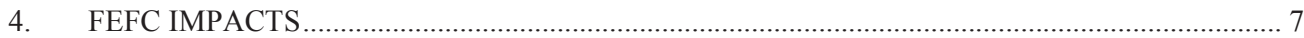

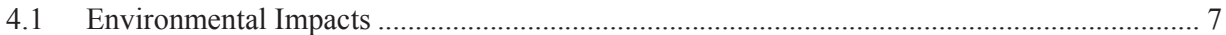

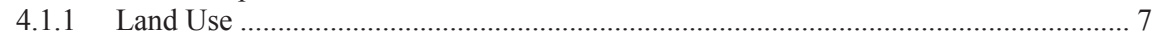

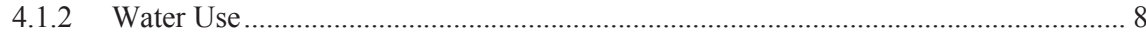

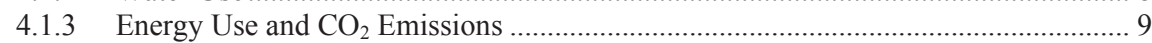

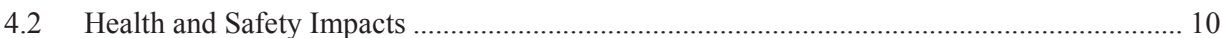

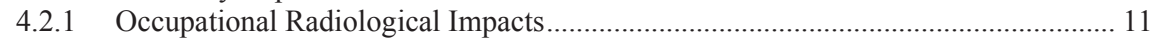

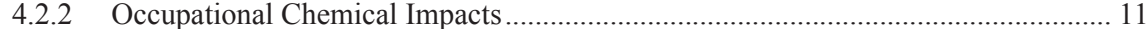

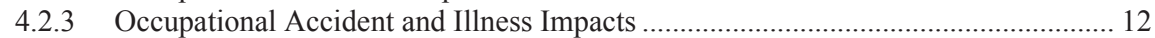

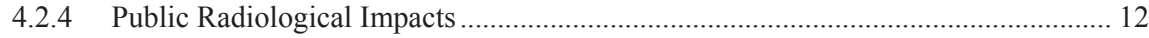

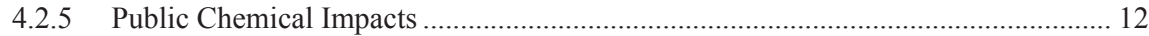

4.2.6 Ecological Radiological Impacts ..................................................................... 13

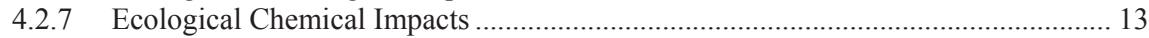

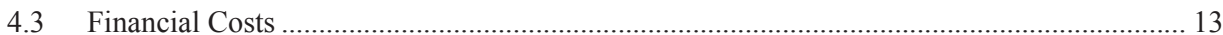

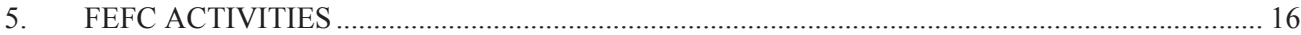

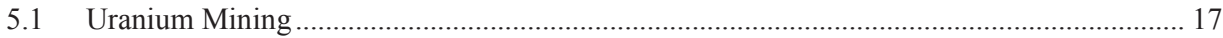

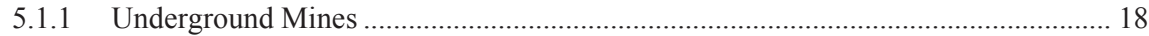

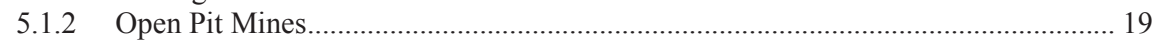

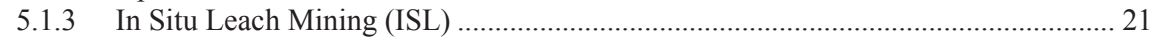

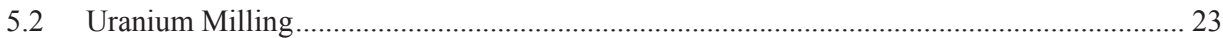

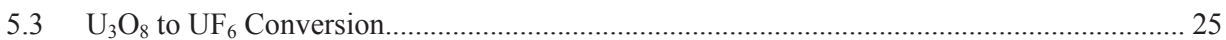

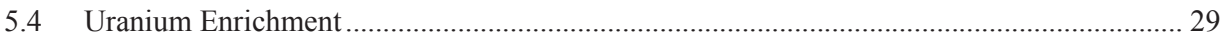

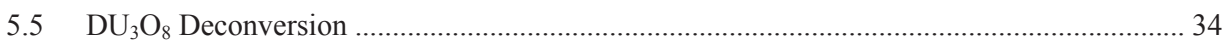

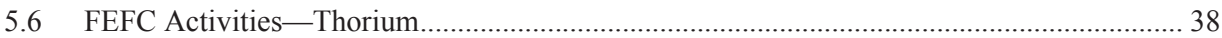

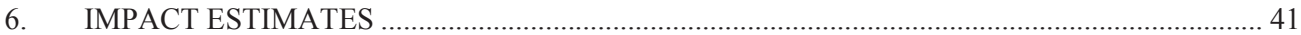

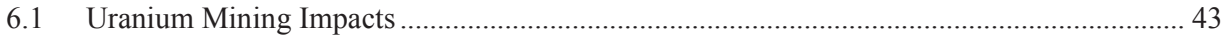

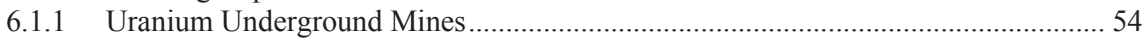

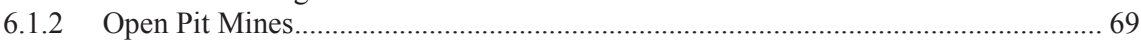

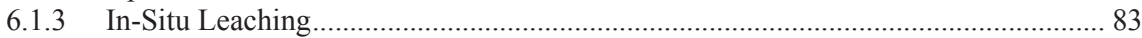


Environmental Impacts, Health and Safety Impacts, and Financial Costs of the Front-End of the Nuclear Fuel Cycle

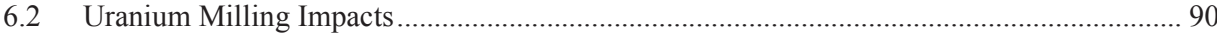

6.2.1 Environmental Impacts - Uranium Milling ........................................................ 90

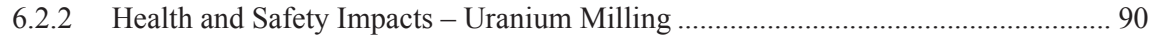

6.2.3 Financial Cost Impacts - Uranium Milling ................................................................. 93

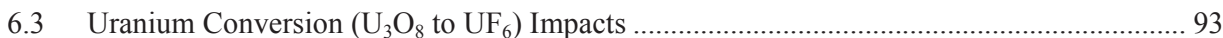

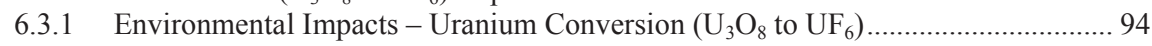

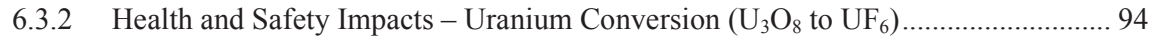

6.3.3 Financial Cost Impacts - Uranium Conversion ................................................... 101

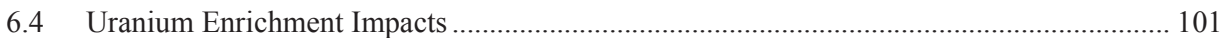

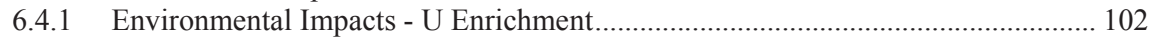

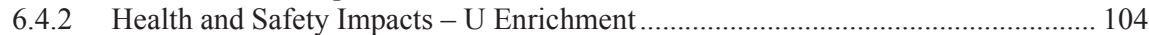

6.4.3 Financial Cost Impacts - U Enrichment................................................................ 108

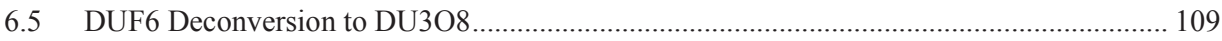

6.5.1 Environmental Impacts - Deconversion ................................................................. 110

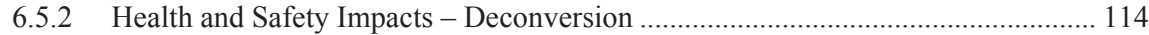

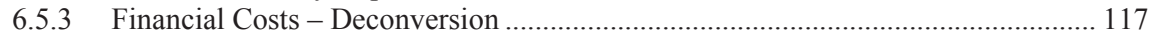

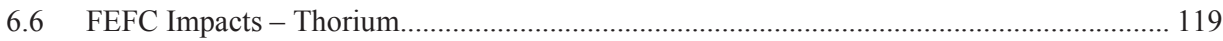

6.6.1 Environmental Impacts - Thorium Extraction and Refining................................... 119

6.6.2 Health and Safety Impacts - Thorium Extraction and Refining............................. 123

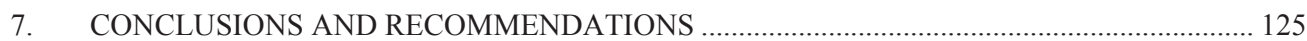

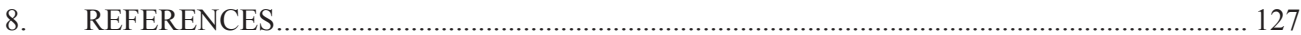

Appendix A Review of Previous Energy, Water, and Land Use Assessment Methodologies................ 139

Appendix B Data Tables and Sources for Energy and $\mathrm{CO}_{2}$ Calculations .......................................... 143

Appendix C Uranium Recovery from Seawater and from Phosphates................................................ 153

Appendix D Comparison of Mining Technology Estimates based on Three Data Sources.................... 158

Appendix E Comparison of Impacts from Wet vs Dry Conversion Process ............................................ 160

Appendix F Thorium Extraction and Refining from By-Products of REE and Ilmenite Mining ........... 163

Appendix G Review of Impacts from Laser Enrichment Technologies .............................................. 184

Appendix H Calculation of FEFC Process Inputs and Outputs ............................................................. 187

\section{FIGURES}

Figure 4-1. Water use in a typical industrial process.......................................................................... 8

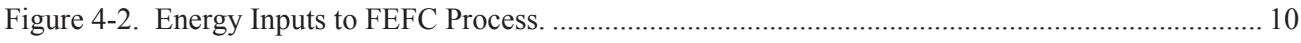

Figure 5-1. Inputs and outputs for open pit and underground mining. .................................................. 20

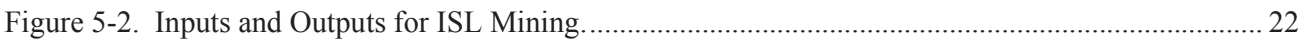

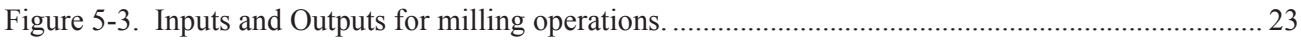


Figure 5-4. Acid and alkaline circuits used to extract dissolved uranium (Merritt, 1971)....................... 24

Figure 5-5. Inputs and Outputs to the Conversion Process. ....................................................................... 27

Figure 5-6. Transportation flows for enrichment facility (LES, 2005) ................................................. 30

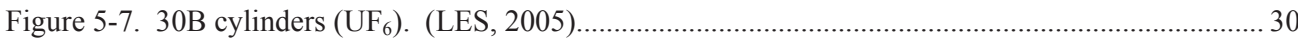

Figure 5-8. 48Y Cylinder (DUF 6 ) being loaded. (LES, 2005)....................................................... 31

Figure 5-9. Inputs and Outputs to the Centrifuge Enrichment Process...................................................... 32

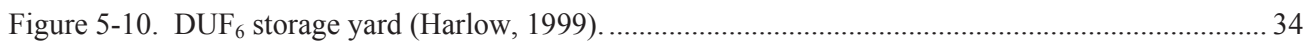

Figure 5-11. Type 48Y DUF 6 Storage Cylinder (Harlow, 1999) ........................................................... 35

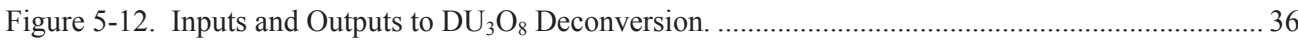

Figure 5-13. Inputs and Outputs to Thorium Extraction and Refining .................................................... 40

Figure B-1. Example table from [Chemical Industry 2000].Describes the energy consumed in the

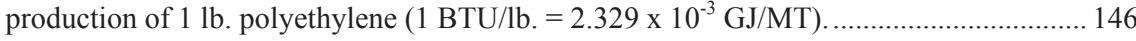

Figure B-2. Energy consumed in the production of an inorganic bulk chemical. ................................. 148

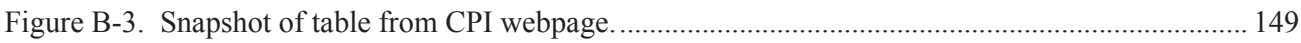

Figure B-4. Example snapshot [ICIS 2006] ................................................................................. 150

Figure B-5. Example ‘Advanced Search’ options for chemical price search........................................ 151

Figure B-6. Example search results from...................................................................................... 151

Figure B-7. Example chemical price listing from search results. ............................................................ 152

Figure C-1.Inputs and Outputs for uranium recovery from phosphates ............................................... 154

Figure C-2. Inputs and Outputs for Seawater Uranium Extraction....................................................... 156

Figure E-1. Impact ratios of dry conversion process to wet conversion process..................................... 162

Figure F-1. Overview of Thorium Recovery Process............................................................................. 169

Figure F-3. Sulfuric Acid Digestion Process for Extraction of Thorium................................................ 172

Figure F-4. Caustic (Alkali) Digestion Process for Extraction of Thorium.......................................... 173

Figure F-5. Refining Thorium to Nuclear Grade................................................................................ 177

Figure F-6. Flowsheet for Caustic Digestion and Extraction of Indian Monazite.................................. 180

Figure F-7. Flowsheet for Refining following Caustic Digestion and Extraction of Indian Monazite

\section{TABLES}

Table 3-1. FEFC Impact Categories and Relevant Section Numbers ....................................................... 6

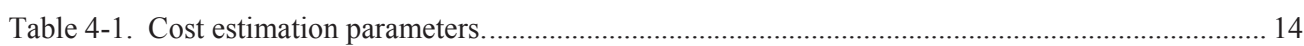

Table 5-1. Profile of uranium mining in 2011. (World Nuclear Association, May 2012) ....................... 17

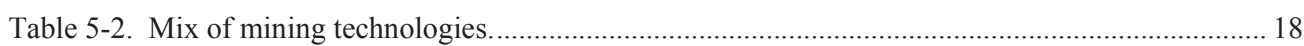


Environmental Impacts, Health and Safety Impacts, and Financial Costs of the Front-End of the Nuclear Fuel Cycle

July 2013

Table 5-3. Underground mining operations data (including milling)................................................. 20

Table 5-4. Open pit mining operations data (including milling).............................................................. 21

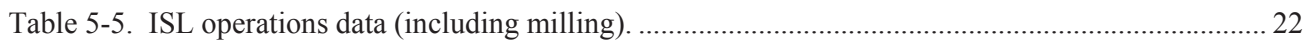

Table 5-6. Representative Process Data for $\mathrm{UF}_{6}$ conversion - wet process. ............................................. 28

Table 5-7. Material and energy balance, centrifuge enrichment ........................................................... 33

Table 5-8. Material and energy balance, $\mathrm{DU}_{3} \mathrm{O}_{8}$ deconversion ............................................................... 37

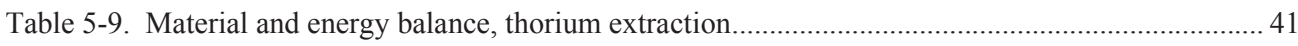

Table 6-1. Summary of Estimated Impacts for FEFC Processes ${ }^{1}$............................................................ 42

Table 6-2. Impacts of Representative Uranium Mining Process............................................................... 44

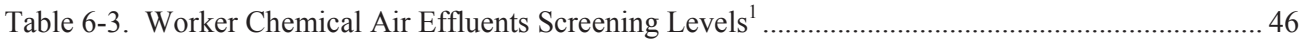

Table 6-4. Public Chemical Air Effluents Screening Levels ${ }^{1}$................................................................ 47

Table 6-5. Public Chemical Liquid Effluents Screening Levels ${ }^{1}$.......................................................... 48

Table 6-6. Ecological Chemical Liquid Effluents Screening Levels ${ }^{1}$...................................................... 49

Table 6-7. Unit mining and milling cost estimate from the 2012 AFC CBR update.............................. 50

Table 6-8. Data for the Colorado Plateau (UG) mine and White Mesa mill. .......................................... 51

Table 6-9. Data for the Trekkopje (OP) operation. ................................................................................. 52

Table 6-10. Data for the Lost Creek (ISL) operation. ........................................................................... 52

Table 6-11. Summary of Financial Cost Inputs and Calculation Outcomes............................................... 53

Table 6-12. Impacts of Underground Uranium Mining Process.............................................................. 54

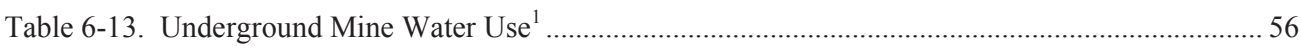

Table 6-14. Energy Consumption and $\mathrm{CO}_{2}$ Emissions for Underground Mining ................................... 57

Table 6-15. UG Mines Information Center for H\&S Metrics. .......................................................................... 58

Table 6-16. Occupational Radiological Impacts for Underground Uranium Mines ................................ 59

Table 6-17. Average Air Emissions and Resultant Above-ground Air Concentrations for a UG Mine.

Table 6-18. Chemical Impacts to Above-Ground Workers from Airborne Effluents at a UG Mine......

Table 6-19. Occupational DPM Exposures and Impacts for Underground Mine..................................... 62

Table 6-20. Occupational Chronic Silica Exposure Impact Data from an Underground Mine................. 63

Table 6-21. Occupational Acute Noise Exposures and Impacts from 2 US Underground Mines ............. 63

Table 6-22. Occupational Chronic Noise Exposures and Impacts from 2 US Underground Mines.......... 63

Table 6-23. Occupational Relative Chemical Impact of UG Mining. ...................................................... 64

Table 6-24. Occupational Accidents and Illnesses Impacts for Underground Mines in Utah .................. 64

Table 6-25. Public Radiological Impact Data from an EPA model Underground Uranium Mine............ 65

Table 6-26. Public Chemical Impact to Critical Receptor from Liquid Effluents from a UG Mine. ........ 65 
Table 6-27. Airborne Emissions and Resultant Fence line Air Concentrations for a UG Mine.....

Table 6-28. Public Chemical Impact to Critical Receptor from Airborne Effluents - UG Mine. ............. 68

Table 6-29. Public Total Chemical Impact from Representative UG Mine. ............................................. 68

Table 6-30. Ecological Radiological Impacts from Liquid Effluents of Underground Mines.................. 69

Table 6-31. Ecological Chemical Impacts from Liquid Effluents of Underground Mines....................... 69

Table 6-32. Summary of Impacts Open Pit Uranium Mining............................................................... 70

Table 6-33. Open Pit Mine Total Land Use - Includes Mining and Milling............................................ 71

Table 6-34. Gross Water Consumption for Open Pit Uranium Mining..................................................... 72

Table 6-35. Energy Use Estimate for open pit mining. ............................................................................. 73

Table 6-36. OP Mines Information Center for Building H\&S Metrics .................................................... 75

Table 6-37. Occupational Radiological Impacts for Open Pit Uranium Mines........................................... 76

Table 6-38. Average Emissions and Resultant Air Chemical Concentrations for an OP Mine................. 77

Table 6-39. Occupational Chemical Impact from Airborne Effluents from an Open Pit Mine................ 78

Table 6-40. Occupational Accident and Injuries Impacts for Open Pit Mining ${ }^{1}$...................................... 78

Table 6-41. Public Radiological Impact Data from an Underground Uranium Mine............................... 79

Table 6-42. Public Chemical Impact from Liquid Effluents from a Representative Open Pit Mine $^{1}$

Table 6-43. Downwind Air Concentrations for an Open Pit Mine. ............................................................ 81

Table 6-44. Public Chemical Impact from Airborne Effluents from an Open Pit Mine ${ }^{1}$......................... 82

Table 6-45. Ecological Radiological Impacts from Liquid Effluents of an Open Pit Mine...................... 83

Table 6-46. Ecological Chemical Impacts from Liquid Effluents of an Open Pit Mine ${ }^{1}$.......................... 83

Table 6-47. Summary of Impacts from ISL Uranium Mining. ................................................................ 84

Table 6-48. Land Use for ISL mine/mill operations data (ERA 2008, South Australia 1998)................ 85

Table 6-49. Beverly ISL Mine/Mill Site Operational Water Use Data (Mudd 2007) ............................. 86

Table 6-50. Energy Consumption and $\mathrm{CO}_{2}$ Emissions for ISL Mining and Milling............................... 87

Table 6-51. Occupational Radiological Impact data from ISL facilities. ................................................ 88

Table 6-52. Occupational Accident and Illness Impacts for ISL Mining ............................................... 89

Table 6-53. Public Radiological Dose Data from ISL Facilities............................................................. 89

Table 6-54. Summary of Impacts from milling uranium........................................................................... 90

Table 6-55. Annual MTNU Processed by Cotter Corp and Mesa Mills ................................................... 91

Table 6-56. Occupational Radiological Impact data from mills processing uranium ore.......................... 91

Table 6-57. Occupational Accident and Illness Impacts for Milling Facilities. ....................................... 92

Table 6-58. Radiological Dose and Impacts to Populations Surrounding Uranium Mills ........................ 92

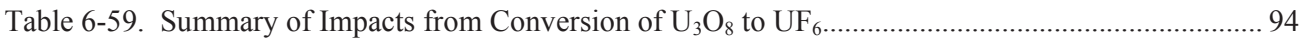


Environmental Impacts, Health and Safety Impacts, and Financial Costs of the Front-End of the Nuclear Fuel Cycle

July 2013

Table 6-60. Energy Inputs to the Conversion Process........................................................................... 95

Table 6-61. Energy Conversion Factors (see Appendix B) ................................................................... 96

Table 6-62. Energy Consumption and CO2 Emissions for U Conversion ............................................... 97

Table 6-63. Occupational Radiological Impact data from wet process conversion facilities. .................. 98

Table 6-64. Occupational Chemical impacts from wet process uranium conversion facilities. ............... 99

Table 6-65. Occupational Accident and Injuries Impact data from wet process uranium

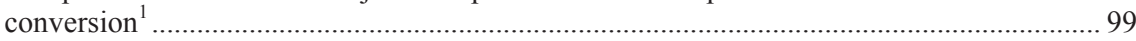

Table 6-66. Public Radiological dose data from wet process conversion facilities. ................................ 99

Table 6-67. Air emission data from wet process conversion facilities. .................................................. 100

Table 6-68. Water effluent data from wet process conversion facilities................................................. 100

Table 6-69. Public Chemical Impact for wet process uranium conversion facilities. ............................. 100

Table 6-70. Ecological Radiological Health Impacts for wet process conversion facilities ................... 100

Table 6-71. Water effluent data from wet process conversion facilities................................................... 101

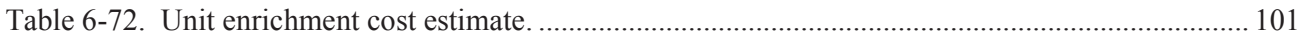

Table 6-73. Summary of Impacts from Uranium Enrichment ............................................................... 102

Table 6-74. Main product and energy and material inputs to enrichment operations ............................. 103

Table 6-75. Conversion Factors for Energy Inputs to Centrifuge Enrichment (see Appendix B) ........... 103

Table 6-76. Energy Consumption and $\mathrm{CO}_{2}$ Emissions for Centrifuge Enrichment ................................ 104

Table 6-77. Occupational Radiological Dose Estimate for Centrifuge Enrichment............................... 105

Table 6-78. Occupational Chemical Impacts for Centrifuge Enrichment................................................. 106

Table 6-79. Occupational Accident and Illness Impacts for centrifuge enrichment .............................. 106

Table 6-80. Dose to Populations within 80 km Centrifuge Enrichment Plants ...................................... 107

Table 6-81. Public Chemical impact from centrifuge enrichment facilities ${ }^{1}$......................................... 107

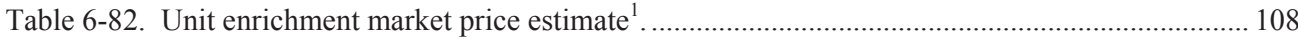

Table 6-83. Costs associated with URENCO USA facility. .................................................................. 108

Table 6-84. Summary of Financial Cost Inputs and Calculation Outcomes........................................... 109

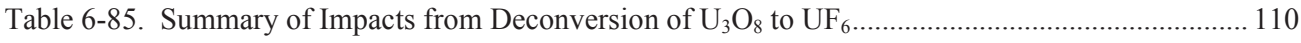

Table 6-87. Energy Conversion Factors for Deconversion Process (see Appendix B).......................... 112

Table 6-88. Energy Consumption and $\mathrm{CO}_{2}$ Emissions for Deconversion Process.................................. 113

Table 6-89. Occupational Radiological Dose Impacts from Deconversion.............................................. 114

Table 6-90. Occupational Chemical Impact data from Deconversion....................................................... 115

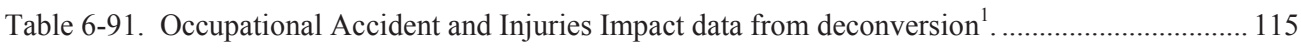

Table 6-92. Public Radiological dose impacts from deconversion........................................................... 116

Table 6-93. Public Chemical Fluoride exposure data from deconversion facilities............................... 117 
Table 6-94. Unit deconversion price estimate ${ }^{1}$.

Table 6-95. Costs associated with Portsmouth deconversion facility.....

Table 6-96. Summary of Financial Cost Inputs and Calculation Outcomes

Table 6-97. Summary of Impacts from Thorium Extraction and Refining

Table 6-98. Main product and Energy and Material Inputs to Thorium Extraction and Refining.....

Table 6-99. Conversion Factors for Energy Inputs to Thorium Extraction and Refining (see Appendix B)

Table 6-100. Energy Consumption and $\mathrm{CO}_{2}$ Emissions for Thorium Extraction and Refining

Table 6-101. Radiological Dose Impacts to Populations Surrounding Lemhi Pass Thorium Mine and Mill

Table 7-1. Example of Applying FEFC Metrics to a Reference LWR Fuel Cycle ${ }^{1,2}$........................... 126

Table B-1. Energy density and conversion factors for final energy carriers ......................................... 143

Table B-2. Energy Densities and Breakdown by Energy Carriers for FEFC Process Chemicals............ 144

Table B-3. Carbon intensity conversion factors for final energy carriers............................................. 145

Table B-4. Assumptions used for mapping energy carriers to those specified in previous table. ........... 145

Table B-5. One entry (row) in an energy embodied in materials table................................................. 145

Table B-6. Example table for polyethylene, containing energy intensities given in Figure B-1............ 147

Table B-7. Partial list of commodity and sector energy intensities reported in [EIA 2011] ................... 148

Table B-8. Sector-average energy intensities for inorganic and organic chemicals obtained from Table B-5 of [AEO 2011]

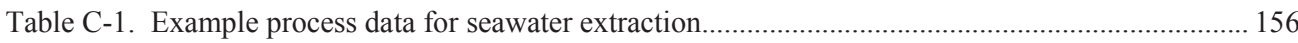

Table C-2. Seawater uranium extraction operations data*.................................................................. 157

Table D-1. Profile of current uranium resources. (Eggert, 2011) ......................................................... 158

Table D-2. Percentage distribution of world production, by production method. (2011 Red Book, OECD, 2012)

Table E-1. Material and Energy Balance, Dry Process UF $_{6}$ Conversion................................................ 161

Table E-2. Comparison of Dry Conversion and Wet Conversion Process Environmental Impacts........ 162

Table F-1. Potential Global Thorium Byproduct Production by Country ${ }^{1}$............................................ 163

Table F-2. Thorium as a Rare-earth By-product by Country ................................................................. 164

Table F-4. Potential U.S. Thorium Production as a Byproduct of Rare-Earth and Titanium-Sand

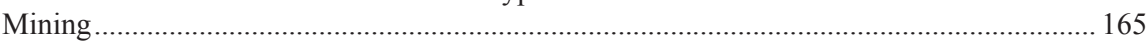

Table F-5. Potential Thorium as By-product from Bokan Mountain, Alaska ........................................ 166

Table F-7. Potential Thorium as By-product from Mountain Pass (California) ...................................... 167

Table F-9. Chemical Requirements for Indian Monazite Refining Process ............................................ 179

Table F-10. Products Generated by Indian Monazite Refining Process ................................................... 181 
Environmental Impacts, Health and Safety Impacts, and Financial Costs of the Front-End of the Nuclear Fuel Cycle

July 2013

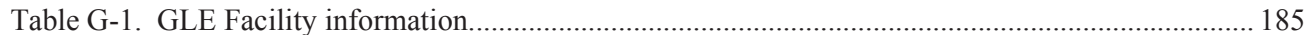

Table G-2. Environmental Impacts associated with GLE SILEX Enrichment Facility......................... 185

Table G-3. Transformation of Raw Data to Table G-2 Entries.............................................................. 186

Table H-1 Transformation of Raw Data ${ }^{1}$ into Energy Inputs in Tables 6-14 and 6-35.......................... 189

Table H-2. Transformation of Raw Data to Table 5-6 Entries ${ }^{1}$ (wet process UF6 Conversion).............. 190

Table H-3. Transformation of Raw Data to Table E-1 Entries ${ }^{1}$ (Dry process UF6 Conversion)............ 191

Table H-5. Transformation of Raw Data to Table 5-8 ${ }^{1}$ (Deconversion).................................................... 193

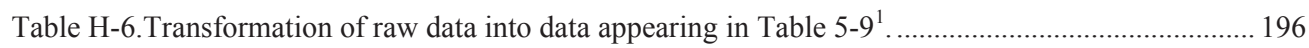


Environmental Impacts, Health and Safety Impacts, and Financial Costs of the Front-End of the

Nuclear Fuel Cycle

\section{ACRONYMS}

ACGIH American Conference of Governmental Industrial Hygienists

ADAMS Agency-wide Documents Access and Management System

AF Amortization factor

AFC CB Advanced Fuel Cycle Cost Basis

ALARA As Low As Reasonably Achievable

BLS United States Bureau of Labor Statistics

$\mathrm{Bq} \quad$ Becquerel (1 disintegration per second, $2.7 \times 10^{-11}$ Curies)

BTU British thermal unit

CDC United States Centers for Disease Control and Prevention

CFR Code of Federal Regulations

$\mathrm{Ci} \quad$ Curies $\left(3.7 \times 10^{10} \mathrm{~Bq}\right)$

CPI Consumer Price Index

CSM Colorado School of Mines

DAC Derived air concentration

dBA Decibels (A-weighted scale)

D\&D Decontamination and decommissioning

DOE-NE United States Department of Energy Office of Nuclear Energy

DPM Diesel particulate matter

DU Depleted uranium

DUF $_{6} \quad$ Depleted uranium hexafluoride

EC Elemental carbon

EDE Effective dose equivalent

EIA United States Energy Information Administration

EIS Environmental Impact Statement

EMWG Economic Modeling Working Group

EPA United States Environmental Protection Agency

EU Enriched uranium

FCRD Fuel Cycle Research and Development

FEFC Front-End of the Nuclear Fuel Cycle

GDP Gaseous diffusion plant

GDP Gross domestic product

GJ Giga Joules $\left(10^{9}\right.$ Joules $)$ 


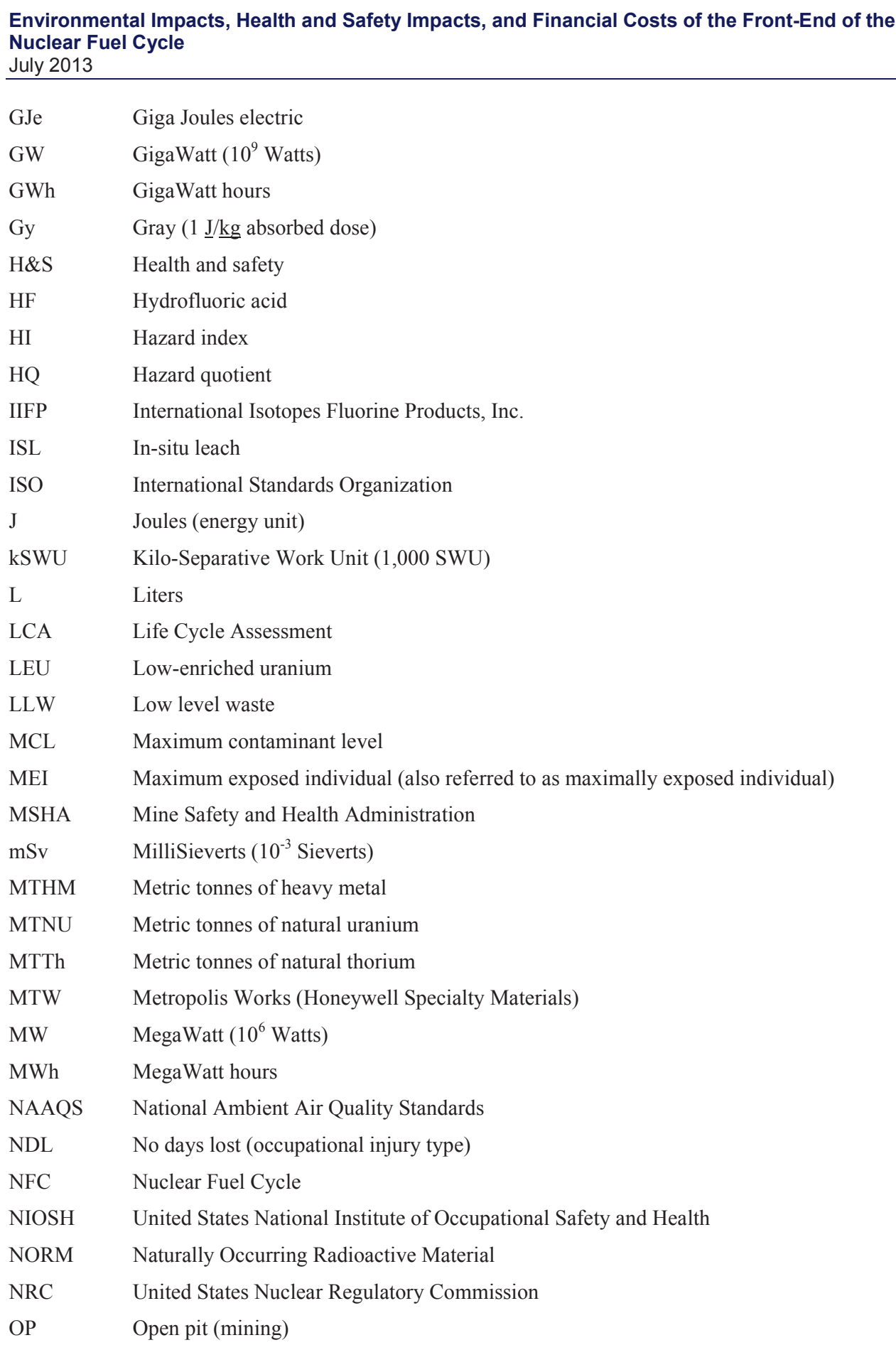

GJe Giga Joules electric

GW GigaWatt $\left(10^{9}\right.$ Watts $)$

GWh GigaWatt hours

Gy $\quad$ Gray $(1 \underline{\mathrm{J}} / \underline{\mathrm{kg}}$ absorbed dose $)$

H\&S Health and safety

HF Hydrofluoric acid

HI Hazard index

HQ Hazard quotient

IIFP International Isotopes Fluorine Products, Inc.

ISL In-situ leach

ISO International Standards Organization

J Joules (energy unit)

kSWU Kilo-Separative Work Unit (1,000 SWU)

L Liters

LCA Life Cycle Assessment

LEU Low-enriched uranium

LLW Low level waste

MCL Maximum contaminant level

MEI Maximum exposed individual (also referred to as maximally exposed individual)

MSHA Mine Safety and Health Administration

$\mathrm{mSv} \quad$ MilliSieverts $\left(10^{-3}\right.$ Sieverts $)$

MTHM Metric tonnes of heavy metal

MTNU Metric tonnes of natural uranium

MTTh Metric tonnes of natural thorium

MTW Metropolis Works (Honeywell Specialty Materials)

MW MegaWatt $\left(10^{6}\right.$ Watts $)$

MWh MegaWatt hours

NAAQS National Ambient Air Quality Standards

NDL No days lost (occupational injury type)

NFC Nuclear Fuel Cycle

NIOSH United States National Institute of Occupational Safety and Health

NORM Naturally Occurring Radioactive Material

NRC United States Nuclear Regulatory Commission

OP Open pit (mining) 
Environmental Impacts, Health and Safety Impacts, and Financial Costs of the Front-End of the

\begin{tabular}{|c|c|}
\hline OSHA & Occupational Safety and Health Administration \\
\hline $\mathrm{pCi}$ & PicoCuries $\left(10^{-12}\right.$ Curies $)$ \\
\hline PEL & Permissible exposure level \\
\hline PM & Particulate matter \\
\hline PRG & Preliminary Remediation Goals \\
\hline $\mathrm{R}$ & Roentgen \\
\hline Ra-226 & Radium-226 (also presented as $226 \mathrm{Ra},{ }^{226} \mathrm{Ra}$ ) \\
\hline rad & Radiation absorbed dose $(0.01 \mathrm{~Gy}, 0.01 \mathrm{~J} / \mathrm{kg})$ \\
\hline RAIS & Risk Assessment Information System \\
\hline rem & Roentgen equivalent man $\left(10^{-2}\right.$ Sieverts $)$ \\
\hline $\mathrm{RfC}$ & Reference concentration \\
\hline $\mathrm{Rn}-220$ & Radon-220 (also presented as $220 \mathrm{Rn},{ }^{220} \mathrm{Rn}$ ) \\
\hline Rn-222 & Radon-222 (also presented as $222 \mathrm{Rn},{ }^{222} \mathrm{Rn}$ ) \\
\hline $\operatorname{scf}$ & Standard cubic feet (quantity) of natural gas (approximately 1028 BTU) \\
\hline $\mathrm{Sv}$ & Sieverts (100 rem, $1 \underline{\mathrm{J}} / \underline{\mathrm{kg}}$ absorbed dose in tissue) \\
\hline SWU & Separative Work Unit \\
\hline TBP & Tributyl phosphate \\
\hline $\mathrm{TC}$ & Total carbon \\
\hline TEDE & Total Effective Dose Equivalents \\
\hline TENORM & Technologically Enhanced Naturally Occurring Radioactive Material \\
\hline TLV & Threshold Limit Value \\
\hline TWA & Time weighted average \\
\hline $\mathrm{U}-234$ & Uranium-234 (also presented as $234 \mathrm{U},{ }^{234} \mathrm{U}$ ) \\
\hline $\mathrm{U}-235$ & Uranium-235 (also presented as $235 \mathrm{U},{ }^{235} \mathrm{U}$ ) \\
\hline $\mathrm{U}-238$ & Uranium-238 (also presented as $238 \mathrm{U},{ }^{238} \mathrm{U}$ ) \\
\hline $\mathrm{U}_{3} \mathrm{O}_{8}$ & Triuraniumoctoxide ("yellowcake") \\
\hline $\mathrm{UC}$ & Unit cost \\
\hline $\mathrm{UF}_{6}$ & Uranium hexafluoride \\
\hline UNSCEAR & United Nations Scientific Commission on Effects of Atomic Radiation \\
\hline $\mathrm{UO}_{2}$ & Uranium dioxide \\
\hline USEC & United States Enrichment Corporation \\
\hline Th-232 & Thorium-232 (also presented as $232 \mathrm{Th},{ }^{232} \mathrm{Th}$ ) \\
\hline WL & Working levels \\
\hline $\mathrm{Yr}$ & Year \\
\hline
\end{tabular}


Environmental Impacts, Health and Safety Impacts, and Financial Costs of the Front-End of the Nuclear Fuel Cycle

July 2013

This Page Intentionally Left Blank 

Environmental Impacts, Health and Safety Impacts, and Financial Costs of the Front-End of the Nuclear Fuel Cycle

July 2013

\section{PURPOSE}

The Department of Energy Office of Nuclear Energy (DOE-NE) is responsible for developing sustainable nuclear fuel cycles as described in the DOE-NE Research and Development Roadmap. This responsibility is implemented through the DOE-NE Fuel Cycle Research and Development (FCRD) Program with a mission to develop a suite of options that will enable future policy makers and stakeholders to make informed decisions about how best to benefit from nuclear technologies.

In fulfilling this responsibility the FCRD program is developing metrics for assessing overall systems performance of various proposed nuclear fuel cycles. The metrics will assess relevant impacts resulting from all phases of the fuel cycle and will help focus research and development (R\&D) efforts and inform allocation of funding to nuclear technologies which will best meet technical objectives as well as other societal needs and concerns. This report addresses the impacts of the front-end of the nuclear fuel cycle (FEFC). Because production of power from a nuclear reactor has a relatively low environmental and safety impact, it is expected that the FEFC will account for a significant fraction of the impacts associated with the nuclear fuel cycle.

FEFC processes, unlike many of the proposed advanced fuel cycles and technologies under consideration, involve mature operational processes presently in use at a number of facilities worldwide. FEFC processes for obtaining $U$ or $T h$ are relatively independent of the various fuel cycles. The objective of this work is to identify and quantify relevant impacts associated with FEFC currently in use. This will support consistent evaluation of proposed fuel cycles and associated technologies based on common FEFC processes.

Although further advances such as seawater extraction and laser-based enrichment technologies are being developed, this report does not attempt to evaluate the impacts of changing the technologies presently in use for the FEFC. If it is determined that promising fuel cycle technologies or other changes to the FEFC process may significantly affect the overall fuel cycle impacts, a future evaluation may consider tailoring FEFC processes to minimize overall impacts of specific fuel cycles.

The objective of this report is to identify significant impacts resulting from the FEFC based on processes and activities representative of those expected to be in use during the next few decades ${ }^{1}$. Impacts considered to be significant are those that are helpful in differentiating between fuel cycle performance and for which the FEFC impact is not negligible relative to those from the remainder of the full fuel cycle. This report

- Defines 'representative' processes that typify impacts associated with each step of the FEFC,

- Systematically identifies FEFC impacts and costs of representative FEFC processes and documents the rationale for selecting those that are considered significant,

- Establishes a framework and architecture for rolling up impacts into normalized measures that can be scaled to quantify their contribution to the total impacts associated with various fuel cycles, and

- Develops and documents the bases for estimates of the impacts and costs associated with the representative FEFC processes.

It is planned that the FEFC impacts and associated measures from this report will be integrated with those being developed for other phases of the nuclear fuel cycle in order to achieve a comprehensive set of metrics for evaluating total system performance (DOE 2013). This approach will support informed decisions and ensure a defensible and successful path forward for the development and implementation of nuclear fuel cycle technologies.

1. Thus the emphasis is on current practices. The authors acknowledge that some past practices resulted in larger impacts. 


\section{SCOPE}

For purposes of this report, FEFC activities include all activities from obtaining raw stock of $\mathrm{U}$ or Th and delivering it, in specified form, to the fuel fabrication facility. For uranium, these activities include mining, milling and refining to produce yellowcake $\left(\mathrm{U}_{3} \mathrm{O}_{8}\right)$, conversion of yellowcake to uranium hexafluoride $\left(\mathrm{UF}_{6}\right)$, deconversion of depleted $\mathrm{UF}_{6}\left(\mathrm{DUF}_{6}\right)$, and enrichment ${ }^{2}$ to obtain the specified U-235 content for fuel fabrication. For thorium-based fuels, these activities include extraction and purification of Th from by-products of ongoing mining operations for other valuable materials such as rare earths and titanium.

FEFC impact estimates normally include those associated with fuel fabrication step. However, by limiting the scope of this report to the activities necessary to deliver the fuel material to the fuel fabrication facility, the FEFC impacts reported herein are common to all fuel cycles requiring $\mathrm{U}$ or Th-based fuel. So, although the impacts in this report do account delivery of UF6 at the specified enrichment, they do not explicitly account for the form or quantity of fuel required to produce a specified amount of energy. As such, this report will provide input for future work that will estimate impacts for fully specified fuel cycles.

Activities are generally limited to ongoing operations and generally do not cover construction or decommissioning. Limited data are available for closure and decommissioning of FEFC processes. Hence, impacts associated with these phases of the life cycle are generally not included in these estimates with the exception of cost impacts, which are based on levelized unit costs that include all phases of the related facility life cycles.

Land use impacts are differentiated between permanent and nonpermanent in order to illustrate the portion of the land that is expected to be reclaimed following decommissioning.

Nine high-level evaluation criteria have been identified for the fuel cycle options assessment ${ }^{3}$. These criteria are described below along with a brief discussion of their applicability to the front-end of the nuclear fuel cycle (FEFC).

i. Nuclear Waste Management: The FEFC produces no irradiated nuclear material. The impacts and costs of tailings and other waste and by-products streams produced by the FEFC - both chemical and radioactive - are addressed as environmental and/or financial impacts.

ii. Proliferation Risk: Proliferation and nuclear material security risks apply only to the enrichment step and subsequent fuel cycle processes. However, because the only distinction in FEFC proliferation risk is associated with use of either a different enrichment specification (determined by the fuel cycle rather than the FEFC process) or a different enrichment technology (outside the scope of this report), this risk is not addressed at this time.

iii. Nuclear Material Security Risk: See explanation of proliferation risk above.

iv. Health and Safety: FEFC processes are mature, operational processes in use today at a number of facilities worldwide. Based on these processes, this report estimates worker exposure and occupational safety as well as public and ecological health risks.

v. Financial Risk and Economics: FEFC financial costs of obtaining and refining $U$ and Th for use in fuel fabrication are.

2. Reenrichment of uranium recovered from chemical separation of used fuel is not included in the scope of this report.

3. Charter for the Evaluation and Screening of Fuel Cycle Options, December 15, 2011; U.S. Department of Energy, Office of Nuclear Energy (available at: http://www.inl.gov/conferences/nfco/d/asc-12-15-11.pdf). 
Environmental Impacts, Health and Safety Impacts, and Financial Costs of the Front-End of the Nuclear Fuel Cycle

July 2013

vi. Environmental Impact: FEFC facilities alter land use and consume water and energy. The associated impacts are addressed in this report.

vii. Resource Utilization: With respect to evaluating fuel cycle technologies, the product of the FEFC (i.e., $\mathrm{U}$ or Th) is the resource against which 'resource utilization' is being measured. Hence it is not appropriate or useful to include these criteria when evaluating FEFC processes. Instead, this report indicates impacts per unit of resource used. Impacts associated with resources used within the FEFC itself are accounted for as either environmental impacts and/or financial costs.

viii. Development and Deployment Risk: The FCRD metrics effort focuses on development and deployment of new fuel cycles and associated technologies. Hence, development and deployment of existing FEFC technologies, any of which can serve the range of contemplated fuel cycles are not the present focus of the FCRD metrics effort. However, the structure developed for determining representative FEFC processes from a mix of existing technologies also enables evaluation of changes to the mix of FEFC technologies - which will readily accommodate a future evaluation of new technologies and/or changes to the mix of presumed FEFC technologies.

ix. Institutional Issues: Institutional issues include a broad range of sociopolitical considerations that affect costs and acceptability of implementing various technologies within various geographic and cultural settings. Because FEFC processes evaluated in this report are already in place and operational, these institutional issues were not considered to be a differentiating factor. However, institutional considerations are intrinsic to the results of this report to the extent that regional issues such as value systems and regulations affect the data used for compiling the impacts and costs.

Hence, this report bins all identified FEFC into three categories - environmental, health and safety, and financial costs. Environmental impacts are further broken down into land, water, and energy use. Similarly, the safety and health impacts are subdivided into occupational, public, and ecological impacts. Financial costs for construction, closure, and operations activities are all rolled into a single dollar cost amortized over the lifetime production of the facility. These categories are considered to adequately represent performance measures of interest to various stakeholders. Further, they crosscut the entire fuel cycle and, as such, are expected to be easily combined with similar measures from other fuel cycle activities downstream of the FEFC activities.

All associated operations, material, and energy inputs necessary to produce the LEU product needed for fuel fabrication were considered when identifying FEFC impacts. Impacts were dismissed if their contribution is considered negligible relative to impacts from other phases of the fuel cycle or if they will not help differentiate between fuel cycles or technologies under consideration. When impacts were dismissed, the basis for dismissal is provided.

The environmental, safety and health, and financial costs vary at different sites, as do the laws and standards governing performance. As a result, the impacts associated with representative FEFC processes may reflect regulations and cultures different than those currently accepted in the U.S.

It is assumed that lessons learned from past (and future) practices will be applied and that future FEFC processes will maintain environmental, safety, and health practices consistent with current standards. For purposes of quantifying impacts, processes were assumed to be operating at steady state. Based on this assumption, low probability but high consequence accidents caused by natural phenomena and other unpredictable causes are not included in this assessment. In cases where significant impacts (e.g., construction and closure activities) would not be captured by strict adherence to this assumption, impacts were quantified and amortized over an assumed operational life. 
Nuclear accidents are not considered in developing the health and safety impacts. Since the FEFC materials are unirradiated, the only possible nuclear accidents are criticality events in the enrichment plants or when transporting enriched $\mathrm{UF}_{6}$. Such accidents are highly unlikely for low enriched uranium, due to design considerations for the enrichment facilities.

It is recognized that there are potential future technologies that could be 'game changers' with respect to the relative impacts of the FEFC. Some known potential technologies (e.g., extraction of uranium from seawater, laser-based enrichment, etc.) are discussed where sufficient information is available to describe the process and speculate on how the FEFC impacts would be affected. This is done in order to enable decision makers to consider the potential impacts if these technologies were to be successfully developed and implemented. However, the impacts quantified by this report are based on technologies that are commercially available and in routine use today. However, the information provided and the methodology developed within this report can be utilized to explore the impacts of different technologies and future scenarios.

While the impacts developed and quantified within this report address only the FEFC, the structure and approach for developing the estimates is intended to serve as a framework for capturing impacts and associated measures that is both adaptable and extensible to the needs both within the FEFC and across other phases of the fuel cycle. The process supports rolling up impact measures to support high-level metrics while maintaining traceable and transparent links to the underlying rationale, data, and assumptions. Estimates and supporting assumptions are not intended to include any bias toward either a best or a worst-case scenario. A key objective is to avoid introducing value judgments or other bias. The measures reported are intended to quantify key impacts for use by a broad set of stakeholders who may apply their own value judgments.

\subsection{Limitations}

This is the first time that the Fuel Cycle Technologies program has attempted to develop a comprehensive assessment of fuel cycle front-end impacts. This effort has systematically identified impacts and established an analysis framework and architecture for calculating and rolling up these impacts. However, the effort has been hampered in many areas by a lack of data, requiring the use of assumptions to fill in gaps. Further, data often came from operations with substantial variations in ore grade, deposit types, and mining techniques, use of PPE, applicable regulations, etc. Available data, supplemented with expert judgment, were used for this study to estimate representative impacts for each of the FEFC processes. However, additional data are needed to better correlate impacts with these variables.

Another significant assumption is that the data that have been located are representative of current and/or future front-end facilities and processes. In some cases (e.g., conversion plants), data were only available for one or two facilities and then only for limited time periods of operations. Similarly, data from U mining was, in many cases very sparse and several decades old. Without significantly more data, it is not possible to demonstrate that the facilities and time periods used in many of the calculations are representative for future processes.

The above limitation impacts how the current report can be used. Although the estimates provided in this document are not appropriate for accurately estimating the absolute impacts of current and future FEFC processes, they are considered sufficient for estimating and comparing relative impacts associated with different proposed fuel cycles. Because impacts scale based on the quantity front-end services needed for each fuel cycle (e.g., MTNU, SWU, etc.), one can confidently presume that a fuel cycle that uses twice as much uranium will also have twice the impacts associated with uranium mining and milling. However, because the impacts of uranium mining are significantly different from those of coal mining or mining of the rare earth elements needed for wind or solar facilities, this relative scaling does not apply across 
Environmental Impacts, Health and Safety Impacts, and Financial Costs of the Front-End of the Nuclear Fuel Cycle

July 2013

different energy technologies. Accurate calculations of the absolute impacts will be necessary to allow a legitimate comparison with other energy technologies.

\section{APPROACH}

A process for systematically identifying FEFC impacts, selecting those that are significant, and rolling them up to a minimum number of meaningful measures was developed by a team of experts representing multiple universities and national laboratories. The process employed follows the general principles of a life cycle assessment (LCA) as outlined in ISO14040 and 14044 .

The overall structure of the process employed for estimating FEFC impacts is represented in Table 3-1, where the columns represent the various activities that compose the FEFC and the rows represent the impact categories (and subcategories). Section 4 of this document describes the impacts addressed by each of the rows along with the units, common assumptions, and data sources used for evaluating these impacts. These impacts are broken down into 3 major categories - Environmental, Safety and Health, and Economic. The methodology for quantifying the estimates of these impacts including assumptions, data sources, and calculations are provided. Section 5 describes each of the major activities that compose the FEFC, (i.e., the columns in Table 3-1).Subsections within Section 5 describe these activities, discuss the different technologies available for achieving them, and document the basis for developing a representative process to reflect the impacts from a typical mix of available technologies. The calculations, assumptions, and data needed to specifically calculate the impacts for each cell are documented in Section 6. The blue text shown within Table 3-1 refers to the specific sections of the document where the impact measures, the FEFC processes, and the estimates are described.

The impact estimates for uranium mining, milling, and conversion are normalized per metric tonne natural uranium (MTNU) or metric tonne thorium (MTTh) mined. Impacts for the enrichment and deconversion processes are normalized per separative work unit (SWU) 5 and per MTDU, respectively. When comparing FEFC impacts between fuel cycles, fuel-cycle-specific conversion factors are applied to renormalize these impacts per unit energy produced by the fuel cycle. Note that this normalization scheme loses facility-specific details such as how the impacts scale with the size of the facility, how the amortized costs are affected by the lifetime of the facility, etc. The normalized impacts are intended to represent industry averages.

In developing this report, subject matter experts were designated for each row and column of Table 3-1. The column lead was given responsibility for defining and documenting the basis for the scope associated with the activity to ensure all relevant phases of the activity are included. The row lead was given responsibility for defining appropriate measures and units for the impacts along with a consistent process for identifying contributing impacts within each activity, determining and documenting their significance, and rolling them up to the single measure presented in the table. The row lead was also responsible to ensure that this was done consistently for each of the activities in the row such that the impacts of the cells in the rows could be defensibly summed. In short, designated subject matter experts as row (impact) and column (activity) leads provided checks and balances to help ensure consistency and defensibility within scopes included for each FEFC activity and the methods used for estimating impacts.

4. ISO 14040 and 14044 prescribe scope definition, inventory analysis, life cycle impact assessment, and life cycle interpretation phases. This report covers the first three phases of an LCA consistent with the intent of the standard. Sections 1 and 2, 4 and 5 , and 6 address the key tenets of these three phases.

5. Uranium enrichment impacts are normalized per separative work units (SWU) consumed. The enrichment process splits the input stream into two product streams, enriched uranium (EU) and depleted uranium (DU). The ratio between these two product streams is correlated to the SWU consumption, determined by a fuel-cycle specific enrichment specification. 


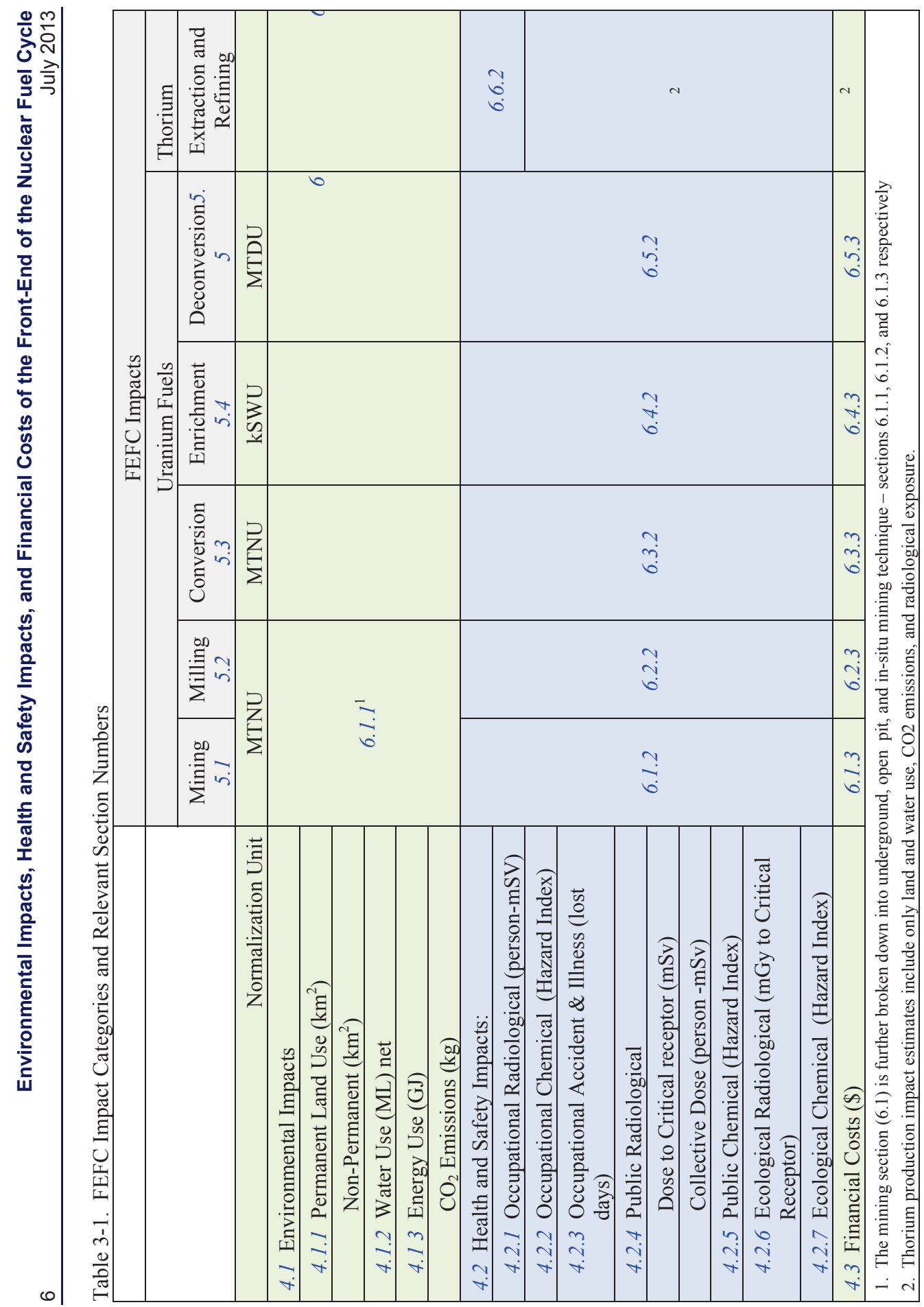


Environmental Impacts, Health and Safety Impacts, and Financial Costs of the Front-End of the Nuclear Fuel Cycle

July 2013

The remainder of this report further defines the impacts of interest, the FEFC processes, and the methods for estimating the impacts to populate the above table. The impacts reported in the table are composite measures representing several sets of contributing data. This report documents the process for identifying and rolling up these contributions.

\section{FEFC IMPACTS}

Each of the impact categories and subcategories are described below along with a discussion of the individual contributions to each impact, the basis for determining their significance, and the methodology for combining the contributions into the single measure for each FEFC activity.

The approach employed in the development of FEFC impact measures is based on the need to provide a consistent, systematic framework for evaluating and quantifying the estimated "impact" related to each phase of the front end of the nuclear fuel cycle. The process is intended to provide an objective "impact" score that can be used to rank activities on the basis of relative impact as well as to document the bases for decisions. Because in the ecological, health, and safety measures this must assess a broad diversity of hazards and/or potential impact pathways, a review was undertaken to identify all significant pathways for the most commonly used technologies for all front-end processes.

To the extent feasible, methods for determining impacts were chosen to be consistent with previous FCT efforts and with accepted practices. Data sources used for estimating impacts can be generally placed into three broad categories. The first is actual data reported by operating facilities, with preference being to more recent data based on current technologies and regulations. The second is data derived from documented studies such as design studies, environmental assessments, and environmental impact statements. And the third category of data sources consists of estimates derived from conceptual studies or scaled from analogous facilities or operations. Of these three categories, the first is deemed to be the most reliable, followed by the second, and then the third.

\subsection{Environmental Impacts}

Environmental impacts are separated into land, water, and energy use. The methodologies employed for developing these impact estimates is provided below. A review of assessment methodologies from previous studies is provided in Appendix A.

$\mathrm{CO} 2$ emissions are derived from energy use.

\subsubsection{Land Use}

Land use is separated into two separate categories: permanent and non-permanent land use. This is an important distinction as some land used in FEFC processes can be rehabilitated for unrestricted use following D\&D while use of other land such as mill tailing impoundments will remain limited for the foreseeable future. Units of measure are in the SI units of square kilometers and normalized either per metric ton heavy metal (MTHNU or, for enrichment facilities, per SWU. Land use impacts that represent $\sim 1 \%$ or less of that associated with FEFC processes were considered negligible. Only the land used directly in the production of uranium or thorium in FEFC processes are considered, which includes land used for mining, milling, conversion, enrichment, deconversion and the land needed to manage the associated waste/by product streams. Land uses resulting from the creation of material inputs used in FEFC activities is outside the scope of the present document. Land use impacts are normalized against the facilities expected lifetime production to obtain a metric for land per unit of production. 
Environmental Impacts, Health and Safety Impacts, and Financial Costs of the Front-End of the

Nuclear Fuel Cycle

\subsubsection{Water Use}

Water use is very specific to the site, type of operation, and technology used in the different types of FEFC activities. Figure 4-1 illustrates water use typical of any industrial process. Gross water use (represented by the blue line) is the total volume of water needed to sustain the process. It includes water withdrawals plus any internally recycled water. Net water use is the water withdrawn from external sources minus water returned at equal or better purity. Investment in both internal water recycling and water cleanup processes (represented by green boxes in Figure 4-1) is very much dependent on the local value of water - both from a cost and an ideological standpoint. Hence there is often considerable variability between sites with respect to both the water withdrawals and net water use. Although gross water use is largely independent of such local factors, true gross water consumption is rarely reported. Hence, for consistency, the impact estimates are based on net water use. When net water use is not available, it is estimated based on reported data. Because the net water use is very dependent on local considerations, estimates are based on best management practices that are reasonably achievable with presently available technology.

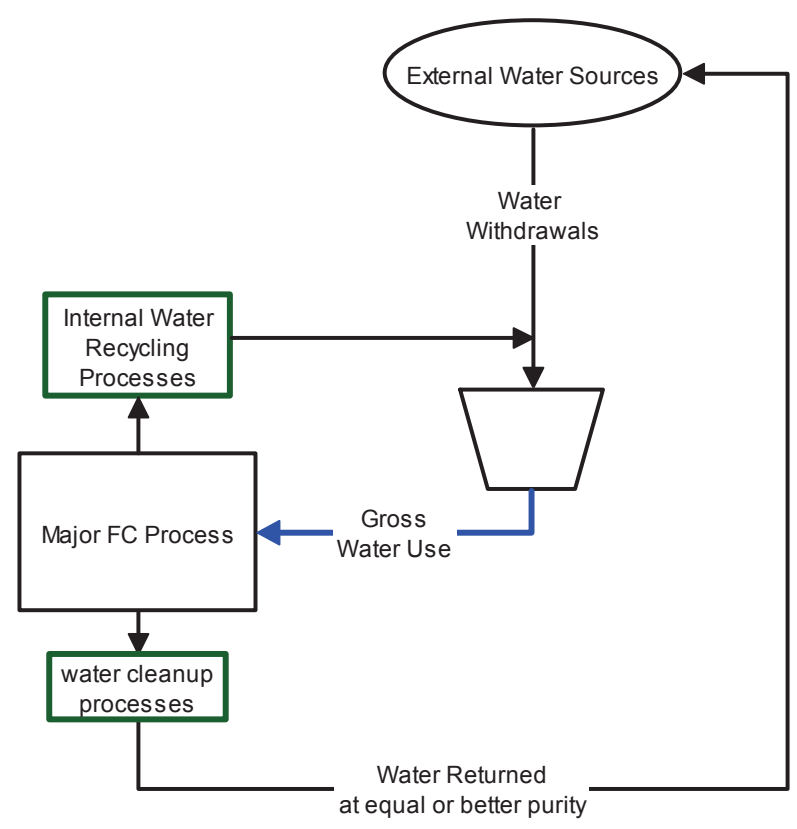

Figure 4-1. Water use in a typical industrial process.

Impact estimates consider only the water used inside the gates used directly in the production of uranium or thorium. Indirect water use associated with creation of material inputs is outside the scope of the current report. Water use that represents $\sim 1 \%$ or less of the impact in a FEFC activity is considered negligible. 
Environmental Impacts, Health and Safety Impacts, and Financial Costs of the Front-End of the Nuclear Fuel Cycle

July 2013

\subsubsection{Energy Use and $\mathrm{CO}_{2}$ Emissions}

The measures for these impacts are energy intensity in GJ and $\mathrm{CO} 2$ emissions in $\mathrm{kg}$ per unit of product or throughput (MTNU, MTDU or SWU) of each FEFC process. Energy Use accounts for final energy (see definition). Final energy ${ }^{6}$ includes three components.

1. Direct energy is the energy content of energy carriers consumed within the system.

2. Embodied energy is the energy used to fabricate equipment and materials inputs to the process.

3. Feedstock energy is the foregone energy associated with the heat of combustion of a raw material input that is consumed within the system but not used as an energy source. For FEFC processes, feedstock energy is considered negligible.

A material balance for each FEFC process is needed in order to ensure that each of these energy components is properly accounted for. Energy use that represents $1 \%$ or less of the impact in a FEFC activity is disregarded in the impact associated with that activity.

Energy such as thermal waste heat in electricity generation and energy used to refine petroleum is also lost or consumed in the recovery and fabrication of the energy carriers. Therefore, along with final energy a second measure of energy consumption, primary energy, is also in wide use. Primary energy represents the energy content of materials in their virgin state, for instance coal or uranium in the ground and solar energy incident on the Earth. It is derivable from final energy and depends on the primary-tofinal energy conversion techniques (e.g., electricity generation mix) (United Nations, 1991). Thus, calculation of primary energy use would require assumptions that lie outside of the scope of this report and final energy use is as selected as the metric.

The final energy intensity $E$ (GJ per unit of throughput) for the operational phase of a fuel cycle technology can be succinctly expressed as

$$
E=\sum_{i=1}^{I} m_{i} \mu_{i}+\sum_{j=1}^{J} e_{j} \varepsilon_{j}
$$

where

$\boldsymbol{m}_{\boldsymbol{i}}$ and $\boldsymbol{e}_{j} \quad=\quad$ the material and direct energy inputs per unit product or throughput

$\boldsymbol{\mu}_{\mathrm{i}}$ and $\boldsymbol{\varepsilon}_{\mathrm{j}} \quad=\quad$ their respective energies (i.e., embodied energy for material inputs and energy density for energy carriers) as explained in Appendix B.

As shown in Figure 4-2, the embodied energy $\boldsymbol{\mu}_{\mathbf{i}}$ from each material input accounts for direct and embodied energy of upstream processes.

6. Final energy includes the energy delivered by the 'final,' refined or processed energy carrier. This includes the heat of combustion of refined products such as diesel fuel or heating oil, the enthalpy of process heat, and the electrical energy consumed within the system boundaries regardless of the primary energy source used to generate it. This approach discards the distinction between Joules (thermal) and Joules (electric) - energies consumed within the system boundaries are additive, and thermal-to-electric conversion efficiencies are embedded in the relationship between primary and final energy consumed. Due to the losses associated with converting primary energy source to the final delivered energy, the final energy is always less than the associated primary energy. 


\section{Environmental Impacts, Health and Safety Impacts, and Financial Costs of the Front-End of the}

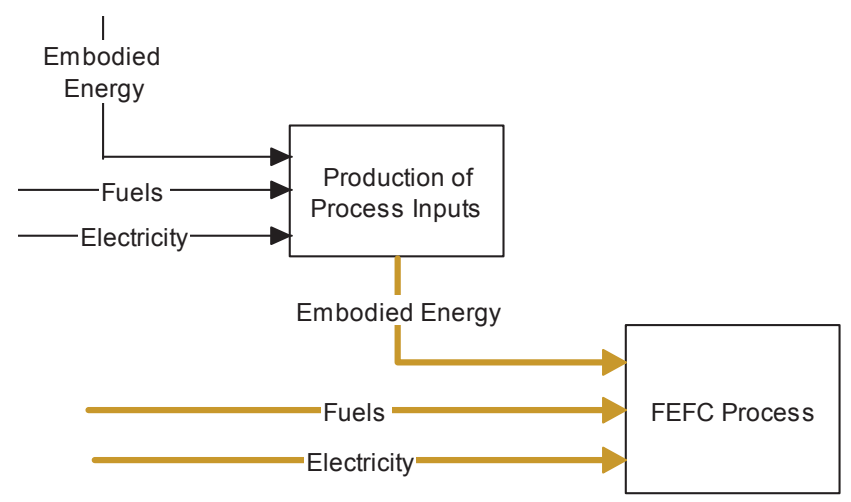

Figure 4-2. Energy Inputs to FEFC Process.

The final carbon intensity in $\mathrm{kg} \mathrm{CO}_{2}$ per unit of product or throughput of each FEFC process is derived from its energy consumption. In order to calculate the $\mathrm{CO}_{2}$ emissions, each of the component energy inputs is disaggregated into its energy sources and the applicable factor $(\mathrm{kgCO} / \mathrm{GJ})$ is applied. The resulting emissions are then summed to arrive at the final $\mathrm{CO}_{2}$ intensity, $\mathrm{C}(\mathrm{kg} \mathrm{CO} 2$ per unit throughput). This approach accounts for direct and indirect carbon emissions associated with consumption of energy carriers and material inputs.

\subsection{Health and Safety Impacts}

Occupational personnel are subject to regulatory limits of radiation dose, chemical, dust, and noise exposures imposed by the Mine Safety and Health Administration (MSHA), the Occupational Safety and Health Administration (OSHA), the Nuclear Regulatory Commission (NRC) (for all parts of the FEFC except underground and open pit mining), and/or agreement states. Mining activities on non-federally owned land are not regulated by federal agencies or programs - state laws and regulations have exclusive jurisdiction over these mining activities. In addition, individual companies often have their own procedures for limiting impacts to workers. The laws, regulations, and policies governing uranium mining and processing depend on the type of mining activity and the location of the work. Depending on the particular characteristics of a specific facility, a mix of federal and state worker protection and environmental laws may apply. Human and ecologic health and safety impacts derived in this document were based on US laws and regulations except where noted.

The objective of this work is to develop a meaningful safety and health metric for the comparison of FEFC technologies. The evaluation focuses on health and safety impacts associated with process operations as they are expected to be of higher impact due primarily to the longer duration of the operational phase. Likewise, transportation between facilities is not considered in the human and ecological impacts assessments.

Health and safety impacts for FEFC processes and facilities are developed for worker, public and ecological receptors. Additionally, given that FEFC processes involve both chemical and radiological risk, impacts are further divided between these two hazards. Generally, the direct routes of exposure are characterized for occupational personnel by organizations such as the Occupational Safety and Health Administration (OSHA), the National Center for Health Statistics, and state regulatory organizations. 
Environmental Impacts, Health and Safety Impacts, and Financial Costs of the Front-End of the Nuclear Fuel Cycle

July 2013

Indirect routes of exposure for members of the public and the ecosystem are typically described and evaluated in Environmental Impact Statements (EIS) of specific sites.

Process documentation often provides only qualitative data sufficient to demonstrate compliance with regulatory limits. Primary data for analysis of impacts to occupational personnel, members of the public and ecological systems was obtained from a variety of sources. Examples include:

- Nuclear Regulatory Commission Agency-wide Documents Access and Management System (ADAMS) and annual reports on radiation exposures to occupational personnel working in the U.S.

- Other nations reports on radiation exposures to occupational personnel, members of the public or ecological impacts

- Environmental Impact Statements for specific facilities, (i.e., mines, mills, enrichment etc.)

- Quarterly and Annual Operating (Compliance) Reports from specific facilities or companies with multiple facilities

- UNSCEAR (United Nations Scientific Commission on Effects of Atomic Radiation) reports

- NIOSH and OSHA documents can be used to identify rates for lost time, accident and injury rates

- Impact analyses conducted by private companies for specific facilities.

Within the assessment of impacts in Section 6, no explicit cutoff criterion is used (e.g., 1\% as utilized in other impacts evaluated in this document) due to the limited amount of data available. Where data was available, it was used. For facilities with little or no history available, data were occasionally adapted from other types of facilities that share similar processes. As a result, there is wide variability in the level of conservatism of some of the health and safety impact estimates, particularly with respect to their applicability to future processes.

A single, reliable measure for human or ecological health (unlike financial costs associated with risk) cannot be calculated. Other methods can be used, for example by monetizing exposures, injuries, mortalities etc., but such methods introduce additional uncertainties. Health and safety impacts identified in Section 6 should not be used as an absolute measure of health risk but rather as a basis for comparison of potential for health impacts.

The following subsections describe each of the health and safety impacts evaluated.

\subsubsection{Occupational Radiological Impacts}

Workers may be exposed to radioactive materials via direct, external exposure or internal exposure via the inhalation, ingestion, dermal or wound pathways. Radiation impacts are based on energy deposited per unit mass of tissue and the known response of the damaged tissue to different forms of radiation. For radiological impacts to for occupational workers, the collective dose is used as the primary metric because it accounts for the number of workers exposed. Annual radiation dose records in Total Effective Dose Equivalents (TEDE) are typically maintained on a quarterly and annual basis. The metric will use the product of the Average Effective Dose and the affected number of workers (Person mSv).

\subsubsection{Occupational Chemical Impacts}

Chemical occupational impacts include exposure to chemicals, dust, and noise. Occupational chemical impacts are based on OSHA eight hour time weighted average (TWA) chemical-specific screening levels. Release concentration data for all chemicals with the potential for occupational exposure is aggregated into a Hazard Index computed as the sum of the Hazard Quotients (HQ) for each chemical. 


$$
H I=\sum H Q=\sum_{n=1}^{N} \frac{\text { Chemical Concentration }}{n}
$$

All FEFC facilities have the potential to result in exposures to multiple chemicals. The HI approach allows aggregation of such exposures in a formalized manner based on toxicological principles. The HI concept for use as an impact metric is based on a standard approach used in risk assessment (USEPA 1989, 1991a, 1991b). The HI is not a direct measure of compliance and, without details of the aggregation, one should be cautious about its interpretation as a measure of health impact. For example, an $\mathrm{HI}$ above, even well above, 1 does not necessarily imply that any limits are exceeded. Nonetheless, it serves as a relative measure of the aggregated potential for exposure to hazardous chemicals. One can deduce however, that for $\mathrm{HQ}<1$, harmful effects are very unlikely. The health metrics (HQ and HI) are not used to identify absolute health impacts but as a standard toxicity-based tool to indicate the relative potential for health impacts.

\subsubsection{Occupational Accident and IIIness Impacts}

A useful measure for occupational accidents and illnesses is the time away from work, aggregate days lost, as a consequence of the occupational accidents and illnesses, commonly referred to as days lost. Work-related illnesses are commonly due to stress, depression or anxiety or musculoskeletal disorders. Accidents and other illnesses, resulting from exposures to workplace chemicals add to the aggregate of days lost. The incidence of lost work days per 100 full time employees (200,000 worker hours) represent a standard U.S. measure commonly reported for U.S. industries.

\subsubsection{Public Radiological Impacts}

The critical receptor (i.e., maximally exposed individual, MEI) is often used as a measure of radiological exposure to the public. Collective dose for the public can also be estimated by measuring the sources of exposure (effluents) and carrying out exposure pathway calculations for all radiation types to the known population distribution within a specified radius.

The metrics used in this document for public radiological include both the collective and the MEI dose. Operating facilities typically report the gaseous and liquid effluents for each radionuclide monitored. Dose estimates in the present report are based on previous studies of real or proposed facilities. The specific dose measure for both is the Total Effective Dose Equivalent, TEDE and impacts are reported in $\mathrm{mSv}$ and person-mSV for the MEI and public collective dose respectively.

\subsubsection{Public Chemical Impacts}

For chemicals of interest in this study, there are only a few for which a dose-response relationship is known, making a complete pathway analysis difficult. Instead, a screening approach is adopted in which the critical receptor is assumed to be continuously exposed to air and water effluents from the process facility. The resulting exposures are then compared to screening levels such as EPA preliminary remediation goals, PRGs (now often referred to as Regional Screening Levels, RSLs; http://www.cleanuplevels.com/) which are commonly used in risk assessment and toxicology (EPA 1989, EPA 1991) to compute a HI as described in section 4.2.2. The PRGs are chemical-specific risk-based media concentrations based on a 70-year exposure duration, a cancer risk in excess of $1 \mathrm{E}-06$ for carcinogens, and a hazard quotient (HQ) of 1 for systemic toxicants. If a chemical of interest has both cancer and non-cancer health effects, the lowest PRG is used as the screening level and the effects are 
Environmental Impacts, Health and Safety Impacts, and Financial Costs of the Front-End of the Nuclear Fuel Cycle

July 2013

assumed to be additive. Additionally, chemicals may present both a carcinogenic and systemic risk, and exposure pathways may include both air and water. Therefore, health impacts are summed across chemicals and exposure pathways to provide a comprehensive Hazard Index, computed as shown below.

$$
H I=\sum_{m=1}^{M} H Q_{\text {air } m}+\sum_{n=1}^{N} H Q_{\text {water } n}
$$

\subsubsection{Ecological Radiological Impacts}

Based on local conditions, and given adequate data, the ecological impacts can be evaluated for a representative plant, terrestrial animal and aquatic organism. To comprehensively estimate the health and safety impacts to for ecological end-points, it is necessary to include a broad range of exposure paths such as direct inhalation, ingestion, and dermal via direct contact with the contaminant as well as indirect paths such as ingesting contaminated food and water. In its simplest form, the effort would require the calculation of "actual" exposures based on source term (emission from the site), transport modeling to various media (e.g., fish, vegetation, drinking water etc.) and assumptions regarding the location of representative receptor populations (including distribution, land use, meteorology). These exposure pathways and the necessary data are not well developed for non-human species. However, if radiation or chemical doses for a given pathway are protective for humans, animals are normally protected. This general rule does not apply for aquatic animals, some of which are considerably more sensitive than humans to selected chemicals. In most, but not all, cases, plants are more tolerant to effluent exposures than humans. In these cases, sensitive aquatic species and/or plants are considered the critical receptors and screening levels are selected based on the affected biota. Where data are inadequate to develop the screening tables, qualitative discussions are presented. Ecological radiological impact is measured as total impact to critical receptor in $\mathrm{mGy}$.

\subsubsection{Ecological Chemical Impacts}

For Ecological Chemical Impact, exposures are included for releases to water since air pathways are not typically assessed for biota. Ecological chemical impacts are also estimated using a hazard index as described in section 4.2.2. The screening levels are selected from chemical-specific ecological benchmarks that are the basis for the protection of biota in most federal and state water quality programs. These aquatic benchmarks are chemical-specific risk-based media concentrations for continuous exposure for various biota and conditions. Thus, continuous exposure at or below the benchmark is thought to result in no adverse impact over a lifetime. For conservatism, the lowest benchmark is used as the screening level. Although not meaningful for determining absolute risk, this metric can be useful as a tool for the comparative analysis of technologies with respect to potential ecological hazards.

\subsection{Financial Costs}

The Advanced Fuel Cycle Cost Basis (AFC CB) (Shropshire, 2009) provides unit costs for reactors as well as technologies across the fuel cycle. For fuel cycle facilities, unit costs are expressed per unit mass of commodity produced or processed. This is consistent with the normalization scheme proposed for the other impacts. Therefore, the financial cost metric for each NFC process will be its unit cost from the most recent update to the 2009 AFC CB (INL 2013).

Although not used as a metric, additional financial cost data for reference facilities are presented in this report when available. This data comprises capital, operating and decommissioning and decontamination 
Environmental Impacts, Health and Safety Impacts, and Financial Costs of the Front-End of the

Nuclear Fuel Cycle

(D\&D) costs for specific plants, which can be used to derive unit costs. They offer advantages over unit costs alone for several reasons. For instance, they permit:

- effects of economies of scale to be accounted for,

- changes in facility design (e.g., throughput, operating and economic lifetimes) to propagate to the unit cost estimates,

- financial parameters (discount rate, interest rate of capital, DD escrow fund rate of return) to be varied.

Assumptions tied to each of the above are embedded in unit cost estimates such as those presented in the AFC CB. In some data sources, these assumptions are nontransparent. Therefore, when it is available, the additional financial cost data will be used to calculate unit costs. These calculated unit costs are for illustrative purposes and are not intended to replace the reported cost metrics from the AFC CB.

The procedure used for calculating a unit cost from the capital, operating, and D\&D costs and other design and financial parameters, adapted from the Generation-IV Economic Modeling Working Group (EMWG) methodology (EMWG, 2007, is described below). Table 4-1 lists the data and parameters defined in the EMWG procedure.

Table 4-1. Cost estimation parameters.

\begin{tabular}{|c|c|c|}
\hline Symbol & Unit & Definition \\
\hline TOC & $\$$ & Total overnight cost (EMWG accounts $1-5$, excluding 58) \\
\hline $\mathrm{OM}$ & $\$ / \mathrm{yr}$ & Annual operations and maintenance cost (EMWG account 7) \\
\hline DD & $\$$ & $\begin{array}{l}\text { Decommissioning cost (EMWG account 58; rule of thumb: estimate at } 33 \% \text { of total } \\
\text { direct capital cost, EMWG accounts } 1 \text { and } 2 \text { ) }\end{array}$ \\
\hline$Y_{\text {basis }}$ & - & Basis year for TOC, OM, DD estimates \\
\hline $\mathrm{T}_{\mathrm{c}}$ & $\mathrm{yr}$ & Duration (years) of construction \\
\hline $\mathrm{T}_{\mathrm{o}}$ & $\mathrm{yr}$ & $\begin{array}{l}\text { Duration (years) of operation (assumed equal to economic lifetime by the EWMG } \\
\text { and in formulas below) }\end{array}$ \\
\hline$M$ & $\mathrm{~kg} / \mathrm{yr}$ & $\begin{array}{l}\text { Annual production (throughput) of product in kg of basis unit/yr: technology- } \\
\text { specific basis unit may be U, IHM, SWU, etc. }\end{array}$ \\
\hline $\mathrm{f}_{\mathrm{i}}$ & - & $\begin{array}{l}\text { Fraction of TOC expended in year } i \text { of construction (Indexed over i in }\left[1, T_{c}\right] \text {, sums to } \\
1.0 \text { ) }\end{array}$ \\
\hline $\mathrm{r}$ & $1 / \mathrm{yr}$ & $\begin{array}{l}\text { Real discount rate (nominal discount rate - inflation rate; EMWG reference values } \\
\text { were } 0.05 \text { and } 0.10 \text { ) }\end{array}$ \\
\hline $\mathrm{r}_{\mathrm{SF}}$ & $1 / \mathrm{yr}$ & Real sinking fund rate (assumed equal to real discount rate by the EMWG) \\
\hline $\mathrm{AF}$ & $1 / \mathrm{yr}$ & $\begin{array}{l}\text { (calculated) capital cost amortization factor (notated FCR, fixed charge rate, } \mathrm{n} \\
\text { EMWG document) }\end{array}$ \\
\hline IDC & $\$$ & (calculated) interest during construction \\
\hline SFF & $1 / \mathrm{yr}$ & (calculated) sinking fund amortization factor \\
\hline $\mathrm{ACC}$ & $\$ / y r$ & (calculated) amortized annual capital cost \\
\hline ADD & $\$ / \mathrm{yr}$ & (calculated) amortized annual D\&D cost \\
\hline $\mathrm{UC}$ & $\$ / \mathrm{kg}$ & (calculated) unit cost of product \\
\hline
\end{tabular}


Environmental Impacts, Health and Safety Impacts, and Financial Costs of the Front-End of the Nuclear Fuel Cycle

July 2013

The EMWG procedure for calculating the unit cost, UC, from the data in Table 4-1 is summarized as follows. The basis year, $\mathrm{Y}_{\text {basis }}$, for the UC calculation should be 2012. If TOC, OM and DD are not expressed in basis year dollars, they must first be adjusted. The EMWG does not recommend a single index for doing so: Suitable indices can include:

- the Consumer Price Index (CPI) or implicit gross domestic product (GDP) price deflator, both available from the US Bureau of Labor Statistics at http://www.bls.gov/cpi/,

- the Chemical Engineering Plant Cost Index (CEPCI), published regularly in the journal Chemical Engineering,

- the Marshall and Swift Equipment Cost indices for industrial plants; see http://www.marshallswift.com/faq-31.aspx

- the Handy-Whitman cost index for public utility construction costs.

The CPI and GDP deflator are broad measures of inflation. The other indices are specific to industrial plants; each defines a basket of goods and services that is intended to be representative of a generic process like chemical production or electrical utility operations.

Given TOC, OM and DD expressed in $\mathrm{Y}_{\text {basis }}$ dollars, the capital and D\&D costs are amortized as follows. The interest during construction, IDC, is calculated by discounting the capital costs for each year of construction forward to the first year of operations:

$$
I D C=\sum_{i=1}^{T_{C}} T O C * f_{i}(1+r)^{T_{C}-i}-1
$$

The total capital cost to be amortized is the sum of IDC and TOC (but note that the EMWG method can account for financial contingencies as well). An amortization factor, AF, is used to calculate the annual capital cost repayment, ACC:

$$
\begin{gathered}
A F=\frac{r}{1-(1+r)^{-T_{o}}} \\
A C C=(T O C+I D C) \bullet A F
\end{gathered}
$$

D\&D costs are handled similarly, except that the liability falls at the end of the facility's lifetime so the amortization models payments into an escrow fund. The annual payments into the escrow or sinking fund, ADD, are calculated using an amortization factor, SFF:

$$
\begin{gathered}
S F F=\frac{r_{S F}}{\left(1+r_{S F}\right)^{T_{o}}-1} \\
A D D=D D \bullet S F F
\end{gathered}
$$


Finally, the unit cost is calculated by dividing the annual capital cost repayment ACC, sinking fund payment $\mathrm{ADD}$, and fixed and variable operations and maintenance cost $\mathrm{OM}$ by the annual throughput of the plant, M. ACC, ADD and OM carry units of $\$ / \mathrm{yr}$ while $\mathrm{M}$ has units of ( $\mathrm{kg}$ of production or throughput)/yr, so that the dimensions of UC are $\$ /(\mathrm{kg}$ of production or throughput).

$$
U C=\frac{A C C+A D D+O M}{M}
$$

\section{FEFC ACTIVITIES}

The FEFC is composed of several activities necessary to extract the raw material from the earth and transform it into material from which nuclear fuel can be fabricated. Each of these activities, represented by a column in Table 3-1, is described more fully in this section.

System boundaries for each FEFC activity are defined in order to establish a threshold into which materials and energy carriers cross (the inputs), and from which wastes, emissions and products exit (the outputs). Transportation between FEFC process facilities is not explicitly considered. Large mining operations will almost always have a milling operation located on site in order to minimize the transportation costs of uranium ore. Since large mining sites represent the vast majority of global uranium mining, it will be assumed that no transportation takes place between mining and milling sites. Thereafter, the quantity of material to be transported is considerably reduced and, as shown by (Schneider 2010), contributes an insignificant portion to $\mathrm{CO}_{2}$ emissions, land and water use, and radiological dose.

For each of the major FEFC activities, a flow diagram is provided to show the scope of what is included in the impact estimate. The main process on the flow diagram is shown as a block that contains a brief description of the included activities. The flow diagram illustrates: 1) input and output flows of the main product stream, 2) other inputs such as supplies of energy and materials, and 3) other outputs such as waste and by-product streams. Following each flow diagram is a table that quantifies inputs and outputs used for estimating impacts. Additional data used as inputs to the impact estimates is provided in section 6 as needed.

Material inputs to the process are identified in order to account for embodied energy and potential chemical exposure associated with these inputs. When identifying system boundaries for FEFC impacts, it should be recognized that, although system boundaries for estimating embodied energy and externalities can be extended indefinitely, the impacts diminish rapidly as the boundary is extended. Hence, for consistency, only the embodied energy associated with material stocks that are consumed as part of steady state operations is considered. Other impacts resulting from activities outside the system boundaries are included only if directly associated with preparation and delivery of a material input shown on the flow diagram (e.g., impacts associated with employee travel to and from work would not be included).

Natural uranium is largely U-238 but contains $\sim 0.7 \% \mathrm{U}-235$, a fissile isotope used in nuclear fuel. Uranium is extracted from the earth by several mining methods, depending on the geologic conditions. Once extracted, it undergoes a milling resulting in $\mathrm{U}_{3} \mathrm{O}_{8}$, often referred to as yellowcake. The yellowcake is then converted to a gas, natural uranium hexafluoride $\left(\mathrm{NUF}_{6}\right)$ before undergoing an enrichment process which splits this into two streams, depleted $\mathrm{UF}_{6}\left(\mathrm{DUF}_{6}\right)$ having a U-235 concentration below that of $\mathrm{NU}$ and enriched $\mathrm{UF}_{6}$, having a U-235 content higher than that of NU. The enriched $\mathrm{UF}_{6}$ product is then sent to the fuel fabrication process. The $\mathrm{DUF}_{6}$ resulting from the enrichment process can be considered as either a reusable material or a waste-depending on the fuel cycle employed. For completeness, a DUF 6 deconversion (to $\mathrm{DU}_{3} \mathrm{O}_{8}$ ) process is included as an FEFC activity that will be employed for $\mathrm{DUF}_{6}$ that is to be considered waste. 
Environmental Impacts, Health and Safety Impacts, and Financial Costs of the Front-End of the Nuclear Fuel Cycle

July 2013

\subsection{Uranium Mining}

Uranium mining possesses various impacts similar to those of other metalliferous mining operations, with a key difference being radioactivity concerns due to the presence of radon, radium and uranium. Different mining approaches (open pit, underground, and in-situ mining) have different impacts both in the type and magnitude. It should be noted that the magnitudes of impacts will be site specific, depending on geologic factors, mine type, environmental regulations in the country of operation, physical location of mine, amount of existing infrastructure, etc. To address this concern, the impacts and assumptions will be developed separately for open pit (OP), underground (UG) and in-situ leach (ISL) mining technologies. Representative mining impacts will then be created from a weighted average of these three mining technologies based upon their respective share of worldwide uranium production.

A topic of great public concern is that of legacy mines that in some instances have caused large degrees of environmental damage. These mines represent old technology and practices that are unacceptable in the majority of mining operations throughout the world today. Modern mining practices incorporate engineering practices that reflect a greater understanding of the impacts caused by mining operations. Some examples of changes in mining practices include the burying below grade of potentially harmful overburden, hydraulic analyses of surface and ground water flow, standardized government regulations, and the incorporation of budgets for mine closures. As the purpose of this report is to assist policy makers with decisions related to future nuclear fuel cycles, mining operations will be selected that represent current technologies.

Scope and Assumptions

- Impacts are based on mining activities and management of associated waste streams that take place within the 'mine gates'.

- Construction materials for facilities and the trucks used to remove overburden/waste rock and transport are included.

\section{Representative Mining Process}

Mines may close due to changes in commodity prices, depletion of resources, worker strikes, and political reasons. New deposits will be developed to meet demand, and improvements in technology will make previous uneconomic deposits viable for mining. There is potential for other technologies, such as uranium extraction from phosphate rock and extraction from seawater, to produce significant uranium in the future. However, as seawater uranium extraction is not currently economically viable, it will not be represented in the process. Uranium recovery from phosphates is a well-known process that has been performed in the past, however it too is not currently economic to produce uranium, thus will be excluded from the mix. With both of these processes there is the potential for technological advancement or an increase in uranium prices that may make them viable in the future. Uranium recovery from phosphates and from seawater is discussed in Appendix C.

Although the mix of mining technologies employed will vary through time, the representative mining process is based on the distribution of mining technologies in 2011 from the World Nuclear Association (2012, see Table 5-1). During the latter stages of this report, the 2011 edition of the Red Book (OECD, 2012) was released. The values in the two sources do not vary significantly. The mining technology mix from these other sources is discussed further in Appendix D.

Table 5-1. Profile of uranium mining in 2011. (World Nuclear Association, May 2012) 
Environmental Impacts, Health and Safety Impacts, and Financial Costs of the Front-End of the

Nuclear Fuel Cycle

\begin{tabular}{|c|c|c|}
\hline Conventional underground (except Olympic Dam) & 16,059 & 30 \\
\hline Conventional open pit & 9,268 & 17.3 \\
\hline In situ leach (ISL) & 24,180 & 45.5 \\
\hline By-product ${ }^{2}$ & 3,987 & 7.5 \\
\hline
\end{tabular}

Olympic dam is an underground mine that represents approximately 3,500 tonnes $\mathrm{U}$ of the by-product category, thus the by-product category will be summed with the conventional underground category to include Olympic Dam. This results in the distribution shown below in Table 5-2.

Table 5-2. Mix of mining technologies.

\begin{tabular}{|l|c|c|}
\hline \multicolumn{1}{|c|}{ Method } & Tonnes U & Percentage \\
\hline Conventional Underground & 20,046 & 37.5 \\
\hline Conventional Open Pit & 9,268 & 17.3 \\
\hline In Situ Leach (ISL) & 24,180 & 45.2 \\
\hline
\end{tabular}

Given this distribution of mining methods, a weighted average is created to distribute the impact data of sample mines that include each type of mine operation resulting in the following roll-up of mine impacts shown here:

$$
I_{j}=\sum_{i=1}^{3} w_{i} x_{i j}
$$

where

Ij $=\quad$ represents impact ' $\mathrm{j}$ ' which is an environmental, economic or health and safety impact that represents an estimate of that impact based upon the distribution of world uranium production by mine type

$w_{i} \quad=\quad$ represents the weight of each mining type with the weight being that type's percentage of overall worldwide production in 2011 as shown in Table 5-2

$x_{i j} \quad=\quad$ the impact ' $\mathrm{j}$ ' associated with mining type ' $\mathrm{I}$ '.

\subsubsection{Underground Mines}

The mining process includes the production of uranium ore from a geologic deposit, transport of ore to a milling facility, and decommissioning of the mine site. Decommissioning is included in the financial cost estimates and is implicit in the land use calculations due to the differentiation between permanent and temporary land use. Water use for decommissioning is considered to be negligible in FEFC processes with the exception of ISL mining which will vary considerably based on the local geology, hydrology, and regulations. Decommissioning impacts were not considered in the health and safety or energy use and $\mathrm{CO}_{2}$ estimates. 
Environmental Impacts, Health and Safety Impacts, and Financial Costs of the Front-End of the Nuclear Fuel Cycle

July 2013

An underground mine, while moving less earth than an open pit mine, will typically have greater risks associated with worker health/safety as workers are exposed to higher concentrations of dust containing alpha particle radiation mostly from radon gas. This risk is minimized through the use of ventilation systems, and water as a dust suppressant.

Direct energy inputs include electricity used on site as well as fossil fuels (gasoline and diesel) used to operate trucks and mining equipment. Material inputs include explosives (primarily ammonium nitrate based), mining machinery, and water. The water used and associated impacts will vary site to site depending on the origin and availability of the water source.

There are solid, liquid, and gaseous waste/by-product streams that must be managed. Solid wastes include waste rock/overburden that may contain hazardous metals such as arsenic and radium that are typically buried on site, subject to government regulation. However, the most toxic and radioactive elements are usually contained in the mill tailings.

In conventional mining the vast majority of liquid wastes will be present in the mill tailings that are pumped to an evaporation pond. Such slurries will contain chemicals such as sulfuric acid to dissolve the uranium. Additionally, mines are often required to follow a zero-discharge policy that requires that any water exiting the mine site be treated and meet specified water quality standards. However, for ISL operations the liquid waste will actually be present in the underlying ore body and will subsequently be dealt with during decommissioning through reverse osmosis or a sweep.

Gaseous emissions resulting in air pollution take the form of $\mathrm{CO}_{2}$ emission from the direct use of fossil fuels and from electricity used in site operations as well as radon gas released. In the United States, Canada, and Australia; underground mining operations are regulated by the state or territory in which they are located.

Figure 5-1 shows, and Table 5-3 quantifies the significant inputs and outputs of the underground mining process.

\subsubsection{Open Pit Mines}

Open pit mine operations involve the removal of soil, rock, and overburden (see definition) in order to extract the underlying ore. Open pit mines are large open excavations of earth, and typically are only economically viable on relatively shallow deposits. The main difference in impacts between underground and open-pit operations is that an open pit will have more of an impact in the sense that more earth will have to be moved resulting in a greater amount of energy use and waste rock to be managed, and because an open pit operation is open to the atmosphere, worker impacts from mine dust containing toxic and radioactive elements are less than for UG mining. Open pit mines are regulated by the same governmental bodies as underground mines. Figure 5-1 also shows, and Table 5-4 quantifies the significant inputs and outputs of the open pit mining process. 
Environmental Impacts, Health and Safety Impacts, and Financial Costs of the Front-End of the

Nuclear Fuel Cycle

Direct Energy Inputs

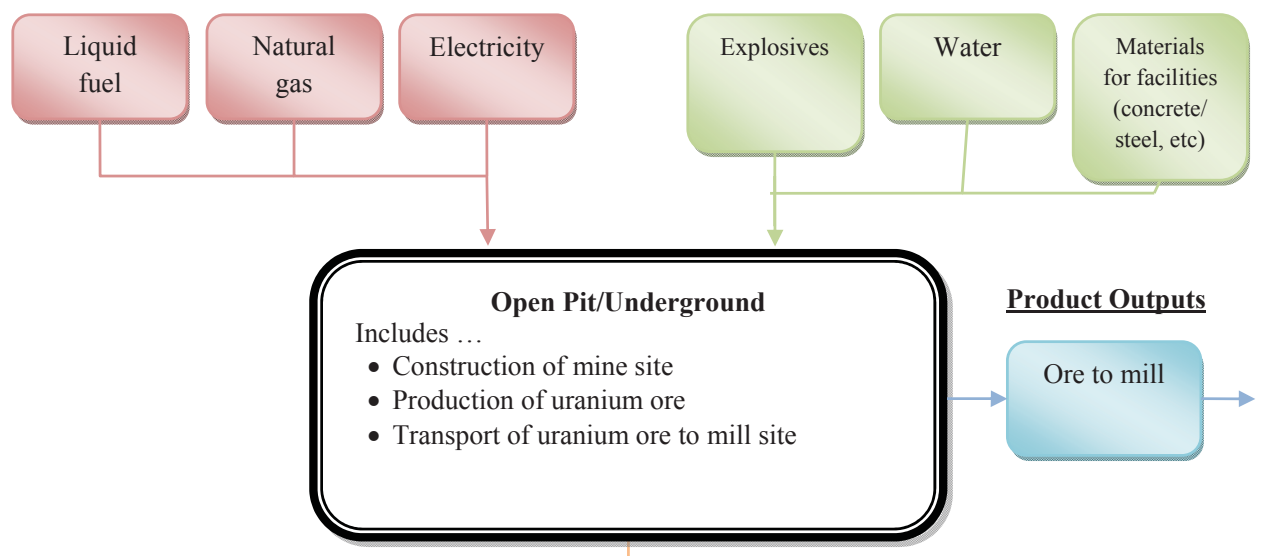

$\underline{\text { Waste/By-Product Streams }}$

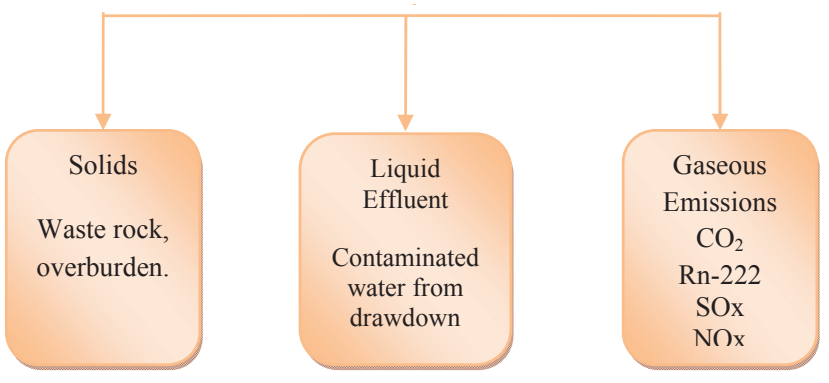

Figure 5-1. Inputs and outputs for open pit and underground mining.

Table 5-3. Underground mining operations data (including milling).

\begin{tabular}{|l|c|c|c|c|}
\hline \multicolumn{1}{|c|}{ Uranium Mining } & Units & Value & Data Source & Comments \\
\hline Main Product & & & & \\
\hline Inflow & MTNU & N/A & & \\
\hline Outflow & MTNU & 1.00 & & \\
\hline Direct Energy Inputs & & & & \\
\hline Electricity & GJ & $2.7 \mathrm{E}+02$ & Schneider 2010 & Multiple Mines \\
\hline Natural Gas & GJ & $1.06 \mathrm{E}+02$ & Schneider 2010 & Multiple Mines \\
\hline Diesel & GJ & $1.22 \mathrm{E}+02$ & Schneider 2010 & Multiple Mines \\
\hline
\end{tabular}


Environmental Impacts, Health and Safety Impacts, and Financial Costs of the Front-End of the Nuclear Fuel Cycle

Table 5-4. Open pit mining operations data (including milling).

\begin{tabular}{|l|c|c|l|l|}
\hline \multicolumn{1}{|c|}{ Uranium Mining } & Units & Value & \multicolumn{1}{c|}{ Data Source } & \multicolumn{1}{c|}{ Comments } \\
\hline Main Product & & & & Inputs normalized \\
\hline Inflow & MTNU & N/A & & Per MT of Natural U \\
\hline Outflow & MTNU & $1.00 \mathrm{E}+00$ & & \\
\hline Direct Energy Inputs & & & & Various Mines \\
\hline Electricity & GJ & $1.5 \mathrm{E}+02$ & Schneider 2010 & Various Mines \\
\hline Natural Gas & GJ & $6.3 \mathrm{E}+01$ & Schneider 2010 & Various Mines \\
\hline Diesel & GJ & $6.0 \mathrm{E}+01$ & Schneider 2010 & \\
\hline
\end{tabular}

\subsubsection{In Situ Leach Mining (ISL)}

Figure 5-2 shows, and Table 5-5 quantifies, the significant inputs and outputs of the ISL mining process. The impact/inputs associated with in situ leach mining differ significantly from conventional open-pit and underground mines. In situ leaching involves construction of the site and injection/recovery wells that are used to inject fortified ground water to dissolve minerals. The pregnant solution is then pumped to the surface where the uranium is recovered at the milling site. Milling usually takes place at the ISL site, but at smaller operations the pregnant solution may be transported by truck to a central plant for stripping. No transportation is assumed as this represents both a small part of energy use, and only a fraction of the industry as a whole. Based on current ISL technology, the ore body should be situated below the natural water table in a permeable zone. Impermeable layers above and below ensure hydrologic control of leaching solution and facilitate restoration of groundwater quality following completion of mining.

The direct inputs include electricity used for process heat and pumping, either generated from a grid or produced through generators using a fossil fuel. The material inputs are site specific depending on the ore geochemistry, and include water, ammonia, hydrogen peroxide, an acid such as sulfuric acid or an alkali leach, such as sodium bicarbonate, and the construction materials used to create the ISL site, such as concrete. If a significant amount of calcium is present in the ore body (such as in limestone or gypsum), alkaline leaching is used. ISL is a water intensive process, however much of the water is recycled and returned to the water table or evaporated.

Upon decommissioning, wells are sealed or capped, pipes and process facilities removed, any evaporation pond revegetated, and in some instances, especially in the U.S., the ground water is restored to its previous use. A major concern for ISL mining is the potential for ground water contamination due to the presence of heavy metals or radionuclides. If the groundwater is to be restored, as is the case in the U.S. and some mines in Australia, alkaline leach is preferred. The preferred use of alkaline mine sites in the U.S. is related to the need to restore groundwater as alkaline ISL sites are often easier to restore (Tweeton, Peterson 1981).

Acid leaching is typically used when it is decided that the groundwater is not to be restored, as is the case at the Beverly and Honeymoon projects in Australia, and many operations in Eastern Europe and Former Soviet Union. The available evidence in sites in the Former Soviet Union suggests that natural attenuation fails to reduce the impacts to ground water from acid ISL mines (Mudd, 2001). Where natural attenuation is defined as the "Reduction in mass or concentration of a compound in groundwater over time or distance from the source of constituents of concern due to naturally occurring physical, chemical, and biological processes, such as; biodegradation, dispersion, dilution, adsorption, and volatilization. (ASTM International, 2003) 
Environmental Impacts, Health and Safety Impacts, and Financial Costs of the Front-End of the

Nuclear Fuel Cycle

Direct Energy Inputs

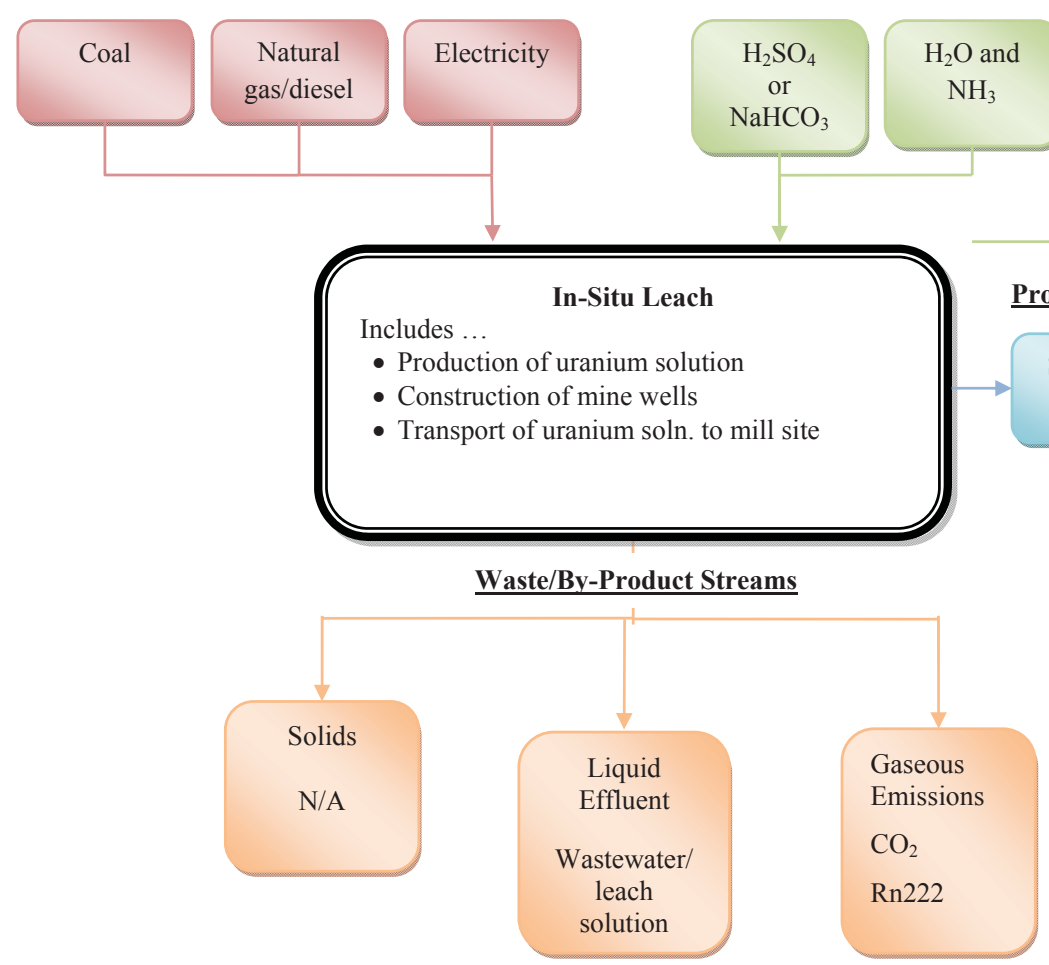

Figure 5-2. Inputs and Outputs for ISL Mining.

Table 5-5. ISL operations data (including milling).

\begin{tabular}{|l|c|c|c|c|}
\hline \multicolumn{1}{|c|}{ Uranium Mining } & Units & Value & Data Source & Comments \\
\hline Main Product & & & & Normalized \\
\hline Inflow & & N/A & & To MTNU \\
\hline Outflow & MTNU & $1.00 \mathrm{E}+00$ & & (except where noted) \\
\hline Direct Energy Inputs & & & & \\
\hline Electricity & GJ & $1.28 \mathrm{E}+02$ & Schneider 2010 & \\
\hline Natural Gas & GJ & $5.20 \mathrm{E}+01$ & Schneider 2010 & \\
\hline
\end{tabular}


Environmental Impacts, Health and Safety Impacts, and Financial Costs of the Front-End of the Nuclear Fuel Cycle

July 2013

\subsection{Uranium Milling}

Milling operations associated inputs and outputs include the construction of a mill for conversion of uranium ore to yellowcake $\left(\mathrm{U}_{3} \mathrm{O}_{8}\right)$. Figure 5-3 provides a block flow diagram of the uranium milling process. Additional detail into the typical milling operation is shown in Figure 5-4. The direct energy inputs include the electricity and fossil fuels needed for milling operations. Material inputs include water and a strong acid or alkali leaching solution depending on the ore geochemistry. If a significant amount of calcium is present in the ore body (such as in limestone or gypsum), alkaline leaching is used.

Otherwise, acid leaching is the preferred method. This leaching extracts approximately $90-95 \%$ of the Uranium in the ore received from the mine ${ }^{7}$. The key difference between milling operations associated with ISL mining is that there is no overburden or ore but only a uranium-pregnant solution. The material inputs shown in Tables 5-3, 5-4 and 5-5 include the chemicals used in the milling process.

Direct Energy Inputs

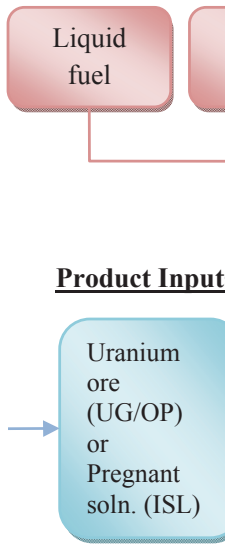

Material Inputs

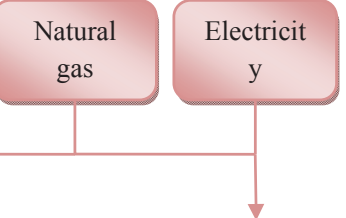

Includes ...

- Construction of mill plant (including tailings management facilities)

- Conversion of ore to $\mathrm{U}_{3} \mathrm{O}_{8}$

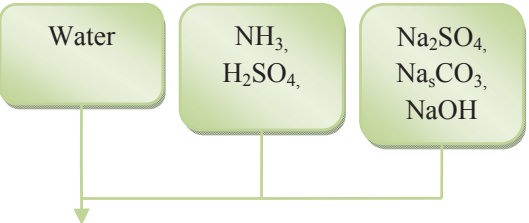

\section{Product Outputs}

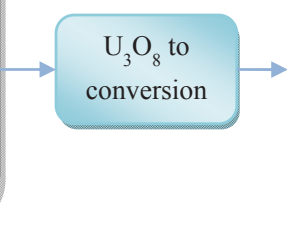

$\underline{\text { Waste/By-Product Streams }}$

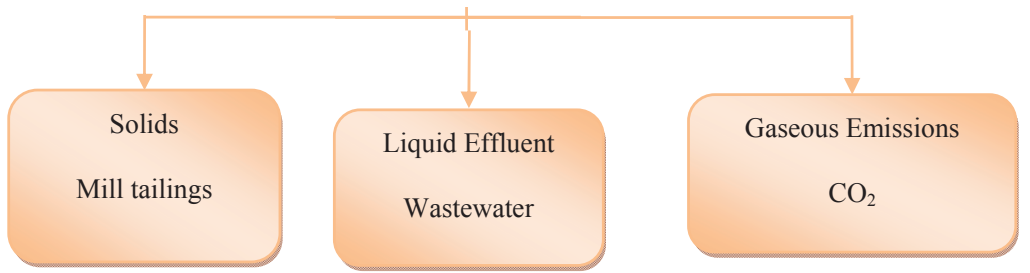

Figure 5-3. Inputs and Outputs for milling operations.

7. Several of the impacts estimated in this report are normalized per MTNU. Milling losses were considered negligible within the context of this report. This is considered appropriate both because milling losses are relatively small relative to other uncertainties and also because the mining impacts used as the basis of the estimates was often normalized based on the MTNU from the milling process (because the mining and milling data was not typically disaggregated). 


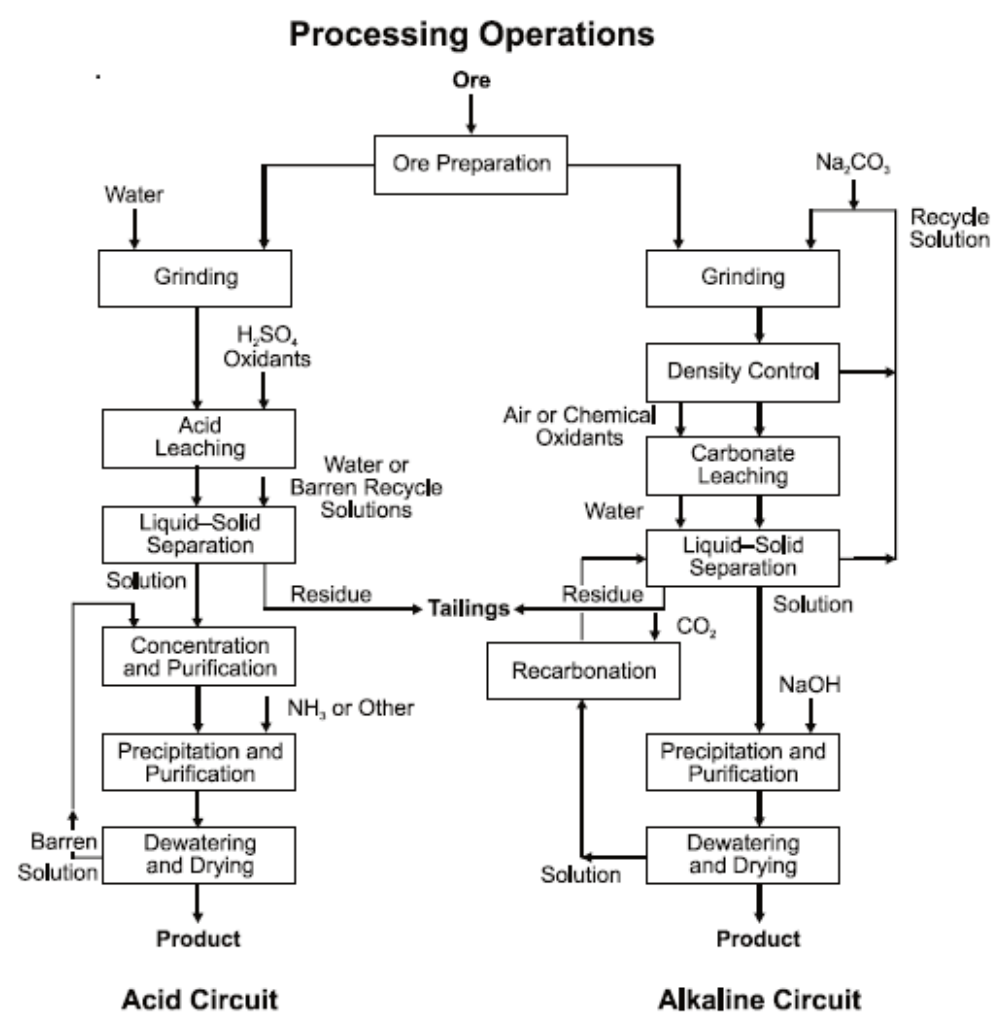

Figure 5-4. Acid and alkaline circuits used to extract dissolved uranium (Merritt, 1971).

EPA has established environmental protection standards for mill tailings under the Uranium Mill Tailings Radiation Control Act (UMTRCA) (http://www.epa.gov/radtown/uranium-mines.html) while the NRC or its agreement States oversee and regulate conventional milling operations under Title 10, Part 40, of the Code of Federal Regulations (10 CFR Part 40), "Domestic Licensing of Source Material." (NRC, http://www.nrc.gov/materials/uranium-recovery/extraction-methods/conventional-mills.html)

Land use for milling operations results from the land occupied by the mill itself, and for the disposal of waste streams. Mill tailings are the major waste stream and are pumped, in slurry-form, into an impoundment. Modern impoundments are buried below grade to minimize the risk of major failures that could release large amounts of toxic and radioactive elements into the environment. The mill site itself represents non-permanent land use, as the land can be restored after decommissioning. However, because mill tailings contain toxic and radioactive elements that will be present long into the future, the tailings impoundments represent permanent land use despite being covered with soil and vegetation to minimize release into the ecosystem.

Milling operations use a significant amount of water for the extraction process and to suppress dust from the crushing process that contain toxic and radioactive elements. Wastewater may be pumped in slurry 
Environmental Impacts, Health and Safety Impacts, and Financial Costs of the Front-End of the Nuclear Fuel Cycle

July 2013

and disposed of in tailings impoundments or it may be collected in retention ponds and is disposed of through evaporation or recirculation in the milling operation.

Additionally, some companies recycle $90+\%$ of their water while many other companies do not. Investment in water-recycling and water treatment programs depend largely upon local environmental regulations, the availability of water at the mining and milling sites, and the costs of associated with recycling water and water treatment.

Direct energy use in milling operations includes the electricity needed to grind/crush rock ore and for the process heat necessary during the leaching and the drying steps of the milling process. The temperatures needed for the leaching step vary with the leaching agent used, but typically fall in the range of 60-90 degrees Celsius. Drying may use a more energy intensive calcinating dryer that heats the precipitated uranium product to approximately 700 degrees Celsius and achieves a very high degree of purity or it may use an indirectly fired dryer that is much less energy intensive but achieves a lower purity. The milling operation also uses significant embodied energy in the process chemicals such as sulfuric acid.

\section{3 $\mathrm{U}_{3} \mathrm{O}_{8}$ to $\mathrm{UF}_{6}$ Conversion}

Yellowcake is converted to uranium hexafluoride $\left(\mathrm{UF}_{6}\right)$ for use in enrichment operations. Enrichment specifications require the purity of this converted product to be at least $99.99 \%$. The major suppliers of conversion capability are BNFL (United Kingdom), Cameco (Canada), AREVA subsidiary Comurhex (France), ConverDyn (U.S.), and Minatom (Russia).

Most facilities employ a 'wet' process that begins with a solvent extraction (SX) step followed by a fluorination step (F). Yellowcake may contain impurities of $1 \%$ to $20 \%$, depending on the source mine and deposit type; potential contaminants include $\mathrm{SO}_{4}, \mathrm{CO}_{3}$, oxides of $\mathrm{V}$, and $\mathrm{Th}$ (Boydell, 1980). In this initial step, the yellowcake is dissolved in nitric acid and an organic solvent, typically tributyl phosphate (TBP) in hexane or kerosene, recovering high purity $(>99.9 \%)$ uranium in the form of hydrated uranyl nitrate. A calcination step heats this compound to form uranium trioxide, $\mathrm{UO}_{3}$. The 'dry' process begins by grinding/resizing the yellowcake particles and subjecting them to a reduction reaction with hydrogen to form $\mathrm{UO}_{2}$.

In both processes, subsequent steps entail hydrofluorination to $\mathrm{UF}_{4}$ via reaction with hydrofluoric acid followed by further fluorination to $\mathrm{UF}_{6}$. The latter step reacts $\mathrm{UF}_{4}$ with $\mathrm{F}_{2}$ that is generally produced onsite at the conversion facility via electrolysis of $\mathrm{HF}$, so that $\mathrm{F}_{2}$ production will be considered to be within the process boundaries. Since the dry process (fluorination-fluorination, F-F) does not begin with a solvent extraction/purification step, some impurities remain with the $\mathrm{UF}_{6}$. Their removal by distillation is the final process stage.

In France, the Comurhex Malvesi plant converts yellowcake to $\mathrm{UF}_{4}$ by the wet hydrofluorination process. The $U_{4}$ is shipped to AREVA's Tricastin facilities, where additional fluorination results in $U_{6}$; the largest chemical input in both steps of the process is hydrofluoric acid (AREVA, 2012). In Canada, the Cameco Blind River facility carries out the solvent extraction and calcination steps. $\mathrm{UO}_{3}$ is shipped to Port Hope for subsequent conversion to $\mathrm{UF}_{6}$ (Senes, 2010). All large plants, except in the US, follow this two-facility model, so that transportation of $\mathrm{UF}_{4}$ or $\mathrm{UO}_{3}$ may be required. In this study, transportation of $\mathrm{UF}_{4}$ as well as $\mathrm{UF}_{6}$ will be assumed ${ }^{8}$. UF 4 , a green, granular solid, is transportable in 55-gallon drums. $\mathrm{UF}_{6}$, a solid at room temperature and pressure, is transported to an enrichment facility within type $48 \mathrm{Y}$

8. Note that this assumption will not be compatible with fuel cycles utilizing natural uranium. As implemented in Canada, this cycle only utilizes the first step of the wet process to obtain purified $\mathrm{UO}_{3}$. The $\mathrm{UO}_{3}$ is then the product that is transported to the next fuel cycle step, fuel fabrication. 
carbon steel cylinders. This container is suitable for autoclave heating at the enrichment plant to sublimate the solid so that it may enter the enrichment cascade.

The domestic facility, Honeywell's Metropolis Works (MTW), located in Metropolis, Illinois, is the only large conversion facility that uses the dry conversion process. At its time of construction, the facility had a capacity of 5,000 tonnes of uranium as $\mathrm{UF}_{6}$ per year (MTNU/yr); it has since been expanded several times. The current capacity of MTW is $14,000 \mathrm{MTNU} / \mathrm{yr}$, with operations underway to increase production to $18,000 \mathrm{MTNU} / \mathrm{yr}$.

Given its prevalence, the wet process will be taken as the reference technology but metrics for the dry process will also be presented ${ }^{9}$. Selection of a single reference plant is complicated by the lack of comprehensive data for all impact categories considered in this study. Incomplete data are available for the French Malvesi and Tricastin plants, along with Cameco's Canadian facilities and two smaller, nowretired US plants, the General Atomics Sequoyah plant in Oklahoma and the DOE Fernald facility in Ohio. Most activities at Fernald supported the US nuclear weapons program, and it was these that gave rise to the uranium dust releases that led the plant to be classified as a Superfund site. While both Sequoyah and Fernald would not adhere to today's environmental standards, historical data from these plants concerning, for example, energy, land and water use is utilized when more modern data are not available. For comparison, similar impacts were calculated for the dry conversion process and are presented in Appendix E.

Conversion is a chemical transformation process, so chemicals dominate material inputs crossing the system boundary. Effluents are treated to mitigate the environmental release of chemical byproducts, for example airborne and aqueous fluorides, uranium compounds, nitrates and ammonia. The composition and prevalence of other byproducts, for example sulfates and eluted solids, depends to an extent on the contaminants present in the feed yellowcake (AEC, 1974). At Port Hope, continuous monitoring programs are in operation for airborne emissions and water releases of uranium, fluorides, ammonia, and nitrogen oxides, as well as ambient air dust fall and water $\mathrm{pH}$ (Cameco, 2011). HF levels are also monitored at multiple locations within the plant. This chemical is monitored especially closely as inhalation of HF vapor at levels of even 10-15 ppm can lead to lung and eye irritation and, if sustained, pulmonary edema and fluorosis. Acute inhalation of higher concentrations of HF at levels of even 30-50 ppm can cause permanent respiratory tract damage and, at the upper end of this range, death.

Radiological emissions are primarily associated with release of trace amounts of waterborne $\mathrm{UO}_{2} \mathrm{~S}$ and $\mathrm{UO}_{2} \mathrm{~N}$ and airborne uranium fluorides.

The basis unit for conversion will be tonnes uranium as $\mathrm{UF}_{6}$ product. Figure 5-5 shows, and Table 5-6 quantifies, the significant inputs and outputs to the reference wet process. The basis for the values given in Table 5-6 is provided in Appendix H, Table H-2.

9. Enercon Federal Services, Inc. (ENERCON), as part of the Fuel Cycle Research and Development (FCRD) program, has obtained data from the MTW dry conversion facility. Enercon reviewed NRC License documents, MTW procedures and facility effluent reports that were submitted to the NRC in their efforts to obtain the data for the dry conversion process. Additionally, Enercon performed a site visit on 7-10 and 7-11-2012 to verify and finalize the data, presented in (Enercon, 2012). 
Environmental Impacts, Health and Safety Impacts, and Financial Costs of the Front-End of the Nuclear Fuel Cycle

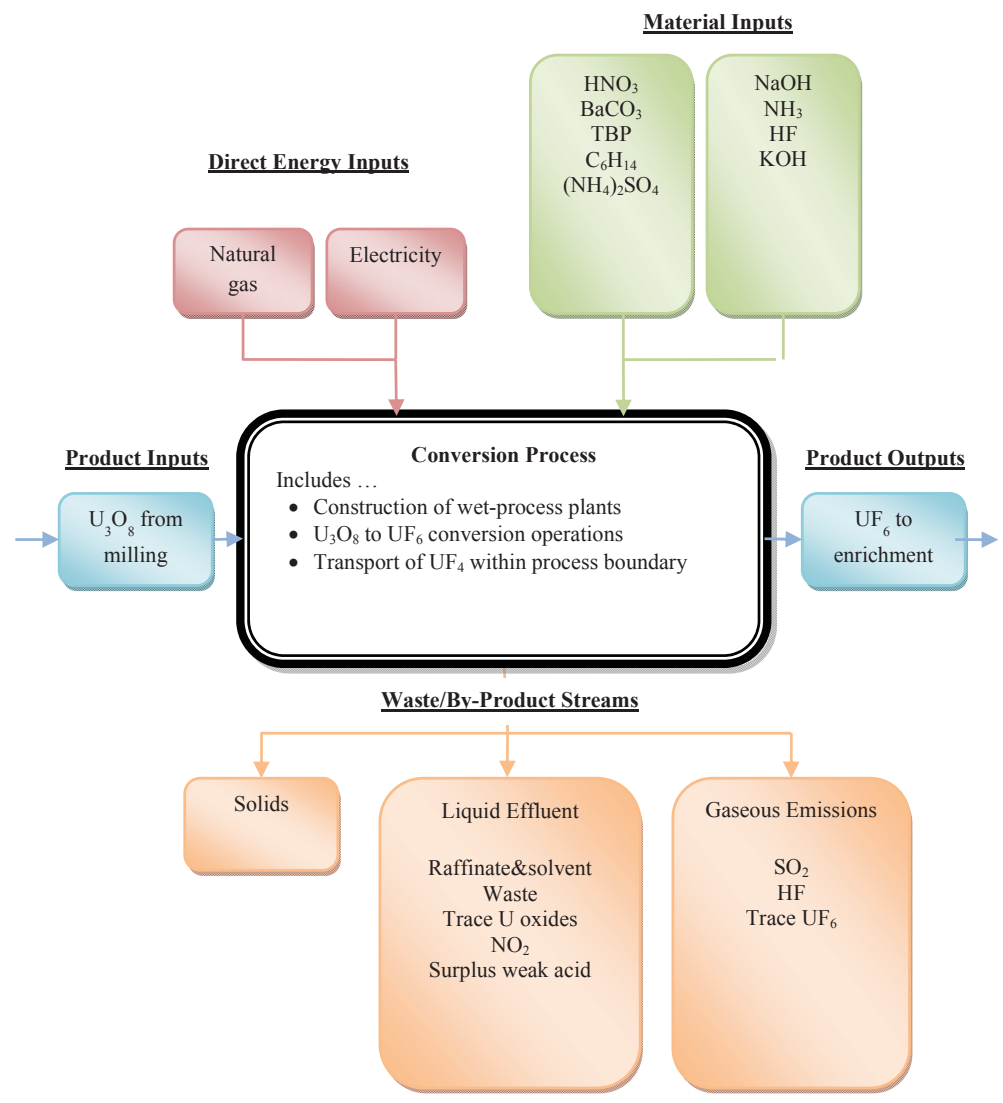

Figure 5-5. Inputs and Outputs to the Conversion Process. 


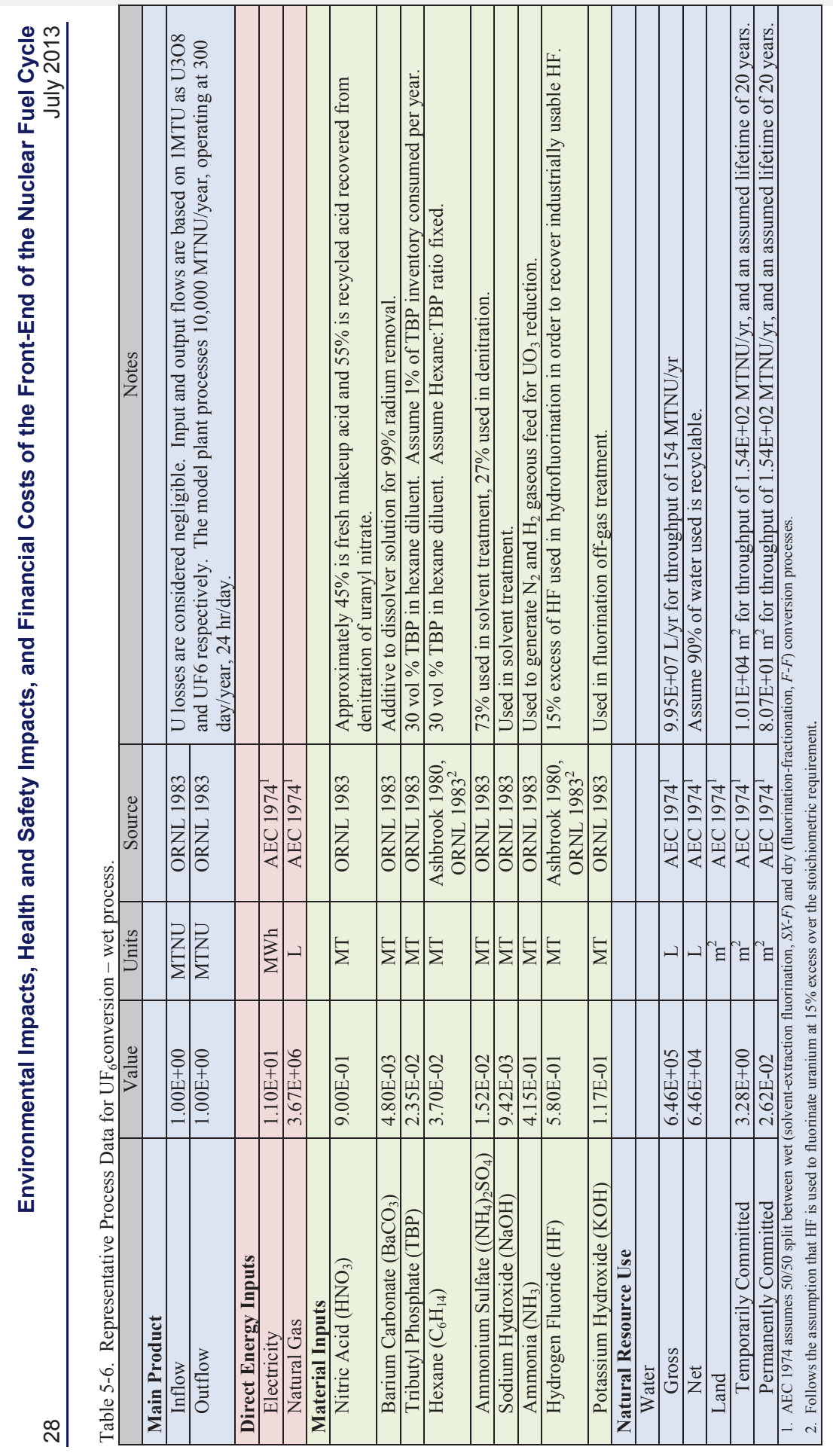


Environmental Impacts, Health and Safety Impacts, and Financial Costs of the Front-End of the Nuclear Fuel Cycle

July 2013

\subsection{Uranium Enrichment}

The unit against which the environmental impacts of enrichment will be normalized is the separative work unit (SWU). SWU carries units of mass and is related to the degree of isotopic separation achieved. It is proportional to the feed mass (of an individual enrichment unit or a collection of units acting in series and parallel, termed a 'cascade') as well as the electrical energy requirement for a given enrichment technology.

The uranium enrichment process splits the input stream, natural uranium as $\mathrm{UF}_{6}$, into two product streams - enriched uranium and depleted uranium (DU). The ratio between these two product streams and the SWU usage to achieve the separation is determined by the specified enrichment and the tails assay. In this study, the tails assay will be assumed to be $0.25 \% \mathrm{U}-235$. The specified enrichment will be a fuelcycle-specific parameter. Once the enrichment is specified, the mass flow splits and SWU consumption for the enrichment process can be determined.

Two enrichment technologies are deployed at industrial scale: gaseous diffusion and gas centrifuge. As diffusion plants in the US and France are being retired in favor of centrifuge technology, they are largely of historical interest.

A third technology, the Silex process being developed by GE-Hitachi, may make a commercial debut as soon as 2014. Unlike the present-day technologies, which rely upon the mass difference between ${ }^{235} \mathrm{UF}_{6}$ and ${ }^{238} \mathrm{UF}_{6}$, the laser-driven Silex process takes advantage of the isotopic shift between ${ }^{235} \mathrm{UF}_{6}$ and ${ }^{238} \mathrm{UF}_{6}$ absorption bands. A recently-issued environmental impact statement (EIS) (NRC 2012b) provides the first set of publicly-available data for many impact categories, particularly those tied to occupational and public health and safety. But other technical and performance data for Silex continues to be covered by corporate and federal (US) classification restrictions. Therefore, several impact categories, for instance cost and energy use, can only be described in qualitative terms.

Given the large investments in centrifuge technology and capital stock by Urenco, AREVA and Minatom, it is certain that centrifuge enrichment will persist for several decades even if Silex achieves commercial success. For this reason, centrifuge technology will be chosen as the reference for this fuel cycle step. However, some of the impacts associated with the Silex process are also given in order to provide an indication of what may be expected as next-generation processes are deployed.

Reference data for centrifuge enrichment can be obtained from facilities operated by Urenco, operator of plants in the United Kingdom, Germany, the Netherlands and the United States. Since AREVA is just entering the centrifuge enrichment market as of 2012, the Urenco plants will form the basis for the reference facility. In particular, an EIS was published in 2005 for the Louisiana Energy Services Urenco USA enrichment facility (formerly known as the National Enrichment Facility) (LES, 2005). This document constitutes the preferred data source for reference material and energy balance values.

This facility began operations in 2010 at a capacity of 3,000kSWU/year. While Urenco has announced plans to expand the capacity to $5,700 \mathrm{kSWU} / \mathrm{year}$ by 2015 , the EIS is based on the lower initial capacity level. This upgrade would be expected to leave impacts unchanged or reduce them on a per-kSWU basis, as the facility attains further benefits from economies of scale. Hence use of (LES, 2005) as a reference document provides a conservative estimate of the ultimate impacts of the Urenco facility.

Figure 5-6 depicts the transportation requirements for the reference Urenco USA facility. Two uraniumbearing mass streams leave the facility: enriched $\mathrm{UF}_{6}$ to fuel fabrication, conveyed in type $30 \mathrm{~B}$ cylinders (Figure 5-7) and depleted $\mathrm{UF}_{6}$ to storage or DU deconversion in type $48 \mathrm{Y}$ cylinders (Figure 5-8). 
Environmental Impacts, Health and Safety Impacts, and Financial Costs of the Front-End of the Nuclear Fuel Cycle

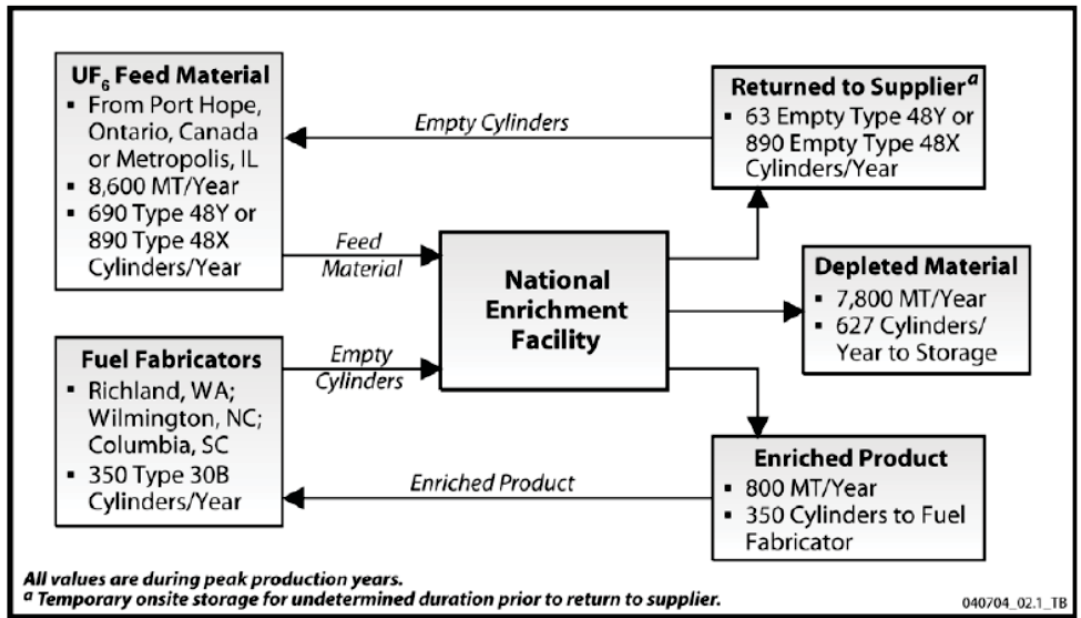

Figure 5-6. Transportation flows for enrichment facility (LES, 2005).

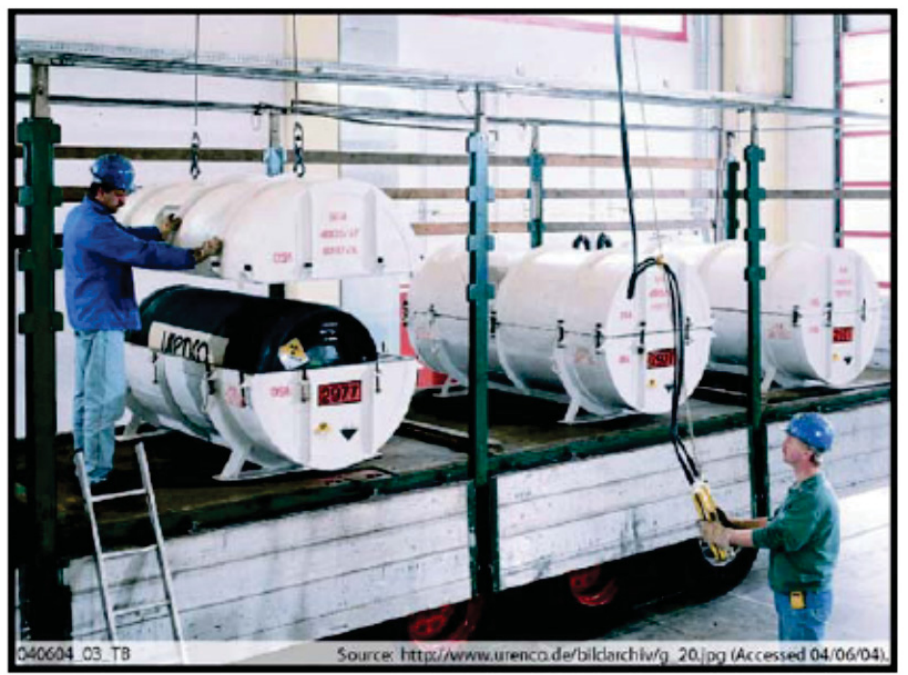

Figure 5-7. 30B cylinders $\left(\mathrm{UF}_{6}\right)$. (LES, 2005) 
Environmental Impacts, Health and Safety Impacts, and Financial Costs of the Front-End of the Nuclear Fuel Cycle

July 2013

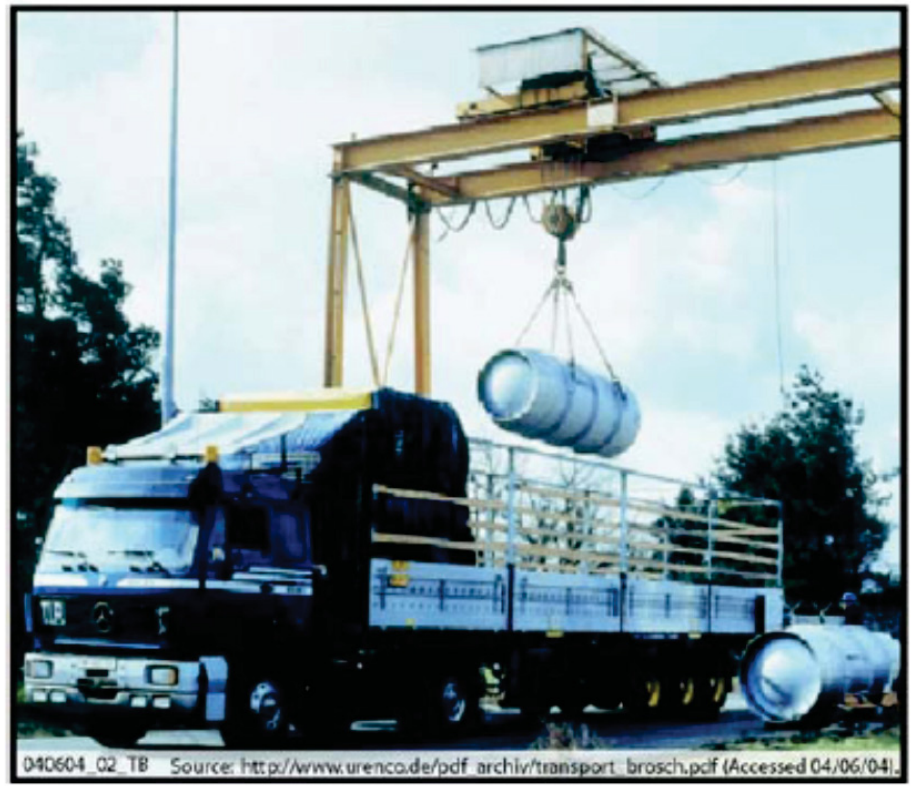

Figure 5-8. 48Y Cylinder (DUF 6 ) being loaded. (LES, 2005).

Figure 5-9 depicts the inputs and outputs for the centrifuge enrichment and Table 5-7 quantifies the significant inputs and outputs. In the figure and table, separative work is represented as an output although it is not a tangible product of the enrichment process. Since each centrifuge machine has a production 'capacity' expressed in SWU/year, the overall capacity for all enrichment facilities is always specified in SWU/year as well. On the other hand, some impacts, for instance those related to health and safety, may depend on the uranium throughput of the plant rather than its SWU capacity.

In Table 5-7, all quantities are normalized against 1 SWU of output. To calculate nominal feed (NU), product (enriched $U$ ) and DU masses per SWU, a product enrichment of $4.2 \%$ is assumed. If the actual product enrichment of a fuel cycle differs from this value, all impacts and material flows documented in Table 5-7 remain valid as they are assessed on the per-SWU basis. The basis for the values given in Table 5-7 is provided in Appendix H, Table H-4. 
Environmental Impacts, Health and Safety Impacts, and Financial Costs of the Front-End of the

Nuclear Fuel Cycle

\section{Direct Energy Inputs}

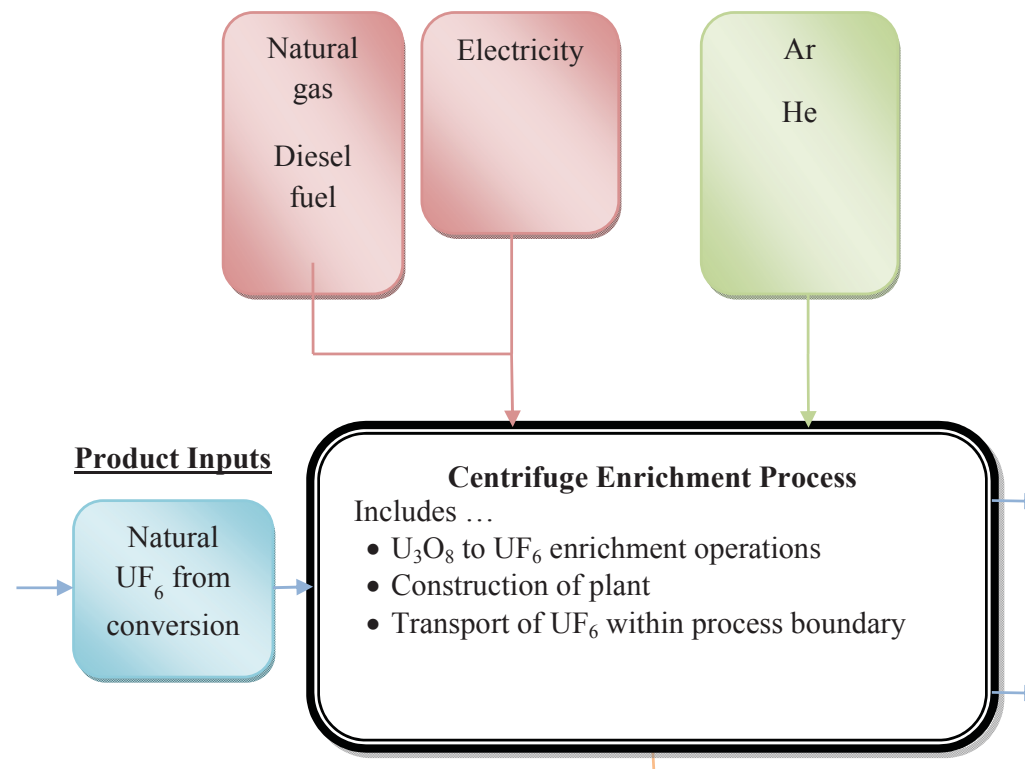

$\underline{\text { Waste/By-Product Streams }}$

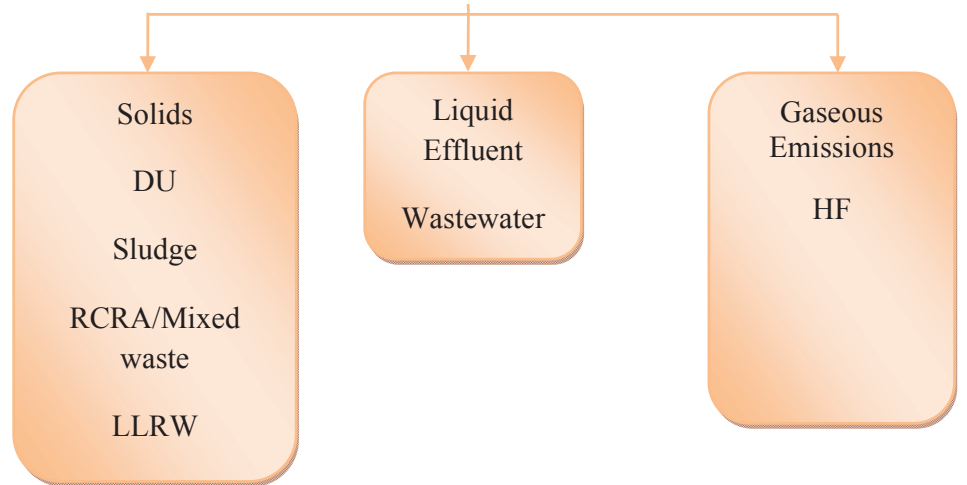

Figure 5-9. Inputs and Outputs to the Centrifuge Enrichment Process. 


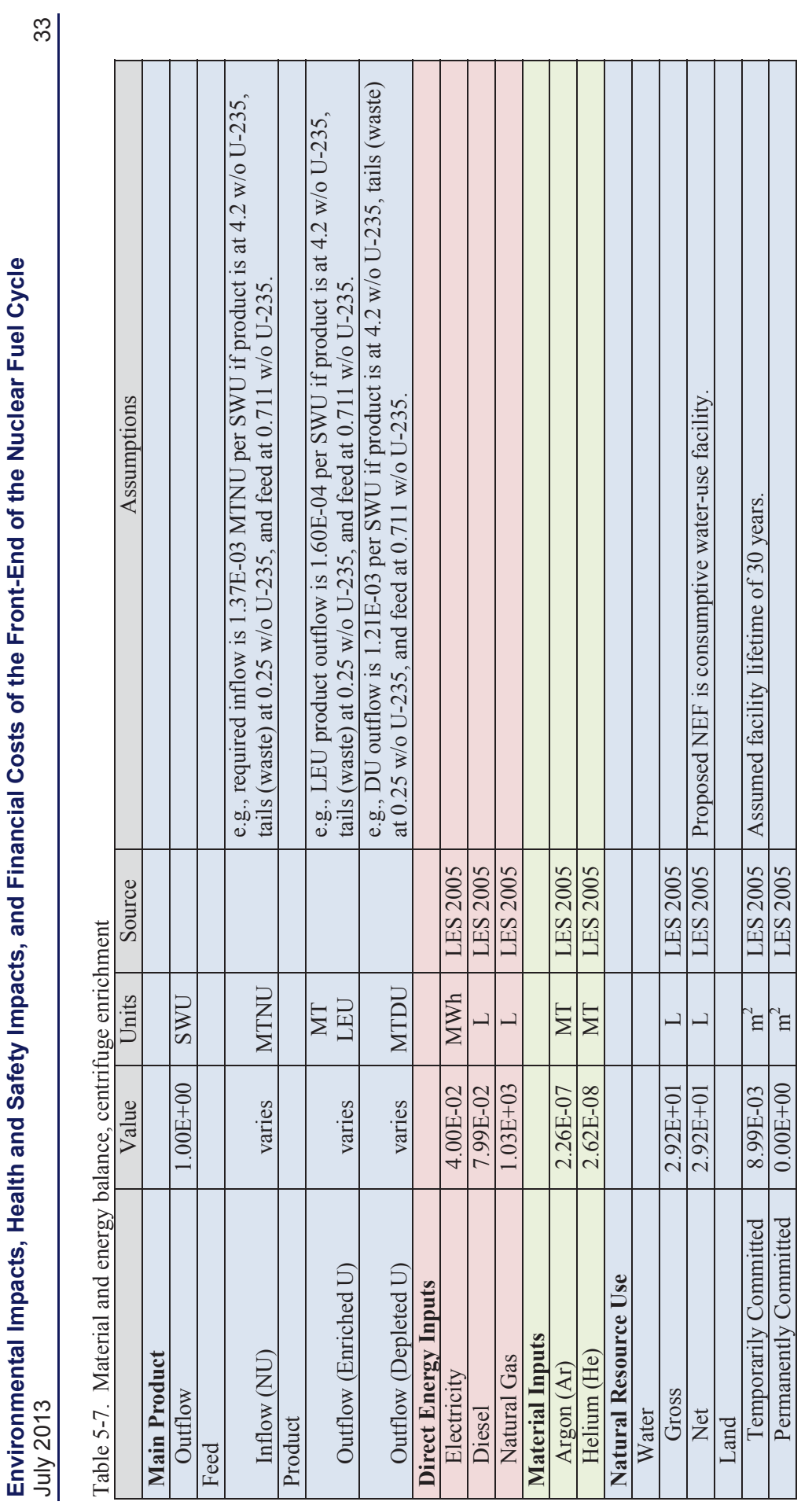




\section{5 $\mathrm{DU}_{3} \mathrm{O}_{8}$ Deconversion}

The enrichment process generates $\mathrm{DUF}_{6}$ tailings. In the US, these tailings typically contain between 0.2 and $0.4 \%$ uranium-235 and have been stored in solid form ${ }^{10}$ in large steel cylinders at enrichment site storage yards (Figure 5-10). A typical DUF 6 container (Figure 5-11) has a 12 tonne capacity. Depleted uranium hexafluoride $\left(D_{U} F_{6}\right)$ is deconverted to yellowcake $\left(\mathrm{DU}_{3} \mathrm{O}_{8}\right)$ where it may be stored as a potential $\mid$ resource for future energy production for disposed of as a waste ${ }^{11}$. In the dry defluorination used at industrial-scale facilities in the US, $\mathrm{DUF}_{6}$ is reacted with steam and hydrogen in a fluidized-bed conversion unit to produce $\mathrm{DU}_{3} \mathrm{O}_{8}$ and hydrogen fluoride (HF). Hydrogen is generated within the plant via ammonia cracking. The recovered $\mathrm{DU}_{3} \mathrm{O}_{8}$ powder is in a more chemically stable form than $\mathrm{DUF}_{6}$ and is generally suitable for disposal as low-level radioactive waste (LLRW). The HF byproduct is collected for commercial sale ${ }^{12}$ or neutralization to calcium fluoride $\left(\mathrm{CaF}_{2}\right)$.

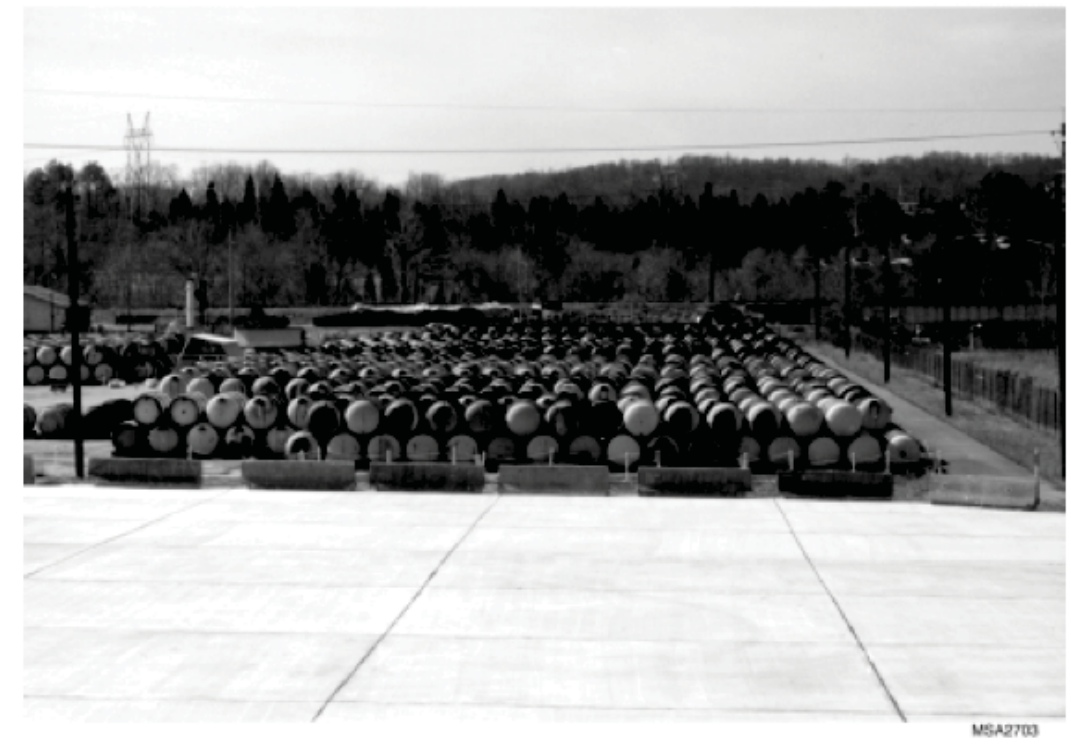

Figure 5-10. DUF 6 storage yard (Harlow, 1999).

Large-scale deconversion is ongoing in France and several other countries incorporate deconversion into their near-term fuel cycle plans. For instance, a deconversion facility processing 3,000 tDU/year is slated to open in the UK in 2020 (HSE, 2004). But as the US program has industrial-scale facilities entering production they will serve as the reference facilities. The DOE has assumed responsibility for

10. At atmospheric pressure, $\mathrm{UF}_{6}$ is a solid at temperatures below $134^{\circ} \mathrm{F}$.

11. Future fuel cycles could utilize this DU as fertile material or for direct fission in a fast-spectrum. Impacts associated with the storage or immobilization and disposal of the products from deconversion are outside the scope of this report. The resulting $\mathrm{DU}_{3} \mathrm{O}_{8}$ may also be used for down-blending HEU.

12. The reference facility concluded a sales contract to supply HF to Solvay Fluorides, a commercial vendor, in May 2006 Hence credit will be taken for both the economic value of the HF and its energy content. 
Environmental Impacts, Health and Safety Impacts, and Financial Costs of the Front-End of the Nuclear Fuel Cycle

management of approximately $700,000 \mathrm{MT}_{\text {of }} \mathrm{DUF}_{6}$, currently stored in about 57,000 cylinders ${ }^{13}$ at the Paducah GDP, the Portsmouth GDP, and the East Tennessee Technology Park (ETTP) (formerly the K25 Site). Due to their age, some $\mathrm{DUF}_{6}$ cylinders show evidence of external corrosion, creating a potential environmental and safety hazard.

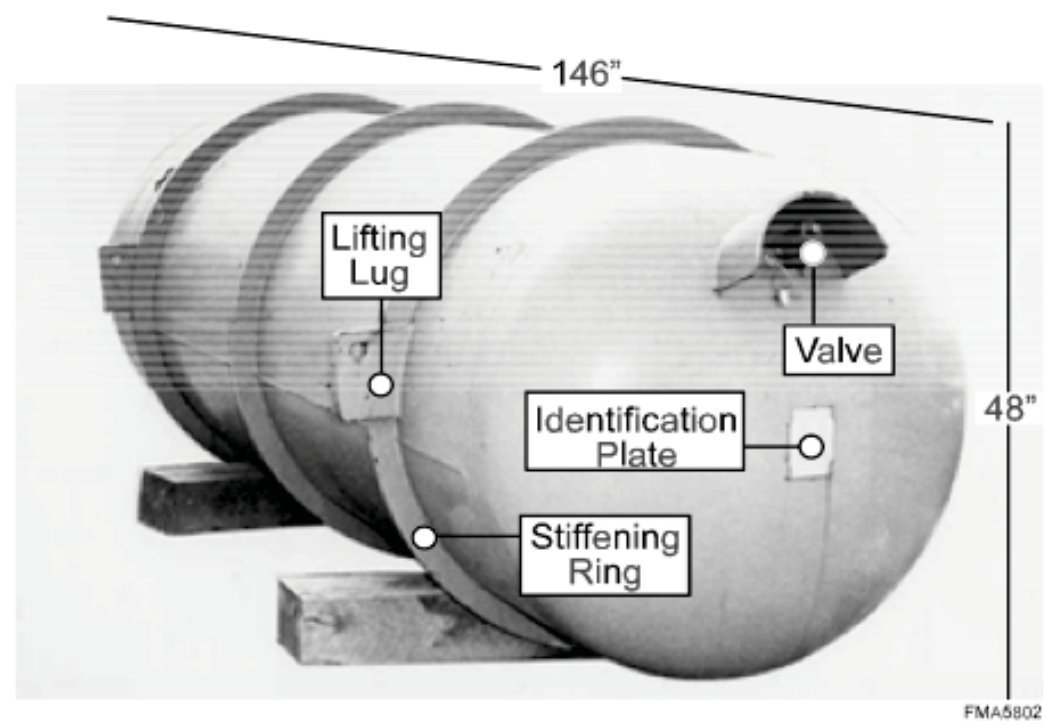

Figure 5-11. Type 48Y DUF 6 Storage Cylinder (Harlow, 1999).

Following an options study (Harlow, 1999), DOE opted to deconvert DUF 6 to depleted uranium oxide, depleted uranium metal, or a combination of both (DOE, 1999a, b). Subsequently DOE elected to pursue the oxide deconversion option (DOE, 2004a, b) and issued EISs for the Paducah and Portsmouth sites (Hartman 2004a, b).

Construction at Portsmouth and Paducah was completed in 2010, and as of 2012 the plants have commenced limited operations. The facilities will employ the dry defluorination process to deconvert the DOE's DUF ${ }_{6}$ inventory to $\mathrm{DU}_{3} \mathrm{O}_{8}$. The Paducah facility is expected to have an annual throughput of $18,000 \mathrm{MT} \mathrm{DUF}_{6} /$ year and operate for 25 years, while the Portsmouth facility will have an annual throughput of 13,500 MT DUF 6 /year and 18-year operational lifetime. These two facilities will be taken as reference plants. Data for all impact categories considered in this study are averaged between the two plants ${ }^{14}$.

The basis unit for deconversion will be tonnes uranium in the $\mathrm{DU}_{3} \mathrm{O}_{8}$ product. Figure 5-12 depicts the inputs and outputs for the technology. Table 5-8 quantifies the significant inputs and outputs. The impacts of deconversion can only be meaningfully estimated in units that correlate directly with the quantity of $\mathrm{DU}_{3} \mathrm{O}_{8}$ processed; like $\mathrm{SWU}$, the $\mathrm{DU}_{3} \mathrm{O}_{8}$ per unit MTNU also depends upon the fuel enrichment specs. The basis for the values given in Table 5-8 is provided in Appendix H, Table H-5.

13. This includes approximately 11,200 cylinders of $\mathrm{DUF}_{6}$ generated by USEC.

14. DOE maintains an information service that provides the current status of the facilities. See (PPPO, 2012) and (DOE, 2012). 
Environmental Impacts, Health and Safety Impacts, and Financial Costs of the Front-End of the

Nuclear Fuel Cycle

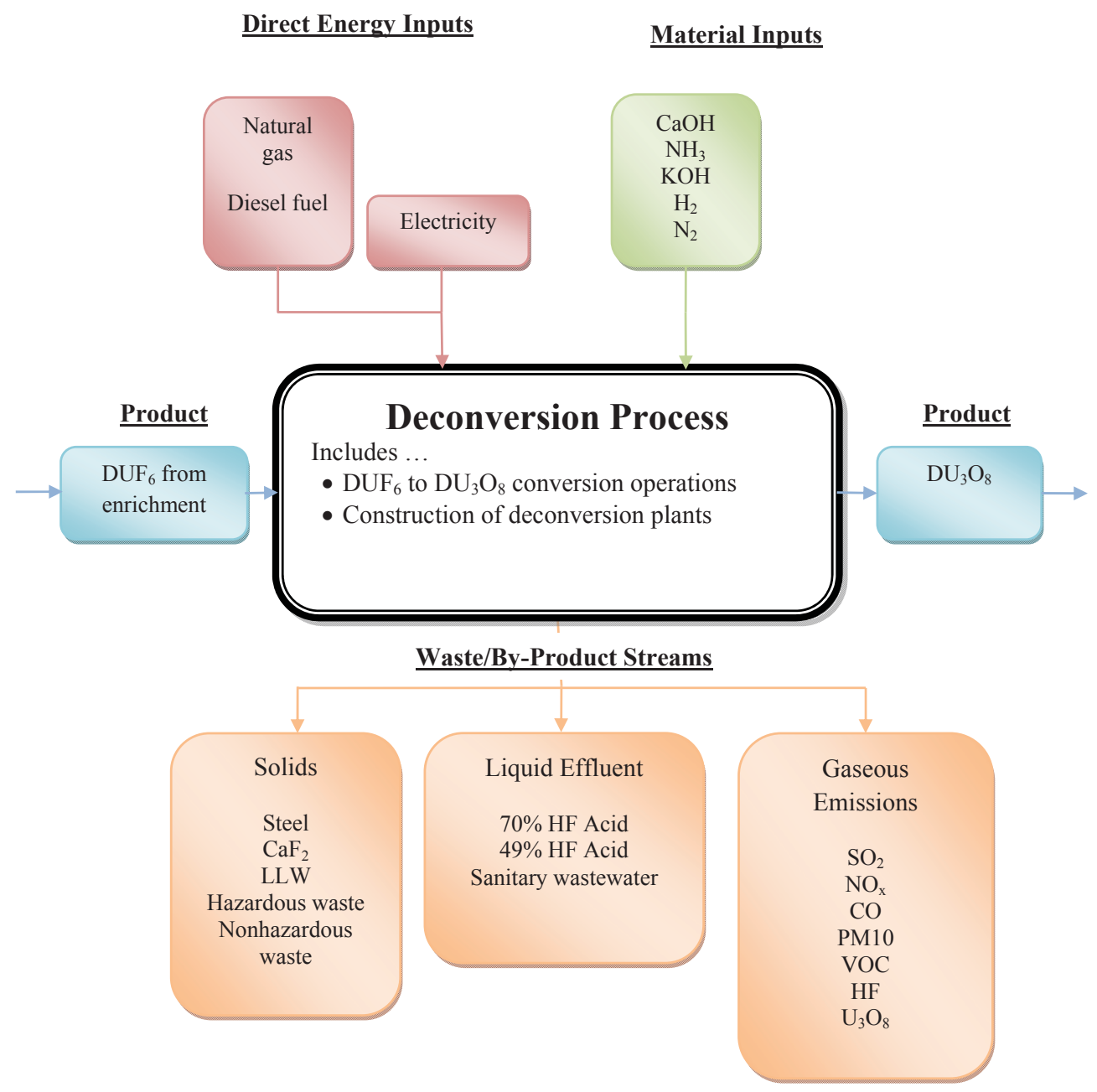

Figure 5-12. Inputs and Outputs to $\mathrm{DU}_{3} \mathrm{O}_{8}$ Deconversion. 
Environmental Impacts, Health and Safety Impacts, and Financial Costs of the Front-End of the Nuclear Fuel Cycle

July 2013

Table 5-8. Material and energy balance, $\mathrm{DU}_{3} \mathrm{O}_{8}$ deconversion

\begin{tabular}{|c|c|c|c|c|}
\hline & Value & Units & Source & Assumptions \\
\hline \multicolumn{5}{|l|}{ Main Product } \\
\hline Inflow & $1.0007 \mathrm{E}+00$ & MT DU & Hartman 2004a, b & $\begin{array}{l}\text { As DUF } 6.18,000 \mathrm{MT} \mathrm{DUF}_{6} \\
\text { and } 13,500 \mathrm{MT} \mathrm{DUF}_{6} \\
\text { processed annually at Paducah } \\
\text { and Portsmouth, respectively. }\end{array}$ \\
\hline Outflow & $1.00 \mathrm{E}+00$ & $\mathrm{MT} \mathrm{DU}^{1}$ & Hartman 2004a, b & As $\mathrm{DU}_{3} \mathrm{O}_{8}$. \\
\hline \multicolumn{5}{|l|}{ Direct Energy Inputs } \\
\hline Electricity & $3.23 \mathrm{E}+00$ & MWh & Hartman 2004a, b & \\
\hline Liquid Fuel & $1.25 \mathrm{E}+00$ & $\mathrm{~L}$ & Hartman 2004a, b & \\
\hline Natural Gas & $1.13 \mathrm{E}+05$ & $\mathrm{~L}$ & Hartman 2004a, b & \\
\hline \multicolumn{5}{|l|}{ Material Inputs } \\
\hline Hydrated Lime $(\mathrm{CaOH})$ & $1.44 \mathrm{E}-03$ & MT & Areva 2012a, b & $\begin{array}{l}\text { Based on usage rate of } 15 \\
\text { MT/a. Assume capacity factor } \\
\text { of } 0.9\end{array}$ \\
\hline Ammonia $\left(\mathrm{NH}_{3}\right)$ & $5.29 \mathrm{E}-02$ & MT & Hartman 2004a, b & 99.95\% minimum $\mathrm{NH}_{3}$. \\
\hline Potassium Hydroxide $(\mathrm{KOH})$ & $5.30 \mathrm{E}-04$ & MT & Areva 2012a, b & $\begin{array}{l}\text { Based on usage rate of } 5.5 \\
\text { MT/a. Assume capacity factor } \\
\text { of } 0.9 \text {. }\end{array}$ \\
\hline Hydrogen $\left(\mathrm{H}_{2}\right)$ & 8.98E-03 & MT & Areva 2012a, b & $\begin{array}{l}\text { Based on usage rate of } 11.9 \\
\mathrm{~kg} / \mathrm{hr} \text {. Assume capacity factor } \\
\text { of } 0.9 \text {. }\end{array}$ \\
\hline Nitrogen $\left(\mathrm{N}_{2}\right)$ & $8.03 \mathrm{E}-01$ & MT & Areva 2012a, b & $\begin{array}{l}\text { Based on usage rate of } 1,064 \\
\mathrm{~kg} / \mathrm{hr} \text {. Assume capacity factor } \\
\text { of } 0.9 \text {. }\end{array}$ \\
\hline \multicolumn{5}{|l|}{ Waste/By-Product Streams } \\
\hline Hydrogen Fluoride Acid (HF) & $5.08 \mathrm{E}-01$ & MT & Areva 2012a, b & \\
\hline \multicolumn{5}{|l|}{ Natural Resource Use } \\
\hline \multicolumn{5}{|l|}{ Water } \\
\hline Gross & $1.31 \mathrm{E}+04$ & $\mathrm{~L}$ & Hartman 2004a, b & Raw water consumption. \\
\hline Net & $5.27 \mathrm{E}+02$ & $\mathrm{~L}$ & Hartman 2004a, b & $\begin{array}{l}\text { Under the assumption that all } \\
\text { water not disposed as waste } \\
\text { water is recycled. }\end{array}$ \\
\hline \multicolumn{5}{|l|}{ Land } \\
\hline Temporarily Committed & $9.29 \mathrm{E}+01$ & $\mathrm{~m}^{2}$ & Areva $2012 b$ & $\begin{array}{l}\text { DOE Exclusion area to occupy } \\
\text { 3714-acre for } 18 \text { years. }\end{array}$ \\
\hline Permanently Committed & $0.00 \mathrm{E}+00$ & $\mathrm{~m}^{2}$ & Areva 2012a, b & $\begin{array}{l}\text { No cumulative land impacts } \\
\text { are anticipated. }\end{array}$ \\
\hline
\end{tabular}




\subsection{FEFC Activities-Thorium}

The demand for thorium has historically been very small because it is only used in small quantities for specialty applications such as catalysts, gas lantern mantles, and welding rods. For example, the U.S. consumption of thorium ranged between six and seven metric tons per year between 1998 and 2000 [Hedrick 2002]. This situation notwithstanding, substantial amounts of thorium are extracted from the earth because thorium occurs in ores containing currently valuable materials such as the rare earth elements (REE), titanium, and iron.

Thorium's usefulness in many types of nuclear reactors has long been known. However, availability of Th coupled with concerns over uranium supply have renewed interest in various countries, government organizations, and private industry. The use of thorium as a source of nuclear fuel was studied as early as 1946 at the Oak Ridge National Laboratory in Tennessee, and electricity has been generated in test reactors developed in the United States, Europe, Japan, Russia, and India. Despite success in the demonstration stage, there are currently no commercial scale reactors, as there has been little incentive to make the required investment necessary to complement or replace existing current fuel-cycle infrastructure (USGS 2010).

Thorium is the 38th most abundant element in the crust of the earth, averaging about $6 \mathrm{ppm}$, with the $\mathrm{Th} / \mathrm{U}$ ratio about 3 . World Th reserves are currently estimated at $\sim 3$ to 7 million MT. This is likely to be a conservative estimate since there has been little financial incentive for exploration to date - and also because tax and other business considerations may discourage reporting excess reserves.

Should a demand for thorium rise, it is likely that supply will come from existing stockpiles, sources such as tailings impoundments, and by-product sources where part of the cost of production has already been paid. Because Th deposits occur coincidental with other valuable deposits (REE, titanium, etc.), it is unlikely that Th would be mined as a primary product. Globally, the amount of REE available alone produced in 2008 was about 124,000 MT and this is expected to increase to 200,000 MT/yr by 2014 [EPA 2012]. As a consequence, large quantities of thorium are currently being separated in impure form and managed as a waste. As shown in Appendix F, approximately 1160 MT could be produced annually based on a conservative estimate of Th available from by-product streams from current mining operations. This conservative estimate presumes an annual US production of only $40 \mathrm{MT}$.

A more detailed estimate of US Th production from by-product materials is also given in Appendix F. This projection estimates that the United States, although a very small contributor to the world REE market, has the potential to annually produce between 245 and 925 metric tonnes of elemental thoriumas byproducts of three rare-earth mines and one titanium-sand operation (Appendix F). This estimate indicates the U.S. could support at least a partial thorium reactor fleet with its own reserves. One of the rare-earth deposits is in production (Mountain Pass, California), and the other two are advanced exploration projects that may come into production by 2020 (Bokan Mountain, Alaska, and Bear Lodge, Wyoming). The titanium-sand production is in Virginia. As long as these projects remain commercially viable based on rare-earth and titanium-sand markets, they represent low-cost potential sources of thorium.

To provide perspective on these rates of thorium production, one should recognize that, because thorium is not itself a fissile material, thorium fuel cycles are inherently breeder systems. Breeder systems are typically much more fuel efficient and can use up to $100 \%$ of the original thorium - resulting in minimal amounts of natural thorium needed compared to once-through uranium fuel cycles in use today. Typical thorium fuel cycles consume, $\sim 1$ to $3.5 \mathrm{MT}$ of thorium to produce $\sim 10$ terawatt-hours of electricity. In 2011, a total of 790 terawatt-hours of electricity were generated by nuclear plants in the U.S. providing 
Environmental Impacts, Health and Safety Impacts, and Financial Costs of the Front-End of the Nuclear Fuel Cycle

$\sim 19 \%$ of the total U.S. electricity ${ }^{15}$. Using a thorium fuel cycle this would have required mining between $\sim 80$ and $280 \mathrm{MT}$ of thorium per year. Globally, nuclear power plants generated 2,600 terawatt-hours of electricity in $2008^{16}$, which would have required $\sim 260$ to 910 MT of thorium. Thus, the Th available from by-product streams of today's mining operations would likely support a fleet of Th-based reactors with generation capacity $\sim 1$ to 4 times that of today's nuclear plants.

Because thorium can be readily obtained as a byproduct of existing mining operations for the foreseeable future, most of the environmental and safety impact resulting from thorium production can be attributed to mining and production of other valuable materials and would occur whether thorium were recovered or not. Thus, the appropriate metric for recovering thorium is the incremental impact resulting from the added thorium recovery operations. Additionally, unlike uranium, thorium does not require conversion to gaseous form, isotopic enrichment, and management of the associated DU. However, because Th is a fertile rather than a fissile material, sustainable Th-based fuel cycles require fissile material for startup, reprocessing to recover U233, and appropriate fuel dissolution and refabrication processes.

Monazite, the primary mineral for Th, typically contains 6 to $8 \%$ (and up to $15 \%$ ) ThO2. Due to its relatively high specific gravity, substantial monazite deposits can be found in shoreline placers and can also be readily separated by mechanical and gravitational processes. Th can also be recovered from monazite within unconsolidated materials such as beach sands or from the by-products of rare earth element (REE) mining processes. However, monazite is highly resistant to both chemical and physical breakdown and, consequently, if mined on any substantial scale, it may be more effective to transport it to a centralized processing facility for separations. Th- bearing ores such as bastnasite can also be recovered from open pit or underground mining. These other Th-bearing minerals are equally or more difficult to process than monazite.

Monazite is also often found in conjunction with the mineral ilmenite, which is the primary source of titanium. Most titanium mining operations currently discard monazite as part of a large waste stream, so processing of monazite in conjunction with ilmenite would involve some additional incremental costs and impacts (when compared to REE operations). The same could be said when monazite is found in conjunction with iron ore. In mining operations where REEs are the primary products, monazite (and/or bastnasite) is generally the primary REE-bearing mineral. In this case, monazite is already being chemically and physically processed, usually leaving behind a thorium-bearing waste slurry.

After physical separation, monazite or bastnasite must be chemically attacked to solubilize its components from a tightly bound mineral structure. After separating undigested solids and/or other byproducts, solvent (liquid-liquid) extraction is generally employed to obtain high grade thorium with very low levels of contamination (depending on mineral composition, a smaller amount of high grade uranium may also be obtained). Appendix F provides a more detailed discussion of the Th recovery process. Figure 5-13 provides a high level system diagram showing key inputs and outputs to the process. Table 5-9 provides quantities for key process inputs and outputs. It should be noted that the tables which follow represent the impacts of the entire thorium extraction and refining process. In the rare-earth by-product scenario, some of these impacts would be offset by the pre-existing rare earth extraction facility (see Appendix F for process details). The basis for the values given in Table 5-9 is provided in Appendix H, Table H-6.

15. Energy Information Agency 2012 Annual Energy Review

16. EIA 2011 International Energy Outlook 
Environmental Impacts, Health and Safety Impacts, and Financial Costs of the Front-End of the Nuclear Fuel Cycle

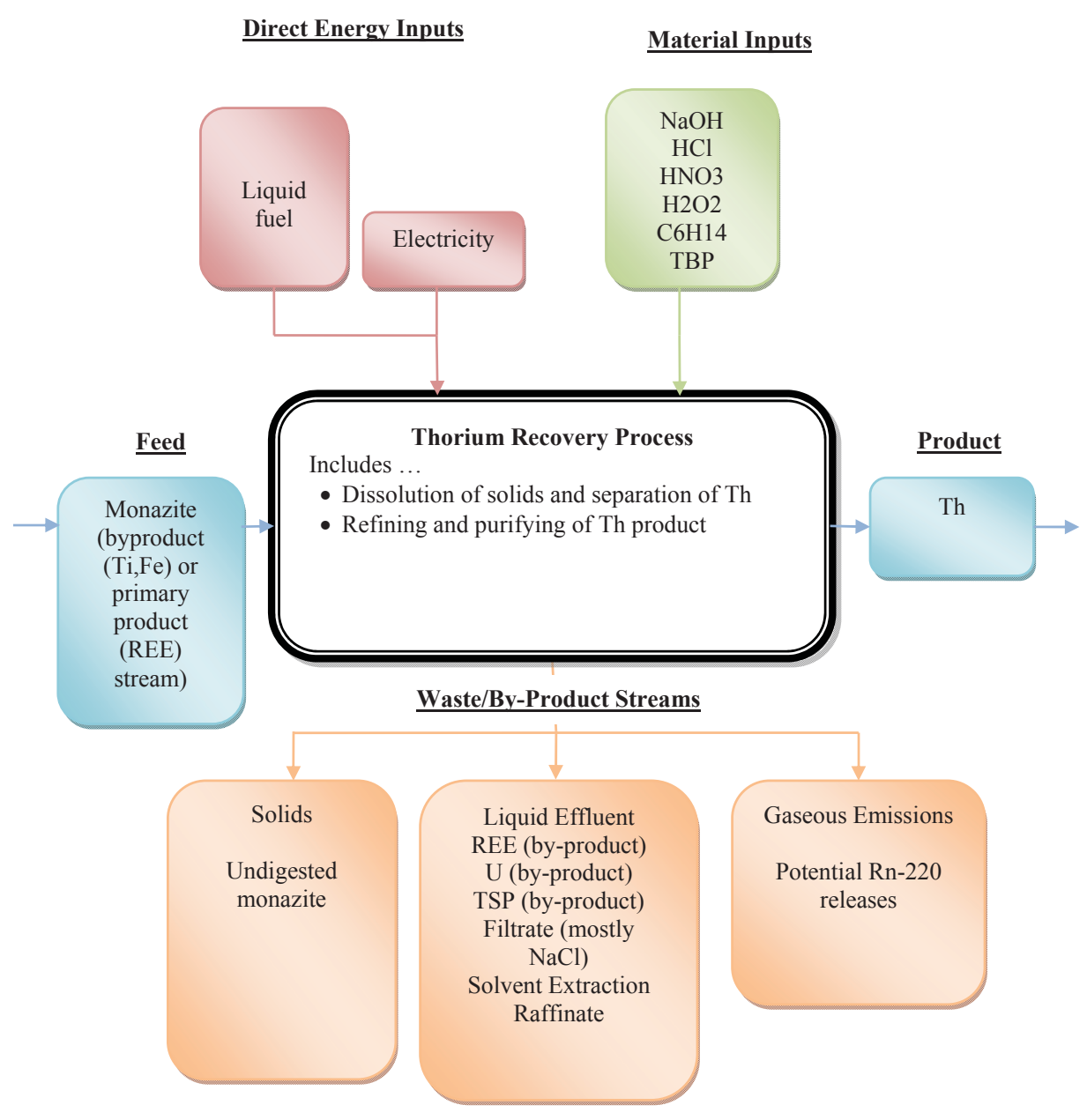

Figure 5-13. Inputs and Outputs to Thorium Extraction and Refining 
Environmental Impacts, Health and Safety Impacts, and Financial Costs of the Front-End of the Nuclear Fuel Cycle

Table 5-9. Material and energy balance, thorium extraction

\begin{tabular}{|c|c|c|c|c|}
\hline & Value & Units & Source & Assumptions \\
\hline \multicolumn{5}{|l|}{ Main Product } \\
\hline Inflow $\left(\right.$ as $\mathrm{ThO}_{2}$ ) & $1.07 \mathrm{E}+00$ & MTTh & [Appendix F] & \\
\hline Outflow $\left(\right.$ asThO $\left._{2}\right)$ & $1.00 \mathrm{E}+00$ & MT Th & [Appendix F] & \\
\hline \multicolumn{5}{|l|}{ Direct Energy Inputs } \\
\hline Electricity & $8.97 \mathrm{E}+00$ & MWh & [PNL 1980] & \\
\hline Liquid Fuel & $2.83 \mathrm{E}+03$ & $\mathrm{~L}$ & [PNL 1980] & \\
\hline \multicolumn{5}{|l|}{ Material Inputs } \\
\hline Sodium Hydroxide $(\mathrm{NaOH})$ & $2.58 \mathrm{E}+01$ & MT & [Appendix F] & \\
\hline Hydrochloric Acid $(\mathrm{HCl})$ & $8.42 \mathrm{E}+00$ & MT & [Appendix F] & \\
\hline Nitric Acid $\left(\mathrm{HNO}_{3}\right)$ & $2.61 \mathrm{E}+00$ & MT & [Appendix F] & \\
\hline Hydrogen Peroxide $\left(\mathrm{H}_{2} \mathrm{O}_{2}\right)$ & $1.14 \mathrm{E}-02$ & MT & [Appendix F] & \\
\hline Hexane $\left(\mathrm{C}_{6} \mathrm{H}_{14}\right)$ & $1.59 \mathrm{E}-01$ & MT & [Appendix F] & $1 \%$ of value derived from Appendix \\
\hline Tributyl Phosphate (TBP) & $7.05 \mathrm{E}-02$ & MT & [Appendix F] & F (assumes $99 \%$ recycle) \\
\hline \multicolumn{5}{|l|}{ By-Product Streams } \\
\hline $\mathrm{U}_{3} \mathrm{O}_{8}$ & $2.78-02$ & MT & [Appendix F] & \\
\hline \multicolumn{5}{|l|}{ Natural Resource Use } \\
\hline Water Use Gross & $2.16 \mathrm{E}+05$ & $\mathrm{~L}$ & [Appendix F] & \\
\hline Water Use Net & $1.08 \mathrm{E}+05$ & $\mathrm{~L}$ & \multicolumn{2}{|c|}{$\begin{array}{l}\text { Assume } 50 \% \text { of water capable of being recycled, } \\
\text { similar to wet conversion process. }\end{array}$} \\
\hline Land Use & Negligible $^{2}$ & & & \\
\hline \multicolumn{5}{|c|}{ 1. Other by-product streams do not contain significant recoverable energy. } \\
\hline $\begin{array}{l}\text { 2. Land use for mining and tailings is } \\
\text { facilities will be relatively small } \\
\text { reduce the hazard associated with }\end{array}$ & $\begin{array}{l}\text { unk cost' associc } \\
\text { extraction of the }\end{array}$ & - & $\begin{array}{l}\text { primary } p \\
\text { ce the land } \\
\text { ery is cons }\end{array}$ & $\begin{array}{l}\text { It. The additional land use for Th extraction } \\
\text { ded for tailings piles since extracting the Th will } \\
\text { ed negligible. }\end{array}$ \\
\hline
\end{tabular}

\section{IMPACT ESTIMATES}

For each of the FEFC processes described in section 5, estimates are derived for each of the impact measures discussed in section 4. The impact estimates are calculated in sections 6.1 through 6.6 and summarized below in Table 6-1. All impacts are reported in normalized units that allow calculating the FEFC impacts for any specific fuel cycle by scaling these normalized impacts using fuel-specific parameters.

Impacts from the mining, milling, and conversion steps are normalized per MTNU from the mill (U losses in the conversion and deconversion processes were assumed to be negligible). Impacts from the enrichment step are normalized per kSWU. And impacts from the deconversion step are normalized per MTDU. The MTNU, kSWU, and MTDU per unit electricity produced are determined by the fuel enrichment, DU tails assay, and fuel utilization efficiency associated with a specified fuel cycle.

In Table 6-1 and subsequent tables, the row and column headers include references to the Sections 4 and 5 where the impacts and FEFC processes are discussed in detail. For example, the row in Table 6-1 for the occupational chemical impacts refers to Section 4.2.2 where one will find a discussion of several types of potential impacts that have been combined into a single hazard index that provides a relative measure of the potential exposure to hazardous chemicals. Table 6-1 also contains references to subsections within section 6 where the data, assumptions, and details associated with the calculation are provided.

In Table 6-1 and other summary tables, impact estimates are rounded to two significant digits. 


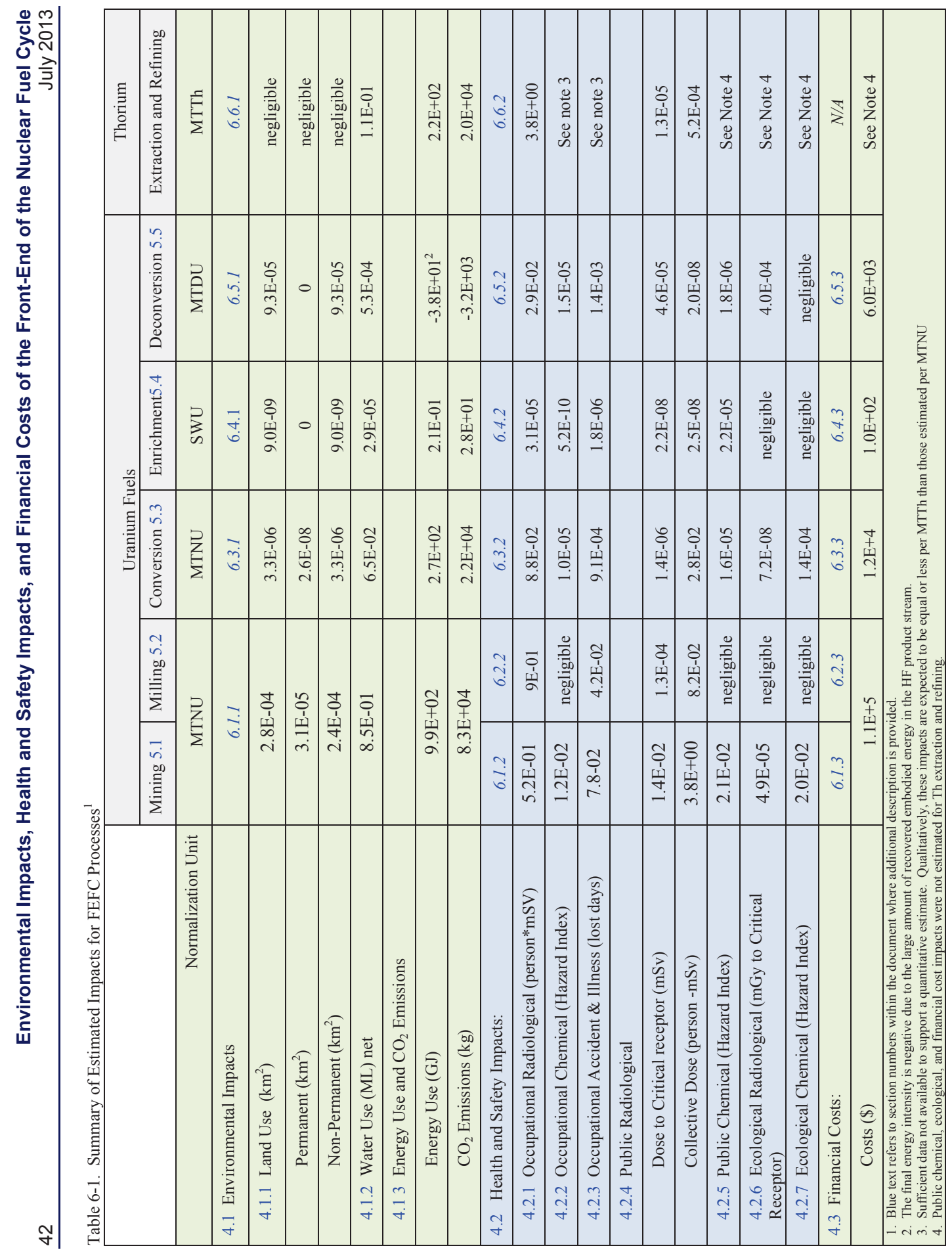




\subsection{Uranium Mining Impacts}

Uranium is currently mined using underground, open pit, and in-situ leaching. Impacts for each of these mining techniques are summarized in Table 6-2. The current fractions of total $U$ mining for each of these mining technologies (see Table 5-2) are used as weighting factors applied to the impacts from each mining technique to estimate impacts from a representative uranium mining process.

The impacts reported in Table 6-2 are developed in Sections 6.1.1 thru 6.1.3, with the exception of the cost impacts which are provided in Section 6.1 and applied to all three mining types. Section 6.1 also includes a brief discussion of the background and assumptions common to the calculations for each of the three mining techniques.

\section{Environmental Impacts}

Land and water use for mining and milling operations are often aggregated in the reporting. Because the impacts for mining and milling will be summed as part of determining the total FEFC impacts, no attempts were made to disaggregate this data and hence mining and milling impacts remain combined in the estimates for land, water, and energy usage.

Water use is sometimes reported as gross water consumption and other times as net water use. Net water use is the total water withdrawal reduced by the quantity of water returned to the environment at equal or better purity and, as such, is the preferred measure of environmental impact. When insufficient data are available to determine the net water use, it may be estimated or, in some cases, the gross water consumption is used as a conservative bound.

In uranium mining and milling operations, land is used for site operations, the support of those operations (buildings for personnel, storage of materials, etc.), and for the disposal of overburden, waste rock, and mill tailings. A portion of the land used in mining and milling can be reclaimed after decommissioning and rehabilitation are completed at the end of the site's operational life, while some land used will remain committed for the foreseeable future due to the presence of long-lived radioactive elements (e.g., mill tailings). Therefore, it is useful to categorize land use into permanent and non-permanent land use. Land use data for uranium mining does not distinguish between permanent land use and lands that can be reclaimed following closure of the mining operation and decommissioning of the mining site.

Mines of all three types (surface, underground, ISL), waste-rock and tailings areas, and mill sites can be, often are, and sometimes must be reclaimed. Given (a) the site-specific nature of whether mining and milling land is reclaimed and (b) the lack of a representative sample on which to base a more-precise breakdown between permanent and non-permanent land use, it is assumed that

- $20 \%$ of the land used for underground mining will be reclaimed,

- $50 \%$ of the land used for open pit mining will be reclaimed,

- $95 \%$ of the land used for in-situ mining will be reclaimed.

There is significant energy use in all types of mining operations. Energy is consumed directly as electricity and fuel for equipment. Earth moving equipment is another example of an operational process that uses a large amount of energy in the form of liquid fuels. For many process operations electricity is used, either produced on site via a generator that is typically is run off of natural gas, or purchased from the electricity grid. For example, dryers, which are used in milling use large amounts of energy with typical temperatures for a calcinating dryer at $\sim 700^{\circ} \mathrm{C}$. Energy for process operations is derived from a variety of sources including petroleum products such as diesel fuel, gasoline, light/heavy fuel oil, and from coal and natural gas. 
Environmental Impacts, Health and Safety Impacts, and Financial Costs of the Front-End of the

Nuclear Fuel Cycle

Table 6-2. Impacts of Representative Uranium Mining Process

\begin{tabular}{|c|c|c|c|c|}
\hline & \multicolumn{4}{|c|}{$\begin{array}{c}\text { FEFC Impacts } \\
\text { (per MTNU mined) }\end{array}$} \\
\hline & $\begin{array}{c}6.1 .1 \\
\text { Underground } \\
\text { Mining }\end{array}$ & $\begin{array}{c}6.1 .2 \\
\text { Open Pit } \\
\text { Mining } \\
\end{array}$ & $\begin{array}{c}6.1 .3 \\
\text { In-Situ } \\
\text { Mining } \\
\end{array}$ & $\begin{array}{c}6.1 \\
\text { Representative } \\
\text { Process }\end{array}$ \\
\hline Weighting factor & $37.5 \%$ & $17.3 \%$ & $45.2 \%$ & $100 \%$ \\
\hline 4.1 Environmental Impacts ${ }^{1}$ & 6.1 .1 .1 & 6.1 .2 .1 & 6.1 .1 .1 & \\
\hline 4.1.1 Land Use & $3.2 \mathrm{E}-05$ & $1.1 \mathrm{E}-04$ & $5.4 \mathrm{E}-04$ & $2.8 \mathrm{E}-04$ \\
\hline Permanent $\left(\mathrm{km}^{2}\right)$ & $2.6 \mathrm{E}-05$ & $5.4 \mathrm{E}-05$ & $2.7 \mathrm{E}-05$ & $3.1 \mathrm{E}-05$ \\
\hline Non-Permanent $\left(\mathrm{km}^{2}\right)$ & $6.4 \mathrm{E}-06$ & $5.4 \mathrm{E}-05$ & $5.1 \mathrm{E}-04$ & $2.4 \mathrm{E}-04$ \\
\hline 4.1.2 Water Use(ML) net & 8.4E-01 & $2.1 \mathrm{E}-01$ & $1.1 \mathrm{E}+00$ & $8.5 \mathrm{E}-01$ \\
\hline \multicolumn{5}{|l|}{4.13 Energy Use and $\mathrm{CO}_{2}$ Emissions } \\
\hline Energy Use (GJ) & $1.4 \mathrm{E}+03$ & $1.2 \mathrm{E}+03$ & $5.9 \mathrm{E}+02$ & $9.9 \mathrm{E}+02$ \\
\hline $\mathrm{CO}_{2}$ Emissions (kg) & $1.2 \mathrm{E}+05$ & $9.3 \mathrm{E}+04$ & $4.9 \mathrm{E}+04$ & $8.3 \mathrm{E}+04$ \\
\hline 4.2 Health and Safety Impacts: & 6.1 .1 .2 & 6.1 .2 .2 & 6.1 .1 .2 & \\
\hline 4.2.1 Occupational Radiological (person-mSv) & $6.7 \mathrm{E}-01$ & $5.1 \mathrm{E}-01$ & $3.9 \mathrm{E}-01$ & $5.2 \mathrm{E}-01$ \\
\hline 4.2.2 Occupational Chemical (Hazard Index) & 2.6E-02 & $1.1 \mathrm{E}-02$ & negligible & $1.2 \mathrm{E}-02$ \\
\hline 4.2.3 Occupational Accident \& Illness (lost days) & $1.7 \mathrm{E}-01$ & $6.8 \mathrm{E}-03$ & $2.8 \mathrm{E}-02$ & 7.8-02 \\
\hline \multicolumn{5}{|l|}{ 4.2.4 Public Radiological } \\
\hline Dose to Critical Receptor (mSv) & $3.5 \mathrm{E}-02$ & $3.6 \mathrm{E}-03$ & $5.7 \mathrm{E}-05$ & $1.4 \mathrm{E}-02$ \\
\hline Collective Dose (person -mSv) & $1.0 \mathrm{E}+01$ & $2.0 \mathrm{E}-01$ & $2.3 \mathrm{E}-03$ & $3.8 \mathrm{E}+00$ \\
\hline 4.2.5 Public Chemical (Hazard Index) & $5.4 \mathrm{E}-02$ & $5.98 \mathrm{E}-03$ & 0 & $2.1 \mathrm{E}-02$ \\
\hline $\begin{array}{l}\text { 4.2.6 Ecological Radiological (mGy to Critical } \\
\text { Receptor) }\end{array}$ & $1.2 \mathrm{E}-04$ & 1.4E-05 & $2.9 \mathrm{E}-06$ & $4.9 \mathrm{E}-05$ \\
\hline 4.2.7 Ecological Chemical (Hazard Index) & $2.0 \mathrm{E}-02$ & See Note 2 & negligible & $2.0 \mathrm{E}-02^{3}$ \\
\hline 4.3Financial Costs: & 6.1 & 6.1 .2 .3 & 6.1 .1 .3 & \\
\hline Cost $(\$)$ & $1.1 \mathrm{E}+05$ & $1.1 \mathrm{E}+05$ & $1.1 \mathrm{E}+05$ & $1.10 \mathrm{E}+05$ \\
\hline \multicolumn{5}{|c|}{$\begin{array}{l}\text { 1. For land, water, and energy use, these values include the impacts from both mining and milling operations } \\
\text { 2. Insufficient data to support development of a credible estimate. See discussion following Table 6-42. } \\
\text { 3. Conservatively assumes the impacts of UG mining. }\end{array}$} \\
\hline
\end{tabular}

Energy embodied in process materials such as sulfuric acid used in mill operations is consumed indirectly. In addition to process chemicals, other material inputs that represent embodied energy include replacement parts and explosives (typically ammonium nitrate fuel oil). Explosives are the largest contributor to embodied energy use associated with uranium mining material requirements (Rotty, 1975). Energy is also consumed during the construction and decommissioning of facilities. The energy required for decommissioning is not considered in this study.

The energy intensity, or the amount of energy used to create the facilities, materials, and run processes necessary to recover uranium is highly variable from site to site. The energy intensity to produce uranium depends on many site-specific factors such as:

- $\quad$ ore grade

- hardness of the rock; which is significant in the energy required to grind/crush ore 
Environmental Impacts, Health and Safety Impacts, and Financial Costs of the Front-End of the Nuclear Fuel Cycle

- mining method employed

- technology used

- the size of the operation

- outside factors; rain or a high water table will require a large amount of pumping to lower the water table

- the stripping ratio; which is the mass of the overburden divided by the mass of ore that is recovered

- energy costs; high energy costs provide incentive for mining companies to invest in energy efficient machines and processes

A large sample is needed to credibly estimate the mean and variation of the energy intensity. However data beyond the process energy used in day-to-day operations is scarce.

\section{Health and Safety Impacts}

Health and safety impacts include radiological and chemical exposures to workers, the public, and the local ecology. The public and local freshwater aquatic ecosystem impacts are estimated with respect to proximity of the mine site by estimating the maximally exposed individual (MEI) from effluents from typical mines.

For chemical exposures, a hazard index, calculated as the sum of the individual chemical hazard quotients, is used as a measure of the potential for exposure to hazardous chemicals. The hazard quotient for each chemical exposure is the ratio of the estimated actual exposure to the screening level, where the screening level is selected from among limits that are promulgated or recommended by various regulatory or research-oriented agencies. In addition to the hazard sources listed in (EPA 1983) for typical mines in the US, worker exposures related to chemical and radioactive source terms include the silica, diesel particulate matter, and noise effects as recommended by the National Academy of Sciences (NAS) to be further investigated (NAS 2011). The various limits that were considered and the values chosen as the screening levels for various water and air contaminants are given in Tables 6-3, 6-4, 6-5, and 6-6 ${ }^{17}$.

Table 6-3 provides occupational screening levels related to airborne contaminants from the EPA and MSHA $^{18}$. Permissible Exposure Levels (PELs) are preferred because the limits are created specifically for mining working conditions. Sometimes PELs are set as the same as the ACGIH-recommended Threshold Limit Values (TLVs). When the PEL or TLV is not available, the EPA Reference concentrations (RfCs) for workers was used as the screening level.

Table 6-4 provides various public screening levels related to airborne contaminants. For conservatism, the lowest of the publicly-designated Preliminary Remediation Guidelines (PRG)s, RfCs, and National Ambient Air Quality Standards (NAAQs) was used as the screening level. For the contaminants that do not have public screening levels designated, the screening levels for workers from Table 6-3 are used.

Table 6-5 provides various public screening levels related to liquid effluents. For conservatism, the lowest screening level is selected from the PRGs and the primary and secondary Maximum Contaminant Levels (MCLs) under the Clean Drinking Water Act (CDWA). MCL Primary standards under the CDWA are related to potable characteristics of drinking water. The MCL Secondary standards are related to aesthetics and palatability of the public drinking water supply.

17. The PRGs and RfCs are listed within an online database, EPA's Integrated Risk Information System (IRIS) and Health Effects Assessment Summary Tables (HEAST) databases (EPA, 2012c).

18. All exposure limit values provided by NIOSH, ACGIH, or OSHA then subsequently adopted by MSHA are time-weighted averages (TWA), which are usually for durations of 8-hours. 


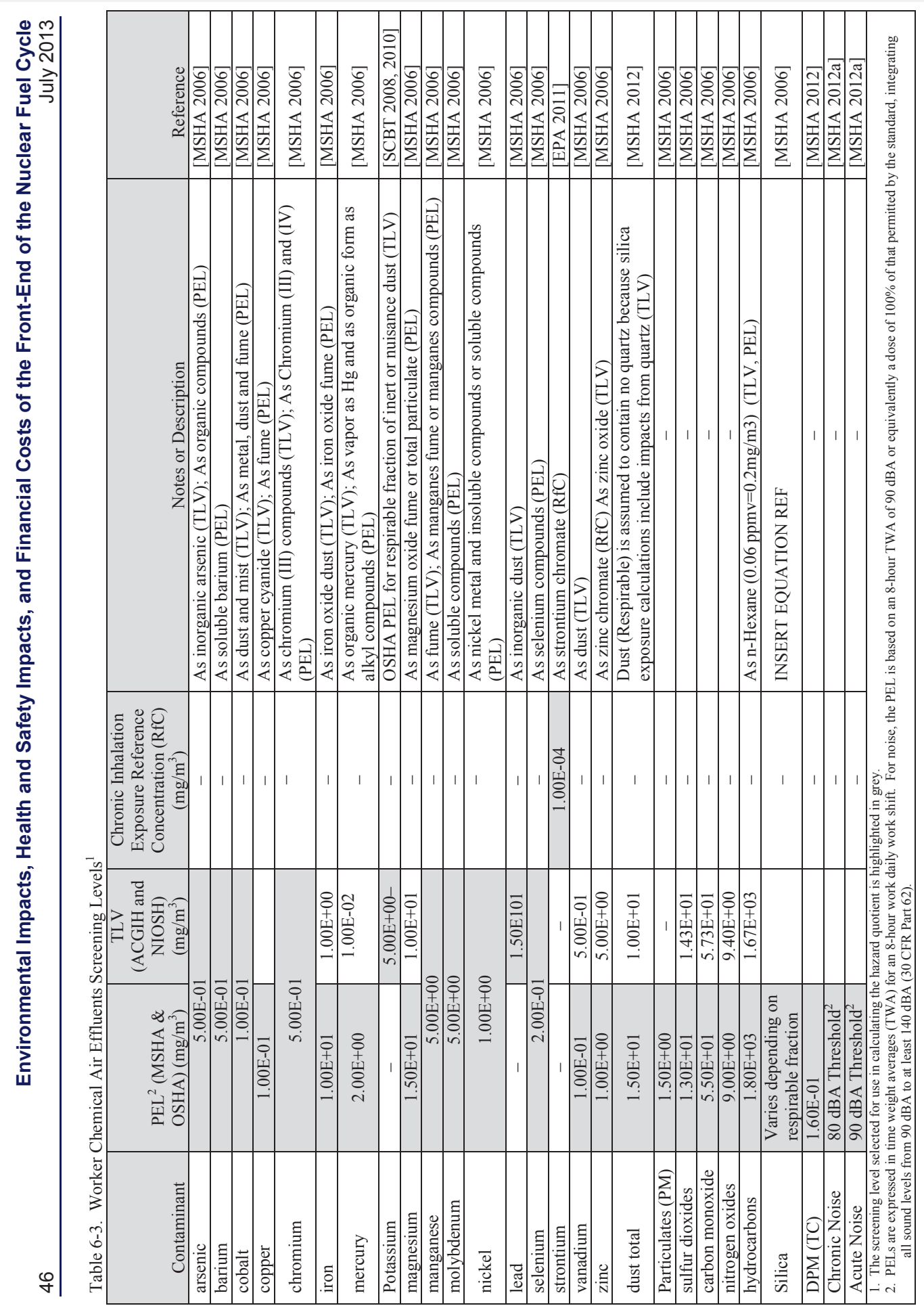




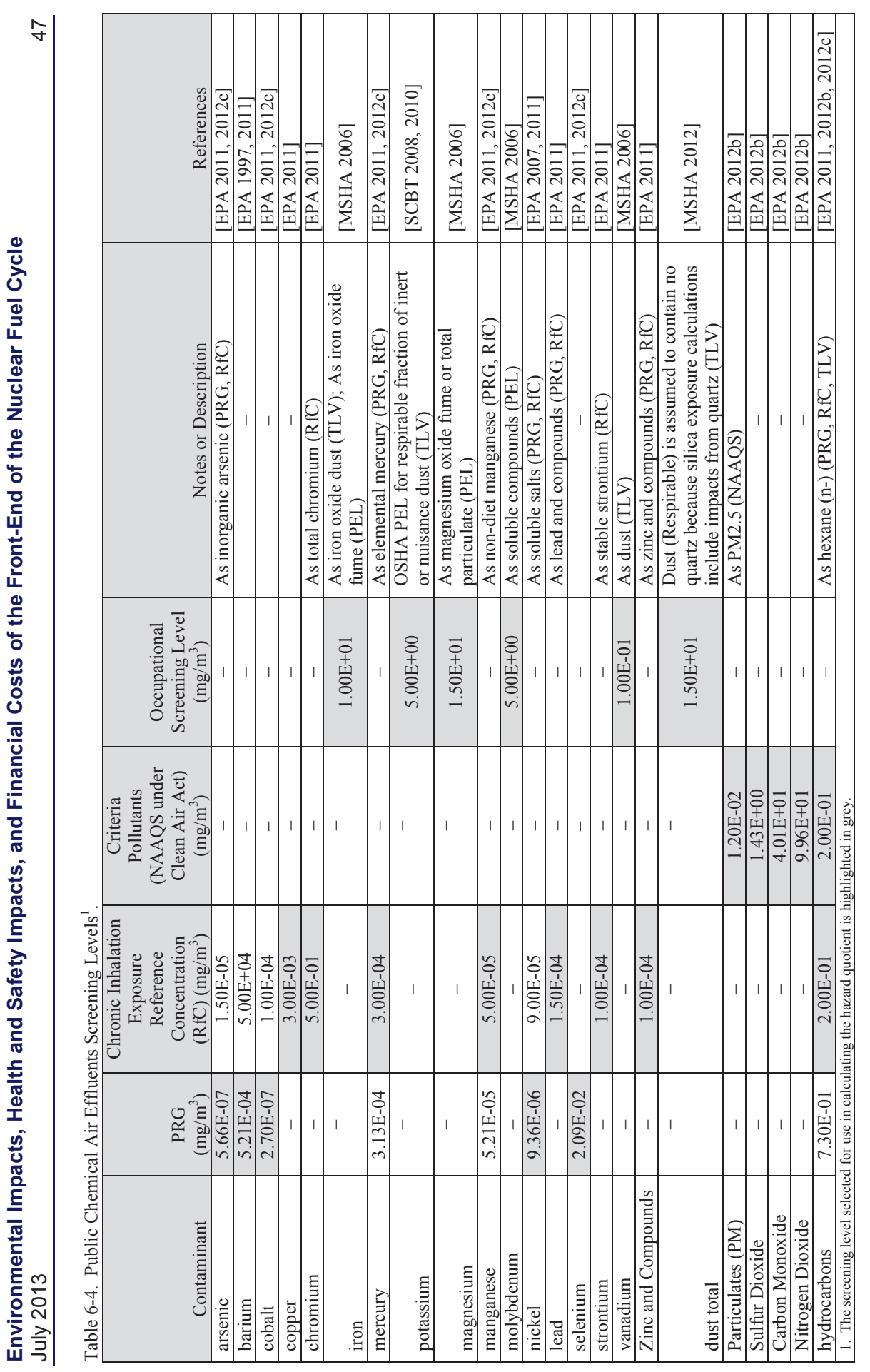


Environmental Impacts, Health and Safety Impacts, and Financial Costs of the Front-End of the

Nuclear Fuel Cycle

Table 6-5. Public Chemical Liquid Effluents Screening Levels ${ }^{1}$.

\begin{tabular}{|c|c|c|c|c|}
\hline Contaminant & $\begin{array}{c}\text { PRG } \\
(\mathrm{mg} / \mathrm{L})\end{array}$ & $\begin{array}{c}\text { MCL Primary } \\
(\mathrm{mg} / \mathrm{L})\end{array}$ & $\begin{array}{c}\text { MCL Secondary } \\
(\mathrm{mg} / \mathrm{L})\end{array}$ & References \\
\hline total uranium & $4.66 \mathrm{E}-02$ & $3.00 \mathrm{E}-02$ & - & [EPA 2012, 2012c] \\
\hline cadmium & $6.91 \mathrm{E}-03$ & $5.00 \mathrm{E}-03$ & - & [EPA 2012, 2012c] \\
\hline arsenic & $4.46 \mathrm{E}-05$ & $1.00 \mathrm{E}-02$ & - & [EPA 2012, 2012c] \\
\hline selenium & $7.77 \mathrm{E}-02$ & $5.00 \mathrm{E}-02$ & - & [EPA 2012, 2012c] \\
\hline molybdenum & $7.77 \mathrm{E}-02$ & - & - & [EPA 2012] \\
\hline barium & $2.86 \mathrm{E}+00$ & $2.00 \mathrm{E}+00$ & - & [EPA 2012, 2012c] \\
\hline zinc & $4.67 \mathrm{E}+00$ & - & $5.00 \mathrm{E}+00$ & [EPA 2012, 2012c] \\
\hline sulfate & - & - & $2.50 \mathrm{E}+02$ & [EPA 2012] \\
\hline total suspended solids & - & - & $5.00 \mathrm{E}+02$ & [EPA 2012] \\
\hline
\end{tabular}

Table 6-6 provides the EPA recommends PRGs, Benchmark screening levels, and criteria for protecting freshwater aquatic life. These are considered as appropriate screening levels for non-human biota. For conservatism, the lowest of the three is used as the screening level. For contaminants that do not have an EPA-recommended screening level for non-human biota, the lowest available human-screening level from Table 6-7 is used.

\section{Financial Costs}

The Advanced Fuel Cycle Cost Basis (AFC CB) (Shropshire, 2009) provides unit costs for technologies across the fuel cycle. For fuel cycle facilities, unit costs are expressed per unit mass of commodity produced or processed. Unit costs from the update (INL 2013) to the 2009 AFC CB, in units of $\$ / \mathrm{kg} \mathrm{U}$, are provided in Table 6-7. The metric for uranium mining and milling is the reference value, $\$ 110 / \mathrm{kg} \mathrm{U}$ $(\$ 110,000 / \mathrm{MTNU})$. Lower and upper bounds are provided to give a sense of the confidence interval associated with the estimate. Please see (Shropshire, 2009) ${ }^{19}$ and (INL 2013) for full documentation of these estimates.

Given the diversity of uranium mining and milling operations, it is not possible to choose a single representative reference site. A senior executive at Cameco, a major operator of uranium mines and mills, listed the following as among the mine-, deposit- and mill-specific drivers (Seitz, 2005):

- Deposit grade;

- Host rock geology/hardness;

- Properties of rock to be crushed and ground;

- Underground mines: shaft depth and decline, ventilation method;

- Open pit mines: strip ratio and overburden removal method;

- ISL mines: well field drilling depth and pattern;

- Leaching process (e.g., carbonate versus acid);

- Distance from mine to mill;

19. Available at www.inl.gov/technicalpublications/Documents/4536700.pd 


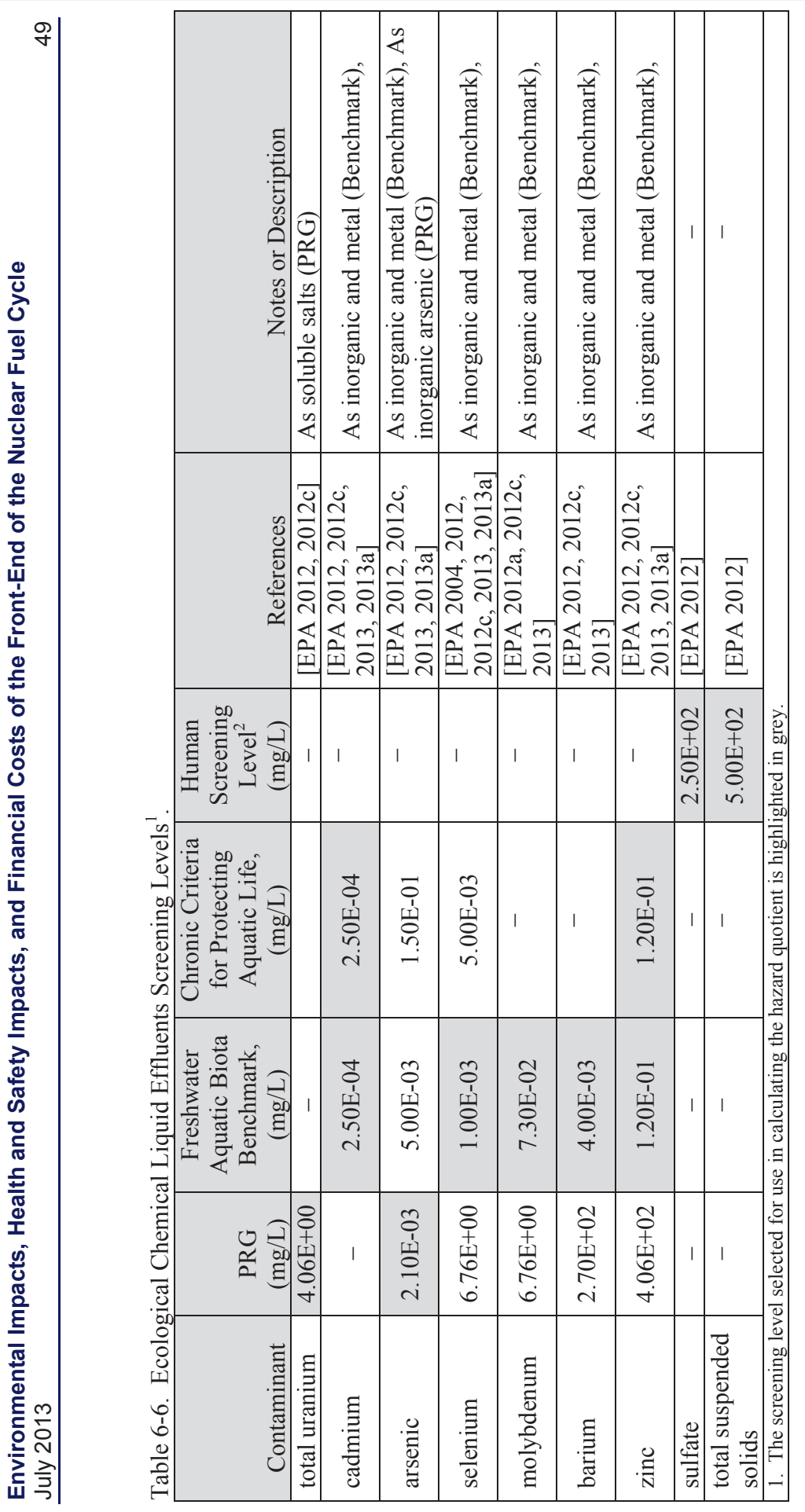


Environmental Impacts, Health and Safety Impacts, and Financial Costs of the Front-End of the

Table 6-7. Unit mining and milling cost estimate from the 2012 AFC CBR update.

\begin{tabular}{|c|c|c|}
\hline Reference Value & $\begin{array}{c}\text { Upside } \\
\text { (Low Value) }\end{array}$ & $\begin{array}{c}\text { Downside } \\
\text { (High Value) }\end{array}$ \\
\hline$\$ 110 / \mathrm{kg} \mathrm{U}$ & $\$ 65 / \mathrm{kg} \mathrm{U}$ & $\$ 230 / \mathrm{kg} \mathrm{U}$ \\
\hline$\$ 1.1 \mathrm{E}+5 / \mathrm{MTNU}$ & $\$ 6.5 \mathrm{E}+4 / \mathrm{MTNU}$ & $\$ 2.3 \mathrm{E}+5 / \mathrm{MTNU}$ \\
\hline
\end{tabular}

- Tailings management strategy (tailing catchment capacity, lining, water treatment approach);

- Jurisdiction-specific licensing, permitting and administrative expenses.

A database available at (Wise Uranium, 2012) provides overnight construction, annual operating and decommissioning costs for over two dozen operating and proposed uranium mining and milling projects. To illustrate uranium production cost calculations, data sets for three projects have been selected from the (Wise Uranium, 2012) database. They are:

- a generic Colorado Plateau mine (underground, UG) with ore processing at the White Mesa mill;

- the Areva Trekkopje (open pit, OP) mine and mill in Namibia;

- the Lost Creek (in-situ leaching, ISL) project in Wyoming.

Tables 6-8, 6-9 and 6-10 provide data from (Wise Uranium, 2012) for each project. All data are minespecific with the exception of the decommissioning and cleanup cost. The UG and ISL mines use a unit decommissioning cost of \$2.2 per tonne tailings in 1993 (escalated to \$3.5 in 2012), a world average given in (Wise Uranium, 2012). The OP mine is located in Namibia, where (Wise Uranium, 2012) provides a country-specific decommissioning cost of $\$ 0.12$ per tonne tailings in $1993^{20}$ (escalated to $\$ 0.238$ in 2012).

Table 6-11 walks through the calculation of the unit $U$ production cost in $\$ / \mathrm{kg} U$ for each deposit. Values in boldface are the project-specific inputs from Tables 6-8, 6-9 and 6-10. Other inputs and values in the table are calculated using EMWG guidelines described in Section 4.3.

These should not be interpreted as representative of $U$ production costs generally or their mining method in particular. As mentioned, costs are highly site- and deposit-specific and these results are just illustrative. For example, most U deposits in the Colorado Plateau of the US are known to be uneconomical at present (OECD, 2010), and this illustration merely confirms that. But underground U mining operations elsewhere, under more favorable conditions, are profitable.

Therefore, the metric quoted at the head of this section should be used for roll-up calculations in fuel cycle analyses. It represents an expected uranium price considering all players in the world uranium market.

Thus the unit U production costs are estimated to range from $\$ 77.9 / \mathrm{kg} U$ at Trekkopje to $\$ 114 / \mathrm{kg} U$ at Lost Creek and $\$ 192 / \mathrm{kg} \mathrm{U}$ at the generic Colorado Plateau mine.

20. This country-specific cost, in $\$$ tonne tailings, is lower than the world average. It reflects the lower ore grades and larger but less concentrated tailings arising, per unit of $U$ produced, of projects in that country. 
Environmental Impacts, Health and Safety Impacts, and Financial Costs of the Front-End of the Nuclear Fuel Cycle

Table 6-8. Data for the Colorado Plateau (UG) mine and White Mesa mill.

\begin{tabular}{|c|c|c|}
\hline \multicolumn{3}{|c|}{ Deposit, Mine and Mill Data from Reference } \\
\hline U3O8 milled & $9.10 \mathrm{E}+02$ & tonne $\mathrm{U} 3 \mathrm{O} 8 / \mathrm{yr}$ \\
\hline ore grade & 0.15 & w/o U3O8 \\
\hline mill losses $(\%)$ & 6.66 & $\%$ of $U$ in ore \\
\hline uranium production & $7.72 \mathrm{E}+02$ & tonne U/yr \\
\hline ore mined to mill & $6.47 \mathrm{E}+05$ & tonne ore/yr \\
\hline tailings & $6.46 \mathrm{E}+05$ & tonne tailings/yr \\
\hline operational lifetime & 15 & years \\
\hline \multicolumn{3}{|c|}{ Cost Data from Reference } \\
\hline mine capital cost & $3.50 \mathrm{E}+02$ & $2012 \$$ per tonne ore $/ \mathrm{yr}$ \\
\hline mine operating cost & $4.90 \mathrm{E}+01$ & $2012 \$$ per tonne ore \\
\hline mill capital cost & $5.50 \mathrm{E}+01$ & $2012 \mathrm{M} \$$ \\
\hline mill operating cost & $7.61 \mathrm{E}+01$ & $2012 \$$ per tonne ore \\
\hline general/administrative operating cost & $3.60 \mathrm{E}+01$ & $2012 \$$ per tonne ore \\
\hline decommissioning / cleanup cost & $3.50 \mathrm{E}+00$ & $2012 \$$ per tonne tailings \\
\hline \multicolumn{3}{|c|}{ Cost Calculation Inputs (Computed from Reference Data) } \\
\hline Mining Capital & $2.26 \mathrm{E}+02$ & 2012M\$ \\
\hline Mining Operations & $3.17 \mathrm{E}+01$ & $2012 \mathrm{M} \$ / \mathrm{yr}$ \\
\hline Milling Operations & $4.93 \mathrm{E}+01$ & $2012 \mathrm{M} \$ / \mathrm{yr}$ \\
\hline General Operations & $2.33 \mathrm{E}+01$ & $2012 \mathrm{M} \$ / \mathrm{yr}$ \\
\hline Total Capital (mining + milling) & $2.81 \mathrm{E}+02$ & $2012 \mathrm{M} \$$ \\
\hline $\begin{array}{c}\text { Total Operations } \\
\text { (mining+milling+general) }\end{array}$ & $1.04 \mathrm{E}+08$ & $2012 \mathrm{M} \$ / \mathrm{yr}$ \\
\hline Decommissioning/cleanup cost & $3.39 \mathrm{E}+01$ & $2012 \mathrm{M} \$$ \\
\hline
\end{tabular}


Environmental Impacts, Health and Safety Impacts, and Financial Costs of the Front-End of the

Nuclear Fuel Cycle

Table 6-9. Data for the Trekkopje (OP) operation.

\begin{tabular}{|c|c|c|}
\hline \multicolumn{3}{|c|}{ Deposit, Mine and Mill Data from Reference } \\
\hline U3O8 milled & $3.73 \mathrm{E}+03$ & tonne $\mathrm{U} 3 \mathrm{O} 8 / \mathrm{yr}$ \\
\hline ore grade & 0.0139 & w/o U3O8 \\
\hline mill losses $(\%)$ & 25 & $\%$ of $U$ in ore \\
\hline uranium production & $3.16 \mathrm{E}+03$ & tonne U/yr \\
\hline ore mined to mill & $3.36 \mathrm{E}+07$ & tonne ore/yr \\
\hline tailings & $3.36 \mathrm{E}+07$ & tonne tailings/yr \\
\hline operating lifetime & 7.4 & years \\
\hline \multicolumn{3}{|c|}{ Cost Data from Reference } \\
\hline mine capital cost & $3.61 \mathrm{E}+00$ & $2012 \$$ per tonne ore/yr \\
\hline mine operating cost & $1.60 \mathrm{E}+00$ & $2012 \$$ per tonne ore \\
\hline mill capital cost & $2.25 \mathrm{E}+02$ & $2012 \mathrm{M} \$$ \\
\hline mill operating cost & $2.93 \mathrm{E}+01$ & $2012 \$$ per tonne ore \\
\hline general/administrative operating cost & $4.84 \mathrm{E}+00$ & $2012 \$$ per tonne ore \\
\hline decommissioning / cleanup cost & $2.38 \mathrm{E}-01$ & $2012 \$$ per tonne tailings \\
\hline \multicolumn{3}{|c|}{ Cost Calculation Inputs (Computed from Reference Data) } \\
\hline Mining Capital & $1.21 \mathrm{E}+02$ & 2012M\$ \\
\hline Mining Operations & $5.38 \mathrm{E}+01$ & $2012 \mathrm{M} \$ / \mathrm{yr}$ \\
\hline Milling Operations & $9.84 \mathrm{E}+01$ & $2012 \mathrm{M} \$ \mathrm{yr}$ \\
\hline General Operations & $1.63 \mathrm{E}+01$ & $2012 \mathrm{M} \$ / \mathrm{yr}$ \\
\hline Total Capital (mining + milling) & $3.46 \mathrm{E}+02$ & 2012M\$ \\
\hline $\begin{array}{c}\text { Total Operations } \\
\text { (mining }+ \text { milling+general) }\end{array}$ & $1.62 \mathrm{E}+02$ & $2012 \mathrm{M} \$ / \mathrm{yr}$ \\
\hline Decommissioning/cleanup cost & $5.92 \mathrm{E}+01$ & $2012 \mathrm{M} \$$ \\
\hline
\end{tabular}

Table 6-10. Data for the Lost Creek (ISL) operation.

\begin{tabular}{|l|l|l|}
\hline \multicolumn{2}{|c|}{ Deposit, Mine and Mill Data from Reference } \\
\hline U3O8 milled & $4.85 \mathrm{E}+02$ & tonne U3O8/yr \\
\hline ore grade & 0.0511 & w/o U3O8 \\
\hline mill losses (\%) & 20 & $\%$ of U in liquor \\
\hline uranium production & $4.12 \mathrm{E}+02$ & tonne U/yr \\
\hline ore mined to mill & $\mathrm{N} / \mathrm{A}$ & tonne ore/yr \\
\hline tailings & $1.19 \mathrm{E}+06$ & tonne tailings/yr \\
\hline operational lifetime & 6.9 & years \\
\hline \multicolumn{3}{|c|}{ Cost Data from Reference } \\
\hline mine/mill capital cost & $1.11 \mathrm{E}+02$ & $2012 \mathrm{M} \$$ \\
\hline mine/mill operating cost & $4.19 \mathrm{E}+01$ & $2012 \$$ per $\mathrm{kg}$ U produced \\
\hline decommissioning / cleanup cost & $3.50 \mathrm{E}+00$ & $2012 \$$ per tonne tailings \\
\hline \multicolumn{2}{|c|}{ Cost Calculation Inputs (Computed from Reference Data) } \\
\hline Mining/Milling Capital & $1.11 \mathrm{E}+02$ & $2012 \mathrm{M} \$$ \\
\hline Mining/Milling Operations & $1.73 \mathrm{E}+01$ & $2012 \mathrm{M} \$ / \mathrm{yr}$ \\
\hline Decommissioning/cleanup cost & $2.86 \mathrm{E}+01$ & $2012 \mathrm{M} \$$ \\
\hline
\end{tabular}


Environmental Impacts, Health and Safety Impacts, and Financial Costs of the Front-End of the Nuclear Fuel Cycle

Table 6-11. Summary of Financial Cost Inputs and Calculation Outcomes.

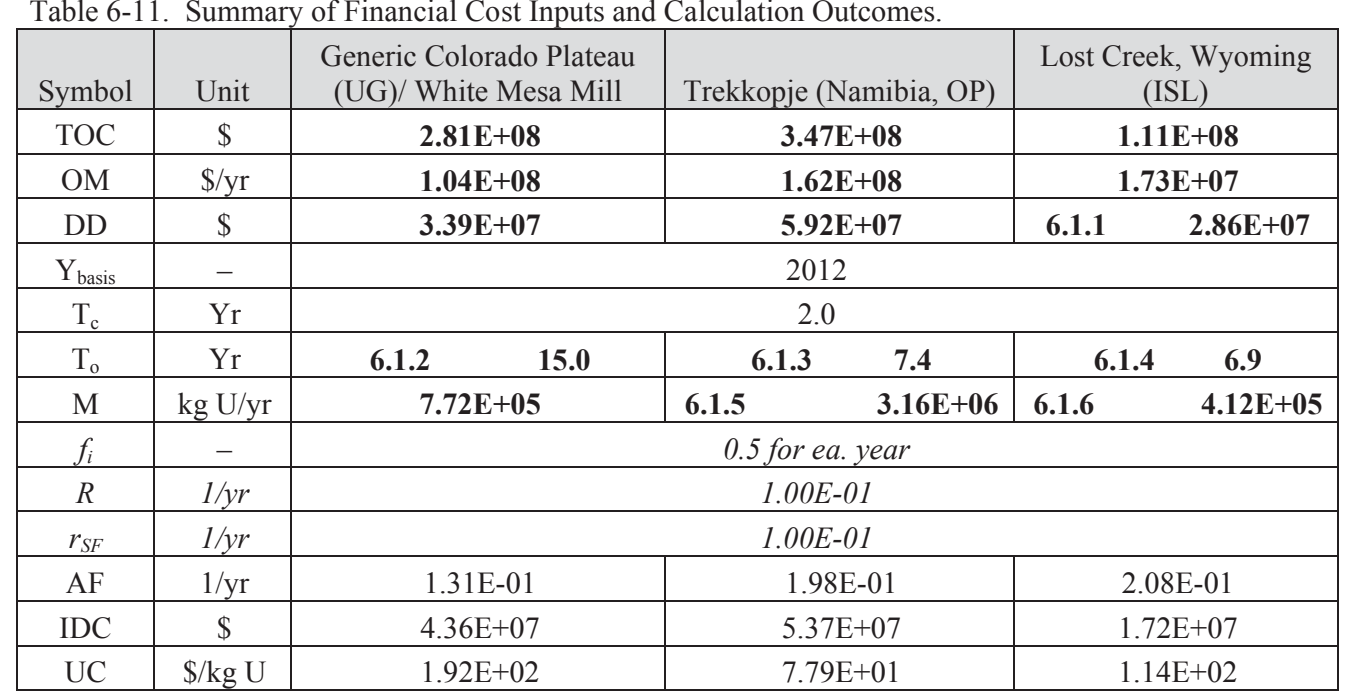


Environmental Impacts, Health and Safety Impacts, and Financial Costs of the Front-End of the

Nuclear Fuel Cycle

\subsubsection{Uranium Underground Mines}

Estimates of environmental, safety and health, and financial cost impacts from underground mining are summarized the Table 6-12. The remainder of Section 6.1.1 provides the basis for each of the estimates shown.

Table 6-12. Impacts of Underground Uranium Mining Process.

\begin{tabular}{|l|l|}
\hline \multicolumn{2}{|c|}{ Underground Mining Impacts(per MTNU) } \\
\hline 4.1 Environmental Impacts & 6.1 .1 .1 \\
\hline 4.1 .1 Land Use & $3.2 \mathrm{E}-05$ \\
\hline Permanent $\left(\mathrm{km}^{2}\right)$ & $2.6 \mathrm{E}-05$ \\
\hline Non-Permanent $\left(\mathrm{km}^{2}\right)$ & $6.4 \mathrm{E}-06$ \\
\hline 4.1 .2 Water Use(ML) net & $8.4 \mathrm{E}-01$ \\
\hline 4.13 Energy Use and CO2 Emissions & $1.4 \mathrm{E}+03$ \\
\hline Energy Use (GJ) & $1.2 \mathrm{E}+05$ \\
\hline $\mathrm{CO}_{2}$ Emissions (kg) & 6.1 .1 .2 \\
\hline 4.2 Health and Safety Impacts: & $6.7 \mathrm{E}-01$ \\
\hline 4.2 .1 Occupational Radiological (person*mSv) & $2.6 \mathrm{E}-02$ \\
\hline 4.2 .2 Occupational Chemical (Hazard Index) & $1.7 \mathrm{E}-01$ \\
\hline 4.2 .3 Occupational Accident \& Illness (lost days) & $3.5 \mathrm{E}-02$ \\
\hline 4.2 .4 Public Radiological & $1.0 \mathrm{E}+01$ \\
\hline Dose to Critical Receptor (mSv) & $5.4 \mathrm{E}-02$ \\
\hline Collective Dose (person*mSv) & $1.2 \mathrm{E}-04$ \\
\hline 4.2.5 Public Chemical (Hazard Index) & $2.0 \mathrm{E}-02$ \\
\hline 4.2.6 Ecological Radiological (mGy to Critical Receptor) & 6.1 \\
\hline 4.2 .7 Ecological Chemical (Hazard Index) & $1.1 \mathrm{E}+05$ \\
\hline 4.3 Financial Costs: & \\
\hline Cost (\$) & \\
\hline $\begin{array}{l}\text { 1. For land, water, and energy use, these values include the impacts from both mining and milling operations } \\
\text { 2. Insufficient data to support development of a credible estimate. See discussion following Table 6-46. }\end{array}$ \\
\hline
\end{tabular}

\subsubsection{Environmental Impacts - Underground Mining}

The impacts of conventional Uranium mining (underground and open-pit) are similar in many impacts, but will be treated separately due to a few key differences. Underground mines have the added difficulty of managing the dust in a closed environment. Dust control is accomplished through well ventilated shafts and by immobilizing particles through other physical processes such as spraying water.

\section{Land Use - Underground Mining}

Land use data are reported is for both mining and milling operations as they are co-located. Ideally, land use would be categorized into non-permanent and permanent land use to distinguish land that cannot be reclaimed in the foreseeable future. However, available data does not distinguish between the natures of its use, and lists only the total land used in site operations. It is conservatively assumed that $80 \%$ of the land used for mining operations will be used for tailings and/or other long-term needs and cannot thus be reclaimed for other uses.

At the conclusion of mining; tailings, equipment that was not able to be salvaged, waste rock, and overburden that may contain hazardous elements, are typically buried at the mine site and covered permanently with enough clay and soil to reduce both gamma radiation and radon emissions to levels near 
Environmental Impacts, Health and Safety Impacts, and Financial Costs of the Front-End of the Nuclear Fuel Cycle

those naturally occurring in the region, and enough rock to resist erosion. A vegetation cover is then established to control run-off from erosion processes. Nonetheless, tailing confinements represent permanent land use because radioactive and toxic elements will remain for long into the future.

Although data on land use for underground uranium mining is limited, it represents a small portion of the total aggregated land use for uranium mining as a whole. This is expected since the majority of site operations take place underground, and most waste rock and over burden is backfilled into the mine once mining operations have ceased. While it is likely that there is a significant range in the amount of land used in underground uranium mining operations, it is not likely that additional data for underground uranium mining will change the overall land use impact for uranium mining significantly as underground mining is the least land intensive type of mining. Hence, land use data from a single mining operation, Cigar Lake, is considered sufficient for this estimate (OECD, 2008).

\begin{tabular}{|l|c|c|c|}
\hline Facility & $\begin{array}{c}\text { Land Use } \\
\left(\mathbf{m}^{2} / \mathbf{M T N U}\right)\end{array}$ & $\begin{array}{c}\text { Conversion factor } \\
\text { to } \mathbf{~} \mathbf{m}^{\mathbf{2}} / \mathbf{M T N U}\end{array}$ & $\begin{array}{c}\text { Land Use } \\
\left(\mathbf{k m}^{\mathbf{2}} / \mathbf{M T N U}\right)\end{array}$ \\
\hline Cigar Lake & 32.4 & $1 \mathrm{E}-6$ & $3.24 \mathrm{E}-5$ \\
\hline
\end{tabular}

Differentiation of land use between permanent and non-permanent is not widely reported, and may vary significantly. The land use reported represents an operating surface area. A large portion of the volume of earth moved in an UG operation will come from its vertical dimension, therefore a significant portion of the reported surface area may be used to manage the tailings. Some mines backfill the shaft with tailings; some mines do not. Instead they dispose of the tailings by pumping the mill slurry to an engineered evaporation pond that, although eventually covered with soil and re-vegetated, is not likely to be released for unrestricted future use.

\section{Water Use - Underground mining}

Underground uranium mining water use is comparable to that of other underground mining activities. Water must be used to suppress dust and for drilling of boreholes for geological samples and the planting of explosives. Depending on the location and depth of the mine, it may be necessary to lower the water table so that mining operations can commence. This is accomplished by placing wells outside the site or within the site itself and pumping large quantities of water in order to create a drawdown that allows mining to take place. Drawdown affects the water table by suppressing it in the shape of a cone, with the deepest part at the location of the withdraw wells. The height of the drawdown is dependent on the flow of water pumped out, and the permeability of the subsurface rock and soil. Thus the amount of water displaced to accomplish this is very site dependent, depending on geological conditions, the location of the mine itself, and the depth of the mine. If the water is contaminated in the process, it must be treated before it is discharged from the mine. Lowering the water table may impact surrounding communities. The impact can be significant if it affects agriculture or other water users near or downstream of the mining operation. Subsurface and surface water contamination from runoff of water in stockpiles at mining operations remains a public concern, despite most mining operations having a "zero discharge" policy. Average water use for the Olympic Dam and the Rabbit Lake/Eagle Point mines are used as the basis for estimating water use of UG uranium mining (Table 6-13).

\section{ENERGY USE and $\mathrm{CO}_{2}$ Emissions - Underground Mining}

Estimates for the underground mining energy use were obtained using the data from the INL technical report (Schneider, 2010) and the 1975 IEA report (Rotty, 1975). Schneider, 2010 bases estimates on mine reported energy consumption data and does not include energy use associated with construction or embodied energy present in process materials such as machine replacement parts and sulfuric acid. 
Environmental Impacts, Health and Safety Impacts, and Financial Costs of the Front-End of the

Nuclear Fuel Cycle

(Rotty 1975) contains the energy input, electrical and thermal, necessary both to construct the mine and mill and the materials needed to operate the processes. Raw data from Rotty was converted into the appropriate units (see Appendix H, Table H-1) to allow summing with the energy consumption from (Schneider 2010). However, because (Rotty 1975) assumed a grade of 2\%, while the Schneider 2010 report assumed a grade of roughly half that, this study assumed that double the amount of process materials (such as explosives, sulfuric acid, and other mill inputs) would be required to produce the same amount of uranium from an ore grade that is $\sim 50 \%$ less.

Key assumptions from Rotty, 1975 include a 95\% mill yield, 75lbs sulfuric acid per short ton of ore milled, an ore grade of $.208 \%$, and a 10 year lifetime. The lifetime is used to amortize the construction energy. Ten years is very conservative as most mining/milling operations have lifetimes that are well beyond 20 years.

The values obtained are shown in Table 6-14.

\subsubsection{Health and Safety Impacts - Underground Mining}

The health and safety impact estimates for average workers, the hypothetical maximally exposed individual members of the public and local non-human biota resulting from underground mining are developed from data sets representing seven mining operations, as shown in Table 6-15.

Table 6-13. Underground Mine Water Use ${ }^{1}$

\begin{tabular}{|c|c|c|c|c|}
\hline & \multicolumn{2}{|c|}{ Olympic Dam } & \multicolumn{2}{|c|}{ Rabbit Lake/Eagle Point } \\
\hline Year & $\begin{array}{c}\mathrm{U}_{3} \mathrm{O}_{8} \\
\text { Production } \\
\text { (Tonne) }\end{array}$ & $\begin{array}{c}\text { Gross Water } \\
\text { Consumption } \\
\text { (ML) }\end{array}$ & $\begin{array}{l}\mathrm{U}_{3} \mathrm{O}_{8} \text { Production } \\
\text { (Tonne) }\end{array}$ & $\begin{array}{c}\text { Gross Water } \\
\text { Consumption } \\
\text { (ML) }\end{array}$ \\
\hline 1998 & 1740 & 1094 & & \\
\hline 1999 & 3198 & 1732 & & \\
\hline 2000 & 4500 & 2112 & & \\
\hline 2001 & 4355 & 2070 & & \\
\hline 2002 & 2881 & 2146 & & \\
\hline 2003 & 3176 & 2094 & & \\
\hline 2004 & 4370 & 2380 & & \\
\hline 2005 & 4362 & & & \\
\hline \multicolumn{5}{|l|}{2006} \\
\hline 2007 & & & 1825 & 4172 \\
\hline Total & 24220 & 13628 & 1825 & 4172 \\
\hline Average Annual & 3460 & 1947 & 1825 & 4172 \\
\hline Average ML/tonne & \multicolumn{2}{|c|}{0.563} & \multicolumn{2}{|c|}{2.29} \\
\hline $\begin{array}{l}\text { Gross Water Use (ML/tonne } \\
\left.\mathrm{U}_{3} \mathrm{O}_{8}\right)\end{array}$ & \multicolumn{4}{|c|}{1.42} \\
\hline Gross Water Use $^{2}$ (ML/MTNU) & \multicolumn{4}{|c|}{1.68} \\
\hline Net Water Use (ML/MTNU & \multicolumn{4}{|c|}{0.84} \\
\hline \multicolumn{5}{|c|}{$\begin{array}{l}\text { 1. Data are from (Mudd 2007). Water use from Olympic Dam is adjusted to account for the fact that uranium is a co-product } \\
\text { of this mining operation. } \\
\text { 2. This estimate represents gross water consumption and is considered a conservative bound on the water usage. Much of the } \\
\text { water used in the operation can be, and often is, recovered, treated and returned to the source. Water recovery varies } \\
\text { significantly depending on factors such as: processes used, local availability of water supply and discharge locations and } \\
\text { regulations. Reported values range from } \sim 10 \% \text { to } \sim 90 \% \text { For the purpose of this study, a mid-range representation of } 50 \% \\
\text { recycle is used. }\end{array}$} \\
\hline
\end{tabular}




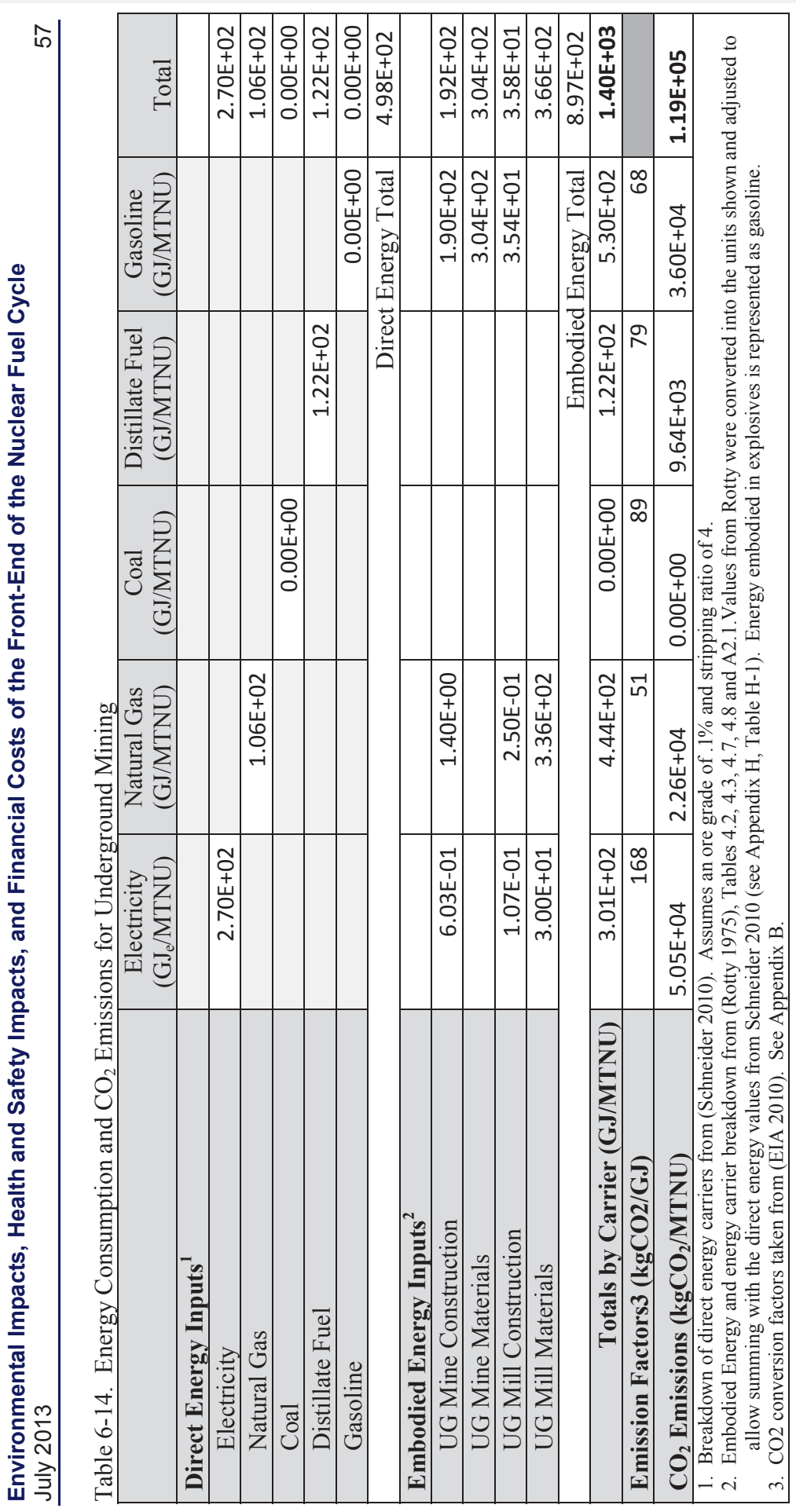




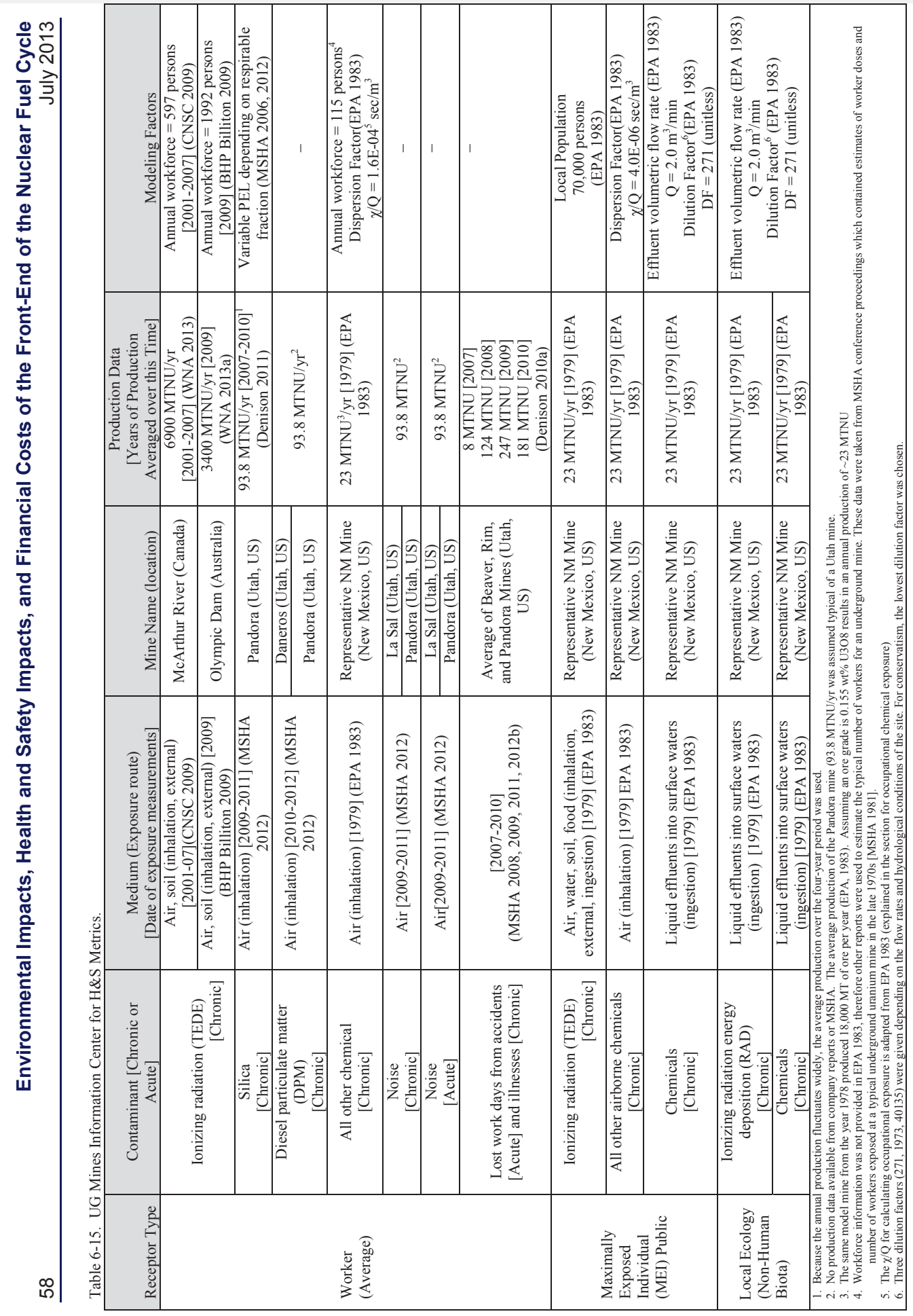


Environmental Impacts, Health and Safety Impacts, and Financial Costs of the Front-End of the Nuclear Fuel Cycle

\section{Occupational Radiological Impacts - UG Mining}

The McArthur River and Olympic Dam mines were identified as having sufficient data to evaluate the potential for occupational radiation exposures. Table 6-16 provides average worker for these mines and calculates the average and total collective worker dose using data provided previously (see Table 6-15).

Table 6-16. Occupational Radiological Impacts for Underground Uranium Mines

\begin{tabular}{|c|c|c|c|c|c|c|}
\hline Site & \begin{tabular}{|c|} 
Average \\
Effective \\
Dose \\
$(\mathrm{mSv} / \mathrm{yr})$ \\
\end{tabular} & $\begin{array}{c}\text { Number of } \\
\text { workers }\end{array}$ & $\begin{array}{l}\text { Collective } \\
\text { dose } \\
\text { (Person- } \\
\text { mSv/yr) }\end{array}$ & $\begin{array}{l}\text { Production } \\
\text { (MTNU/yr) }\end{array}$ & $\begin{array}{c}\text { Average } \\
\text { Effective } \\
\text { Impact } \\
\text { (mSv/MTNU) }\end{array}$ & $\begin{array}{l}\text { Collective } \\
\text { Impact } \\
\text { (Person- } \\
\text { mSv/MTNU }\end{array}$ \\
\hline McArthur $\mathrm{F}$ & 1.19 & 613 & 729 & & & $1.05 \mathrm{E}-01$ \\
\hline Olymp & 2.12 & & 4223 & 3.40 & 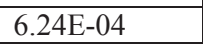 & $1.24 \mathrm{E}+00$ \\
\hline \multicolumn{5}{|c|}{ Average Impact (mSv/MTNU) } & & $3.98 \mathrm{E}-04$ \\
\hline \multicolumn{5}{|c|}{ Total Collective Impact (Person-mSv/MTNU) } & & 6.74 \\
\hline \multicolumn{7}{|c|}{$\begin{array}{l}\text { 1. Dose data are a seven year average from "Occupational Dose Data for Major Canadian Nuclear Facilities 2001-2007, } \\
\text { Canadian Nuclear Safety Commission, INFO-0775, June 2009. http://www.world-nuclear.org/info/inf49.html, accessed } 4 \\
\text { Dec } 2012 \\
\text { 2. Source: “Annual Radiation Protection Report } 1 \text { July } 2008 \text { - } 30 \text { June 2009”, BHP Billiton Limited. } \\
\text { http://www.epa.sa.gov.au/xstd files/Radiation/Other/olympic annual_2009.pdf. Exposure data include both designated } \\
\text { and non-designated workers with measurable radiation dose. }\end{array}$} \\
\hline
\end{tabular}

\section{Occupational Non-Radiological Impacts - UG Mining Chemical Exposures- UG Mining:}

Occupational chemical impact estimates include all airborne chemicals listed (EPA, 1983) along with diesel particulate matter (DPM), silica, and noise (MSHA, 2006) (NAS, 2011). Noise is included even though it is a physical impact. Noise exposure is the only acute impact considered for this report.

The worker chemical exposure estimates are based on the representative mine from New Mexico shown in Table 6-15. Details of the air concentrations underground were not provided in the primary reference (EPA 1983), thus insufficient data was available to estimate chemical exposures to miners working underground. However, the annual air emissions on the surface above the underground mine were listed in (EPA, 1983) and is used below to estimate chemical exposures to above-ground workers. Although perhaps nonconservative for miners working under ground, the above-ground worker exposures are used herein as the best estimate for the chemical exposure of underground mine workers.

Airborne contaminants may be generated from surfaces of the piles where ore, sub-ore (protore), and waste are stored $\left(2,700 \mathrm{~m}^{2}, 680 \mathrm{~m}^{2}\right.$, and $18,800 \mathrm{~m}^{2}$ respectively) and from forced air circulation systems in the mine. The wind can carry released radon and suspend aerosols for movement across the work space and off site. Since workers will be subject to exposure to these materials, it is necessary to estimate the air concentrations to which they will be exposed and compare those concentrations with the respective screening values.

The atmospheric dispersion factor $\chi / \mathrm{Q}$ at the off site location of maximum public exposure (the fence line at 1600 meters) was calculated for gases and particulates with an average of $4.0 \mathrm{E}-06 \mathrm{sec} / \mathrm{m}^{3}$ (EPA 1983 , Table K-1). The method for calculating this dispersion metric assumes all of the material originates in the center of the mine area which is a reasonable assumption for calculations of $\chi / Q$ at off-site locations. Assuming that the workers will be, on average, within a few hundred meters of the sources, they will be exposed to a higher concentration of gases and particulates than the location of maximum public 
exposure. Based on the graphs for estimating atmospheric dispersion (USAEC 1962) it is estimated that the atmospheric dispersion factor at a few hundred meters would be approximately $40 \mathrm{X}$ greater than at $1600 \mathrm{~m}$, or $1.6 \mathrm{E}-04 \mathrm{sec} / \mathrm{m}^{3}$. Using these above assumptions as a basis, the average annual air emissions and resultant surface air concentrations of chemicals from an underground mine are provided in Table 617. Table 6-18 shows the hazard quotients and hazard index calculated using these air concentrations and the screening levels from Table 6-3.

\section{Diesel Particulate Matter- UG Mining:}

The MSHA uses elemental carbon (EC) and total carbon (TC) as surrogates for diesel particulate matter (DPM) (MSHA, 2006). EC and TC are listed under the category of "Pulmonary Disease" causes and are listed in between the chronic and acute toxicity categories with no further definitive explanation of the degree of chronic impacts (MSHA, 2006). For this report, it is conservatively assumed that the DPM has chronic health impacts for occupational workers.

The Mine Data Retrieval System (as developed by PEIR on the MSHA's website was accessed for DPM exposure estimates in Table 6-19.

\section{Respirable Silica (Quartz) - UG Mining:}

The estimated impact resulting from occupational exposures to silica (in the form of respirable quartz aerosols) during mine operations, based on data the Pandora mine, is given in Table 6-20.

The MSHA does not promulgate a fixed-value for the PEL for silica (quartz). The PEL is dependent on the percent weight of the quartz (as silica dioxide) of the respirable fines in the ambient mine air. The empirical relationship to find the PEL for silica dioxide provided below (MSHA, 2006)

$$
P E L_{\text {respirable silica dioxide }}=\frac{10}{\% \text { respirable } \mathrm{SiO}_{2}+2} \mathrm{mg} / \mathrm{m}^{3}
$$

\section{Noise - UG Mining:}

The MSHA measures noise exposures to miners with the noise weighting scale "A" and the associated units are decibels (dBA) (MSHA, 2006). MSHA requires that noise levels be monitored (30 CFR Part 62 ) in order to: 1) determine if employee must be enrolled in a hearing conservation program and 2) ensure that their exposure does not exceed the Permissible Exposure Limit (PEL). The threshold for the Action Level (triggering an administrative response) is $80 \mathrm{dBA}$ and the threshold for the PEL is $90 \mathrm{dBA}$ Therefore all sound levels above $80 \mathrm{dBA}$ are integrated into the Action Level dose and all sound levels above $90 \mathrm{dBA}$ are integrated into the PEL dose ${ }^{21}$. Therefore noise measurements at or above the $90 \mathrm{dBA}$ threshold will be taken to be acute and those that meet the $80 \mathrm{dBA}$ threshold will be taken to be chronic.

Occupational noise exposures in the mines were taken during periods of normal operation. Occupational acute noise exposure estimates are provided in Table 6-21 and chronic noise exposures are shown in Table 6-22. It should be noted that hearing protection was worn during 133 out of the 146 samples taken for noise levels, both for the 80dBA and 90dBA levels ( $\sim 91 \%$ of total use during the active production of ore), therefore the actual hazard quotient is anticipated to be considerably less than calculated in the table.

21. The MSHA mandates the criterion level (maximum allowable accumulated noise exposure) to be 90 dBA for 8 hours. Thus for an 8 hour exposure, an average level of $90 \mathrm{dBA}$ will result in $100 \%$ dose. Higher noise levels than $90 \mathrm{dBA}$ lead to $100 \%$ dose in less time. For example, $100 \%$ dose at $95 \mathrm{dBA}$ is accumulated in 4 hours and at $100 \mathrm{dBA}$ in 2 hours (MSHA, 2012a). 


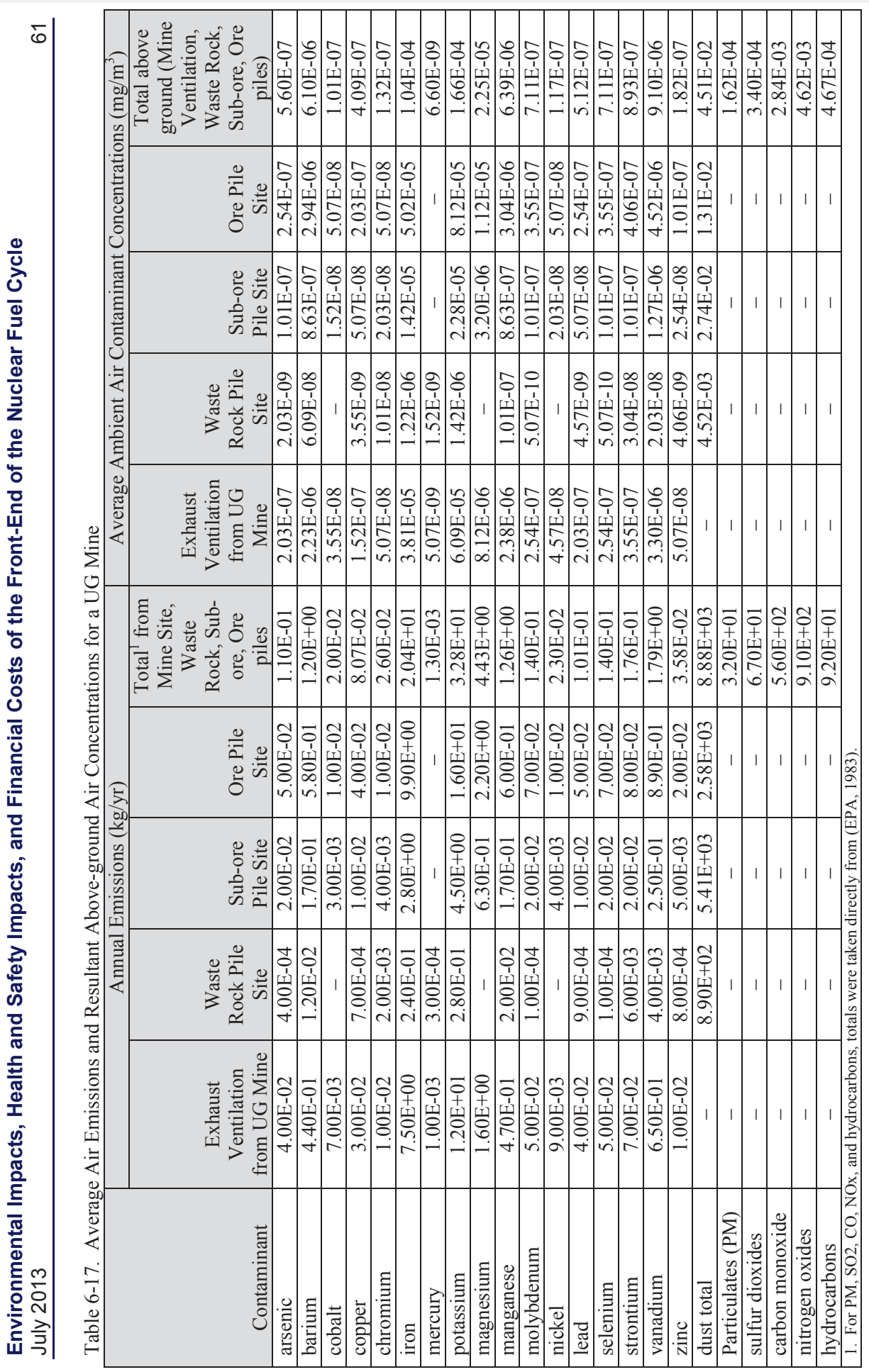


Environmental Impacts, Health and Safety Impacts, and Financial Costs of the Front-End of the

Nuclear Fuel Cycle

Table 6-18. Chemical Impacts to Above-Ground Workers from Airborne Effluents at a UG Mine.

\begin{tabular}{|c|c|c|c|}
\hline Contaminant & $\begin{array}{c}\text { Average Ambient Air Contaminant } \\
\text { Concentration at UG mines for } \\
\text { Aboveground Operation } \\
\left(\mathrm{mg} / \mathrm{m}^{3}\right)\end{array}$ & $\begin{array}{l}\text { Screening } \\
\text { Level }^{1} \\
\left(\mathrm{mg} / \mathrm{m}^{3}\right)\end{array}$ & Average Hazard Quotient \\
\hline arsenic & $5.60 \mathrm{E}-07$ & $5.00 \mathrm{E}-01$ & $1.12 \mathrm{E}-06$ \\
\hline barium & $6.10 \mathrm{E}-06$ & $5.00 \mathrm{E}-01$ & $1.22 \mathrm{E}-05$ \\
\hline cobalt & $1.01 \mathrm{E}-07$ & $1.00 \mathrm{E}-01$ & $1.01 \mathrm{E}-06$ \\
\hline copper & $4.09 \mathrm{E}-07$ & $1.00 \mathrm{E}-01$ & $4.09 \mathrm{E}-06$ \\
\hline chromium & $1.32 \mathrm{E}-07$ & $5.00 \mathrm{E}-01$ & 2.64E-07 \\
\hline iron & $1.04 \mathrm{E}-04$ & $1.00 \mathrm{E}+01$ & $1.04 \mathrm{E}-05$ \\
\hline mercury & $6.60 \mathrm{E}-09$ & $2.00 \mathrm{E}+00$ & 3.30E-09 \\
\hline potassium & $1.66 \mathrm{E}-04$ & $5.00 \mathrm{E}+00$ & $3.33 \mathrm{E}-05$ \\
\hline magnesium & $2.25 \mathrm{E}-05$ & $1.50 \mathrm{E}+01$ & $1.50 \mathrm{E}-06$ \\
\hline manganese & $6.39 \mathrm{E}-06$ & $5.00 \mathrm{E}+00$ & $1.28 \mathrm{E}-06$ \\
\hline molybdenum & 7.11E-07 & $5.00 \mathrm{E}+00$ & $1.42 \mathrm{E}-07$ \\
\hline nickel & $1.17 \mathrm{E}-07$ & $1.00 \mathrm{E}+00$ & $1.17 \mathrm{E}-07$ \\
\hline lead & 5.12E-07 & $1.50 \mathrm{E}-01$ & $3.41 \mathrm{E}-06$ \\
\hline selenium & $7.11 \mathrm{E}-07$ & $2.00 \mathrm{E}-01$ & $3.55 \mathrm{E}-06$ \\
\hline strontium & 8.93E-07 & $1.00 \mathrm{E}-04$ & 8.93E-03 \\
\hline vanadium & $9.10 \mathrm{E}-06$ & $1.00 \mathrm{E}-01$ & $9.10 \mathrm{E}-05$ \\
\hline zinc & $1.82 \mathrm{E}-07$ & $1.00 \mathrm{E}+00$ & $1.82 \mathrm{E}-07$ \\
\hline dust total & $4.51 \mathrm{E}-02$ & $1.50 \mathrm{E}+01$ & $3.00 \mathrm{E}-03$ \\
\hline Particulates (PM) & $1.62 \mathrm{E}-04$ & $1.50 \mathrm{E}+00$ & $1.08 \mathrm{E}-04$ \\
\hline sulfur dioxides & $3.40 \mathrm{E}-04$ & $1.30 \mathrm{E}+01$ & $2.61 \mathrm{E}-05$ \\
\hline carbon monoxide & 2.84E-03 & $5.50 \mathrm{E}+01$ & $5.17 \mathrm{E}-05$ \\
\hline nitrogen oxides & $4.62 \mathrm{E}-03$ & $9.00 \mathrm{E}+00$ & $5.13 \mathrm{E}-04$ \\
\hline hydrocarbons & 4.67E-04 & $1.80 \mathrm{E}+03$ & $2.59 \mathrm{E}-07$ \\
\hline \multicolumn{3}{|c|}{ Summation of Individual Hazard Quotients (Hazard Index) } & $1.28 \mathrm{E}-02$ \\
\hline \multicolumn{3}{|c|}{ Total Relative Chemical Impact ${ }^{2}$ (Hazard Index /MTNU) } & $5.56 \mathrm{E}-04$ \\
\hline
\end{tabular}

Table 6-19. Occupational DPM Exposures and Impacts for Underground Mine

\begin{tabular}{|c|c|c|}
\hline $\begin{array}{c}\text { Average TC readings } \\
\text { (34 separate measurements) }\end{array}$ & $\begin{array}{c}\text { PEL }^{2} \\
\left(\mu \mathrm{g} / \mathrm{m}^{3}\right)\end{array}$ & Hazard Quotient \\
\hline \multicolumn{2}{|c|}{128.3} & 160 \\
\hline \multicolumn{2}{|c|}{ Total Relative DPM Chemical Impact (Hazard Index /MTNU) } & $\mathbf{8 . 5 4 E - 0 3}$ \\
\hline 1. TC data was taken at Pandora Mine between 1/27/2010 and 2/15/2012. \\
2. PEL used as screening level (see Table 6-3) \\
3. Average production at Pandora Mine of 93.8 MTNU/yr (Table 6-15) \\
\hline
\end{tabular}


Environmental Impacts, Health and Safety Impacts, and Financial Costs of the Front-End of the Nuclear Fuel Cycle

July 2013

Table 6-20. Occupational Chronic Silica Exposure Impact Data from an Underground Mine.

\begin{tabular}{|l|c|c|c|}
\hline $\begin{array}{c}\text { Contaminant - Site - Year of Measurement - } \\
\text { Number of Readings }\end{array}$ & $\begin{array}{c}\text { Average Respirable Silica } \\
(\text { Quartz) Concentration } \\
\left(\mathrm{mg} / \mathrm{m}^{3}\right)^{1}\end{array}$ & $\begin{array}{c}\text { PEL } \\
\left(\mathrm{mg} / \mathrm{m}^{3}\right)^{1}\end{array}$ & $\begin{array}{c}\text { Silica } \\
\text { Hazard } \\
\text { Quotient }\end{array}$ \\
\hline $\begin{array}{l}\text { US Pandora Mine [UG] (6/2009-12/2011) } \\
\text { (32 readings) }\end{array}$ & 0.358 & 1.307 & $2.743 \mathrm{E}-01$ \\
\hline \multicolumn{2}{|l|}{ Total Relative Silica Chemical Impact ${ }^{2}$ (Hazard Index /MTNU) } & $\mathbf{2 . 9 2 5 E - 0 3}$ \\
\hline $\begin{array}{l}\text { 1. Silica Exposure data and the PEL are from the Mine Data Retrieval System (MSHA 2012). } \\
\text { 2. Average production at Pandora Mine of 93.8 MTNU/yr (Table 6-15) }\end{array}$ & \\
\hline
\end{tabular}

Table 6-21. Occupational Acute Noise Exposures and Impacts from 2 US Underground Mines

\begin{tabular}{|c|c|c|c|}
\hline $\begin{array}{c}\text { Mine - Year of Measurement - Number of } \\
\text { Readings }\end{array}$ & $\begin{array}{l}\text { Average of } \\
\text { Reported } \\
\text { Exposure Levels } \\
(\% \text { of PEL })^{1}\end{array}$ & $\begin{array}{c}\text { Hazard } \\
\text { Quotient }^{2}\end{array}$ & $\begin{array}{l}\text { Average Hazard } \\
\text { Quotient of the two } \\
\text { mines }\end{array}$ \\
\hline $\begin{array}{l}\text { US La Sal Mine [UG] }(5 / 2011-7 / 2011)(11 \\
\text { @ } 90 \text { dBA threshold; } 22 \text { readings total) }\end{array}$ & 57.6 & $5.8 \mathrm{E}-01$ & \multirow[b]{2}{*}{$6.0 \mathrm{E}-01$} \\
\hline $\begin{array}{l}\text { US Pandora Mine [UG] }(7 / 2009-12 / 2011) \\
(62 @ 90 \text { dBA threshold; } 124 \text { readings total) }\end{array}$ & 62.6 & $6.3 \mathrm{E}-01$ & \\
\hline \multicolumn{3}{|c|}{ Total Relative Acute Noise Impact ${ }^{3}$ (Hazard Index /MTNU) } & $6.4 \mathrm{E}-03$ \\
\hline \multicolumn{4}{|c|}{$\begin{array}{l}\text { 1. Data from the Mine Data Retrieval System (MSHA 2012) } \\
\text { 2. MSHA defines PEL as a TWA ( } 8 \text {-hour) of } 90 \mathrm{dBA} \text { or equivalently a dose of } 100 \% \text { of that permitted by the standard, } \\
\text { integrating all sound levels from } 90 \mathrm{dBA} \text { to at least } 140 \mathrm{dBA} \text { ( } 30 \mathrm{CFR} \text { Part } 62 \text { ). The HQ is thus the same number as the } \% \\
\text { of PEL, represented as a fraction. } \\
\text { 3. Average production at each of these mines is } 93.8 \mathrm{MTNU} / \mathrm{yr} \text { (Table 6-15). }\end{array}$} \\
\hline
\end{tabular}

Table 6-22. Occupational Chronic Noise Exposures and Impacts from 2 US Underground Mines.

\begin{tabular}{|l|c|c|c|}
\hline Site - Year of Measurement - Number of Readings & $\begin{array}{c}\text { Average Reported } \\
\text { Exposure Levels } \\
\text { (\% of PEL) }\end{array}$ & $\begin{array}{c}\text { Hazard } \\
\text { Quotient }\end{array}$ & $\begin{array}{c}\text { Average Hazard } \\
\text { Quotient of Two } \\
\text { Mines }\end{array}$ \\
\hline $\begin{array}{l}\text { US La Sal Mine [UG] (5/2011-7/2011) (11 @ } 80 \\
\text { dBA threshold; 22 readings total) }\end{array}$ & 72.6 & $7.3 \mathrm{E}-01$ & \multirow{2}{*}{$7.4 \mathrm{E}-01$} \\
\hline $\begin{array}{l}\text { US Pandora Mine [UG] (7/2009-12/2011) (62@80 } \\
\text { dBA threshold; 124 readings total) }\end{array}$ & 74.7 & $7.5 \mathrm{E}-01$ & \\
\hline \multicolumn{2}{|l|}{ Total Relative Chronic Noise Impact (Hazard index /MTNU) ${ }^{2}$} & & $\mathbf{7 . 9 E - 0 3}$ \\
\hline $\begin{array}{l}\text { 1. Data from the Mine Data Retrieval System (MSHA 2012) } \\
\text { 2. Average production at each of these mines is 93.8 MTNU/yr (Table 6-15) }\end{array}$
\end{tabular}

\section{Occupational Total Relative Chemical Impacts from Airborne Contaminants and Noise - UG Mining:}

The EPA recommends the summation of individual health quotients from individual chemicals from each exposure pathway to calculate a cumulative Hazard Index for a particular site. If there are more than one cumulative Hazard Indexes because there multiples sites under evaluation, the average is taken. This report sums indexes from chemicals and noise exposures in Table 6-23. 
Environmental Impacts, Health and Safety Impacts, and Financial Costs of the Front-End of the Nuclear Fuel Cycle

Table 6-23. Occupational Relative Chemical Impact of UG Mining.

\begin{tabular}{|l|c|}
\hline \multicolumn{1}{|c|}{ Contaminant } & Hazard Index/MTNU \\
\hline Airborne Chemicals (From Table 6-18) & $5.56 \mathrm{E}-04$ \\
\hline DPM (Table 6-19) & $8.54 \mathrm{E}-03$ \\
\hline Silica (Table 6-20) & $2.93 \mathrm{E}-03$ \\
\hline Noise (Acute) (Table 6-21) & $6.4 \mathrm{E}-03$ \\
\hline Noise (Chronic) (Table 6-22) & $7.9 \mathrm{E}-03$ \\
\hline \multicolumn{2}{|c|}{ Total Relative Chemical Impact (Hazard Index/MTNU) } \\
\hline
\end{tabular}

\section{Occupational Accidents and Illnesses Impacts- UG Mining}

The safety data for mines in the US are published each year by the MSHA. Data are presented for the whole state, not by mine. Data for the years 2007- 2010 were obtained for the Beaver, Rim, and Pandora operating UG mines in Utah (MSHA 2008, 2009, 2011, 2012b). The pertinent data for the Utah mines in the MSHA references were found in Tables 8 and 9 and summarized below in Table 6-24.

Table 6-24. Occupational Accidents and Illnesses Impacts for Underground Mines in Utah

\begin{tabular}{|l|r|r|c|}
\hline \multicolumn{1}{|c|}{ Year } & Days Lost per year & $\begin{array}{c}\text { Annual Production } \\
\text { MTNU/year }\end{array}$ & Days Lost/MTNU \\
\hline 2007 & 0 & 8 & 0 \\
\hline 2008 & 28 & 124 & 0.226 \\
\hline 2009 & 106 & 247 & 0.429 \\
\hline 2010 & 8 & 181 & 0.0419 \\
\hline \multicolumn{2}{|c|}{ Total Average Accident and Injury Impact (days lost/MTNU) } \\
\hline $\begin{array}{l}\text { 1. All of the accidents were incurred by the underground workers, none by the above-ground workers at underground mines. } \\
\text { 2. Combined annual production of the 3 Utah Mines (Beaver, Rim, and Pandora) is from (Denison 2010a) }\end{array}$
\end{tabular}

\section{Public Radiological Impacts- UG Mining:}

The representative New Mexico mine (Table 6-15) was used as the basis for estimating public radiological impacts. The regional population (roughly $80 \mathrm{~km}$ ) was estimated, using county statistics, to be 64,950 people (EPS 1983 Ch 5). Appendix K of EPA (1983) states; "The population data for both generic sites were generated by a computer program that uses an edited and compressed version of the 1970 United States Census Bureau's Master Enumeration District List with Coordinates”. An explicit number is not found for the algorithm used to calculate risk. The two discussions suggest different ideas about the method for identifying the population subject to dose analysis. Inference from tabular results suggests that the actual number used was very close to 35,000 . The 2010 census indicates that the population density in New Mexico is almost exactly twice that assumed in the EPA study: thus the current population estimate to be used in calculation of Impact is 70,000 persons.

Calculations were performed using source terms derived from extensive measurements (EPA 1983, Appendix K). Impacts to the public were based on release rates of Uranium, Thorium and Radon-222, as well as Working Level exposure from the daughters of radon-222 (EPA 1983, Tables 6.1 and 6.3). The EPA performed extensive calculations on a risk basis for individual organs using a pathway analysis that included direct exposure, and inhalation as well as uptake via food and water (see Soldat 1974). . Doses presented below in Table 6-25 were derived from EPA risk tables by back calculating using the risk per 
Environmental Impacts, Health and Safety Impacts, and Financial Costs of the Front-End of the Nuclear Fuel Cycle

Table 6-25. Public Radiological Impact Data from an EPA model Underground Uranium Mine.

\begin{tabular}{|c|c|c|c|c|}
\hline Site & $\begin{array}{c}\text { Population } \\
\text { (Persons) }\end{array}$ & $\begin{array}{c}\text { Critical Receptor } \\
\text { TEDE } \\
(\mathrm{mSv} / \mathrm{yr})\end{array}$ & $\begin{array}{c}\text { Average } \\
\text { Annual TEDE } \\
(\mathrm{mSv} / \mathrm{yr})\end{array}$ & $\begin{array}{c}\text { Average Annual } \\
\text { Collective TEDE } \\
\text { (Person-mSv/yr) }\end{array}$ \\
\hline Average Underground Mine & 70,000 & 0.8 & 0.0034 & 238 \\
\hline \multicolumn{2}{|l|}{ Total Impact to Critical Receptor (mSv/MTNU) } & $\mathbf{3 . 5 E - 0 2}$ \\
\hline \multicolumn{2}{|l|}{ Total Collective Impact (Person-mSv/MTNU) } \\
\hline 1. Average annual production of 23MTNU (see Table 6-15) \\
\hline
\end{tabular}

rem of 1.4E-04 (estimated using tables of dose and risk within EPA 1983). It should be noted that information derived from the process described above is necessarily imprecise and that many current dust suppression and other mitigative features may not have been in use during the data gathering time for the development of the EPA (1983) report. The critical receptor is taken at the fenceline $1600 \mathrm{~m}$ from the center of the mining property. Due to these considerations, the impacts found in Table 6-25 must be considered as upper limits relative to current and future underground mining operations.

\section{Public Chemical Impacts- UG Mining:}

\section{Liquid Effluents and Water Quality-UG Mining:}

The basis for public impacts resulting from liquid effluents from underground mining are given in Table 6-26. It should be noted that the estimate assumes ingestion of contaminants directly from surface waters (mine effluents diluted by a factor of 271) and not further treated for public consumption. The resulting Hazard Quotient is considered useful in this case only as a guide for future public protection since it is highly improbable that anyone would ingest surface waters near a mine on a regular basis. Potable water sources in regions near the reference UG mine are underground (USEPA 1983).

Table 6-26. Public Chemical Impact to Critical Receptor from Liquid Effluents from a UG Mine.

\begin{tabular}{|c|c|c|c|c|}
\hline Contaminant & $\begin{array}{l}\text { Concentration in } \\
\text { mine effluent } \\
(\mathrm{mg} / \mathrm{L})^{1}\end{array}$ & $\begin{array}{l}\text { Concentration in Surface Water } \\
\text { after Dilution Factor of } 271 \text { is } \\
\text { Applied (mg/L) }\end{array}$ & $\begin{array}{l}\text { Screening } \\
\text { Level }^{2} \\
(\mathrm{mg} / \mathrm{L})\end{array}$ & $\begin{array}{l}\text { Average } \\
\text { Hazard } \\
\text { Quotient }\end{array}$ \\
\hline total uranium & $1.41 \mathrm{E}+00$ & $5.20 \mathrm{E}-03$ & $3.00 \mathrm{E}-02$ & $1.73 \mathrm{E}-01$ \\
\hline cadmium & $7.00 \mathrm{E}-03$ & $2.58 \mathrm{E}-05$ & $5.00 \mathrm{E}-03$ & $5.17 \mathrm{E}-03$ \\
\hline arsenic & $1.20 \mathrm{E}-02$ & 4.43E-05 & $4.46 \mathrm{E}-05$ & $9.93 \mathrm{E}-01$ \\
\hline selenium & $7.60 \mathrm{E}-02$ & $2.80 \mathrm{E}-04$ & $5.00 \mathrm{E}-02$ & $5.61 \mathrm{E}-03$ \\
\hline molybdenum & $2.90 \mathrm{E}-01$ & $1.07 \mathrm{E}-03$ & $7.77 \mathrm{E}-02$ & $1.38 \mathrm{E}-02$ \\
\hline barium & $8.10 \mathrm{E}-01$ & $2.99 \mathrm{E}-03$ & $2.00 \mathrm{E}+00$ & $1.49 \mathrm{E}-03$ \\
\hline zinc & 4.30E-02 & $1.59 \mathrm{E}-04$ & $4.67 \mathrm{E}+00$ & $3.40 \mathrm{E}-05$ \\
\hline sulfate & $5.80 \mathrm{E}+02$ & $2.14 \mathrm{E}+00$ & $2.50 \mathrm{E}+02$ & $8.56 \mathrm{E}-03$ \\
\hline total suspended solids & $2.78 \mathrm{E}+01$ & $1.03 \mathrm{E}-01$ & $5.00 \mathrm{E}+02$ & $2.05 \mathrm{E}-04$ \\
\hline \multicolumn{4}{|c|}{ Summation of Individual Hazard Quotients (Hazard Index) } & $1.20 \mathrm{E}+00$ \\
\hline \multicolumn{4}{|c|}{ Total Relative Liquid Chemical Impact ${ }^{3}$ (Hazard Index / MTNU) } & $5.22 \mathrm{E}-02$ \\
\hline
\end{tabular}




\section{Gaseous Effluents and Air Quality- UG Mining:}

Contaminants with potential to become airborne, come from forced-air circulation systems in the mine and surface areas where ore and waste are stored. The representative NM mine (see Table 6-15) was used as the basis for estimating annual air emissions and the resultant downwind air concentrations. Data from (EPA 1983) allow evaluation of chemical exposures to members of the public proximate to the open pit mine, particularly the person assumed to reside at the site boundary, referred to as the Critical Receptor. The atmospheric dispersion at the site boundary(1600 meters) was calculated for gases and particulates with an average $\chi / \mathrm{Q}$ of $4.0 \mathrm{E}-06 \mathrm{sec} / \mathrm{m}^{3}$ (EPA 1983, Table K.1). Using this dispersion factor, the ambient air concentrations of various chemicals were computed from the average annual emissions and are provided in Table 6-27.

A public chemical hazard index representing potential human health impacts to the public from gaseous effluents and airborne contaminants from an underground mine is calculated in Table 6-28.

\section{Public Total Relative Chemical Impacts from Airborne and Liquid Contaminants - UG Mining:}

The EPA recommends the summation of individual health quotients from individual chemicals from each exposure pathway to calculate a cumulative Hazard Impact for a particular site. Impacts from both liquid and gaseous effluents are summed below in Table 6-29.

\section{Ecological Radiological Impacts- UG Mining:}

As discussed in Section 4.2, with respect to radiation exposure, it is generally agreed that protection of humans also protects most other animals. Hence, the estimated ecological impact to local freshwater ecology from radioactivity associated with underground mining given in Table 6-30 is based on the annual dose estimates to a human critical receptor, converted to units of mGy to the critical receptor (local ecology). For radium-226, primarily alpha particle decay, a factor of $1 / 20$ is used to convert from mSv. For lead-210, primarily beta decay, a factor of 1.0 is used.

\section{Ecological Chemical Impacts- UG Mining:}

\section{Liquid Effluents and Water Quality-UG Mining:}

The impact estimates shown below in Table 6-31 are based on the downstream concentration of contaminants from the representative New Mexico mine.

\section{Gaseous Effluents and Air Quality- UG Mining:}

Data are currently not available for calculating the potential impact gaseous effluents to the local ecosystem. However, it is standard practice in Environmental Impact Statements (EISs) to consider the local ecology as protected if the local human population is protected. However, there are some noted exceptions that are described in Section 4.2.

Because the hazard index per MTNU for downwind human populations is low, it can be qualitatively estimated that impact to local ecosystems is not significant. 


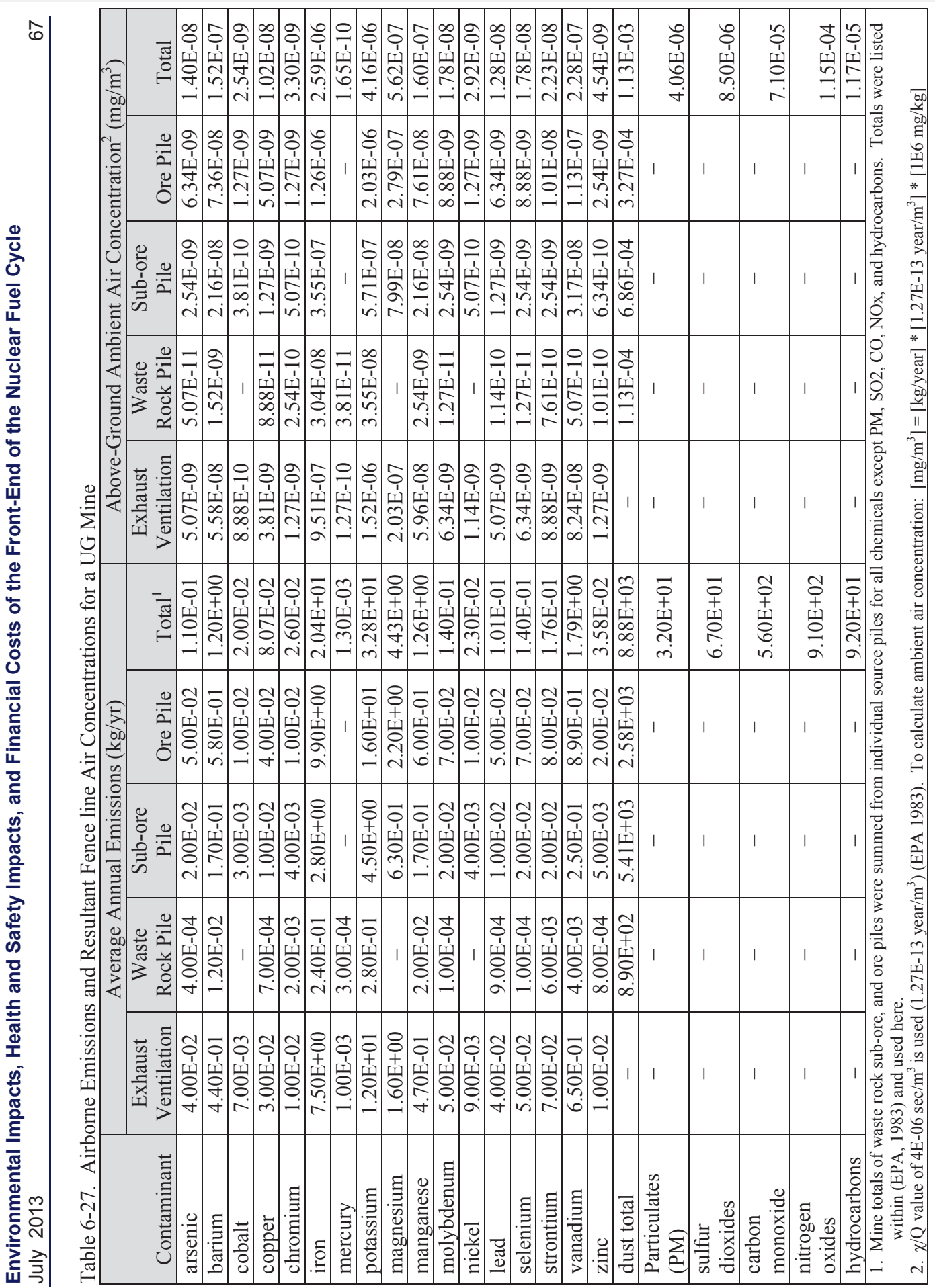


Environmental Impacts, Health and Safety Impacts, and Financial Costs of the Front-End of the

Nuclear Fuel Cycle

Table 6-28. Public Chemical Impact to Critical Receptor from Airborne Effluents - UG Mine.

\begin{tabular}{|l|c|c|c|}
\hline \multicolumn{1}{|c|}{ Contaminant } & $\begin{array}{c}\text { Average Ambient Contaminant } \\
\text { Concentration (mg/m3) } \\
\text { Downwind }\end{array}$ & $\begin{array}{c}\text { Screening Level } \\
\text { (mg/m3) }\end{array}$ & $\begin{array}{c}\text { Average Hazard } \\
\text { Quotient }\end{array}$ \\
\hline Arsenic, Inorganic & $1.40 \mathrm{E}-08$ & $5.66 \mathrm{E}-07$ & $2.47 \mathrm{E}-02$ \\
\hline Barium & $1.52 \mathrm{E}-07$ & $5.21 \mathrm{E}-04$ & $2.93 \mathrm{E}-04$ \\
\hline Cobalt & $2.54 \mathrm{E}-09$ & $2.70 \mathrm{E}-07$ & $9.40 \mathrm{E}-03$ \\
\hline Copper & $1.02 \mathrm{E}-08$ & $3.00 \mathrm{E}-03$ & $3.41 \mathrm{E}-06$ \\
\hline Chromium, Total & $3.30 \mathrm{E}-09$ & $5.00 \mathrm{E}-01$ & $6.60 \mathrm{E}-09$ \\
\hline Iron & $2.59 \mathrm{E}-06$ & $1.00 \mathrm{E}+01$ & $2.59 \mathrm{E}-07$ \\
\hline Mercury (elemental) & $1.65 \mathrm{E}-10$ & $3.00 \mathrm{E}-04$ & $5.50 \mathrm{E}-07$ \\
\hline Potassium & $4.16 \mathrm{E}-06$ & $5.00 \mathrm{E}+00$ & $8.32 \mathrm{E}-07$ \\
\hline Magnesium & $5.62 \mathrm{E}-07$ & $1.50 \mathrm{E}+01$ & $3.75 \mathrm{E}-08$ \\
\hline Manganese (Non-diet) & $1.60 \mathrm{E}-07$ & $5.00 \mathrm{E}-05$ & $3.20 \mathrm{E}-03$ \\
\hline Molybdenum & $1.78 \mathrm{E}-08$ & $5.00 \mathrm{E}+00$ & $3.55 \mathrm{E}-09$ \\
\hline Nickel Soluble Salts & $2.92 \mathrm{E}-09$ & $9.36 \mathrm{E}-06$ & $3.12 \mathrm{E}-04$ \\
\hline Lead and Compounds & $1.28 \mathrm{E}-08$ & $1.50 \mathrm{E}-04$ & $8.53 \mathrm{E}-05$ \\
\hline Selenium & $1.78 \mathrm{E}-08$ & $2.09 \mathrm{E}-02$ & $8.50 \mathrm{E}-07$ \\
\hline Strontium, Stable & $2.23 \mathrm{E}-08$ & $1.00 \mathrm{E}-04$ & $2.23 \mathrm{E}-04$ \\
\hline Vanadium and Compounds & $2.28 \mathrm{E}-07$ & $1.00 \mathrm{E}-01$ & $2.28 \mathrm{E}-06$ \\
\hline Zinc and Compounds & $4.54 \mathrm{E}-09$ & $1.00 \mathrm{E}-04$ & $4.54 \mathrm{E}-05$ \\
\hline dust total & $1.13 \mathrm{E}-03$ & $1.50 \mathrm{E}+01$ & $7.51 \mathrm{E}-05$ \\
\hline Particulates (PM) & $4.06 \mathrm{E}-06$ & $1.20 \mathrm{E}-02$ & $3.38 \mathrm{E}-04$ \\
\hline Sulfur Dioxide & $8.50 \mathrm{E}-06$ & $1.43 \mathrm{E}+00$ & $5.94 \mathrm{E}-06$ \\
\hline Carbon Monoxide & $7.10 \mathrm{E}-05$ & $4.01 \mathrm{E}+01$ & $1.77 \mathrm{E}-06$ \\
\hline Nitrogen Dioxide & $1.15 \mathrm{E}-04$ & $9.96 \mathrm{E}+01$ & $1.16 \mathrm{E}-06$ \\
\hline Hexane, N- & $1.17 \mathrm{E}-05$ & $2.00 \mathrm{E}-01$ & $5.83 \mathrm{E}-05$ \\
\hline & Total Relative Air Chemical Impact & $\mathbf{3 . 8 8 E - 0 2}$ \\
\hline \multicolumn{2}{|c|}{ (Hazard Index / MTNU) } & $\mathbf{1 . 6 9 E - 0 3}$ \\
\hline The screening level options for airborne contaminants for the public are listed in Table 6-4. & \\
\hline The annual production data used was 23 MTNU/year (Table 6-15). & & \\
\hline
\end{tabular}

Table 6-29. Public Total Chemical Impact from Representative UG Mine.

\begin{tabular}{|c|c|}
\hline \multicolumn{1}{|c|}{ Contaminant } & Hazard Index/MTNU \\
\hline Chemicals from Liquid Effluents(From Table 6-26) & $5.22 \mathrm{E}-2$ \\
\hline Chemicals from Gaseous Effluents (from Table 6-28) & $1.69 \mathrm{E}-03$ \\
\hline Total Relative Chemical Impact (Hazard Index/MTNU) & $\mathbf{5 . 3 9 E - 0 2}$ \\
\hline
\end{tabular}


Environmental Impacts, Health and Safety Impacts, and Financial Costs of the Front-End of the Nuclear Fuel Cycle

July 2013

Table 6-30. Ecological Radiological Impacts from Liquid Effluents of Underground Mines.

\begin{tabular}{|c|c|c|c|c|}
\hline \multirow[b]{2}{*}{ Contaminant } & \multicolumn{2}{|c|}{$\begin{array}{l}\text { Concentration in Surface Water after } \\
\text { Dilution Factor of } 271 \text { is Applied }\end{array}$} & \multirow{2}{*}{$\begin{array}{c}\text { Average Annual } \\
\text { Dose Equivalent to } \\
\text { Critical Receptor } \\
(\mathrm{mSv})\end{array}$} & \multirow{2}{*}{$\begin{array}{c}\text { Annual Average } \\
\text { Absorbed Dose to } \\
\text { Critical Receptor } \\
\text { (mGy) }\end{array}$} \\
\hline & Measurement Value & Unit & & \\
\hline radium- $226^{2}$ & $5.06 \mathrm{E}-02$ & $\mathrm{pCi} / \mathrm{L}$ & 4.22E-04 & $2.1 \mathrm{E}-05$ \\
\hline lead-210 & $2.69 \mathrm{E}-01$ & $\mathrm{mrem} / \mathrm{yr}$ & $2.69 \mathrm{E}-03$ & 03 \\
\hline \multicolumn{4}{|c|}{ Summation of Absorbed Dose } & 2.7E-03 \\
\hline \multicolumn{4}{|c|}{ Total Impact to Critical Receptor ${ }^{3}$ (mGy/MTNU) } & 1.2E-04 \\
\hline \multicolumn{5}{|c|}{$\begin{array}{l}\text { 1. Contaminant concentrations and dilution factor from the New Mexico representative mine described in (EPA 1983). } \\
\text { 2. The reported value of } 5.06 \mathrm{E}-02 \mathrm{pCi} / \mathrm{L} \text { was converted to an annual dose of } 4.22 \mathrm{E}-04 \mathrm{mSv} \text { to the critical receptor using the } \\
\text { correlation from } 10 \mathrm{CFR} 20 \text { - Appendix B - Table } 2 \text { [NRC 2012]) intended for calculating TEDE for members of the } \\
\text { public (i.e., } 6.0 \mathrm{E}-8 \mu \mathrm{Ci} / \mathrm{mL} \text { of Radium-226, ingested at a rate of } 2 \mathrm{~L} / \text { day over the course of a year, would produce a total } \\
\text { effective dose equivalent } 50 \text { millirem or } 0.5 \text { millisieverts) from http://www.nrc.gov/reading-rm/doc- } \\
\text { collections/cfr/part020/appb/Radium-226.html. }\end{array}$} \\
\hline
\end{tabular}

Table 6-31. Ecological Chemical Impacts from Liquid Effluents of Underground Mines.

\begin{tabular}{|c|c|c|c|c|}
\hline Contaminant & $\begin{array}{l}\text { Concentration in } \\
\text { mine effluent } \\
(\mathrm{mg} / \mathrm{L})\end{array}$ & $\begin{array}{l}\text { Resultant Concentration in } \\
\text { Surface Water after Dilution } \\
\text { Factor of } 271(\mathrm{mg} / \mathrm{L})\end{array}$ & $\begin{array}{c}\text { Screening } \\
\text { Level }^{2} \\
(\mathrm{mg} / \mathrm{L})\end{array}$ & $\begin{array}{c}\text { Average } \\
\text { Hazard } \\
\text { Quotient }\end{array}$ \\
\hline total uranium & $1.41 \mathrm{E}+00$ & $5.20 \mathrm{E}-03$ & $4.06 \mathrm{E}+00$ & $1.28 \mathrm{E}-03$ \\
\hline cadmium & $7.00 \mathrm{E}-03$ & $2.58 \mathrm{E}-05$ & $2.50 \mathrm{E}-04$ & $1.03 \mathrm{E}-01$ \\
\hline arsenic & $1.20 \mathrm{E}-02$ & $4.43 \mathrm{E}-05$ & $2.10 \mathrm{E}-03$ & $2.11 \mathrm{E}-02$ \\
\hline selenium & $7.60 \mathrm{E}-02$ & $2.80 \mathrm{E}-04$ & $1.00 \mathrm{E}-03$ & $2.80 \mathrm{E}-01$ \\
\hline molybdenum & $2.90 \mathrm{E}-01$ & $1.07 \mathrm{E}-03$ & $7.30 \mathrm{E}-02$ & $1.47 \mathrm{E}-02$ \\
\hline zinc & 4.30E-02 & $1.59 \mathrm{E}-04$ & $4.00 \mathrm{E}-03$ & $3.97 \mathrm{E}-02$ \\
\hline \multicolumn{4}{|c|}{ Summation of Individual Hazard Quotients (Hazard Index) } & $4.60 \mathrm{E}-01$ \\
\hline \multicolumn{4}{|c|}{$\begin{array}{r}\text { Total Relative Liquid Chemical Impact to Critical Receptor (Hazard Index } \\
\text { /MTNU) }\end{array}$} & $2.00 \mathrm{E}-02$ \\
\hline \multicolumn{5}{|c|}{$\begin{array}{l}\text { 1. Contaminant concentrations and dilution factor from (EPA 1983). } \\
\text { 2. Screening level from Table 6-6. } \\
\text { 3. Average annual production of } 23 \text { MTNU (see Table 6-15). }\end{array}$} \\
\hline
\end{tabular}

\subsubsection{Financial Cost Impacts - Underground Mining}

Financial costs associated with underground, open pit, and ISL mining are addressed in section 6.1.

\subsubsection{Open Pit Mines}

Estimates of environmental, safety and health, and financial cost impacts from open pit uranium mining are summarized in the Table 6-32. The remainder of section 6.1.2 provides the basis for the estimates shown. 
Environmental Impacts, Health and Safety Impacts, and Financial Costs of the Front-End of the Nuclear Fuel Cycle

Table 6-32. Summary of Impacts Open Pit Uranium Mining.

\begin{tabular}{|c|c|}
\hline \multicolumn{2}{|c|}{$\begin{array}{c}\text { Open Pit Mining Impacts } \\
\text { (per MTNU) }\end{array}$} \\
\hline 4.1 Environmental Impacts ${ }^{1}$ & 6.1 .2 .1 \\
\hline 4.1 .1 Land Use & $1.1 \mathrm{E}-04$ \\
\hline Permanent $\left(\mathrm{km}^{2}\right)$ & $5.4 \mathrm{E}-05$ \\
\hline Non-Permanent (km) & $5.4 \mathrm{E}-05$ \\
\hline 4.1 .2 Water Use(ML) net & $2.1 \mathrm{E}-01$ \\
\hline 4.13 Energy Use and CO2 Emissions & $1.2 \mathrm{E}+03$ \\
\hline Energy Use (GJ) & $9.3 \mathrm{E}+04$ \\
\hline CO2 Emissions (kg) & 6.1 .2 .2 \\
\hline 4.2 Health and Safety Impacts: & $5.1 \mathrm{E}-01$ \\
\hline 4.2 .1 Occupational Radiological (person-mSv) & $1.1 \mathrm{E}-02$ \\
\hline 4.2 .2 Occupational Chemical (Hazard Index) & $6.8 \mathrm{E}-03$ \\
\hline 4.2 .3 Occupational Accident \& Illness (lost days) & \\
\hline 4.2 .4 Public Radiological & $3.6 \mathrm{E}-04$ \\
\hline Dose to Critical Receptor (mSv) & $2.0 \mathrm{E}-01$ \\
\hline Collective Dose (person -mSv) & $5.98 \mathrm{E}-03$ \\
\hline 4.2 .5 Public Chemical (Hazard Index) & $1.4 \mathrm{E}-05$ \\
\hline 4.2 .6 Ecological Radiological (mGy) & See Note 2 \\
\hline 4.2.7 Ecological Chemical (Hazard Index) & 6.1 .2 .3 \\
\hline 4.3 Financial Costs: & $1.1 \mathrm{E}+05$ \\
\hline Cost \$) & \\
\hline 1. For land, water, and energy use, these values include the impacts from both mining and milling operations. \\
\hline Insufficient data to support development of a credible estimate. See discussion following Table 6-42. \\
\hline
\end{tabular}

\subsubsection{Environmental Impacts - Open Pit Mining}

Land, water, and energy related environmental impacts of open pit mining are discussed below.

\section{Land Use - Open Pit Mining}

Open-pit mines are large open excavations that can disturb large areas of earth, referred to as overburden, in order to reach the underlying ore body. The management of overburden results in significant land use while the mine is active. Although much of the land used for open pit mining may eventually be reclaimed. For the purpose of this study, it is conservatively assumed that $50 \%$ of the land used for mining operations will be used for tailings and/or other long-term needs and cannot thus be reclaimed for other uses.

Table 6-33, below, provides the data and the estimate for land use for open pit mining. 
Environmental Impacts, Health and Safety Impacts, and Financial Costs of the Front-End of the Nuclear Fuel Cycle

Table 6-33. Open Pit Mine Total Land Use - Includes Mining and Milling.

\begin{tabular}{|l|c|c|c|c|c|}
\hline \multicolumn{1}{|c|}{ Facility } & Source & $\begin{array}{c}\text { Uranium } \\
\text { Produced }^{1}\end{array}$ & $\begin{array}{c}\text { Land Use per } \\
\text { Product } \\
\left(\mathrm{m}^{2} / \mathrm{MTNU}\right)\end{array}$ & $\begin{array}{c}\% \text { of } \\
\text { Production }\end{array}$ & $\begin{array}{c}\text { Weighted land use } \\
\left(\mathrm{m}^{2} / \mathrm{MTNU}\right)\end{array}$ \\
\hline Mary Kathleen & Harries 1997 & 10,700 & 139 & 4.14 & 5.75 \\
\hline Nabarlek & Evans 2005 & 9,210 & 152 & 3.56 & 5.41 \\
\hline Ranger & Mudd 2007a & 121,000 & 41.2 & 46.79 & 19.28 \\
\hline Rössing & Rössing 2010 & 117,700 & 170 & 45.51 & 77.37 \\
\hline \multicolumn{5}{|c|}{ Weighted average land use $\left(\mathrm{m}^{2} / \mathrm{MTNU}\right)$} & 107.8 \\
\hline \multicolumn{7}{|c|}{ Weighted average land use $\left(\mathrm{km}^{2} / \mathrm{MTNU}\right)$} & $1.08 \mathrm{E}-4$ \\
\hline 1. Lifetime production based on estimated probable reserves
\end{tabular}

\section{Water Use - Open Pit Mining}

As is the case for underground mines, water may be used in drilling of boreholes for geological sampling and for planting explosives, dust suppression, and lowering the water table. The amount of water used will again be very site specific, and any water use for lowering of the water table will depend greatly on the location and depth of the mine. Water use data from several open pit mines are given in Table 6-34.

Note that this data represents gross water consumption, and is considered a conservative bound on the water usage. Much of the water used in the operation can be, and often is, recycled. Similar to underground mining, water recycle values for open pit mining may vary significantly depending on local factors. For the purpose of this study, a mid-range representation of $50 \%$ recycle will be used.

Note that this water use estimate is skewed significantly higher due to the large water use at the Rössing mine. The ore grade at Rössing is much lower than the others in this data set (Rössing $\mathrm{G}=.03 \%$, Ranger $\mathrm{G}=.21 \%$ McClean $=1.38 \%$ ). The water use can be explained largely because the milling of uranium is a water intensive process. Further water losses may result from evaporation due to its dessert location.

\section{Energy Use and $\mathrm{CO}_{2}$ Emissions - Open Pit Mining}

Estimates for the open pit mining energy use were developed as described in section 4.1.3. Data from (Rotty 1975) were extracted as described in Section 6.1.1.1 to produce the estimates shown below in Table 6-35. $\mathrm{CO}_{2}$ emissions factors are taken from Appendix B.

Key assumptions from Rotty 1975 include a 95\% mill yield, 75lbs sulfuric acid per short ton of ore milled, an ore grade of $.208 \%$, and a 10 year lifetime ${ }^{22}$. Because Schneider 2010 assumed an ore grade of $0.1 \%$, it was assumed in this estimate that roughly twice as much ore at a grade of $.1 \%$ must be mined to produce the same amount of uranium as a grade of .208\%. Consequently, value for the energy intensity of Rotty 1975 mine materials energy was doubled to account for the additional process materials (e.g. explosives, roof bolts, and machinery part replacements, sulfuric acid and other mill inputs, etc.) necessary to produce one MT U from an ore grade of .1\%.

\subsubsection{Health and Safety Impacts - Open Pit Mining}

Open pit mines were historically operated in the US but none have operated recently in the US. However, several substantially larger mines, than those historically operated in the US have been in recent production in other countries. Data for two such mines, the Rössing mine in Namibia and the Ranger

22. The lifetime is used to amortize the construction energy. 10 years is very conservative as most mining/milling operations have lifetimes that are well beyond 20 years. 


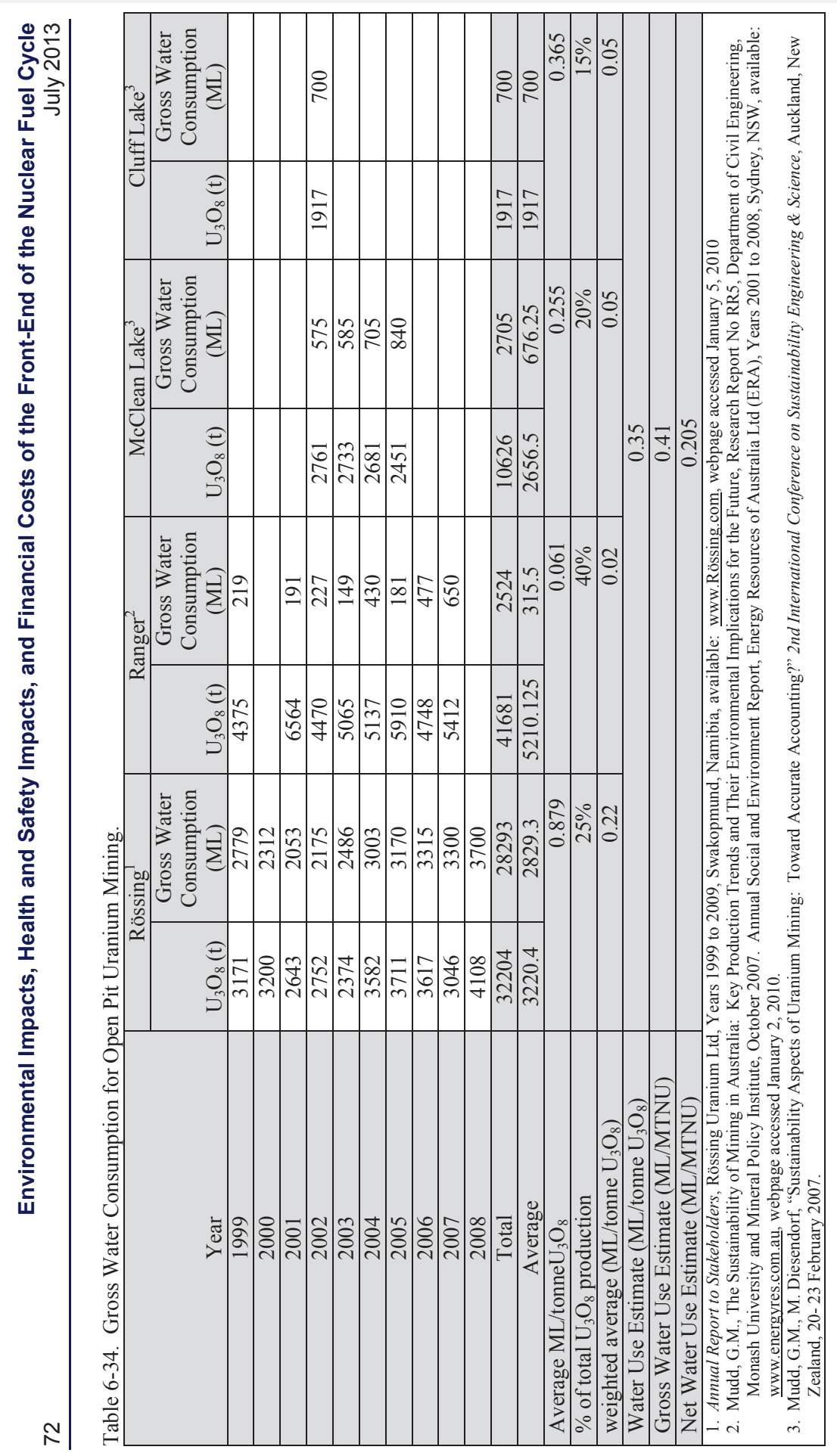




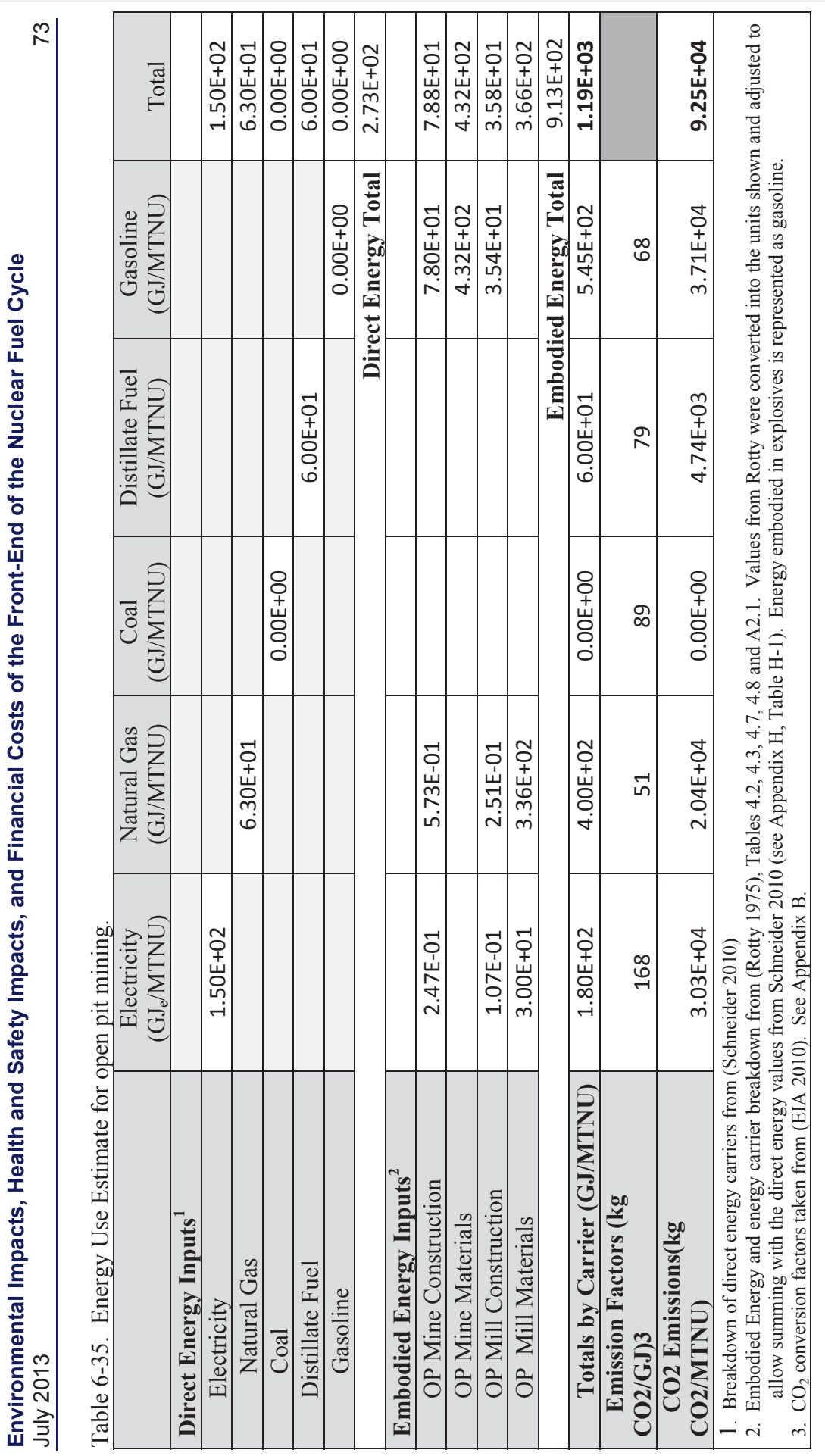


mine in Canada, will be used along with a representative Wyoming open pit mine from the late 1970s in order to understand potential health implications of typical open pit mines. These three OP mine data sets are described below in Table 6-36.

\section{Occupational Radiological Impacts - OP Mining}

Data from the Ranger operation in Australia and the Rössing mine in Namibia are used to develop the occupational radiation exposure estimates presented in Table 6-37. Annual production data and number of workers are used from Table 6-36.

\section{Occupational Chemical Impacts - OP Mining}

The human health impacts with regard to chemical toxicity from liquid effluents are not considered as the ingestion exposure route is generally not significant for occupational personnel. Occupational chemical impact estimates include all airborne chemicals listed (EPA, 1983). Diesel particulate matter (DPM), silica, and noise have also recently been identified as having potential for adverse health impacts on mine workers (MSHA, 2006) (NAS, 2011). However, no data was available to assess occupational exposure at open pit mines, US or international, for either DPM, silica or noise. The data could not be obtained from the MSHA's Mine Data Retrieval System (as developed by PEIR) because records are only available for currently operating open pit mines within the US (MSHA 2012). The Mine Data Retrieval System only allows access to years from 1996 to more recent years. The latest year that an open pit mine was operated was in the early $1990 \mathrm{~s}$.

It should be noted that because the open pit mine is open to natural air circulation, the concentration of aerosols in the ambient mine air will be significantly less than the concentrations present in underground mines (NAS 2011). The human health impacts from chronic exposure to such low concentrations of DPM and silica are considered insignificant for this report and are not included in the roll-up metric. Although the occupational health impacts from noise are not included in the present study, large mining equipment is used in open pit mines. Hence, it is recommended that this impact be considered in future reports.

The annual air emissions for an average open pit mine were listed in (EPA 1983) and ambient mine air concentrations were calculated given the characteristics of the representative Wyoming OP mine (Table 6-36). The areas where gaseous effluents and particulate emissions may be generated are the excavation area for mining uranium, piles where ore, waste, and sub-ore (protore) are stored. The average atmospheric dispersion at the off site location of maximum public exposure (the fence line at 1600 meters) was calculated for gases and particulates with an average $\chi / \mathrm{Q}$ of $2.0 \mathrm{E}-06 \mathrm{sec} / \mathrm{m}^{3}$ (EPA 1983 , Table K.1). As explained in the section for occupational chemical exposure for UG mines, the workers are estimated to receive about $40 \mathrm{X}$ greater exposure than a receptor at the 1600 meter fence line: therefore for the occupational personnel, $\chi / \mathrm{Q}=8.0 \mathrm{E}-05 \mathrm{sec} / \mathrm{m}^{3}$. Using this dispersion factor, the resultant surface air concentrations are derived in Table 6-38 and, using the screening levels identified in Table 63 , the resulting impacts, assuming no PPE are used, are calculated in Table 6-39.

\section{Occupational Accidents and Illnesses Impacts- OP Mining:}

No data was presented in the EPA (1983) document regarding occupational accidents and injuries. However such data were available, from operation of the Ranger open pit mine in Australia and are summarized in Table 6-40.

\section{Public Radiological Impacts- OP Mining:}

Doses presented below in Table 6-41 are based on the representative Wyoming OP mine (Table 6-36) and were back-calculated using a risk per rem of 1.4E-04 based on tables of dose and risk found in EPA (1983). It should be noted that information derived from this process is necessarily imprecise. Estimates are however expected to be conservative. Many current dust suppression features may not have been in 


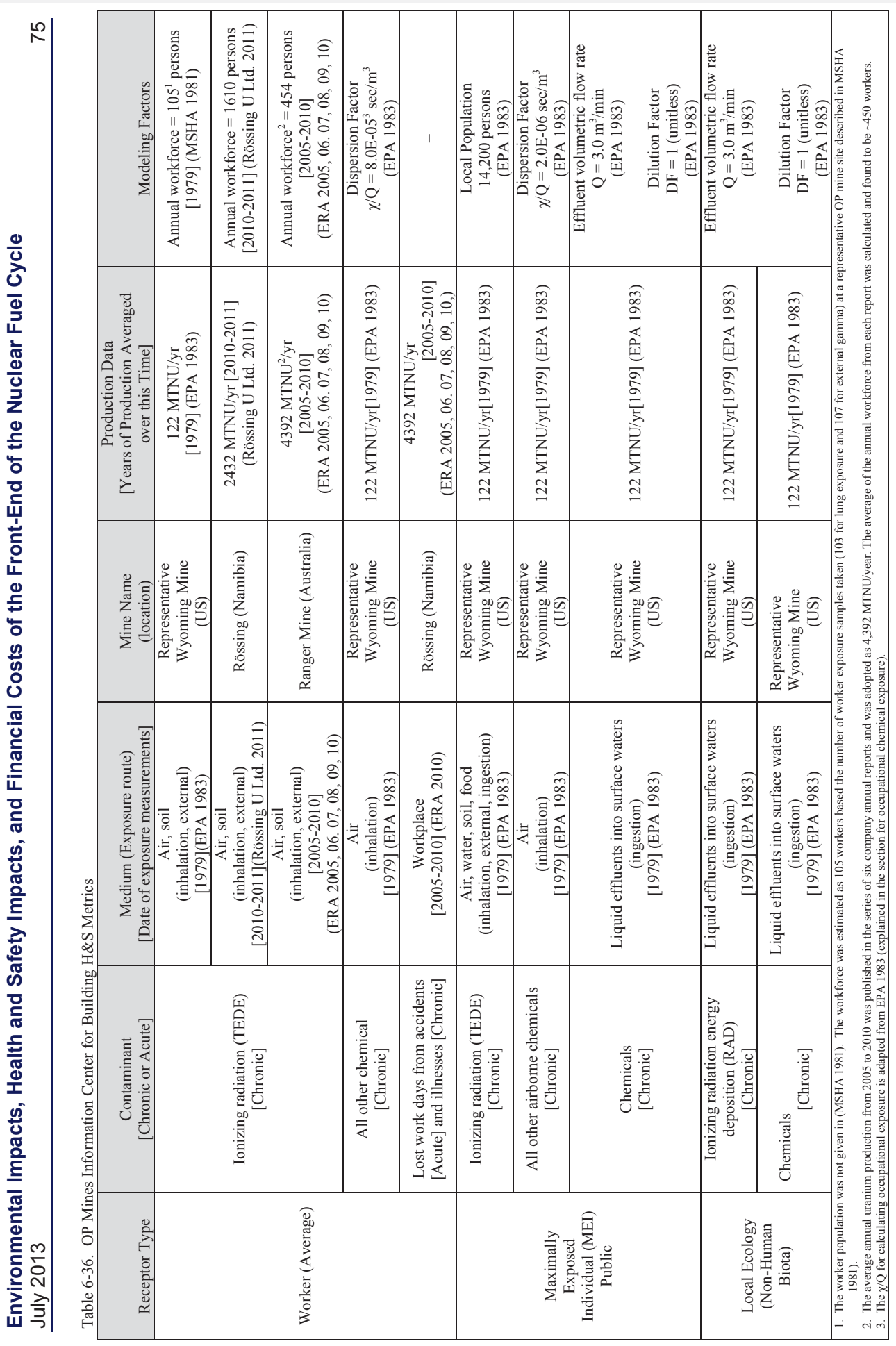


Environmental Impacts, Health and Safety Impacts, and Financial Costs of the Front-End of the

Nuclear Fuel Cycle

Table 6-37. Occupational Radiological Impacts for Open Pit Uranium Mines

\begin{tabular}{|c|c|c|c|c|}
\hline Site & $\begin{array}{c}\text { Average } \\
\text { Effective Dose } \\
(\mathrm{mSv} / \mathrm{yr})\end{array}$ & $\begin{array}{l}\text { Collective dose } \\
\text { (Person-mSv/yr) }\end{array}$ & $\begin{array}{l}\text { Average Effective Impact } \\
\text { (mSv/MTNU) }\end{array}$ & $\begin{array}{c}\text { Collective Impact } \\
\text { (Person-mSv/MTNU) }\end{array}$ \\
\hline Ranger & 0.81 & 367 & $1.84 \mathrm{E}-04$ & 8.37E-02 \\
\hline Rössing & 1.40 & 2254 & $5.76 \mathrm{E}-04$ & $9.27 \mathrm{E}-01$ \\
\hline \multicolumn{3}{|c|}{ Average Impact (mSv/MTNU) } & \\
\hline \multicolumn{3}{|c|}{ Total Collective Impact (Person-mSv/MTNU) } & \multicolumn{2}{|r|}{$5.05 E-01$} \\
\hline
\end{tabular}




\begin{tabular}{|c|c|c|c|c|c|c|c|c|c|c|c|c|c|c|c|c|c|c|c|}
\hline & 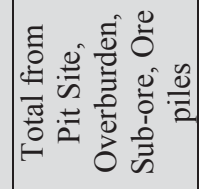 & 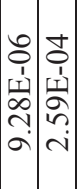 & 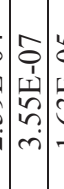 & 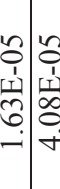 & $\begin{array}{c}0 \\
0 \\
1 \\
1 \\
0 \\
\sim \\
i n\end{array}$ & $\mid \begin{array}{c}0 \\
0 \\
1 \\
1 \\
0 \\
0 \\
0 \\
0\end{array}$ & 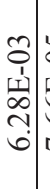 & 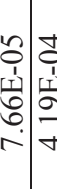 & & $\mid \begin{array}{c}0 \\
0 \\
1 \\
1 \\
0 \\
0 \\
\dot{\gamma} \\
\end{array}$ & & 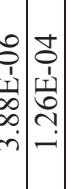 & & 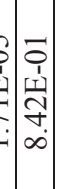 & $\begin{array}{c}\tilde{o} \\
1 \\
\omega \\
0 \\
r\end{array}$ & \begin{tabular}{c}
$\mathcal{O}$ \\
0 \\
1 \\
$\infty$ \\
$\infty$ \\
\multirow{-}{1}{} \\
-
\end{tabular} & $\begin{array}{l}\overrightarrow{0} \\
\text { 1े } \\
\text { के } \\
\text { +. }\end{array}$ & $\begin{array}{c}\overrightarrow{0} \\
+1 \\
\stackrel{1}{m} \\
\stackrel{i}{1}\end{array}$ & 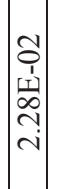 \\
\hline 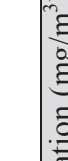 & 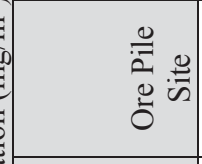 & 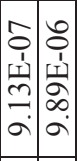 & $\mid \begin{array}{c}0 \\
0 \\
1 \\
0 \\
0 \\
2 \\
-1\end{array}$ & 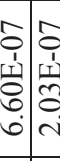 & $\begin{array}{l}0 \\
0 \\
1 \\
1 \\
\\
\stackrel{-}{-} \\
-\end{array}$ & & 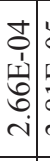 & 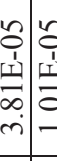 & 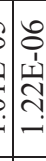 & 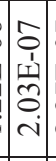 & 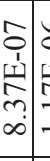 & 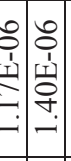 & 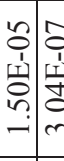 & 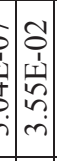 & 1 & 1 & 1 & 1 & \\
\hline 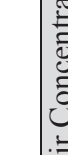 & 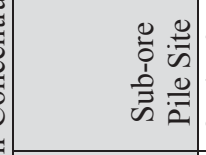 & 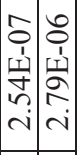 & 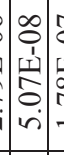 & 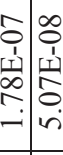 & 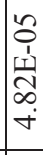 & & 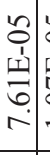 & 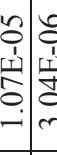 & 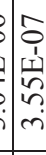 & $\begin{array}{l}\infty \\
0 \\
0 \\
1 \\
\vdots \\
0 \\
n \\
n\end{array}$ & 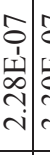 & 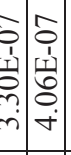 & 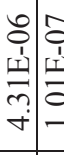 & 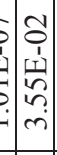 & 1 & 1 & 1 & 1 & \\
\hline$\frac{0}{\overline{0}}$ & 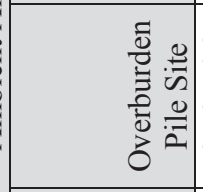 & 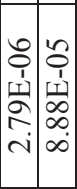 & & 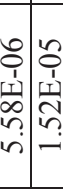 & $\begin{array}{c}0 \\
i \\
1 \\
\\
\infty \\
- \\
-\end{array}$ & 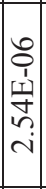 & 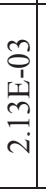 & $\mid \begin{array}{l}7 \\
\frac{7}{7} \\
\frac{1}{7} \\
\frac{1}{7}\end{array}$ & 章 & & 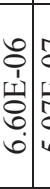 & 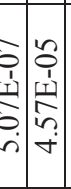 & 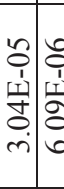 & 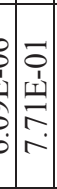 & 1 & 1 & 1 & 1 & \\
\hline 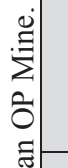 & $\begin{array}{l}. \\
.0 \\
.0 \\
.0\end{array}$ & 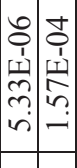 & 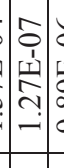 & 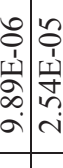 & 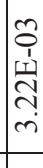 & \begin{tabular}{|c|}
0 \\
0 \\
0 \\
1 \\
1 \\
0 \\
0 \\
$\dot{+}$ \\
\end{tabular} & 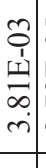 & 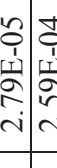 & $\left\{\begin{array}{l}0 \\
\vdots \\
1 \\
\frac{1}{2} \\
2\end{array}\right.$ & & 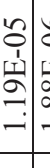 & 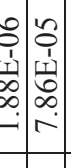 & 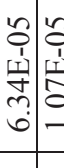 & \begin{tabular}{ll|l}
0 \\
$\vdots$ \\
$\vdots$
\end{tabular} & 1 & 1 & 1 & 1 & \\
\hline 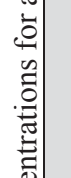 & 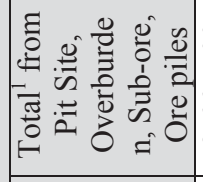 & 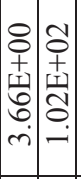 & 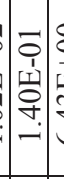 & 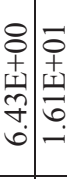 & $\begin{array}{l}m \\
0 \\
+ \\
1 \\
\infty \\
0 \\
i \\
i\end{array}$ & $\begin{array}{l}8 \\
0 \\
+ \\
+1 \\
0 \\
0 \\
i \\
\end{array}$ & 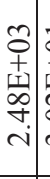 & 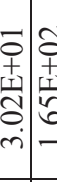 & \begin{tabular}{l}
8 \\
$\vdots$ \\
1 \\
2 \\
2 \\
\hdashline \\
\hdashline
\end{tabular} & \begin{tabular}{|c|}
- \\
0 \\
1 \\
$\vdots$ \\
0 \\
0 \\
-1 \\
-1
\end{tabular} & 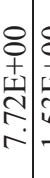 & 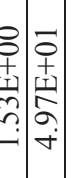 & 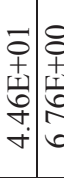 & 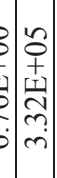 & $\begin{array}{c}m \\
0 \\
+ \\
+1 \\
0 \\
\dot{0} \\
\dot{m}\end{array}$ & \begin{tabular}{l}
0 \\
+ \\
+ \\
1 \\
\multirow{1}{0}{} \\
$\vdots$ \\
$r$
\end{tabular} & $\begin{array}{l} \pm \\
0 \\
+ \\
\pm \\
0 \\
n \\
n\end{array}$ & $\begin{array}{c} \pm \\
0 \\
+ \\
\text { I } \\
0 \\
a\end{array}$ & 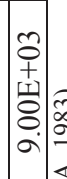 \\
\hline 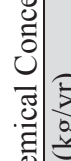 & 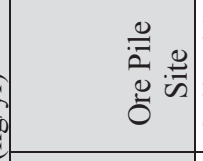 & 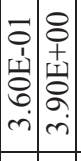 & 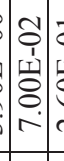 & 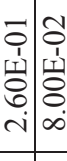 & 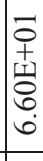 & 1 & 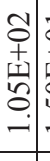 & 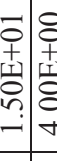 & 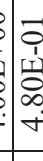 & $\begin{array}{c}2 \\
0 \\
1 \\
1 \\
\vdots \\
0 \\
\infty \\
\infty\end{array}$ & 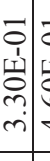 & \begin{tabular}{l|l}
0 & \\
0 & 0 \\
1 \\
1 & 1 \\
0 & 1 \\
0 & 0 \\
+ & $n$ \\
\end{tabular} & 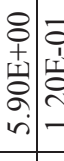 & 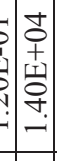 & 1 & 1 & 1 & 1 & \\
\hline 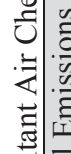 & 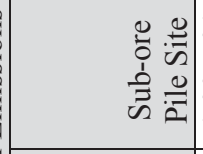 & 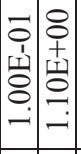 & 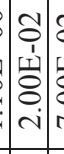 & 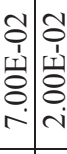 & 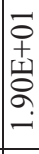 & & $\begin{array}{c}- \\
0 \\
+ \\
1 \\
\vdots \\
0 \\
\dot{1} \\
\end{array}$ & 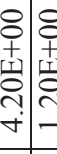 & 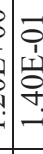 & 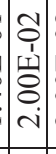 & 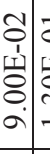 & 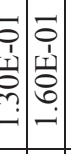 & 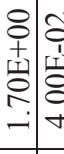 & 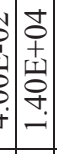 & 1 & 1 & 1 & 1 & \\
\hline 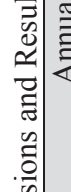 & $\begin{array}{l}\overline{0} \\
\overline{0} \\
\vdots \\
\overline{0} \\
\overline{0} \\
0 \\
0 \\
0\end{array}$ & 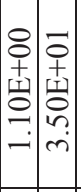 & 1 & 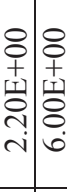 & 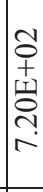 & $\begin{array}{l}8 \\
0 \\
+ \\
+1 \\
\vdots \\
0 \\
-1\end{array}$ & $\begin{array}{c}\mathcal{1} \\
0 \\
+ \\
1 \\
0 \\
\vdots \\
0 \\
\infty \\
0\end{array}$ & 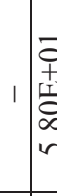 & 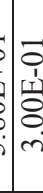 & & 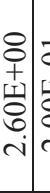 & 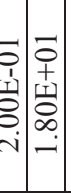 & 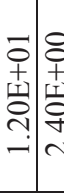 & 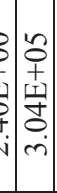 & 1 & 10 & 1 & 1 & \\
\hline $\begin{array}{l}5 \\
0 \\
8 \\
0 \\
\frac{\pi}{0}\end{array}$ & 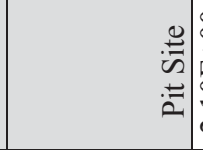 & 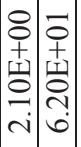 & 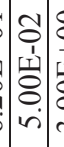 & 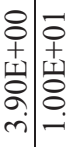 & & $\mid \begin{array}{c}8 \\
0 \\
+ \\
1 \\
0 \\
0 \\
-1\end{array}$ & 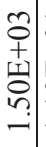 & 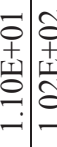 & $\begin{array}{l}0 \\
0 \\
1 \\
0 \\
0 \\
0 \\
0 \\
\infty\end{array}$ & $\begin{array}{c}c \\
0 \\
1 \\
1 \\
\vdots \\
0 \\
0 \\
0\end{array}$ & \begin{tabular}{l|l}
8 & \\
+ & \\
+ & \\
0 & 5 \\
8 & \\
$\dot{+}$ &
\end{tabular} & 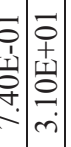 & 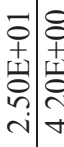 & & 1 & 1 & 1 & 1 & \\
\hline $\begin{array}{l}4 \\
\infty \\
\infty \\
\tilde{b} \\
\frac{0}{0} \\
\frac{0}{\pi}\end{array}$ & 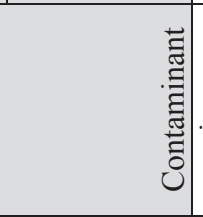 & 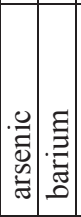 & 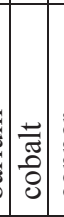 & 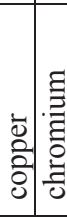 & & & 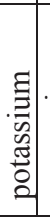 & 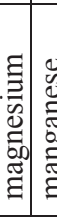 & 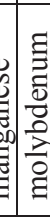 & & & 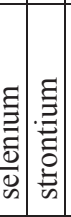 & 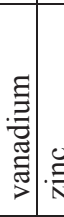 & va & 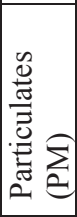 & 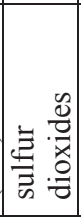 & 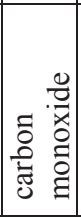 & 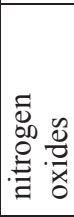 & 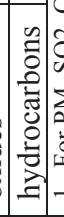 \\
\hline
\end{tabular}


Environmental Impacts, Health and Safety Impacts, and Financial Costs of the Front-End of the

Nuclear Fuel Cycle

Table 6-39. Occupational Chemical Impact from Airborne Effluents from an Open Pit Mine.

\begin{tabular}{|c|c|c|c|}
\hline Contaminant & $\begin{array}{c}\text { Average Ambient Contaminant } \\
\text { Concentration at Mine Site } \\
(\mathrm{mg} / \mathrm{m} 3)\end{array}$ & $\begin{array}{c}\text { Screening Level }^{1} \\
(\mathrm{mg} / \mathrm{m} 3)\end{array}$ & $\begin{array}{c}\text { Average Hazard } \\
\text { Quotient }\end{array}$ \\
\hline arsenic & $9.28 \mathrm{E}-06$ & $5.00 \mathrm{E}-01$ & $1.86 \mathrm{E}-05$ \\
\hline barium & $2.59 \mathrm{E}-04$ & $5.00 \mathrm{E}-01$ & $5.18 \mathrm{E}-04$ \\
\hline cobalt & $3.55 \mathrm{E}-07$ & $1.00 \mathrm{E}-01$ & $3.55 \mathrm{E}-06$ \\
\hline copper & $1.63 \mathrm{E}-05$ & $1.00 \mathrm{E}-01$ & $1.63 \mathrm{E}-04$ \\
\hline chromium & $4.08 \mathrm{E}-05$ & $5.00 \mathrm{E}-01$ & $8.17 \mathrm{E}-05$ \\
\hline iron & $5.26 \mathrm{E}-03$ & $1.00 \mathrm{E}+01$ & $5.26 \mathrm{E}-04$ \\
\hline mercury & $6.60 \mathrm{E}-06$ & $2.00 \mathrm{E}+00$ & $3.30 \mathrm{E}-06$ \\
\hline potassium & $6.28 \mathrm{E}-03$ & $5.00 \mathrm{E}+00$ & $1.26 \mathrm{E}-03$ \\
\hline magnesium & $7.66 \mathrm{E}-05$ & $1.50 \mathrm{E}+01$ & $5.11 \mathrm{E}-06$ \\
\hline manganese & 4.19E-04 & $5.00 \mathrm{E}+00$ & $8.38 \mathrm{E}-05$ \\
\hline molybdenum & $4.52 \mathrm{E}-06$ & $5.00 \mathrm{E}+00$ & $9.03 \mathrm{E}-07$ \\
\hline nickel & $4.06 \mathrm{E}-07$ & $1.00 \mathrm{E}+00$ & $4.06 \mathrm{E}-07$ \\
\hline lead & $1.96 \mathrm{E}-05$ & $1.50 \mathrm{E}-01$ & $1.31 \mathrm{E}-04$ \\
\hline selenium & $3.88 \mathrm{E}-06$ & $2.00 \mathrm{E}-01$ & $1.94 \mathrm{E}-05$ \\
\hline strontium & $1.26 \mathrm{E}-04$ & $1.00 \mathrm{E}-04$ & $1.26 \mathrm{E}-01$ \\
\hline vanadium & $1.13 \mathrm{E}-04$ & $1.00 \mathrm{E}-01$ & $1.13 \mathrm{E}-03$ \\
\hline zinc & $1.71 \mathrm{E}-05$ & $1.00 \mathrm{E}+00$ & $1.71 \mathrm{E}-05$ \\
\hline dust total & $8.42 \mathrm{E}-01$ & $1.50 \mathrm{E}+01$ & $5.61 \mathrm{E}-02$ \\
\hline Particulates (PM) & $7.61 \mathrm{E}-03$ & $1.50 \mathrm{E}+00$ & $5.07 \mathrm{E}-03$ \\
\hline sulfur dioxides & $1.78 \mathrm{E}-02$ & $1.30 \mathrm{E}+01$ & $1.37 \mathrm{E}-03$ \\
\hline carbon monoxide & $1.40 \mathrm{E}-01$ & $5.50 \mathrm{E}+01$ & $2.54 \mathrm{E}-03$ \\
\hline nitrogen oxides & $2.31 \mathrm{E}-01$ & $9.00 \mathrm{E}+00$ & $2.56 \mathrm{E}-02$ \\
\hline hydrocarbons & $2.28 \mathrm{E}-02$ & $1.80 \mathrm{E}+03$ & $1.27 \mathrm{E}-05$ \\
\hline \multicolumn{3}{|c|}{ Summation of Individual Hazard Quotients (Hazard Index) } & $1.35 \mathrm{E}+00$ \\
\hline \multicolumn{3}{|c|}{ Total Relative Chemical Impact (Hazard Index /MTNU) ${ }^{2}$} & $1.11 \mathrm{E}-02$ \\
\hline
\end{tabular}

Table 6-40. Occupational Accident and Injuries Impacts for Open Pit Mining ${ }^{1}$.

\begin{tabular}{|c|c|c|c|c|}
\hline $\begin{array}{l}\text { Average Incidence of Lost } \\
\text { Days per 200,000 Person- } \\
\text { hours }\end{array}$ & $\begin{array}{l}\text { Average Person- } \\
\text { hours at } \\
\text { Ranger/yr }\end{array}$ & $\begin{array}{c}\text { \# of Incidents per } \\
\text { Year }\end{array}$ & $\begin{array}{l}\text { Average Severity } \\
\text { (days lost per } \\
\text { incident })^{2}\end{array}$ & $\begin{array}{c}\text { Days Lost } \\
\text { per year }\end{array}$ \\
\hline 0.66 & 908,000 & 3.0 & 10 & 30 \\
\hline \multicolumn{4}{|c|}{ Total Average Accident and Injury Impact (days lost/MTNU) ${ }^{3}$} & $6.8 \mathrm{E}-03$ \\
\hline \multicolumn{5}{|c|}{$\begin{array}{l}\text { 1. Data based on 6-year average (2005-2010) from the Ranger open pit mine in Australia (ERA 2005, 06. 07, 08,09, } 10 \\
\text { http://www.energyres.com.au/library/44.asp } \\
\text { 2. Days lost per incident are estimated. The median days away from work from the top three causes of occupational illnesses and injuries is } 10 \\
\text { days per incident. http://www.bls.gov/iif/oshwc/osh/os/osh06 33.pdf }\end{array}$} \\
\hline
\end{tabular}


Environmental Impacts, Health and Safety Impacts, and Financial Costs of the Front-End of the Nuclear Fuel Cycle

Table 6-41. Public Radiological Impact Data from an Underground Uranium Mine.

\begin{tabular}{|c|c|c|c|c|c|}
\hline Site & $\begin{array}{c}\text { Annual } \\
\text { Production } \\
\text { (MTNU/year) }\end{array}$ & $\begin{array}{c}\text { Critical } \\
\text { Population } \\
\text { (Persons) }\end{array}$ & $\begin{array}{c}\text { Average } \\
\text { TEDE } \\
(\mathrm{mSv} / \mathrm{yr})\end{array}$ & $\begin{array}{c}\text { Annual } \\
\text { TEDE } \\
(\mathrm{mSv} / \mathrm{yr})\end{array}$ & $\begin{array}{c}\text { Average Annual } \\
\text { Collective TEDE } \\
\text { (Person-mSv/yr) }\end{array}$ \\
\hline Average Open Pit Mine & 122 & 28,400 & $4.4 \mathrm{E}-02$ & $8.5 \mathrm{E}-4$ & 24 \\
\hline \multicolumn{2}{|r|}{ Total Impact to Critical Receptor (mSv/MTNU) } & $\mathbf{3 . 6 E - 0 3}$ \\
\hline \multicolumn{2}{|r|}{ Total Collective Impact (Person-mSv/MTNU) } & $\mathbf{2 . 0 E - 0 1}$ \\
\hline
\end{tabular}

use during the data gathering time for the development of the EPA (1983) report. Further, this mine is much smaller than most current open pit mines, thus not obtaining efficiencies of scale. Hence, the impacts found in Table 6-41 should be considered as upper limits for future OP mining operations.

Calculations were performed using source terms derived from extensive measurements (EPA 1983, Appendix K). Impacts to the public were based on release rates of Uranium, Thorium and Radon-222, as well as Working Level exposure from the daughters of radon-222 (EPA 1983, Tables 6.1 and 6.3). Extensive calculations were performed on a risk basis for the individual organs using the same pathways described in Section 4.2.

The critical receptor is taken at the fenceline $1600 \mathrm{~m}$ from the center of the mining property. The regional population (roughly $80 \mathrm{~km}$ ) for the representative Wyoming OP mine was estimated, using county statistics, to be 16,230 people (EPA $1983 \mathrm{Ch} 5$ ). However, inference from tabular results suggests that the actual number used was closer to 14,200 . The 2010 census indicates that the population density in New Mexico is currently twice that assumed in the EPA (1983) study: thus the population estimate used in calculation of Impact is 28,400 persons.

\section{Public Chemical Impacts - OP Mining:}

The EPA recommends summing health quotients from each chemical from each exposure pathway to calculate a cumulative Hazard Impact for a particular site. However, as noted below, sufficient data was not found to support development of a credible estimate of public the exposure due to liquid effluents.

\section{Liquid Effluents and Water Quality - OP Mining:}

Average concentrations of seven different contaminants in liquid effluents were calculated from one selected open pit mine in the state of Wyoming in the US with samples taken in the year 1979 (EPA 1983). The resultant concentration once the liquid effluent mixes completely with local surface waters is the quotient of the liquid effluent concentration and the dilution factor. The dilution factor applied within the [EPA 1983] document was 1.0, meaning that no surface water other than the liquid effluents from the model open pit mine was present. The hazard quotients and resulting hazard index (HI) are calculated in Table 6-42.

The elevated HI suggests that a person drinking untreated mine effluent would be subject to possible ill health for an individual directly ingesting mine effluents. Given the high sulfate and arsenic levels, it would be the responsibility of the mine owner and the regulatory authority to investigate and take appropriate action to ensure that no hazard to humans is presented. It should be noted that it is extremely unlikely that a person would drink directly from an untreated mine outfall. Drinking water limits were not presented in (EPA 1983) in this case because public water supplies are normally derived from groundwater rather than surface water, so drinking surface water would not be a pathway of concern for a typical individual in the assessment area, and the above calculated liquid hazard index is considered to be zero for subsequent use in hazard indices. Additional information is needed to allow a reliable prediction of groundwater concentrations, in order to estimate the impact of nonradioactive waterborne emission on 
Table 6-42. Public Chemical Impact from Liquid Effluents from a Representative Open Pit Mine ${ }^{1}$

\begin{tabular}{|l|c|c|c|c|}
\hline \multicolumn{1}{|c|}{ Contaminant } & $\begin{array}{c}\text { Concentration } \\
\text { in mine effluent } \\
(\mathrm{mg} / \mathrm{L})\end{array}$ & $\begin{array}{c}\text { Resultant Concentration in Surface } \\
\text { Water after Dilution Factor }{ }^{1} \text { is } \\
\text { Applied } \\
(\mathrm{mg} / \mathrm{L})\end{array}$ & $\begin{array}{c}\text { Screening } \\
\text { Level }^{3} \\
(\mathrm{mg} / \mathrm{L})\end{array}$ & $\begin{array}{c}\text { Average } \\
\text { Hazard } \\
\text { Quotient }\end{array}$ \\
\hline total uranium & $7.00 \mathrm{E}-02$ & $7.00 \mathrm{E}-02$ & $3.00 \mathrm{E}-02$ & $2.33 \mathrm{E}+00$ \\
\hline cadmium & $4.00 \mathrm{E}-03$ & $4.00 \mathrm{E}-03$ & $5.00 \mathrm{E}-03$ & $8.00 \mathrm{E}-01$ \\
\hline arsenic & $5.00 \mathrm{E}-03$ & $5.00 \mathrm{E}-03$ & $4.46 \mathrm{E}-05$ & $1.12 \mathrm{E}+02$ \\
\hline zinc & $7.10 \mathrm{E}-02$ & $7.10 \mathrm{E}-02$ & $4.67 \mathrm{E}+00$ & $1.52 \mathrm{E}-02$ \\
\hline sulfate & $8.75 \mathrm{E}+02$ & $8.75 \mathrm{E}+02$ & $2.50 \mathrm{E}+02$ & $3.50 \mathrm{E}+00$ \\
\hline total suspended solids & $2.09 \mathrm{E}+01$ & $2.09 \mathrm{E}+01$ & $5.00 \mathrm{E}+02$ & $4.18 \mathrm{E}-02$ \\
\hline Summation of Individual Hazard Quotients (Hazard Index) & $1.19 \mathrm{E}+02$ \\
\hline Total Relative Liquid Chemical Impact (Hazard Index /MTNU) ${ }^{2}$ & $9.74 \mathrm{E}-01$ \\
\hline $\begin{array}{l}\text { 1. Screening levels for public chemicals in liquid effluents are from Table 6-5. } \\
\text { 2. Annual Production was 122 MTNU/year for the representative Wyoming mine and the dilution factor used was 1 (see Table } \\
\text { 6-36). }\end{array}$ \\
\hline
\end{tabular}

the maximum exposed individual. Consequently, the above estimate associated with this exposure pathway is not considered credible. Minimally, data are needed on water use patterns in the vicinity of the mines and the degree to which the mine discharges may infiltrate groundwater supplies.

\section{Gaseous Effluents and Air Quality - OP Mining:}

The annual air emissions at the mine site for the representative Wyoming open pit mine (Table 6-36) were listed in (EPA 1983).

Contaminants at an OP mine site have the potential to become airborne and expose members of the public. The critical receptor is a person assumed to reside at the site boundary, the fence line at 1600 meters). The average atmospheric dispersion at the site boundary was calculated for gases and particulates with an average $\chi / \mathrm{Q}$ of $2.0 \mathrm{E}-06 \mathrm{sec} / \mathrm{m} 3$ (EPA 1983, Table K.1). Air concentrations at the site boundary (the product of the emissions from the different materials piles and the atmospheric dispersion factor) are given below in Table 6-43. The associated health impacts to the critical receptor are estimated in Table 6-44.

The public chemical impact is the sum of the impacts from liquid, which is taken to be zero based on the above discussion, and airborne chemical effluents.

\section{Ecological Radiological Impacts- OP Mining:}

The radioactive contaminant of radium-226 in the liquid effluent from the representative Wyoming open pit mine (EPA 1983) is reported as a volumetric specific activity $(\mathrm{pCi} / \mathrm{L})$. The dose to the critical receptor resulting from water ingestion is calculated as $3.4 \mathrm{E}-02 \mathrm{mSv}$ using correlations from radionuclide concentrations to exposure found in 10 CFR 20 - Appendix B - Table 2 [NRC 2012]. These correlations are intended for calculating TEDE for members of the public, that is humans, and not for other species. However, it is generally agreed that protection of the human from radiation exposure protects most other animals [DOE 2002]. The correlations are considered conservative as they assume contaminated effluents are inhaled or ingested continuously over the course of a year. The TEDE unit of mSv to the 


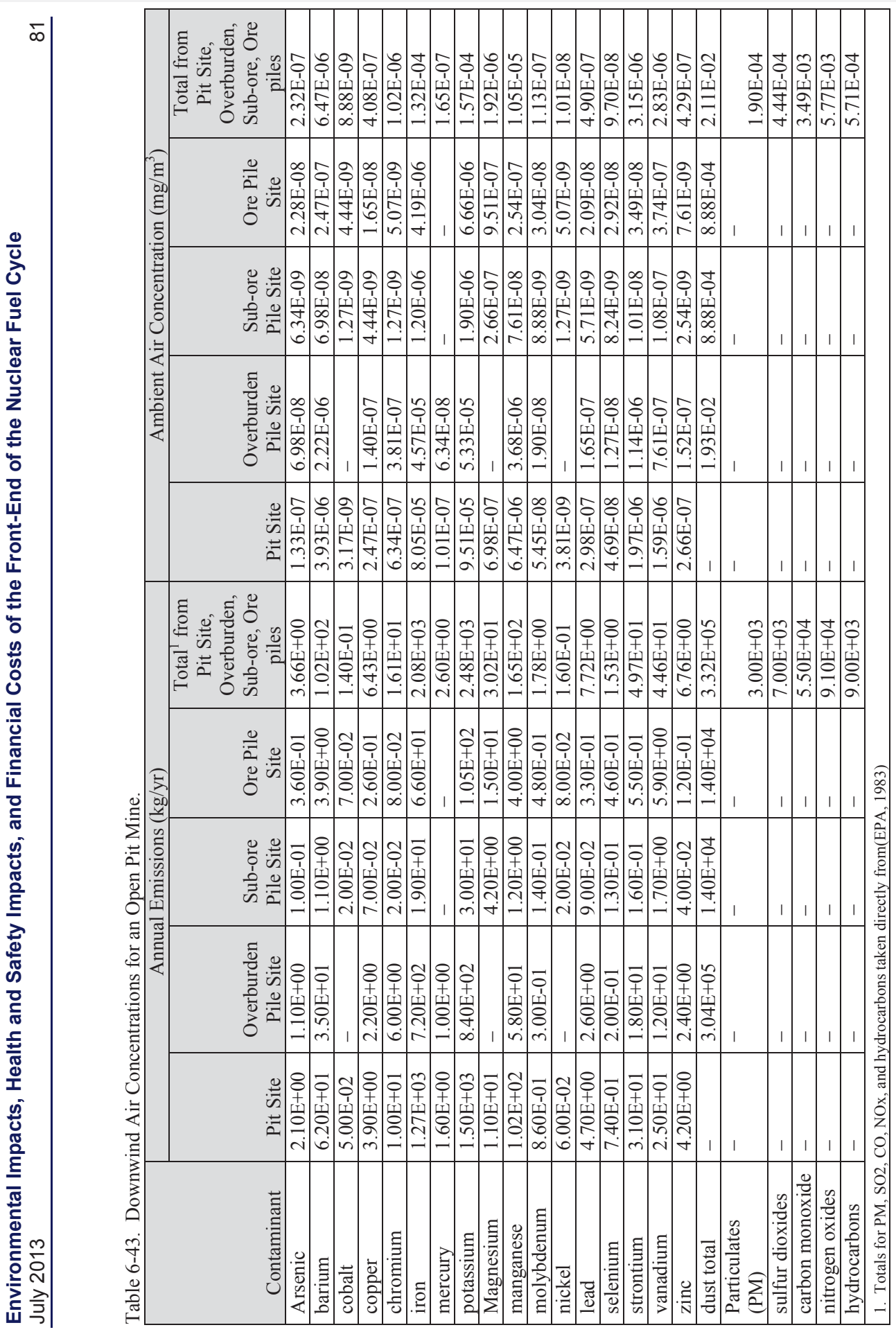


Environmental Impacts, Health and Safety Impacts, and Financial Costs of the Front-End of the

Nuclear Fuel Cycle

Table 6-44. Public Chemical Impact from Airborne Effluents from an Open Pit Mine ${ }^{1}$

\begin{tabular}{|l|c|c|c|}
\hline \multicolumn{1}{|c|}{ Contaminant } & $\begin{array}{c}\text { Average Ambient Contaminant } \\
\text { Concentration at Mine Site } \\
(\mathrm{mg} / \mathrm{m} 3)\end{array}$ & $\begin{array}{c}\text { Screening Level } \\
(\mathrm{mg} / \mathrm{m} 3)\end{array}$ & $\begin{array}{c}\text { Average Hazard } \\
\text { Quotient }\end{array}$ \\
\hline arsenic & $2.32 \mathrm{E}-07$ & $5.66 \mathrm{E}-07$ & $4.10 \mathrm{E}-01$ \\
\hline barium & $6.47 \mathrm{E}-06$ & $5.21 \mathrm{E}-04$ & $1.24 \mathrm{E}-02$ \\
\hline cobalt & $8.88 \mathrm{E}-09$ & $2.70 \mathrm{E}-07$ & $3.29 \mathrm{E}-02$ \\
\hline copper & $4.08 \mathrm{E}-07$ & $3.00 \mathrm{E}-03$ & $1.36 \mathrm{E}-04$ \\
\hline chromium & $1.02 \mathrm{E}-06$ & $5.00 \mathrm{E}-01$ & $2.04 \mathrm{E}-06$ \\
\hline iron & $1.32 \mathrm{E}-04$ & $1.00 \mathrm{E}+00$ & $1.32 \mathrm{E}-04$ \\
\hline manganese & $1.65 \mathrm{E}-07$ & $3.00 \mathrm{E}-04$ & $5.50 \mathrm{E}-04$ \\
\hline potassium & $1.57 \mathrm{E}-04$ & $5.00 \mathrm{E}+00$ & $3.14 \mathrm{E}-05$ \\
\hline magnesium & $1.92 \mathrm{E}-06$ & $1.00 \mathrm{E}+01$ & $1.92 \mathrm{E}-07$ \\
\hline manganese & $1.05 \mathrm{E}-05$ & $5.00 \mathrm{E}-05$ & $2.10 \mathrm{E}-01$ \\
\hline molybdenum & $1.13 \mathrm{E}-07$ & $5.00 \mathrm{E}+00$ & $2.26 \mathrm{E}-08$ \\
\hline nickel & $1.01 \mathrm{E}-08$ & $9.36 \mathrm{E}-06$ & $1.08 \mathrm{E}-03$ \\
\hline mercury & $4.90 \mathrm{E}-07$ & $1.50 \mathrm{E}-04$ & $3.26 \mathrm{E}-03$ \\
\hline selenium & $9.70 \mathrm{E}-08$ & $2.09 \mathrm{E}-02$ & $4.64 \mathrm{E}-06$ \\
\hline strontium & $3.15 \mathrm{E}-06$ & $1.00 \mathrm{E}-04$ & $3.15 \mathrm{E}-02$ \\
\hline vanadium & $2.83 \mathrm{E}-06$ & $5.00 \mathrm{E}-01$ & $5.66 \mathrm{E}-06$ \\
\hline zinc & $4.29 \mathrm{E}-07$ & $1.00 \mathrm{E}-04$ & $4.29 \mathrm{E}-03$ \\
\hline dust total & $2.11 \mathrm{E}-02$ & $5.00 \mathrm{E}+00$ & $4.21 \mathrm{E}-03$ \\
\hline Particulates (PM) & $1.90 \mathrm{E}-04$ & $1.20 \mathrm{E}-02$ & $1.59 \mathrm{E}-02$ \\
\hline sulfur dioxides & $4.44 \mathrm{E}-04$ & $1.43 \mathrm{E}+00$ & $3.10 \mathrm{E}-04$ \\
\hline carbon monoxide & $3.49 \mathrm{E}-03$ & $4.01 \mathrm{E}+01$ & $8.70 \mathrm{E}-05$ \\
\hline nitrogen oxides & $5.77 \mathrm{E}-03$ & $9.96 \mathrm{E}+01$ & $5.79 \mathrm{E}-05$ \\
\hline hydrocarbons & $5.71 \mathrm{E}-04$ & $2.00 \mathrm{E}-01$ & $2.85 \mathrm{E}-03$ \\
\hline \multicolumn{1}{|c|}{ Summation } & $\mathbf{5 . 9 8 E - 0 3}$ \\
\hline Total Relative Airborne Chemical Impact (Hazard Index /MTNU) & 1 \\
\hline The annual production of the representative Wyoming mine was 122 MTNU/yr (Table 6-36). & \\
\hline & & & \\
\hline
\end{tabular}

human critical receptor is converted to the unit of mGy to the local ecology (non-human biota critical receptor). Radium-226 is a pure alpha emitter. The conversion from human-weighted effective dose ( $\mathrm{mSv}$ ) to absorbed energy (mGy) is: $20 \mathrm{mSv}=1 \mathrm{mGy}$ of alpha exposure. Using the above, the dose to the local ecology is estimated in Table 6-45.

\section{Ecological Chemical Impacts- OP Mining:}

\section{Liquid Effluents and Water Quality-OP Mining:}

Data from the representative Wyoming open pit mine (EPA 1983) were used to estimate the chemical impacts to freshwater biota from liquid effluents shown in Table 6-46.

Clearly, the elevated HQs suggest that, for this mine, aquatic species living in the discharge waters may be at risk for ill health. However, an ecological impact for organisms in undiluted mine effluents is not a credible basis for calculating ecological impact. Given the high levels of sulfate, arsenic and cadmium; it would be the responsibility of the mine owner and the regulatory authority to 
Environmental Impacts, Health and Safety Impacts, and Financial Costs of the Front-End of the Nuclear Fuel Cycle

Table 6-45. Ecological Radiological Impacts from Liquid Effluents of an Open Pit Mine.

\begin{tabular}{|c|c|c|c|}
\hline Contaminant & $\begin{array}{l}\text { Annual Production } \\
\text { (MTNU/year) }^{1}\end{array}$ & $\begin{array}{c}\text { Annual Average } \\
\text { Contaminant Concentration }^{1} \\
(\mathrm{pCi} / \mathrm{L})\end{array}$ & $\begin{array}{c}\text { Average Absorbed Dose to } \\
\text { Critical Receptor } \\
(\mathrm{mGy})^{1}\end{array}$ \\
\hline radium-226 & 122 & $4.10 \mathrm{E}+00$ & $1.7 \mathrm{E}-03$ \\
\hline \multicolumn{3}{|c|}{ Total Impact to Critical Receptor (mGy/MTNU) ${ }^{2}$} & 1.4E-05 \\
\hline
\end{tabular}

Table 6-46. Ecological Chemical Impacts from Liquid Effluents of an Open Pit Mine ${ }^{1}$.

\begin{tabular}{|c|c|c|c|c|}
\hline Contaminant & $\begin{array}{l}\text { Concentration in } \\
\text { mine effluent } \\
(\mathrm{mg} / \mathrm{L})\end{array}$ & $\begin{array}{l}\text { Concentration in Surface Water } \\
\text { after Dilution Factor is Applied } \\
(\mathrm{mg} / \mathrm{L})\end{array}$ & $\begin{array}{l}\text { Screening } \\
\text { Level }^{2} \\
(\mathrm{mg} / \mathrm{L})\end{array}$ & $\begin{array}{l}\text { Average } \\
\text { Hazard } \\
\text { Quotient }\end{array}$ \\
\hline total uranium & $7.00 \mathrm{E}-02$ & $7.00 \mathrm{E}-02$ & $4.06 \mathrm{E}+00$ & $1.72 \mathrm{E}-02$ \\
\hline cadmium & $4.00 \mathrm{E}-03$ & $4.00 \mathrm{E}-03$ & $2.50 \mathrm{E}-04$ & $1.60 \mathrm{E}+01$ \\
\hline arsenic & $5.00 \mathrm{E}-03$ & $5.00 \mathrm{E}-03$ & $2.10 \mathrm{E}-03$ & $2.38 \mathrm{E}+00$ \\
\hline zinc & $7.10 \mathrm{E}-02$ & $7.10 \mathrm{E}-02$ & $1.20 \mathrm{E}-01$ & $5.92 \mathrm{E}-01$ \\
\hline sulfate & $8.75 \mathrm{E}+02$ & $8.75 \mathrm{E}+02$ & $2.50 \mathrm{E}+02$ & $3.50 \mathrm{E}+00$ \\
\hline total suspended solids & $2.09 \mathrm{E}+01$ & $2.09 \mathrm{E}+01$ & $5.00 \mathrm{E}+02$ & $4.18 \mathrm{E}-02$ \\
\hline \multicolumn{4}{|c|}{ Summation of Individual Hazard Quotients (Hazard Index) } & $2.25 \mathrm{E}+01$ \\
\hline \multicolumn{4}{|c|}{ Total Relative Liquid Chemical Impact to Critical Receptor (Hazard Index /MTNU) } & $1.85 \mathrm{E}-01$ \\
\hline
\end{tabular}

investigate and take appropriate action to ensure that the operation presented no unacceptable hazard. Consequently, this result not considered to be a reasonable representative of the average ecological impacts of open pit uranium mining. Additional data are needed to estimate the ecological impacts of open pit uranium mining.

\section{Gaseous Effluents and Air Quality-OP Mining:}

Data are currently not available for calculating gaseous effluents relating to the potential impact to the local ecosystem. However, it is standard practice in Environmental Impact Statements (EISs) to consider the protection of local ecology as protected if the local human population is protected. Some exceptions are noted in Section 4.2.

Because the cumulative hazard index for downwind human populations for this mine below one (see Table 6-44), it can be qualitatively estimated that local ecosystems are not impacted for this pathway.

\subsubsection{Financial Cost Impacts - Open Pit Mining}

Financial costs for underground, open pit, and ISL mining are addressed in section 6.1.

\subsubsection{In-Situ Leaching}

Unlike open pit and underground mines, the occupational radiological exposure for ISL sites in the U.S. is under the purview of the NRC (NRC 2009, 2012a). The updated generic Environmental Impact Statement (GEIS) for US ISL sites includes three supplemental EISs from specific sites in Wyoming, Nichols Ranch, Lost Creek, and Moore Ranch (NRC 2009, 2010, 2011, 2011a). The three supplemental 
statements provide site-specific information on many topics of relevance to the environmental review process but are incomplete relative to the type of information needed within the present document. Other supportive documents include Technical Reports supporting EIS analyses, independent reviews, web sites etc.

A commercial ISL facility consists of both an underground and a surface infrastructure. The underground infrastructure includes injection and production wells drilled to the uranium mineralization zone,

monitoring wells drilled to the surrounding ore body aquifer and to the adjacent overlying and underlying aquifers, and perhaps deep injection wells to dispose of liquid wastes. Offsite radon may originate from well heads. ISL facilities in the NRC GEIS differ principally from conventional mills in that a well field is developed from which dissolved uranium is collected on resin beds. The well field maybe at a remote "satellite" location requiring transportation to the "mill", or it may be directly connected with the "mill" portion of the facility. After removing the uranium from the resin beds, the processes in ISL are similar to those in conventional mills. For ISL mines, impacts to humans and the ecology often include the milling stage because the analyses provided by the operators include the production of $\mathrm{U}_{3} \mathrm{O}_{8}$.

Estimates of environmental, safety and health, and financial cost impacts from ISL mining uranium are summarized in the Table 6-47. The remainder of Section 6.1.3 provides the basis for each of the estimates shown.

Table 6-47. Summary of Impacts from ISL Uranium Mining.

\begin{tabular}{|c|c|}
\hline \multicolumn{2}{|c|}{ In-Situ Mining Impacts (per MTNU) } \\
\hline 4.1 Environmental Impacts ${ }^{1}$ & 6.1 .1 .1 \\
\hline 4.1 .1 Land Use & $5.4 \mathrm{E}-04$ \\
\hline Permanent $\left(\mathrm{km}^{2}\right)$ & $2.7 \mathrm{E}-05$ \\
\hline Non-Permanent $(\mathrm{km})$ & $5.1 \mathrm{E}-04$ \\
\hline 4.1 .2 Water Use(ML) net & $1.1 \mathrm{E}+00$ \\
\hline 4.13 Energy Use and CO2 Emissions & $5.9 \mathrm{E}+02$ \\
\hline Energy Use (GJ) & $4.9 \mathrm{E}+04$ \\
\hline CO2 Emissions (kg) & 6.1 .1 .2 \\
\hline 4.2 Health and Safety Impacts: & $3.9 \mathrm{E}-01$ \\
\hline 4.2 .1 Occupational Radiological (person-mSv) & negligible \\
\hline 4.2 .2 Occupational Chemical (Hazard Index) & $4.7 \mathrm{E}-02$ \\
\hline 4.2 .3 Occupational Accident \& Illness (lost days) & \\
\hline 4.2 .4 Public Radiological & $5.7 \mathrm{E}-05$ \\
\hline Dose to Critical Receptor (mSv) & $2.3 \mathrm{E}-03$ \\
\hline Collective Dose (person -mSv) & 0 \\
\hline 4.2 .5 Public Chemical (Hazard Index) & $2.9 \mathrm{E}-06$ \\
\hline 4.2 .6 Ecological Radiological (mGy) & negligible \\
\hline 4.2 .7 Ecological Chemical (Hazard Index) & 6.1 .1 .3 \\
\hline 4.3 Financial Costs: & $1.1 \mathrm{E}+05$ \\
\hline Cost (\$) & \\
\hline 1. For land, water, and energy use, these values include the impacts from both mining and milling operations. \\
\hline
\end{tabular}


Environmental Impacts, Health and Safety Impacts, and Financial Costs of the Front-End of the Nuclear Fuel Cycle

\subsubsection{Environmental Impacts - ISL Mining}

Environmental impacts ISL mining differ significantly from conventional open pit and underground mining. Land, water, and energy related environmental impacts of ISL mining are discussed below.

\section{Land Use - ISL Mining}

ISL operations have minimal land use, as the operation has little land disturbance. There is only a uranium pregnant solution, and no ore, or overburden to be removed as is the case in conventional mining. Upon decommissioning, wells are sealed or capped, pipes and process facilities removed, any evaporation pond revegetated, and much of the land can be returned to its previous uses (World Nuclear Organization, http://www.world-nuclear.org/info/inf25.html).

The total land use for four ISL mining operations is shown above in Table 6-48. While the operating surface facilities may be removed when the operations cease, the portion of land occupied by tailings from the ISL processing would be considered permanent use. Tailings from ISL result from the precipitation of unwanted elements during the milling process. Since there is no ore, these tailings represent a very small volume of waste relative to other $U$ mining operations. For the purpose of this study, it is conservatively assumed that $5 \%$ permanent use and $95 \%$ non-permanent use.

Table 6-48. Land Use for ISL mine/mill operations data (ERA 2008, South Australia 1998).

\begin{tabular}{|l|l|c|c|c|c|}
\hline \multicolumn{1}{|c|}{ Facility } & \multicolumn{1}{|c|}{ Source } & $\begin{array}{c}\text { Size of } \\
\text { Deposit } \\
\text { (MTNU) }\end{array}$ & $\begin{array}{c}\% \text { of } \\
\text { total } \\
\text { deposit }\end{array}$ & $\begin{array}{c}\text { Land Use } \\
\text { Per } \\
\left(\mathrm{m}^{2} / \mathrm{MTNU}\right)\end{array}$ & $\begin{array}{c}\text { Weighted } \\
\text { land use }\end{array}$ \\
\hline Rosita & ERA 2008 & 1630 & 7.7 & 916 & 70.7 \\
\hline Kingsville & ERA 2008 & 1730 & 8.2 & 875 & 71.7 \\
\hline Holiday/El Mesquite & ERA 2008 & 1450 & 17.8 & 583 & 103.6 \\
\hline Beverly & South Australia 1998 & 14000 & 66.3 & 440 & 291.8 \\
\hline \multicolumn{5}{|c|}{ Weighted average land use $\left(\mathrm{m}^{2} / \mathrm{MTNU}\right)$} & 537.8 \\
\hline \multicolumn{5}{|r|}{} \\
\hline
\end{tabular}

\section{Water Use -- ISL Mining}

In-situ leach operations are a water-intensive process. Lixiviant (water containing added oxygen and a compound to mobilize uranium in the ore body, which is typically sodium bicarbonate for deposits containing large amounts of calcium and on sites requiring ground water restoration, or sulfuric acid otherwise) is injected into the ore body which is separated from the water table by an impermeable rock layer (EPA, TENORM report). Water is then recycled in the operation or evaporated. The main environmental consideration with ISL is avoiding pollution of any groundwater away from the ore body, and leaving the immediate groundwater no less useful than it was initially (World Nuclear Organization, http://www.world-nuclear.org/info/inf25.html). Many countries' regulations require that the water be restored to its original state. The costs of restoration of the water table are very site dependent.

Water use data could only be obtained for the Beverly Mine in Australia. Unfortunately, such a small sample size does little to capture the high degree of variability in mining operations. The Beverly ISL mine uses an acid-leach process that represents the majority of worldwide ISL production (although the U.S. almost exclusively uses an alkaline leach circuit). Table 6-49 provides gross water consumption and 
Environmental Impacts, Health and Safety Impacts, and Financial Costs of the Front-End of the

Table 6-49. Beverly ISL Mine/Mill Site Operational Water Use Data (Mudd 2007)

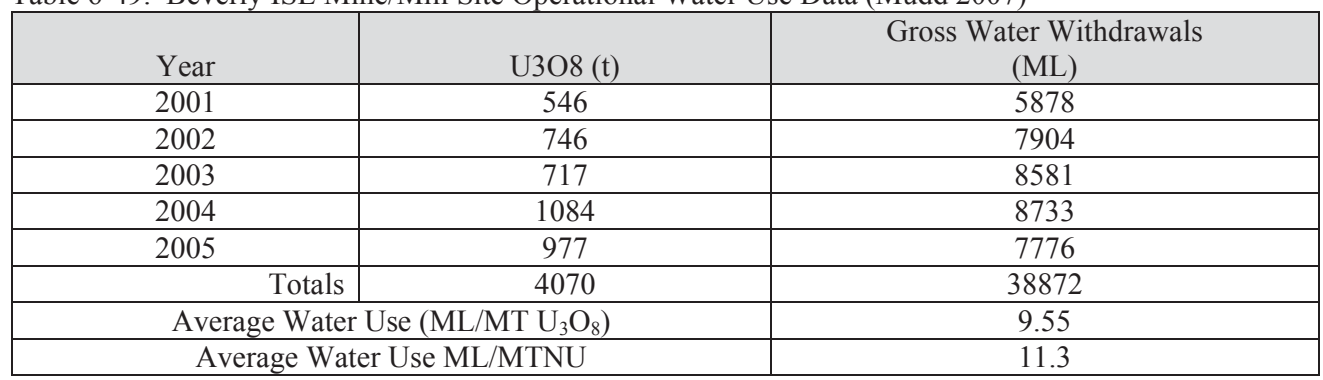

annual production from the Beverly mine for 2001-2005. It should be noted that this data represents gross water withdrawals, and it is expected that much of the water used in the operation is treated and returned to the aquifer.

However, the amount of water extracted from the aquifer is not an accurate representation of actual water use in ISL mining as the bulk of water is treated and purified before being returned to the aquifer. Although some of the water is retained in waste products, approximately $90 \%$ can be acceptably treated and returned to its source. Assuming that $10 \%$ of the gross withdrawal is not returned, the estimated ISL net water use becomes:

\section{ISL net Water Use Metric $=\mathbf{1 . 1 3}$ ML/MTNU}

Note that there will be additional water use resulting from decommissioning of the site. The EPA has estimated that to remediate the ground water located in the ore body, up to 10 pore volumes of water could potentially be circulated through the site (EPA 2011). A pore volume is a term used by the ISL industry to measure the volume of water affected by ISL recovery. Pore volumes represent the volume of water that fills up void spaces in a volume of rock/sediment. Pore volumes are usually calculated by multiplying the surface area of the mine site by the thickness of the ore body by the estimated porosity of the aquifer being exploited (NRC 2003a.)

\section{Energy Use - ISL Mining}

No data was obtained for construction energy for ISL mining and it is assumed to be negligible relative to the energy used during the ISL mining and milling operations. Materials used during ISL mining operations include steel used in the wells, sulfuric acid used for leaching, and ammonia used for milling.

Because sulfuric acid is not used at every mining operation, and the amount used to produce 1 MTNU is also site-dependent, a large sample of mines is needed to obtain an accurate assessment of ISL energy use. The Doka life cycle assessment of ISL mining (Doka 2011) estimates that an ISL mine uses 20 MT of sulfuric acid and $0.108 \mathrm{MT}$ of steel to produce $1 \mathrm{MTNU}$. The milling process for the product-stream from ISL mining is similar to that used for conventional open pit and underground mining. The embodied energy for milling of the ISL product was assumed the same as for open pit mining.

These values and the embodied energies from Appendix B are used in Table 6-50 along with the direct energy estimated in (Schneider 2010) to estimate energy use and $\mathrm{CO}_{2}$ emissions for ISL mining. 


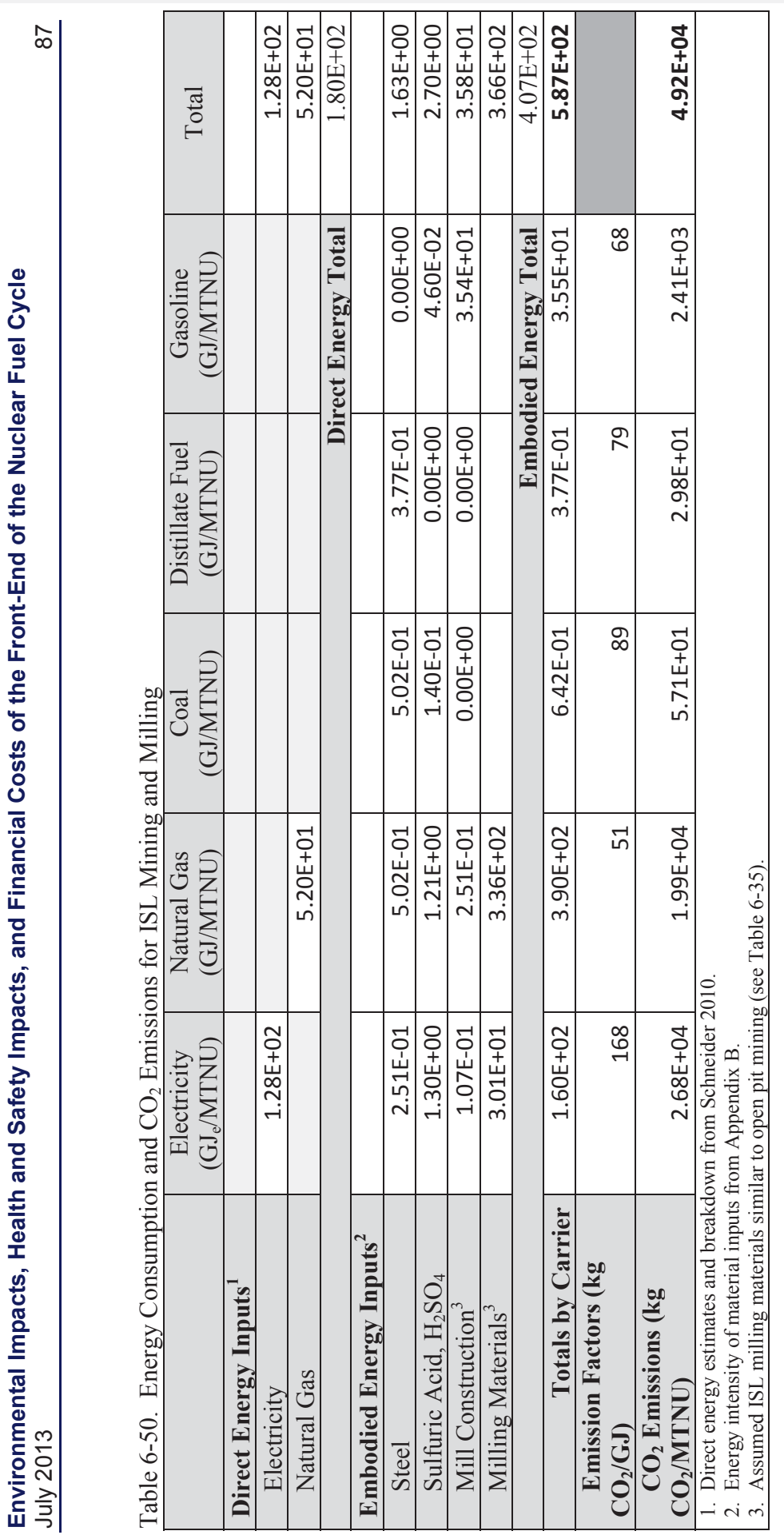


Environmental Impacts, Health and Safety Impacts, and Financial Costs of the Front-End of the Nuclear Fuel Cycle

July 2013

Table 6-52. Occupational Accident and Illness Impacts for ISL Mining

\begin{tabular}{|l|c|c|c|c|c|}
\hline \multicolumn{1}{|c|}{ Site } & Annual MTNU & Workers & \# lost day injuries & \# lost days & Days Lost/MTNU \\
\hline Crow Butte & 300 & 29.5 & 0.95 & 9.5 & 0.032 \\
\hline Nichols Ranch & 769 & 55 & 1.77 & 17.7 & 0.023 \\
\hline \multicolumn{7}{|r|}{ Total Average Accident \& Illness Impact (days lost/MTNU) } & $\mathbf{0 . 0 2 8}$ \\
\hline
\end{tabular}

Dose to the maximally exposed individual (critical receptor) can vary from site-to-site due to factors such as the proximity of the nearest resident, weather patterns, and emission stack height. Design features and processing quantities also play a role. The NRC dose limit for a member of the public (10 CFR Part 20.1301 ) is $1 \mathrm{mSv} /$ year. Critical receptor and collective dose data for four facilities is presented in Table 6-53.

Table 6-53. Public Radiological Dose Data from ISL Facilities

\begin{tabular}{|c|c|c|c|c|c|}
\hline Site & $\begin{array}{l}\text { Dose to } \\
\text { Critical } \\
\text { Receptor } \\
(\mathrm{mSv} / \mathrm{yr})\end{array}$ & $\begin{array}{l}\text { Collective Dose } \\
\text { (Person-mSv/yr) }\end{array}$ & $\begin{array}{l}\text { Production } \\
\text { (MTNU/yr) }\end{array}$ & $\begin{array}{c}\text { Impact to Critical } \\
\text { Receptor } \\
\text { (mSv/MTNU) }\end{array}$ & $\begin{array}{c}\text { Collective Impact } \\
\text { (Person- } \\
\text { mSv/MTNU) }\end{array}$ \\
\hline Lost Creek $^{1}$ & 0.03 & 0.19 & 770 & $3.9 \mathrm{E}-05$ & $2.47 \mathrm{E}-04$ \\
\hline Moore Ranch $^{2}$ & 0.008 & 0.9 & 1134 & $7.05 \mathrm{E}-06$ & 7.94E-04 \\
\hline Nichols Ranch $^{3}$ & 0.11 & 2.0 & 769 & $1.43 \mathrm{E}-04$ & $2.60 \mathrm{E}-03$ \\
\hline Smith Ranch $^{4}$ & 0.022 & 3.0 & 539 & $4.08 \mathrm{E}-05$ & $5.57 \mathrm{E}-03$ \\
\hline \multicolumn{4}{|c|}{ Average Impact to Critical Receptor(mSv/MTNU) } & \multicolumn{2}{|l|}{$5.75 E-05$} \\
\hline \multicolumn{5}{|c|}{ Average Collective Impact (Person-mSv/MTNU) } & $2.30 \mathrm{E}-03$ \\
\hline \multicolumn{6}{|c|}{$\begin{array}{l}\text { 1. Dose data from Lost Creek ISR Technical Report Vol 4, March 2008. NRC document ML081060510.<http://www.wol } \\
\text { nuclear-news.org/ENF-Wyoming uranium project clears final hurdle-1010127.html> } \\
\text { 2. USNRC NUREG-1910 Supplement 1. EIS for the Moore Ranch ISR Project in Campbell County, Wyoming, NRC } \\
\text { document ML102290470. } \\
\text { 3. NUREG-1910 Supplement 2, Nichols Ranch ISR Project, 2011. NRC document ML10340120. } \\
\text { 4. Data from Appendix L: Radiation doses from Cameco's Smith Ranch and Reynolds Ranch Expansion Area In-Situ } \\
\text { Uranium Leaching Operations. NRC document ML12163A148; Cameco Resources Smith Ranch Project Technical } \\
\text { Report- February 2012; Nuclear Regulatory Commission Source Material License No. SUA-1548 Renewal. } \\
\text { http://pbadupws.nrc.gov/docs/ML1216/ML12163A037.pdf. }\end{array}$} \\
\hline
\end{tabular}

\section{Public Chemical Impacts - Mine In Situ Leach}

While hazardous chemicals are used at the ISL facilities, the amount and variation of such chemical usage is small compared to large chemical facilities. The GEIS and all three supplements for site specific application state clearly that no liquid wastes are planned and no application for liquid waste discharge permits are planned (NRC 2009, 2010, 2011, 2011a). Impacts related to chemical discharges from new ISL facilities are expected to be negligible.

\section{Ecological Radiological Impacts - Mine In Situ Leach}

Ecological Impacts are anticipated to be identical to public radiation doses above, with a conversion from Sv to Gy, as discussed in the OP and UG mine sections. Essentially all of the dose results from alpha decaying radionuclides, principally radon and radon daughters, resulting in an estimated dose of $2.9 \mathrm{E}-06$ 
Environmental Impacts, Health and Safety Impacts, and Financial Costs of the Front-End of the

$\mathrm{mGy} / \mathrm{MTNU}[(5.75 \mathrm{E}-05 \mathrm{mSv} / \mathrm{MTNU})(\mathrm{mGy} / 20 \mathrm{mSv})]$ to the critical ecological receptor (non-human biota).

\section{Ecological Chemical Impacts - Mills Processing Ore}

As with the public, chemical impacts to ecological organisms are expected to be negligible.

\subsubsection{Financial Costs - ISL Mining}

Financial costs for underground, open pit, and ISL mining are addressed in section 6.1.

\subsection{Uranium Milling Impacts}

Estimates of environmental, safety and health, and financial cost impacts from uranium milling are summarized in the Table 6-54 below. Sections 6.2.1 thru 6.2.3 provide the basis for the estimates shown.

Table 6-54. Summary of Impacts from milling uranium

\begin{tabular}{|c|c|}
\hline & Milling Impacts \\
\hline Normalization Unit & MTNU \\
\hline 4.1 Environmental Impacts & \multirow{6}{*}{ See section 6.2 .1} \\
\hline 4.1.1 Land Use & \\
\hline Permanent $\left(\mathrm{km}^{2} / \mathrm{MTNU}\right)$ & \\
\hline Non-Permanent $\left(\mathrm{km}^{2}\right.$-yrs/MTNU) & \\
\hline 4.1.2 Water Use Net (ML) & \\
\hline 4.13 Energy Use and $\mathrm{CO}_{2}$ Emissions (GJ/MTNU and $\mathrm{Kg}$ ) & \\
\hline 4.2 Health and Safety Impacts: & See Section 6.2 .2 \\
\hline 4.2.1 Occupational Radiological (person -mSv/MTNU) & 9E-01 \\
\hline 4.2.2 Occupational Chemical (Hazard Index) & negligible \\
\hline 4.2.3 Occupational Accident \& Illness (lost days) & $4.2 \mathrm{E}-02$ \\
\hline 4.2.4 Public Radiological & \\
\hline Dose to Critical receptor (mSv) & $1.3 \mathrm{E}-04$ \\
\hline Collective Dose (person -mSv) & $8.2 \mathrm{E}-02$ \\
\hline 4.2.4 Public Chemical (Hazard Index /MTU) & negligible \\
\hline 4.2.6 Ecological Radiological (mGy to Critical Receptor) & negligible \\
\hline 4.2.7 Ecological Chemical (Hazard Index) & negligible \\
\hline 4.3 Financial Costs: $(\$)$ & See Section 6.2 .3 \\
\hline Cost $(\$)$ & Included in Mining Cost \\
\hline
\end{tabular}

\subsubsection{Environmental Impacts - Uranium Milling}

Because industry data for land, water, and energy usage estimates for milling is not well segregated from the accompanying mining operations, these impact estimates are included with those given in Section 6.1.1.

\subsubsection{Health and Safety Impacts - Uranium Milling}

\section{Occupational Radiological Impacts - Mills Processing Ore}

Radiological impacts to workers from operation of uranium mills processing ore are estimated following the methodology defined in Section 4.2.1. Estimates are based on information from the operation of the 
Environmental Impacts, Health and Safety Impacts, and Financial Costs of the Front-End of the Nuclear Fuel Cycle

Cotter Corp and White Mesa mills. Production data and radiological impacts are provided in Tables 6-55 and 6-56.

Table 6-55. Annual MTNU Processed by Cotter Corp and Mesa Mills

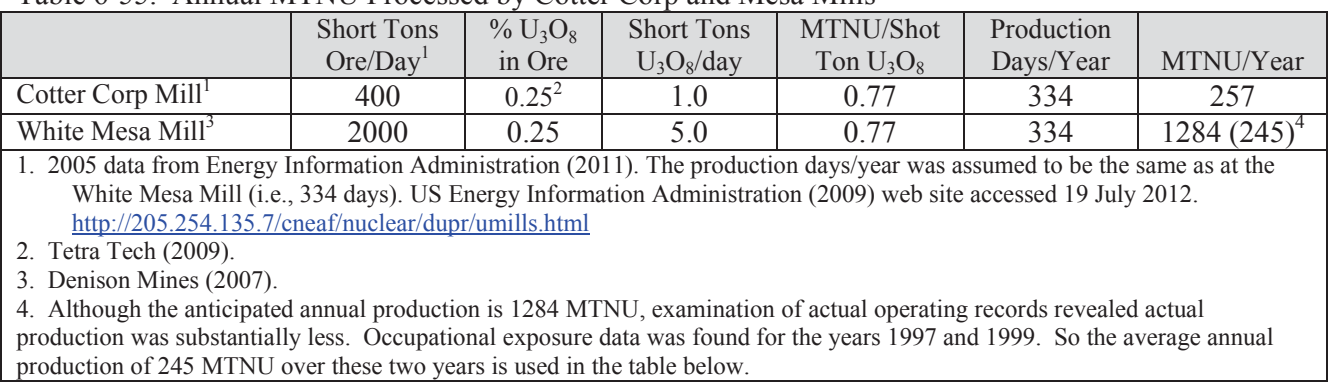

Table 6-56. Occupational Radiological Impact data from mills processing uranium ore.

\begin{tabular}{|c|c|c|c|c|c|}
\hline Site & Workers & $\begin{array}{c}\text { Avg Effective } \\
\text { Dose } \\
(\mathrm{mSv} / \mathrm{yr})\end{array}$ & $\begin{array}{l}\text { Collective Dose } \\
\text { (Person-mSv/yr) }\end{array}$ & $\begin{array}{l}\text { Avg Effective } \\
\text { Impact } \\
(\mathrm{mSv} / \mathrm{MTNU})\end{array}$ & $\begin{array}{c}\text { Collective Impact } \\
\text { (Person-mSv/MTNU) }\end{array}$ \\
\hline Cotter Corp $^{1}$ & 167 & 1.68 & 281 & $6.5 \mathrm{E}-03$ & $1.09 \mathrm{E} 00$ \\
\hline White Mesa $^{2}$ & 80 & 2.2 & 245 & 9E-03 & $7.18 \mathrm{E}-01$ \\
\hline \multicolumn{4}{|c|}{ Average Effective Impact (person-mSv/MTNU) } & 7.7E-03 & \\
\hline \multicolumn{5}{|c|}{ Average Collective Impact (person-mSv/MTNU) } & 9.0E-01 \\
\hline
\end{tabular}

\section{Occupational Chemical Impacts - Mills Processing Ore}

The representative mill for assessing occupational chemical impacts is the Piñon Ridge mill (SENES 2009. Based on its modern state-of-the-art design (monitoring; containment and control of hazardous materials, dust and fume emissions; HVAC systems; process control; etc.) combined with the implementation of the health and safety plan, extensive training program, availability of personal protection equipment, and compliance with Federal (e.g., MSHA, EPA) and Colorado (CDPHE, CDOPS) regulations; chemical-related impacts to workers from the routine operation of the mill) are anticipated to be negligible.

\section{Occupational Lost Days Impacts - Mills Processing Ore}

Because no explicit data for current operating mills was found, data from similar industries that involve chemical processing and material movement. The BLS lists the rate of occupational illnesses and injuries associated with days lost as 0.7 and 1.6, respectively, per 100 full time workers in chemical manufacturing and mining (except oil and gas), for an average of $1.15 / 100$ workers. ${ }^{24}$ The median days away from work from the top three causes of occupational illnesses and injuries is 10 days per incident. ${ }^{25}$ With these inputs, estimates for days lost are presented in Table 6-57.

24. http://www.bls.gov/iag/tgs/iag325.htm\#fatalities_injuries_and_illnesses

25. http://www.bls.gov/iif/oshwc/osh/os/osh06_33.pdf 
Environmental Impacts, Health and Safety Impacts, and Financial Costs of the Front-End of the

Nuclear Fuel Cycle

Table 6-57. Occupational Accident and Illness Impacts for Milling Facilities.

\begin{tabular}{|l|c|c|c|c|c|}
\hline \multicolumn{1}{|c|}{ Site } & workers & $\begin{array}{c}\text { Annual Lost time } \\
\text { incidents per 100 } \\
\text { workers }\end{array}$ & $\begin{array}{c}\text { Lost days per } \\
\text { year }\end{array}$ & $\begin{array}{c}\text { Annual Production } \\
\text { (MTNU/yr) }\end{array}$ & $\begin{array}{c}\text { Lost Days } \\
\text { (days/MTNU) }\end{array}$ \\
\hline Cotter Corp & $105^{1}$ & 1.15 & 12.1 & 257 & $4.70 \mathrm{E}-02$ \\
\hline White Mesa & 80 & 1.15 & 9.2 & 245 & $3.76 \mathrm{E}-02$ \\
\hline \multicolumn{5}{|l}{ Average Accident \& Injury Impact (days lost/MTNU) } & $\mathbf{4 . 2 3 - 0 2}$ \\
\hline
\end{tabular}

\section{Public Radiological Impacts - Mills Processing Ore}

Table 6-58 provides radiological doses to the public within $80 \mathrm{~km}$ of the Piñon Ridge and White Mesa Mills.

Table 6-58. Radiological Dose and Impacts to Populations Surrounding Uranium Mills

\begin{tabular}{|l|c|c|c|c|c|}
\hline \multicolumn{1}{|c|}{ Site } & $\begin{array}{c}\text { Annual } \\
\text { Production } \\
\text { (MTNU/Yr) }\end{array}$ & $\begin{array}{c}\text { Dose to Critical } \\
\text { (Actual Nearest) } \\
\text { Receptor } \\
\text { (mSv/yr) }\end{array}$ & $\begin{array}{c}\text { Impact to } \\
\text { Critical } \\
\text { Receptor } \\
\text { (mSv/MTNU) }\end{array}$ & $\begin{array}{c}\text { Collective } \\
\text { Dose } \\
\text { (Person- } \\
\text { mSv/yr) }\end{array}$ & $\begin{array}{c}\text { Collective } \\
\text { Impact } \\
\text { (Person- } \\
\text { mSv/MTNU) }\end{array}$ \\
\hline Piñon Ridge $^{1}$ & 294 & 0.0046 & $1.56 \mathrm{E}-05$ & 7.39 & $2.51 \mathrm{E}-02$ \\
\hline White Mesa $^{2}$ & 245 & 0.058 & $2.37 \mathrm{E}-04$ & 34.0 & $1.39 \mathrm{E}-01$ \\
\hline \multicolumn{7}{|c|}{ Average Impact to Critical Receptor (mSv/MTNU) } & $\mathbf{1 . 2 6 E - 0 4}$ \\
\hline \multicolumn{7}{|c|}{ Average Collective Impact (Person-mSv/MTNU) } & $\mathbf{8 . 2 0 E - 0 2}$ \\
\hline $\begin{array}{l}\text { 1. Two Lines, Inc., (2009). } \\
\text { 2. Denison Mines Corp., (2007) }\end{array}$
\end{tabular}

\section{Public Chemical Impacts - Mills Processing Ore}

Chemical impact estimates from the proposed Pinion Ridge Mill illustrate that modern uranium milling facilities can be designed and operated to provide high confidence in a negligible chemical discharge. The mill process areas, ore pad, tailings cells, and evaporation ponds are designed as "zero discharge" facilities. Mill facilities with potential for release of dust or toxic fumes (e.g., dryers, precipitation tanks) are equipped with bag house and wet scrubbers to minimize emissions of dust or fumes to the atmosphere. As a result, the impact of the routine use and handling of these chemicals during routine mill operations on the members of the public and wildlife is expected to be negligible (Two Lines 2009).

\section{Ecological Radiological Impacts - Mills Processing Ore}

A screening exposure pathway assessment was conducted to estimate the radiation dose to a bird (mallard duck) landing on the tailing ponds (SENES 2009). The major exposure pathways considered were the ingestion of the water and direct gamma exposure. A chemical analysis for the tailing solution from a conventional uranium mill was used for the dose estimation. The calculations show that the total dose from Ra-226, Pb-210, Th230, and Th232 could be as high as 1,400 mGy/d, which significantly exceeds the benchmark of $5 \mathrm{mGy} / \mathrm{d}$ for birds. Therefore, several measures will be implemented to eliminate the access of wildlife to the tailings cells and evaporation ponds. These measures will include the following (SENES 2009). 
- A six-ft high chain-link fence topped by three strands of barbed wire will be installed around the entire perimeter of the tailings and evaporation ponds. The fence will be inspected daily and repaired, as necessary, to prevent access to the area by wildlife.

- Bird balls placed on top of the ponded portion of the tailings area to prevent birds from landing on the water. The hollow balls are made of plastic and float on top of the water concealing the water surface and creating a physical barrier.

- Woven bird netting will be installed over and along the sides of the evaporation pond.

- Mill personnel will inspect the tailings cells on a daily basis. As part of their inspection, they will identify and record any wildlife mortalities and, where possible, will implement measures to reduce or eliminate future occurrences.

The reason that impacts are expected to be low is not that there is an absence of hazard, rather the acknowledgement of a hazard followed by specific actions to address the hazard. With the described radiological hazard in the preceding section, approaches were developed to minimize the danger to wildlife. Those approaches will also inhibit chemical exposures to wildlife. In addition, the FEIS (NUREG-0558) contains a description of chemical hazards and how they might interact with the local ecology. To balance yearly water inputs with yearly net evaporation, the evaporation cell design will require a surface area of about 40 ha ( 98 acres) of tailings water. These liquids will be unsuitable for use by wildlife due to radionuclides and other contaminants. However, the fencing around the tailings impoundment will exclude large animals. And the acidic nature of the pond ( $\mathrm{pH}$ of about 1.8 to 2.0), and the high salinity will make it unsuitable for most aquatic organisms and subsequently an unattractive feeding place for waterfowl. However, a few waterfowl or other birds may rest on the impoundment for a short time during migration. Following termination of the mill operations, the tailings disposal area would remain fenced until released from its status as a restricted area and will not be used for any purpose other than tailings stabilization and reclamation. Consequently, the chemical impacts to the ecological organisms living near the proposed Piñon Ridge mine are anticipated to be small.

The above illustrates that ecological hazards associated with milling can be identified and managed to such that the anticipated ecological impacts will be negligible. Actual operating data is needed to confirm this presumption. Permanent land use and associated controls are part of the costs of safely managing and disposing of mill tailings.

\section{Ecological Chemical Impacts - Mills Processing Ore}

For the reasons noted in the public chemical impacts discussion, above, chemical impacts to ecological organisms are also expected be negligible.

\subsubsection{Financial Cost Impacts - Uranium Milling}

Because industry cost data for milling are not well segregated from the accompanying mining operations, these impact estimates are included with those given in section 6.1 .

\subsection{Uranium Conversion $\left(\mathrm{U}_{3} \mathrm{O}_{8}\right.$ to $\left.\mathrm{UF}_{6}\right)$ Impacts}

Estimates of environmental, safety and health, and financial cost impacts from conversion of $\mathrm{U}_{3} \mathrm{O}_{8}$ to $\mathrm{UF}_{6}$ are summarized in the Table 6-59 below. Sections 6.3.1 thru 6.3.3 provide the basis for the estimates shown. 
Environmental Impacts, Health and Safety Impacts, and Financial Costs of the Front-End of the

Nuclear Fuel Cycle

Table 6-59. Summary of Impacts from Conversion of $\mathrm{U}_{3} \mathrm{O}_{8}$ to $\mathrm{UF}_{6}$

\begin{tabular}{|c|c|}
\hline & Conversion Impacts \\
\hline Normalization Unit & MTNU \\
\hline 4.1 Environmental Impacts & See Section 6.3.1 \\
\hline 4.1.1 Land Use $\left(\mathrm{km}^{2}\right)$ & $3.3 \mathrm{E}-06$ \\
\hline Permanent $\left(\mathrm{km}^{2}\right)$ & $2.6 \mathrm{E}-08$ \\
\hline Non-Permanent $\left(\mathrm{km}^{2}\right)$ & $3.3 \mathrm{E}-06$ \\
\hline 4.1.2 Water Use - Net(ML) & $6.5 \mathrm{E}-02$ \\
\hline \multicolumn{2}{|l|}{4.13 Energy Use and $\mathrm{CO}_{2}$ Emissions } \\
\hline Energy Use (GJ) & $2.7 \mathrm{E}+02$ \\
\hline $\mathrm{CO} 2$ Emissions $\mathrm{kG} \mathrm{CO} 2$ & $2.2 \mathrm{E}+04$ \\
\hline 4.2 Health and Safety Impacts: & See Section 6.3 .2 \\
\hline 4.2.1 Occupational Radiological (person- $\mathrm{mSv}$ ) & $8.8 \mathrm{E}-02$ \\
\hline 4.2.2 Occupational Chemical (Hazard Index) & $1.0 \mathrm{E}-05$ \\
\hline 4.2.3 Occupational Accident \& Illness (lost days) & $9.1 \mathrm{E}-04$ \\
\hline \multicolumn{2}{|l|}{ 4.2.4 Public Radiological } \\
\hline Dose to Critical receptor (mSv) & $1.4 \mathrm{E}-06$ \\
\hline Collective Dose (person -mSv) & $2.8 \mathrm{E}-02$ \\
\hline 4.2.5 Public Chemical (Hazard Index) & $1.6 \mathrm{E}-05$ \\
\hline 4.2.6 Ecological Radiological (mGy to Critical Receptor) & 7.1E-08 \\
\hline 4.2.7 Ecological Chemical (Hazard Index) & $1.4 \mathrm{E}-04$ \\
\hline 4.3 Financial Costs & See Section 6.3.3 \\
\hline Cost $(\$)$ & $1.2 \mathrm{E}+04$ \\
\hline
\end{tabular}

\subsubsection{Environmental Impacts - Uranium Conversion $\left(\mathrm{U}_{3} \mathrm{O}_{8}\right.$ to $\left.\mathrm{UF}_{6}\right)$}

Land and water use estimates associated with the conversion process are taken directly from Table 5-10 $\underline{6}$ and converted to the units shown above. Estimates for energy consumption and $\mathrm{CO}_{2}$ emissions from the representative $\mathrm{U}_{3} \mathrm{O}_{8}$ to $\mathrm{UF}_{6}$ conversion process identified in Section 5.3 are developed below using the | approach described in Section 4.1.3. The direct and embodied energy inputs from Table 5-10 $\underline{6}$ (reproduced in Table 6-60) are converted to GJ per MTNU in the UF6 product and broken down into their constituent energy carriers using the conversion factors shown in Table 6-61. The result, shown in Table 6-62, provides the total energy intensity of the conversion process broken down by energy carriers. The $\mathrm{CO}_{2}$ emission factors for each energy carrier (Appendix B) are then applied to obtain the total $\mathrm{CO} 2$ emissions for the process.

\subsubsection{Health and Safety Impacts - Uranium Conversion $\left(\mathrm{U}_{3} \mathrm{O}_{8}\right.$ to $\left.\mathrm{UF}_{6}\right)$}

\section{Occupational Radiological Impacts - Conversion}

Radiological impacts to workers from conversion operations are assessed based on data obtained from quarterly and annual compliance reports from the Port Hope $\mathrm{UF}_{6}$ plant. Data from the Port Hope facility were from the first and second quarter of 2010 and the third quarter of 2011. Port Hope quarterly reports tabulate doses combining employees and subcontractors, but do not include the dominant lung dose. The table below uses dose data from annual reports that include employees, not subcontractors, but does include lung dose in the TEDE. Data represent averaged 2007-2011 employee radiation doses. Hence, an 
Environmental Impacts, Health and Safety Impacts, and Financial Costs of the Front-End of the Nuclear Fuel Cycle

July 2013

Table 6-60. Energy Inputs to the Conversion Process

\begin{tabular}{|l|c|}
\hline & Process Inputs per Table 5-10 \\
\hline Direct Energy Inputs & $1.10 \mathrm{E}+01$ \\
\hline Electricity (MWh/MTNU) & $3.67 \mathrm{E}+06$ \\
\hline Natural Gas (L/MTNU) & $0.00 \mathrm{E}+00$ \\
\hline Coal (MT/MTNU) & $0.00 \mathrm{E}+00$ \\
\hline Distillate Fuel (Diesel) (MT/MTNU) & $0.00 \mathrm{E}+00$ \\
\hline Gasoline (MT/MTNU) & \\
\hline Embodied Energy Inputs & $9.00 \mathrm{E}-01$ \\
\hline Nitric Acid, HNO3 (MT/MTNU) & $4.80 \mathrm{E}-03$ \\
\hline Barium Carbonate, BaCO $(\mathrm{MT} / \mathrm{MTNU})$ & $2.35 \mathrm{E}-02$ \\
\hline Tributyl Phosphate, TBP (MT/MTNU) & $3.70 \mathrm{E}-02$ \\
\hline Hexane, C6H14 (MT/MTNU) & $1.52 \mathrm{E}-02$ \\
\hline Ammonium Sulfate, $(\mathrm{NH} 4)_{2} \mathrm{SO}_{4}$ (MT/MTNU) & $9.42 \mathrm{E}-03$ \\
\hline Sodium Hydroxide (NaOH) & $4.15 \mathrm{E}-01$ \\
\hline Ammonia, NH3 (MT/MTNU) & $5.80 \mathrm{E}-01$ \\
\hline Hydrogen Fluoride, $\mathrm{HF}(\mathrm{MT} / \mathrm{MTNU})$ & $1.17 \mathrm{E}-01$ \\
\hline Potassium Hydroxide, KOH (MT/MTNU) & \\
\hline
\end{tabular}




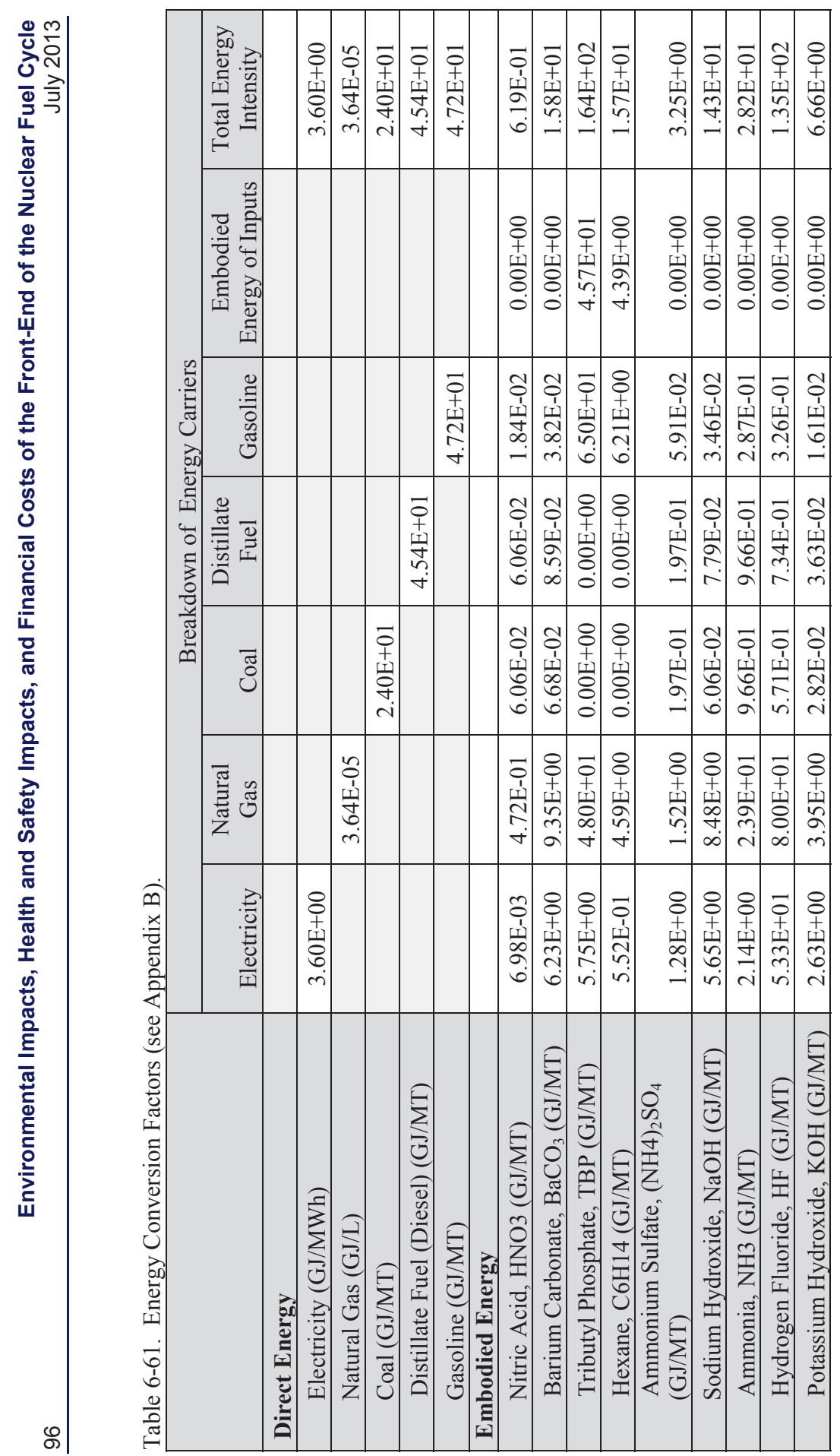




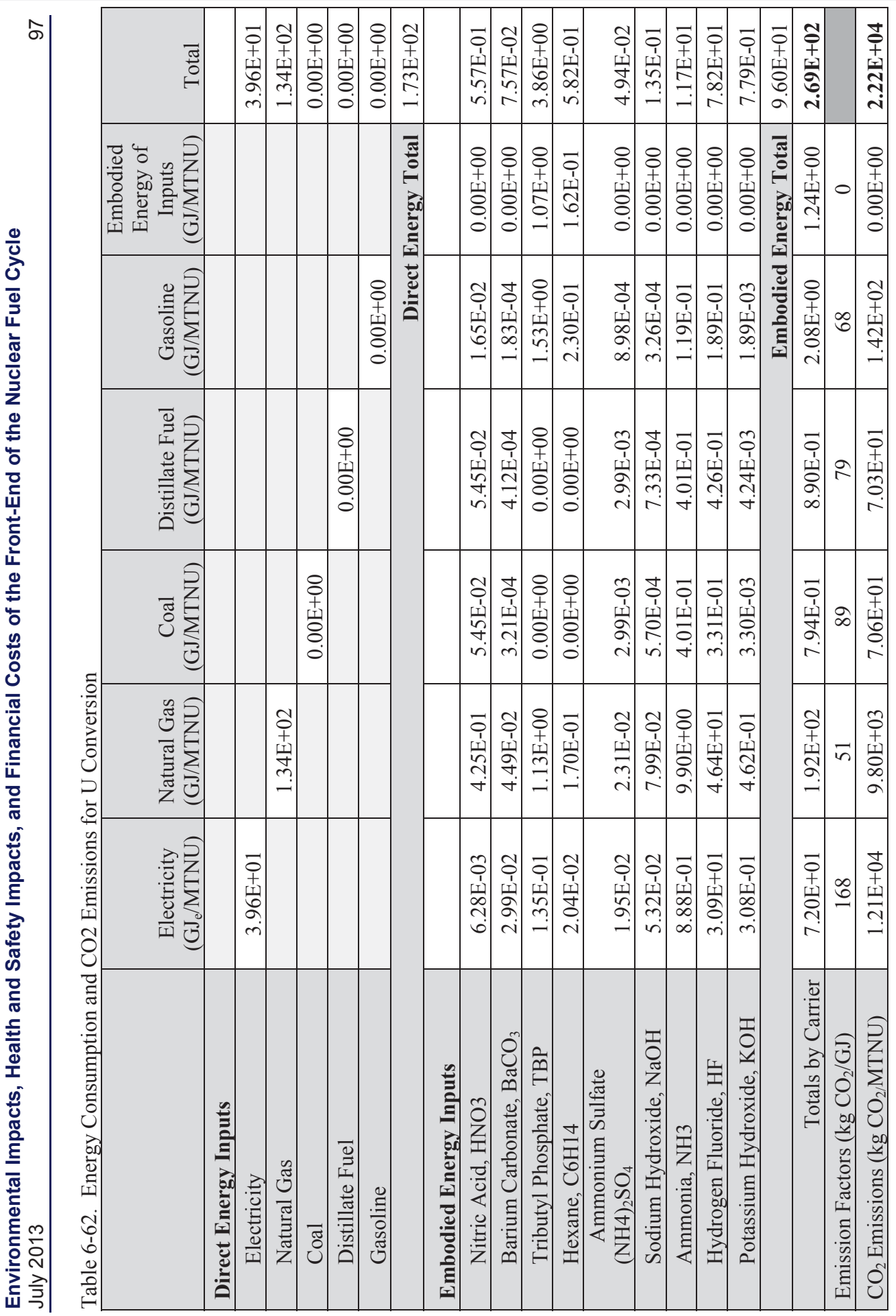


adjustment was made to the data shown in Table 6-63 to reflect the additional contractor workforce. The Port Hope facility is licensed to produce 12,500 metric tonnes of $\mathrm{UF}_{6}(8450 \mathrm{MTNU})$ per year, and 2,800 metric tons of $\mathrm{UO}_{3}(2330 \mathrm{MTNU})$. Assuming the facility operates at rated capacity, combined uranium throughput is 10,780 MTNU per year.

Data was also available from a report containing health and safety information for the COMURHEX Pierrelatte conversion facility on the Tricastin Site operated by Areva (AREVA 2010, 2011a). This data however was not used due to uncertainty as to whether it included internal dose $\mathrm{e}^{26}$. A summary of occupational radiation exposure data obtained from the reports is presented below.

Table 6-63. Occupational Radiological Impact data from wet process conversion facilities.

\begin{tabular}{|c|c|c|c|c|c|}
\hline Facility & $\begin{array}{l}\text { Workers }{ }^{2} \\
\text { (People/yr) }\end{array}$ & $\begin{array}{l}\text { Annual Throughput } \\
\text { (MTNU) }\end{array}$ & $\begin{array}{c}\text { Max Effective } \\
\text { Dose } \\
(\mathrm{mSv} / \mathrm{yr})\end{array}$ & $\begin{array}{c}\text { Avg Effective } \\
\text { Dose } \\
(\mathrm{mSv} / \mathrm{yr})\end{array}$ & $\begin{array}{l}\text { Collective Dose } \\
\text { (Person-mSv/yr) }\end{array}$ \\
\hline Port Hope $^{1}$ & 540 & 10,780 & 8.86 & 1.76 & 950 \\
\hline \multirow{2}{*}{\multicolumn{5}{|c|}{\begin{tabular}{c|c} 
Avg Effective Impact(mSv/MTNU) & $1.63 \mathrm{E}-04$ \\
Total Collective Impact(Person-mSv/MTNU)
\end{tabular}}} & \\
\hline & & & & & 8.8E-02 \\
\hline \\
\hline \multicolumn{6}{|c|}{$\begin{array}{l}\text { 2. The } 540 \text { workers account for a } 5 \text {-year average of } \sim 440 \text { employees and an estimated } 300 \text { contractors each receiving } \sim 1 / 3 \text { the } \\
\text { average employee dose. Contractor represents } \sim 40 \% \text { of the workforce and data from the separated components of the } \\
\text { work force at COMURHEX suggest that they generally receive about } 1 / 3 \text { of the average employee dose. }\end{array}$} \\
\hline
\end{tabular}

\section{Occupational Chemical Impacts - Conversion}

Relative chemical impacts to workers from conversion operations are assessed based on fluoride exposure levels to occupational personnel, the only personnel monitoring other than uranium. Fluoride levels were obtained from the first and second quarter of 2010 and the third quarter of 2011 for $\mathrm{UF}_{6}$ production at Port Hope (Cameco 2010a, b, 2011). The three quarters (while not consecutive) give evidence of a relatively constant average fluoride level. A summary of the data obtained from the reports and the associated impacts are presented in Table 6-64. The maximum is provided as an indication of the potential shortterm extremes.

\section{Occupational Accidents and Illnesses - Conversion}

Occupational accidents and illnesses from conversion operations are assessed using the methodology defined in Section 4.2.3 and shown in Table 6-65 below.

\section{Public Radiological Impacts - Conversion}

Radiological impacts to the public from conversion operations are based on reports from Comurhex and Port Hope that reported results from environmental pathway analyses. These are presented in Table 666.For reference, the 10 CFR Part 20.1301 dose limit for a member of the public is $1 \mathrm{mSv} /$ year.

26. COMURHEX data includes employees and subcontractors, however doses appear to only reflect personnel dosimeter measurements, as the average effective doses are of the same order as the external doses reported for Port Hope. No mention is made of internal dose measurements. See for example the discussion relating to occupational dose in Areva (2007) where the only mention of dose measurements is the detection limit of the external personnel dosimeters. As a note added in support, the COMURHEX II facility which makes $\mathrm{UF}_{4}$ underwent a detailed study on the benefit of using personal air sampling to estimate internal dose (European Commission 2004). The study demonstrated that personnel were receiving internal doses similar those reported at Port Hope). 
Environmental Impacts, Health and Safety Impacts, and Financial Costs of the Front-End of the Nuclear Fuel Cycle

Table 6-64. Occupational Chemical impacts from wet process uranium conversion facilities.

\begin{tabular}{|c|c|c|c|c|}
\hline Quarter & $\begin{array}{c}\text { Max Fluoride Levels } \\
\left(\mathrm{mg} / \mathrm{m}^{3}\right)\end{array}$ & $\begin{array}{l}\text { Average Fluoride Levels } \\
\left(\mathrm{mg} / \mathrm{m}^{3}\right)\end{array}$ & $\begin{array}{l}\text { Screening Level } \\
\left(\mathrm{mg} / \mathrm{m}^{3}\right)\end{array}$ & HQ \\
\hline Q1 2010 & 5.6 & 0.3 & 2.5 & 0.12 \\
\hline Q2 2010 & 4.1 & 0.23 & 2.5 & 0.092 \\
\hline Q3 2011 & 9.9 & 0.3 & 2.5 & 0.12 \\
\hline \multicolumn{4}{|c|}{ Total Relative Chemical Impact ${ }^{2}$ (Hazard Index/MTNU) } & $1.0 \mathrm{E}-05$ \\
\hline
\end{tabular}

Table 6-65. Occupational Accident and Injuries Impact data from wet process uranium conversion ${ }^{1}$

\begin{tabular}{|c|c|c|c|}
\hline $\begin{array}{c}\text { Average Incidence Rate } \\
\text { (Lost Work Days per } \\
200,000 \text { Person-hours) }\end{array}$ & $\begin{array}{c}\text { Average Person- } \\
\text { person-hours per yr }\end{array}$ & $\begin{array}{c}\text { Average Severity } \\
\text { (lost days/incident) }\end{array}$ & $\begin{array}{c}\text { Average Days Lost per } \\
\text { year }\end{array}$ \\
\hline 0.32 & 878,000 & 7.0 & 9.8 \\
\hline Total Average Accident \& Injury Impact (days lost/MTNU) & $\mathbf{9 . 1 E - 0 4}$ \\
\hline 1. Data from Port Hope (Cameco 2012) with annual uranium throughput of 10,780 MTNU. \\
\hline
\end{tabular}

Table 6-66. Public Radiological dose data from wet process conversion facilities.

\begin{tabular}{|c|c|c|c|c|c|}
\hline \multirow[b]{2}{*}{ Facility } & \multirow[b]{2}{*}{$\begin{array}{c}\text { Annual Throughput } \\
\text { (MTNU) }\end{array}$} & \multicolumn{2}{|c|}{ Dose to Critical Receptor } & \multicolumn{2}{|c|}{ Collective Dose $^{1}$} \\
\hline & & $(\mathrm{mSv} / \mathrm{yr})$ & (mSv/MTNU) & (Person-mSv) & $\begin{array}{c}\text { (Person- } \\
\text { mSv/MTNU) }\end{array}$ \\
\hline COMURHEX $^{2}$ & 7994 & 0.0008 & $1.0 \mathrm{E}-07$ & 15.7 & $1.96 \mathrm{E}-03$ \\
\hline Port Hope ${ }^{3}$ & 10780 & 0.03 & $2.78 \mathrm{E}-06$ & 588 & $5.45 \mathrm{E}-02$ \\
\hline \multicolumn{3}{|c|}{ Average Impact } & $1.4 \mathrm{E}-06$ & & \\
\hline \multicolumn{5}{|c|}{ Total Collective Impact (person-mSv/MTNU) } & $2.8 \mathrm{E}-02$ \\
\hline \multicolumn{6}{|c|}{$\begin{array}{l}\text { 1. Collective dose was estimated using a scaling factor based on the relationship between the collective dose and dose to } \\
\text { critical receptor from the deconversion facility (see section 6.5.2). This assumes similar source terms, population } \\
\text { distribution, weather patterns, stack height, and other factors affecting off-site dose. } \\
\text { 2. Data source: (Areva 2010). COMURHEX produced } 10271,12329 \text {, and } 12869 \mathrm{MT} \mathrm{UF}_{6} \text { in } 2008,2009 \text {, and } 2010 \\
\text { respectively - for an average annual throughput of } 7994 \text { MTNU. } \\
\text { 3. Port Hope data are averaged over 2007-2011 from Cameco (2012). }\end{array}$} \\
\hline
\end{tabular}

\section{Public Chemical Impacts - Conversion}

Chemical impacts to the public from conversion operations are assessed following the methodology defined in Section 4.2.5.Data from the Port Hope and COMURHEX facilities to arrive at the estimated impacts to the public in Table 6-69.

The air and water Hazard Quotients are shown in Tables 6-67 and 6-68 were summed for each site to provide overall Hazard Indices (HI). These HIs for each site were divided by their respective uranium production (MTNU) to yield impacts for each site. The impacts for the two sites were then averaged to yield the Total Relative Chemical Impact as seen in Table 6-69. 
Environmental Impacts, Health and Safety Impacts, and Financial Costs of the Front-End of the

Nuclear Fuel Cycle

Table 6-67. Air emission data from wet process conversion facilities.

\begin{tabular}{|c|c|c|c|c|}
\hline Facility & $\begin{array}{c}\text { Average Fluoride } \\
\text { Air Emissions } \\
(\mathrm{g} \mathrm{F} / \mathrm{h})\end{array}$ & $\begin{array}{l}\text { Air Public Health } \\
\text { Screening Level } \\
\quad\left(\mathrm{mg} \mathrm{F} / \mathrm{m}^{3}\right)^{1}\end{array}$ & $\begin{array}{l}\text { Fluoride Concentration at } \\
\text { Nearest Receptor } \\
\left(\mathrm{mg} / \mathrm{m}^{3}\right)\end{array}$ & HQ \\
\hline COMURHEX $^{2}$ & 87 & $1.36 \mathrm{E}-02$ & $1.60 \mathrm{E}-05$ & $1.2 \mathrm{E}-03$ \\
\hline Port Hope $^{3}$ & 21.4 & $1.36 \mathrm{E}-02$ & $2.97 \mathrm{E}-04^{3}$ & $2.2 \mathrm{E}-02$ \\
\hline \multicolumn{5}{|c|}{$\begin{array}{l}\text { 1. Preliminary Remediation Goal (PRG) from http://rais.ornl.gov } \\
\text { 2. Air emissions from } 2008 \text { - } 2011 \text { averaged data (AREVA 2010, and 2011a). Fluoride concentration at nearest receptor from } \\
\text { (AREVA 2011b, p339). } \\
\text { 3. Air emissions from Quarterly Compliance reports (Cameco } 2010 \mathrm{a}, \mathrm{b}, 2011 \text { ) and annual compliance report for } 2011 \text { (Cameco } \\
\text { 2012). Fluoride concentration at nearest receptor calculated using atmospheric dispersion }\left(5 \mathrm{E}-05 \mathrm{~s} / \mathrm{m}^{3}\right) \text { based on receptor } \\
500 \mathrm{~m} \text { east across the Ganaraska River with } 3.5 \mathrm{~m} / \mathrm{s} \text { average wind speed (Canadian Nuclear Safety Commission } 2012 \text { ) and } \\
\text { assumed average stability class "C" Fig } 3 \text { (USAEC 1962). }\end{array}$} \\
\hline
\end{tabular}

Table 6-68. Water effluent data from wet process conversion facilities.

\begin{tabular}{|c|c|c|c|}
\hline Facility & $\begin{array}{l}\text { Average Fluoride Water } \\
\text { Concentrations } \\
(\mathrm{mg} \mathrm{F} / \mathrm{L})\end{array}$ & $\begin{array}{c}\text { Water Public Health Screening } \\
\text { Level } \\
\left(\mathrm{mg} \mathrm{F} / \mathrm{L}^{3}\right.\end{array}$ & HQ \\
\hline COMURHEX & $0.12^{1}$ & 1.15 & 0.10 \\
\hline Port Hope & $0.21^{2}$ & 1.15 & 0.18 \\
\hline
\end{tabular}

Table 6-69. Public Chemical Impact for wet process uranium conversion facilities.

\begin{tabular}{|l|c|c|c|}
\hline \multicolumn{1}{|c|}{ Site } & Hazard Index & $\begin{array}{c}\text { Annual Throughput } \\
\text { (MTNU) }\end{array}$ & $\begin{array}{c}\text { Total Chemical Impact } \\
\text { (Hazard Index/MTNU) }\end{array}$ \\
\hline COMURHEX & $1.01 \mathrm{E}-01$ & 7994 & $1.27 \mathrm{E}-05$ \\
\hline Port Hope & $2.02 \mathrm{E}-01$ & 10780 & $1.87 \mathrm{E}-05$ \\
\hline \multicolumn{2}{|r|}{ Total Relative Chemical Impact (Hazard Index/ MTNU) } \\
\hline
\end{tabular}

\section{Ecological Radiological Impacts - Conversion}

Radiological impacts to the ecosystem are unable to be fully modeled from the available data. The ecological impacts from radiological sources are assumed to be similar to the radiological impacts to the public (critical receptor) with the provision that the results are reported in units of absorbed dose, or mGy. Hence, the estimated radiological impacts to the ecosystem are based on Table 6-66 and are given in Table 6-70.

Table 6-70. Ecological Radiological Health Impacts for wet process conversion facilities

\begin{tabular}{|l|c|}
\hline \multicolumn{1}{|c|}{ Facility } & $\begin{array}{c}\text { Impact to Critical Receptor } \\
\text { (mGy/MTNU) }\end{array}$ \\
\hline Areva COMURHEX & $5.0-09$ \\
\hline Cameco Port Hope & $1.39 \mathrm{E}-07$ \\
\hline Total Impact to Critical Receptor (mGy/MTNU) & \\
\hline
\end{tabular}


Environmental Impacts, Health and Safety Impacts, and Financial Costs of the Front-End of the Nuclear Fuel Cycle

\section{Ecological Chemical Impacts - Conversion}

Ecological chemical impacts from conversion operations are assessed using measured fluoride concentrations as shown in Table 6-71. Note that the HQ will be the same as the HI in this case since there is a single chemical and pathway being considered.

Table 6-71. Water effluent data from wet process conversion facilities.

\begin{tabular}{|c|c|c|c|c|c|}
\hline Facility & $\begin{array}{l}\text { Average Fluoride } \\
\text { Concentrations } \\
(\mathrm{mg} \mathrm{F} / \mathrm{L})^{1}\end{array}$ & $\begin{array}{c}\text { Screening } \\
\text { Level } \\
(\mathrm{mg} \mathrm{F} / \mathrm{L})^{2}\end{array}$ & $\begin{array}{l}\text { Hazard } \\
\text { Quotient }\end{array}$ & $\begin{array}{c}\text { Annual } \\
\text { Throughput } \\
\text { (MTNU) }\end{array}$ & $\begin{array}{c}\text { Chemical Impact } \\
\text { (Hazard Index/MTNU) }\end{array}$ \\
\hline COMURHEX & 0.12 & 0.12 & 1.0 & 7994 & $1.25 \mathrm{E}-04$ \\
\hline Port Hope & 0.21 & 0.12 & 1.75 & 10780 & $1.62 \mathrm{E}-04$ \\
\hline \multicolumn{5}{|c|}{ Average Relative Chemical Impact (Hazard Index/MTNU) } & 1.44E-04 \\
\hline
\end{tabular}

\subsubsection{Financial Cost Impacts - Uranium Conversion}

The Advanced Fuel Cycle Cost Basis (AFC CB) [Shropshire 2009] provides unit costs for technologies across the fuel cycle. For fuel cycle facilities, unit costs are expressed per unit mass of commodity produced or processed. Unit costs from the 2012 update (INL 2013) to the 2009 AFC CB, in units of $\$ / M T N U$ as $\mathrm{UF}_{6}$, are provided in Table 6-72. The metric for conversion is the reference value. Lower and upper bounds are provided to give a sense of the confidence interval associated with the estimate.

Capital, operating and decommissioning costs for a single reference facility are not available for this technology. There has been no recent green-field conversion plant construction project, nor any publically available study offering sufficient detail on construction and operating costs.

Table 6-72. Unit enrichment cost estimate.

\begin{tabular}{|c|c|c|}
\hline Reference Value(s) & $\begin{array}{c}\text { Upside } \\
\text { (Low Value) }\end{array}$ & $\begin{array}{c}\text { Downside } \\
\text { (High Value) }\end{array}$ \\
\hline $\mathbf{1 . 2 E}+\mathbf{4}$ / MTNU & $\mathbf{6 E}+\mathbf{3} /$ MTNU & $\mathbf{1 . 8 E + 4} /$ MTNU \\
\hline
\end{tabular}

\subsection{Uranium Enrichment Impacts}

Estimates of environmental, safety and health, and financial cost impacts from uranium enrichment are developed in sections 6.4.1 thru 6.4.3, respectively, and summarized in Table 6-73 below. Impact estimates developed in this section are based on the centrifuge enrichment process. It should be noted that the impacts are estimated per separative work unit (SWU). The SWU needed to enrich UF6 is a function of the specified enrichment and tails assay. For purposes of normalizing the impacts per MTNU, an enrichment of $4.2 \%$ and a tails assay of $0.25 \%$ is assumed. However, the impacts per SWU can be used to readily estimate the impacts of any specified product enrichment and tails assay. 
Environmental Impacts, Health and Safety Impacts, and Financial Costs of the Front-End of the Nuclear Fuel Cycle

Table 6-73. Summary of Impacts from Uranium Enrichment

\begin{tabular}{|c|c|}
\hline & Enrichment Impacts \\
\hline Normalization Unit & SWU \\
\hline 4.1 Environmental Impacts & $\begin{array}{c}\text { See Section } \\
6.4 .1 \\
\end{array}$ \\
\hline 4.1.1 Land Use $\left(\mathrm{km}^{2}\right)$ & $9.0 \mathrm{E}-09$ \\
\hline Permanent $\left(\mathrm{km}^{2}\right)$ & 0 \\
\hline Non-Permanent $\left(\mathrm{km}^{2}\right)$ & $9.0 \mathrm{E}-09$ \\
\hline 4.1.2 Water Use Net (ML) & $2.9 \mathrm{E}-05$ \\
\hline \multicolumn{2}{|l|}{ 4.13 Energy Use and $\mathrm{CO} 2$ Emissions } \\
\hline Energy Use (GJ) & $2.1 \mathrm{E}-01$ \\
\hline $\mathrm{CO} 2$ Emissions $\mathrm{kG} \mathrm{CO} 2$ & $2.8 \mathrm{E}+01$ \\
\hline 4.2 Health and Safety Impacts: & $\begin{array}{c}\text { See Section } \\
6.4 .2 \\
\end{array}$ \\
\hline 4.2.1 Occupational Radiological (person- mSv) & $3.1 \mathrm{E}-05$ \\
\hline 4.2.2 Occupational Chemical (Hazard Index)] & $5.2 \mathrm{E}-10$ \\
\hline 4.2.3 Occupational Accident \& Illness (lost days) & $1.8 \mathrm{E}-06$ \\
\hline \multicolumn{2}{|l|}{ 4.2.4 Public Radiological } \\
\hline Dose to Critical Receptor (mSv) & $2.2 \mathrm{E}-08$ \\
\hline Collective Dose (person -mSv) & $2.5 \mathrm{E}-08$ \\
\hline 4.2.5 Public Chemical (Hazard Index) & $2.2 \mathrm{E}-05$ \\
\hline 4.2.6 Ecological Radiological (mGy to Critical Receptor) & negligible \\
\hline 4.2.7 Ecological Chemical (Hazard Index) & negligible \\
\hline 4.3 Financial Costs: $(\$)$ & $\begin{array}{c}\text { See Section } \\
6.4 .3 \\
\end{array}$ \\
\hline Costs $(\$)$ & $1.0 \mathrm{E}+2$ \\
\hline
\end{tabular}

\subsubsection{Environmental Impacts - U Enrichment}

Land and water use estimates associated with the conversion process are taken directly from Table 5-7 and converted to the units shown above. As noted in section 5.4, a laser-based enrichment process (SILEX) has recently been licensed by the NRC. Although this technology was not selected as the reference technology because it has not yet been deployed, it is expected to be more representative of the impacts of next-generation enrichment technologies. Data from the EIS (NRC 2012b) indicate that the | SILEX process will use approximately $65 \%$ of the water and $17 \%$ of the land relative to centrifuge enrichment shown above. The basis for this comparative estimate is shown in Appendix G.

Estimates for energy consumption and $\mathrm{CO} 2$ emissions from the representative enrichment process identified in Section 5.4 are developed below using the approach described in Section 4.1.3. The direct and embodied energy inputs from Table 5-7 (reproduced in Table 6-74) are converted to GJ per SWU and broken down into their constituent energy carriers using the conversion factors shown in Table 6-75. The result, shown in Table 6-76, provides the total energy intensity of the centrifuge enrichment process broken down by energy carriers. The $\mathrm{CO}_{2}$ emission factors for each energy carrier (per Appendix B) are then applied to obtain the total $\mathrm{CO} 2$ emissions for the process. 
Environmental Impacts, Health and Safety Impacts, and Financial Costs of the Front-End of the Nuclear Fuel Cycle

July 2013

Table 6-74. Main product and energy and material inputs to enrichment operations

\begin{tabular}{|c|c|}
\hline & Process Inputs per Table 5-7 \\
\hline Direct Energy Inputs & $4.00 \mathrm{E}-02$ \\
\hline Electricity (MWh/SWU) & $1.03 \mathrm{E}+03$ \\
\hline Natural Gas (L/SWU) & $7.99 \mathrm{E}-02$ \\
\hline Distillate Fuel (Diesel) (L/SWU) & \\
\hline Embodied Energy Inputs & $2.26 \mathrm{E}-07$ \\
\hline Argon, Ar (MT/SWU) & $2.62 \mathrm{E}-08$ \\
\hline Helium, He (MT/SWU & \\
\hline
\end{tabular}

Table 6-75. Conversion Factors for Energy Inputs to Centrifuge Enrichment (see Appendix B)

\begin{tabular}{|c|c|c|c|c|c|c|}
\hline \multirow{2}{*}{} & \multicolumn{5}{|c|}{ Breakdown of Energy Carriers } \\
\cline { 2 - 7 } & Electricity & $\begin{array}{c}\text { Natural } \\
\text { Gas }\end{array}$ & Coal & $\begin{array}{c}\text { Distillate } \\
\text { Fuel }\end{array}$ & Total \\
Gasoline & $\begin{array}{c}\text { Energy } \\
\text { Intensity }\end{array}$ \\
\hline Direct Energy Inputs & & & & & & \\
\hline Electricity (GJ/MWh) & $3.60 \mathrm{E}+00$ & & & & & $3.60 \mathrm{E}+00$ \\
\hline Natural Gas (GJ/L)) & & $3.64 \mathrm{E}-05$ & & & & $3.64 \mathrm{E}-05$ \\
\hline $\begin{array}{c}\text { Distillate Fuel (Diesel) } \\
(\mathrm{GJ} / \mathrm{L})\end{array}$ & & & & $3.86 \mathrm{E}-02$ & & $3.86 \mathrm{E}-02$ \\
\hline Embodied Energy Inputs & & & & & & \\
\hline Argon, Ar (GJ/MT) & $1.56 \mathrm{E}+04$ & $2.33 \mathrm{E}+04$ & $1.67 \mathrm{E}+02$ & $2.14 \mathrm{E}+02$ & $9.52 \mathrm{E}+01$ & $3.94 \mathrm{E}+04$ \\
\hline Helium, He (GJ/MT) & $1.71 \mathrm{E}+05$ & $2.57 \mathrm{E}+05$ & $1.83 \mathrm{E}+03$ & $2.36 \mathrm{E}+03$ & $1.05 \mathrm{E}+03$ & $4.33 \mathrm{E}+05$ \\
\hline
\end{tabular}


Environmental Impacts, Health and Safety Impacts, and Financial Costs of the Front-End of the Nuclear Fuel Cycle

Table 6-76. Energy Consumption and $\mathrm{CO}_{2}$ Emissions for Centrifuge Enrichment

\begin{tabular}{|c|c|c|c|c|c|c|}
\hline & $\begin{array}{l}\text { Electricity } \\
\left.\text { GJ }_{\mathrm{e}} / \mathrm{SWU}\right)\end{array}$ & $\begin{array}{c}\text { Natural } \\
\text { Gas } \\
(\mathrm{GJ} / \mathrm{SWU})\end{array}$ & $\begin{array}{c}\text { Coal } \\
(\mathrm{GJ} / \mathrm{SWU})\end{array}$ & $\begin{array}{c}\text { Distillate Fue } \\
\text { (GJ/SWU) }\end{array}$ & $\begin{array}{l}\text { Gasoline } \\
\text { (GJ/SWU) }\end{array}$ & Total \\
\hline \multicolumn{7}{|l|}{ Direct Energy Inputs } \\
\hline Electricity & $1.44 \mathrm{E}-01$ & & & & & $1.44 \mathrm{E}-01$ \\
\hline Natural Gas & & $3.75 \mathrm{E}-02$ & & & & $3.75 \mathrm{E}-02$ \\
\hline Distillate Fuel & & & & $3.08 \mathrm{E}-03$ & & 3.08E-03 \\
\hline \multicolumn{6}{|c|}{ Direct Energy Total } & $1.85 \mathrm{E}-01$ \\
\hline \multicolumn{7}{|l|}{$\begin{array}{l}\text { Embodied Energy } \\
\text { Inputs }\end{array}$} \\
\hline Argon, Ar & $3.53 \mathrm{E}-03$ & $5.27 \mathrm{E}-03$ & $3.77 \mathrm{E}-05$ & 4.84E-05 & $2.15 \mathrm{E}-05$ & $8.90 \mathrm{E}-03$ \\
\hline Helium, $\mathrm{He}$ & $4.48 \mathrm{E}-03$ & $6.73 \mathrm{E}-03$ & $4.81 \mathrm{E}-05$ & $6.18 \mathrm{E}-05$ & $2.75 \mathrm{E}-05$ & $1.13 \mathrm{E}-02$ \\
\hline \multicolumn{6}{|c|}{ Embodied Energy Total } & $2.02 \mathrm{E}-02$ \\
\hline Totals by Carrier & $1.52 \mathrm{E}-01$ & $4.95 \mathrm{E}-02$ & $8.57 \mathrm{E}-05$ & $3.19 \mathrm{E}-03$ & $4.90 \mathrm{E}-05$ & 2.05E-01 \\
\hline $\begin{array}{l}\text { Emission Factors }(\mathrm{kg} \\
\left.\mathrm{CO}_{2} / \mathrm{GJ}\right)\end{array}$ & 168 & 51 & 89 & 79 & 68 & \\
\hline $\begin{array}{l}\mathrm{CO}_{2} \text { Emissions (kg } \\
\left.\mathrm{CO}_{2} / \mathrm{SWU}\right)\end{array}$ & $2.55 \mathrm{E}+01$ & $2.52 \mathrm{E}+00$ & 7.63E-03 & $2.52 \mathrm{E}-01$ & $3.33 \mathrm{E}-03$ & $2.83 E+01$ \\
\hline
\end{tabular}

\subsubsection{Health and Safety Impacts - U Enrichment}

\section{Occupational Radiological Impacts Centrifuge Enrichment Facilities}

Radiological impacts to workers from operation of centrifuge enrichment facilities processing UF6 are assessed using a combination of data from operating facilities and projections for future facilities. Estimates of radiological impacts to occupational workers are based on information presented in documents evaluating impacts in the Environmental Impact Statements of the proposed National Enrichment Facility (NEF), American Centrifuge Plant (ACP), and the proposed Eagle Rock Enrichment Facility (centrifuge). The above three are centrifuge processes. Information for one operating enrichment facility (Capenhurst) and two operating gaseous diffusion plants (Portsmouth and Paduccah) is also provided for reference.

Data in Table 6-77 gives the range of anticipated and actual occupational doses. These values are in some contrast to data from Table 64, of "Estimated Worldwide Levels of Exposure due to Uranium Enrichment" (UNSCEAR 2008). This table gives average occupational exposure of $0.09 \mathrm{mSv}$ to a combined work force of 18,200 persons for the year 2002. Although this appears to be a smaller average exposure, this workforce represents about 5 times more people per SWU than the proposed US facilities and, as a result, the 2002 global workforce exposure is 50 to $100 \%$ higher per SWU produced than that projected at the US facilities as shown in Table 6-77. ${ }^{27}$

Doses presented in Table 6-77appear to be significantly greater than those identified by Schneider (2010). Data from that report was produced in the ExternE 1995 effort (European Commission 1995) and is derived from a single facility, the EURODIF Tricastin gaseous diffusion plant that has a capacity of about $11 \times 10^{6}$ SWU. Recent data for that facility, averaged from 2009-2011, (Areva 2011b) are consistent with

27. http://theenergylibrary.com/node/539Assessed 7 August 2012 to obtain global enrichment capacity of $47 \mathrm{M}$ SWU in 2002. 
Environmental Impacts, Health and Safety Impacts, and Financial Costs of the Front-End of the Nuclear Fuel Cycle

Table 6-77. Occupational Radiological Dose Estimate for Centrifuge Enrichment

\begin{tabular}{|c|c|c|c|c|c|c|}
\hline Site & $\begin{array}{l}\text { Plant } \\
\text { Capacity } \\
\text { (SWU/yr) }\end{array}$ & $\begin{array}{l}\text { Workers } \\
\text { With } \\
\text { Measurable } \\
\text { Exposure }\end{array}$ & $\begin{array}{l}\text { Avg } \\
\text { Effective } \\
\text { Dose } \\
(\mathrm{mSv} / \mathrm{yr})\end{array}$ & $\begin{array}{l}\text { Max } \\
\text { Effective } \\
\text { Dose } \\
(\mathrm{mSv} / \mathrm{yr})\end{array}$ & $\begin{array}{l}\text { Collective Dose } \\
\text { (Person-mSv/yr) }\end{array}$ & $\begin{array}{c}\text { Collective Dose } \\
\text { (Person-mSv/SWU) }\end{array}$ \\
\hline $\mathrm{NEF}^{2}$ & $3 \mathrm{E}+06$ & 210 & $0.415^{2}$ & 3.0 & 87.2 & $2.91 \mathrm{E}-05$ \\
\hline $\mathrm{ACP}^{3}$ & $7 \mathrm{E}+06$ & 600 & 0.305 & - & 183 & $2.61 \mathrm{E}-05$ \\
\hline Capenhurst $^{2}$ & $3.7 \mathrm{E}+06$ & 325 & 0.415 & 3.0 & 135 & $3.65 \mathrm{E}-05$ \\
\hline $\begin{array}{l}\text { Eagle } \\
\text { Rock }^{4}\end{array}$ & - & 550 & - & 3.0 & - & - \\
\hline Paducah $^{3}$ & - & 341 & 0.37 & - & 126 & - \\
\hline Portsmouth $^{3}$ & - & 661 & 0.24 & - & 159 & - \\
\hline \multicolumn{6}{|c|}{ Average Collective Impact(Person-mSv/ SWU) } & $3.06 E-05$ \\
\hline \multicolumn{7}{|c|}{$\begin{array}{l}\text { 1. SWU capacity taken from www.osti.gov/bridge/servlets/purl/932144-njhbTH/932144.PDF } \\
\text { 2. Average data for } 2006 \text { \&2007 radiation worker employees, see URENCO Health, Safety and Environment Report, } 2006 \\
\text { \&2007 http://www.corporateregister.com/a10723/ure06-ehs-uk.pdfwww.urenco.com/Download.aspx?fileid=15 }\end{array}$} \\
\hline \multicolumn{7}{|c|}{$\begin{array}{l}\text { 3. Gaseous diffusion plant data from NUREG-0713 Vol. 22, 2001. Available at http://www.nrc.gov/reading-rm/doc- } \\
\text { collections/nuregs/staff/sr0713/ } \\
\text { 4. EIS for proposed Eagle Rock enrichment facility (NUREG 1945) }\end{array}$} \\
\hline
\end{tabular}

that found in Schneider (2010) when the total number of workers (exposed plus unexposed) is used to calculate average and collective dose. Similarly, if the total number of workers is used, the EURODIF facility has more workers per SWU and less average occupational dose than the facilities in Table 6-77. When only workers with measurable exposure are used (about 311/yr for EURODIF) the average exposure is $0.41 \mathrm{mSv}$, similar to the URENCO Capenhurst gaseous diffusion plant (Table below).

\section{Occupational Chemical Impacts - Centrifuge Enrichment Facilities}

Based on the analysis within the American Centrifuge Plant EIS (NUREG 1834), the greatest potential for occupational exposures to chemicals is in the product and tails withdrawal buildings, where cylinder connections and disconnections have the potential to release small amounts of UF 6 into the workplace environment. Any released $\mathrm{UF}_{6}$ would react with ambient moisture to form HF and uranyl fluoride. Gulper systems, utilizing a flexible hose or ventilation hood, would be used to evacuate any such releases from the workplace. Airborne concentrations of HF and uranyl fluoride are expected to be insignificant with respect to worker exposure except in the area in the immediate vicinity of the release area and the gulper. Based on historical monitoring results and the anticipated amount of $U_{6}$ released from their centrifuge operations, USEC estimates that workplace concentrations of HF would be less than one percent of the Occupational Safety and Health Administration's Permissible Exposure Limit of 2.5 milligrams per cubic meter over an eight-hour averaging time (actual data not supplied). Concentrations of $\mathrm{HF}$ in the immediate vicinity of the $\mathrm{UF}_{6}$ release point could be briefly higher, but are still expected to be less than 10 percent of the Permissible Exposure Limit. Similar observations are made within the Eagle Rock Enrichment Facility EIS (NUREG 1945). Table 6-78 portrays the potential impacts to NEF workers using estimated HF worker exposure from its EIS (NUREG 1790).

\section{Occupational Accident \& Illness Impacts - Centrifuge Enrichment Facilities}

Estimated occupational accident and illness impacts for centrifuge enrichment facilities, based on their EIS statements (NUREGs 1790, 1945, and 1834) are estimated below in Table 6-79. 
Environmental Impacts, Health and Safety Impacts, and Financial Costs of the Front-End of the

Nuclear Fuel Cycle

Table 6-78. Occupational Chemical Impacts for Centrifuge Enrichment

\begin{tabular}{|c|c|c|c|}
\hline Facility & $\begin{array}{l}\text { Average Fluoride Levels } \\
\qquad\left(\mathrm{mg} / \mathrm{m}^{3}\right)\end{array}$ & $\begin{array}{l}\text { Screening Level }{ }^{1} \\
\left(\mathrm{mg} / \mathrm{m}^{3}\right)\end{array}$ & HQ \\
\hline NEF & $3.9 \mathrm{E}-03$ & 2.5 & $1.56 \mathrm{E}-03$ \\
\hline \multicolumn{3}{|c|}{ Total Relative Chemical Impact (Hazard Index/SWU) } & 5.2E-10 \\
\hline
\end{tabular}

Table 6-79. Occupational Accident and Illness Impacts for centrifuge enrichment

\begin{tabular}{|l|c|c|c|c|c|}
\hline \multicolumn{1}{|c|}{ Site } & $\begin{array}{c}\text { Plant Capacity } \\
\text { (SWU/yr) }\end{array}$ & $\begin{array}{c}\text { Estimated Lost Time } \\
\text { Accidents per year }\end{array}$ & $\begin{array}{c}\text { Days Lost } \\
\text { per Accident }\end{array}$ & $\begin{array}{c}\text { Days Lost } \\
\text { per Year }\end{array}$ & $\begin{array}{c}\text { Impact } \\
\text { (days lost/SWU) }\end{array}$ \\
\hline NEF & $3 \mathrm{E}+06$ & 0.67 & 7 & 4.7 & $1.57 \mathrm{E}-06$ \\
\hline Eagle Rock & $6.6 \mathrm{E}+06$ & 1.76 & 7 & 12.3 & $1.87 \mathrm{E}-06$ \\
\hline ACP & $7 \mathrm{E}+06$ & 1.92 & 7 & 13.4 & $1.92 \mathrm{E}-06$ \\
\hline \multicolumn{5}{|c|}{ Average Accident \& Illness Impact (days lost/SWU) } & $\mathbf{1 . 7 8 E - 0 6}$ \\
\hline $\begin{array}{l}\text { 1. Average days lost per accident were not reported in the EISs. Because hazardous operations (e.g., cylinder handling) are } \\
\text { similar to a conversion facility, the value from the Port Hope conversion facility (see Table 6-65) is used as an estimate. } \\
\text { This estimate seems reasonable since the Port Hope injury rate of .32 is similar to a .28 rate observed among URENCO } \\
\text { Capenhurst workers between 2007 and 2011. http://www.urenco.com/page/335/Sustainability-Report-2011.aspx }\end{array}$ \\
\hline
\end{tabular}

\section{Public Radiological Impacts - Centrifuge Enrichment}

Data from the three proposed centrifuge enrichment facilities, based on complete exposure pathway analyses, are presented in Table 6-80 to provide a view of the potential radiation doses to the public. The National Enrichment Facility estimate yields the highest dose to the critical receptor. The critical receptor for a planned facility is taken to be the location on the fence line that would yield the greatest radiation dose. This is $0.189 \mathrm{mSv} / \mathrm{yr}$ and is essentially all attributable to direct radiation from the storage pad for $\mathrm{UF}_{6}$ cylinders. Persons at the nearest actual residence or business were estimated to receive 0.026 $\mathrm{mSv} / \mathrm{yr}$. The collective population dose for persons living within 80 kilometers (50 miles) of the representative facility was estimated to be 0.14 Person-mSv/yr. Due to the large distance between the actual population and the stored $\mathrm{UF}_{6}$ cylinders, inhalation of uranium compounds from atmospheric releases during normal operations comprises the vast majority of the total public dose.

Radiological impacts to the public seen in the above table differ significantly from those identified by Schneider (2010). Collective impacts to the public in the present analysis are much smaller, just the opposite of occupational doses. Major differences can be ascribed to the methods of calculation. The US uses an $80 \mathrm{~km}$ population, while the ExternE project calculated doses on a regional scale that extended throughout most of the European Continent (except for the former Soviet Union) (Spadaro and Rabl 1998). The ExternE calculation projected doses for 500 years while the proposed facilities used a typical lifetime of 70 years. There exist many other differences in the data developed in the present study and that of the ExternE project. 
Environmental Impacts, Health and Safety Impacts, and Financial Costs of the Front-End of the Nuclear Fuel Cycle

Table 6-80. Dose to Populations within $80 \mathrm{~km}$ Centrifuge Enrichment Plants

\begin{tabular}{|c|c|c|c|c|c|c|}
\hline \multirow[b]{2}{*}{ Site } & \multirow[b]{2}{*}{$\begin{array}{c}\text { Plant Capacity } \\
\text { (SWU/yr) }\end{array}$} & \multicolumn{2}{|c|}{ Dose to Critical Receptor } & \multicolumn{3}{|c|}{ Collective Dose to Public } \\
\hline & & $(\mathrm{mSv} / \mathrm{yr})^{1}$ & (mSv/SWU) & $\begin{array}{c}\text { Affected } \\
\text { Population }\end{array}$ & $\begin{array}{l}\text { (Person- } \\
\mathrm{mSv} / \mathrm{yr} \text { ) }\end{array}$ & $\begin{array}{c}\text { (Person- } \\
\text { mSv/SWU) }\end{array}$ \\
\hline $\mathrm{NEF}^{2}$ & $3 \mathrm{E}+06$ & 0.189 & $6.3 \mathrm{E}-08$ & 94758 & 0.14 & $4.67 \mathrm{E}-08$ \\
\hline Eagle Rock & $6.6 \mathrm{E}+06$ & 0.014 & 2.12E-09 & 267256 & 0.017 & $2.58 \mathrm{E}-09$ \\
\hline $\mathrm{ACP}^{3}$ & $7 \mathrm{E}+06$ & 0.01 & $1.43 \mathrm{E}-09$ & - & - & - \\
\hline \multicolumn{3}{|c|}{ Average Impact } & 2.22E-08 & & & $2.46 \mathrm{E}-08$ \\
\hline
\end{tabular}

\section{Public Chemical Impacts - Centrifuge Enrichment}

With respect to public health impacts from liquid effluent emissions, calculations presented in the American Centrifuge Plant EIS (NUREG-1834) conclude that non-radiological releases from proposed operations to surface water and groundwater should be small and should not degrade existing water quality. The other two proposed facilities plan for little to no releases to the aquatic system, therefore, the public health impacts associated with liquid effluents are anticipated to be negligible.

Airborne emissions of potential significance include $\mathrm{HF}$ and $\mathrm{UF}_{6}$. While additional hazardous chemicals are used at enrichment facilities, the quantities and potential for release are small by comparison. An estimate of impact due to HF and UF6 emissions from centrifuge enrichment facilities, based on the American Centrifuge Plant EIS is provided in Table 6-81. Similar, but qualitative, analyses are presented in Eagle Rock Enrichment Facility and the National Enrichment Facility EIS's with similar conclusions.

Table 6-81. Public Chemical impact from centrifuge enrichment facilities ${ }^{1}$.

\begin{tabular}{|l|c|c|c|}
\hline $\begin{array}{c}\text { American Centrifuge } \\
\text { Plant }\end{array}$ & $\begin{array}{c}\text { Exposure at Critical Receptor } \\
\left.\left(\mu \mathrm{g} / \mathrm{m}^{3}\right)\right]\end{array}$ & $\begin{array}{c}\text { Screening Level } \\
\left(\mu \mathrm{g} / \mathrm{m}^{3}\right)\end{array}$ & HQ \\
\hline Fluoride & $2.4 \mathrm{E}-03$ & 13 & $1.8 \mathrm{E}-04$ \\
\hline Uranium & $6.1 \mathrm{E}-03$ & 0.04 & $1.5 \mathrm{E}-01$ \\
\hline \multicolumn{3}{|c|}{ Hazard Index } & $1.5 \mathrm{E}-01$ \\
\hline \multicolumn{3}{|c|}{ Total Relative Chemical Impact (Hazard Index/SWU) } & $\mathbf{2 . 2 E - 0 5}$ \\
\hline $\begin{array}{c}\text { 1. Exposure is the peak 8-hour concentration at the point of the Ohio National Guard building located onsite } 555 \text { meters (1,820 } \\
\text { feet) from the proposed ACP buildings (NUREG1834). } \\
\text { 2. Public Risk Screening Levels from http://rais.ornl.gov/cgi-bin/prg/PRG search?select=chem }\end{array}$ \\
\hline
\end{tabular}

\section{Ecological Radiological Impacts - Centrifuge Enrichment}

As with public radiation exposures, radiological impacts to ecological organisms are expected to be negligible.

\section{Ecological Chemical Impacts - Centrifuge Enrichment}

As with public chemical impacts, chemical impacts to ecological organisms are expected be negligible. 


\subsubsection{Financial Cost Impacts - U Enrichment}

Table 6-82 provides cost estimates for enrichment. This estimate considers all plants participating in the enrichment market and is best described as a forecast of the long-run average SWU market price rather than the SWU production cost of an individual facility. Lower and upper bounds are provided to give a sense of the confidence interval associated with the estimate.

Table 6-82. Unit enrichment market price estimate ${ }^{1}$.

\begin{tabular}{|c|c|c|}
\hline Reference Value(s) & $\begin{array}{c}\text { Upside } \\
\text { (Low Value) }\end{array}$ & $\begin{array}{c}\text { Downside } \\
\text { (High Value) }\end{array}$ \\
\hline$\$ 100 / \mathrm{SWU}$ & $\$ 70 /$ SWU & $\$ 115 / \mathrm{SWU}$ \\
\hline
\end{tabular}

This section also provides capital, operating and decommissioning costs for the reference URENCO USA facility identified in Section 5.1.4. These disaggregated cost components are used to estimate unit SWU production costs at each facility by the methodology defined in Section 4.3. Individual plant unit production costs thus calculated should be less than or equal to the estimated market price cited in Table 6-82.

[NRC 2005] provides overnight construction, annual operating and decommissioning costs furnished by URENCO. Given in year 2004 dollars, these costs are inflated to 2012 dollars using the consumer price index. The URENCO data and adjusted costs are given in Table 6-83.

Table 6-83. Costs associated with URENCO USA facility.

\begin{tabular}{|l|l|l|}
\hline \multicolumn{1}{|c|}{ Item } & \multicolumn{1}{|c|}{$\begin{array}{c}\text { Cost } \\
\text { (year 2004 \$) }\end{array}$} & \multicolumn{1}{c|}{\begin{tabular}{c}
\multicolumn{1}{c|}{ Cost } \\
(year 2012\$)
\end{tabular}} \\
\hline Total Overnight Cost & \$1.24 B & \$1.52 B \\
\hline Operation Cost & \$20.8 M per year & \$25.4M per year \\
\hline Decommissioning Cost & $\$ 164 \mathrm{M}$ & \$201 M \\
\hline
\end{tabular}

The construction period identified in [NRC 2005] was 2 years, while the duration of its operating license was 30 years. At the time [NRC 2005] was issued, the design capacity of URENCO USA was to be 3 MSWU/year.

Table 6-84 walks through the calculation of the unit production cost in \$/SWU. Values in italics are inputs generic to all technologies. These follow EMWG guidelines as defined in Section 4.3, with the exception of the sinking fund rate of return, $\mathrm{r}_{\mathrm{SF}}$. [NRC 2005] stated that "LES is required to put in place a financial surety bonding mechanism to assure that adequate funds would be available" to meet decommissioning and disposal related liabilities. Hence $\mathrm{r}_{\mathrm{SF}}$ was chosen to be 0.02 , representative of a risk free rate of return.

The last six values in the table are calculated according to the procedure defined in Section 4.3. The EMWG recommended two real discount rates, $\mathrm{R}=0.05$ and $\mathrm{R}=0.10$, as bounding values for the cost of capital that might be faced by owners and operators of fuel cycle facilities. This parameter has a 
Environmental Impacts, Health and Safety Impacts, and Financial Costs of the Front-End of the Nuclear Fuel Cycle

substantial impact on the unit production cost, and the two production cost values appearing in the final row of Table 6-84 may be interpreted as lower and upper bounds on the true production cost at this facility.

Thus the production cost at the reference facility is estimated at $\$ 45.5-\$ 72.1 / \mathrm{SWU}$.

Table 6-84. Summary of Financial Cost Inputs and Calculation Outcomes.

\begin{tabular}{|c|c|c|c|}
\hline Symbol & Unit & Value $(R=0.05)$ & Value $(R=0.10)$ \\
\hline TOC & $\$$ & \multicolumn{2}{|c|}{$1.52 \mathrm{E}+09$} \\
\hline $\mathrm{OM}$ & $\$ / y r$ & \multicolumn{2}{|c|}{$2.54 \mathrm{E}+07$} \\
\hline $\mathrm{DD}$ & $\$$ & \multicolumn{2}{|c|}{$2.01 \mathrm{E}+08$} \\
\hline$Y_{\text {basis }}$ & -- & \multicolumn{2}{|c|}{2012} \\
\hline $\mathrm{T}_{\mathrm{c}}$ & $\mathrm{yr}$ & \multicolumn{2}{|c|}{2} \\
\hline $\mathrm{T}_{\mathrm{o}}$ & $\mathrm{yr}$ & \multicolumn{2}{|c|}{30} \\
\hline $\mathrm{M}$ & SWU/yr & \multicolumn{2}{|c|}{$3.00 \mathrm{E}+06$} \\
\hline$f_{i}$ & -- & \multicolumn{2}{|c|}{0.5 for ea. year } \\
\hline$R$ & $1 / y r$ & 0.05 & 0.10 \\
\hline$r_{S F}$ & $1 / y r$ & \multicolumn{2}{|c|}{0.02} \\
\hline $\mathrm{AF}$ & $1 / \mathrm{yr}$ & $6.51 \mathrm{E}-02$ & $1.06 \mathrm{E}-01$ \\
\hline IDC & $\$$ & $1.16 \mathrm{E}+08$ & $2.35 \mathrm{E}+08$ \\
\hline SFF & $1 / \mathrm{yr}$ & \multicolumn{2}{|c|}{$2.46 \mathrm{E}-02$} \\
\hline $\mathrm{ACC}$ & $\$ / y r$ & $1.06 \mathrm{E}+08$ & $1.86 \mathrm{E}+08$ \\
\hline $\mathrm{ADD}$ & $\$ / y r$ & \multicolumn{2}{|c|}{$4.94 \mathrm{E}+06$} \\
\hline $\mathrm{UC}$ & \$/SWU & $4.55 \mathrm{E}+01$ & $7.21 \mathrm{E}+01$ \\
\hline
\end{tabular}

\subsection{DUF6 Deconversion to DU308}

Estimates of environmental, safety and health, and financial cost impacts from deconversion of $\mathrm{DUF}_{6}$ to $\mathrm{DU}_{3} \mathrm{O}_{8}$ are summarized in the Table 6-85 below. Sections 6.5.1 thru 6.5.3 provide the basis for the estimates shown. Note that the impacts are normalized per MTDU. The impacts per MTDU can renormalized per MTNU for any specified enrichment and tails assay. 
Environmental Impacts, Health and Safety Impacts, and Financial Costs of the Front-End of the Nuclear Fuel Cycle

Table 6-85. Summary of Impacts from Deconversion of $\mathrm{U}_{3} \mathrm{O}_{8}$ to $\mathrm{UF}_{6}$

\begin{tabular}{|c|c|}
\hline & Deconversion Impacts \\
\hline Normalization Unit & MTDU \\
\hline 4.1 Environmental Impacts & See Section 6.5 .1 \\
\hline 4.1.1 Land Use $\left(\mathrm{km}^{2}\right)$ & $9.3 \mathrm{E}-05$ \\
\hline Permanent $\left(\mathrm{km}^{2}\right)$ & 0 \\
\hline Non-Permanent $\left(\mathrm{km}^{2}\right)$ & $9.3 \mathrm{E}-05$ \\
\hline 4.1.2 Water Use Net (ML) & $5.3 \mathrm{E}-04$ \\
\hline \multicolumn{2}{|l|}{4.13 Energy Use and $\mathrm{CO} 2$ Emissions } \\
\hline Energy Use (GJ) & $-3.8 \mathrm{E}+01^{1}$ \\
\hline $\mathrm{CO} 2$ Emissions $\mathrm{kG} \mathrm{CO}_{2}$ & $-3.2 \mathrm{E}+03$ \\
\hline 4.2 Health and Safety Impacts: & See Section 6.5.2 \\
\hline 4.2.1 Occupational Radiological (person- $\mathrm{mSv}$ ) & 2.9E-02 \\
\hline 4.2.2 Occupational Chemical (Hazard Index) & $1.5 \mathrm{E}-05$ \\
\hline 4.2.3 Occupational Accident \& Illness (lost days) & $1.4 \mathrm{E}-03$ \\
\hline \multicolumn{2}{|l|}{ 4.2.4 Public Radiological } \\
\hline Dose to Critical Receptor (mSv) & 4.6E-05 \\
\hline Collective Dose (person -mSv) & $2.0 \mathrm{E}-08$ \\
\hline 4.2.5 Public Chemical (Hazard Index) & $1.8 \mathrm{E}-06$ \\
\hline 4.2.6 Ecological Radiological (mGy to Critical Receptor) & $4.0 \mathrm{E}-04$ \\
\hline 4.2.7 Ecological Chemical (Hazard Index) & negligible \\
\hline 4.3 Financial Costs: $(\$)$ & See Section 6.5.3 \\
\hline Costs $(\$)$ & $6.0 \mathrm{E}+03$ \\
\hline
\end{tabular}

\subsubsection{Environmental Impacts - Deconversion}

This section considers the environmental impacts of the reference Portsmouth and Paducah deconversion facilities identified in Section 5.5. The basis unit for deconversion will be tonnes U as DU3O8 (i.e., tonnes of uranium in the DU3O8 product). The MTDU per MTNU for a given fuel cycle are dependent upon the fuel enrichment and tails assay specifications. For example, using the equations given in section 6 with a tails assay of $0.25 \%$ and a product enrichment of $4.2 \%$ results in a conversion factor of .883 MTDU per MTNU feed.

Land and water use estimates associated with the conversion process are taken directly from Table 5-8 and converted to the units shown above. Estimates for energy consumption and $\mathrm{CO}_{2}$ emissions from the representative enrichment process identified in Section 5.4 are developed below using the approach

described in Section 4.1.3. The direct and embodied energy inputs from Table 5-8 (reproduced in Table 6-86) are converted to GJ per MTDU and broken down into their constituent energy carriers using | the conversion factors shown in Table 6-87. The result, shown in Table_6-88, provides the total energy intensity of the centrifuge enrichment process broken down by energy carriers. The $\mathrm{CO}_{2}$ emission factors 
Environmental Impacts, Health and Safety Impacts, and Financial Costs of the Front-End of the Nuclear Fuel Cycle

July 2013

for each energy carrier (per Appendix B) are then applied to obtain the total $\mathrm{CO}_{2}$ emissions for the process.

When embodied energy is included, the final energy intensity of the $\mathrm{DUF}_{6}$ deconversion process is seen to be negative due to the liberation of HF. HF is recovered as a useful byproduct and marketed for subsequent industrial use. Hence, for our reference FEFC process $(4.2 \%$ enriched LEU and $.25 \%$ tails assay) the estimated $68.5 \mathrm{GJ} / \mathrm{MTDU}(60.5 \mathrm{GJ} / \mathrm{MTNU})$ of energy embodied in the HF byproduct represents recovery of $\sim 75 \%$ of the $78.2 \mathrm{GJ} / \mathrm{MTNU}$ embodied in HF input to the yellowcake-to-UF 6 conversion process (see Table 6-62 in section 6.3.1).

Table 6-86. Energy and Material Inputs to Deconversion Process

\begin{tabular}{|l|c|}
\hline & \multicolumn{1}{|c|}{ Process Inputs per Table 5-8 } \\
\hline Direct Energy Inputs & $3.23 \mathrm{E}+00$ \\
\hline Electricity (MWh/MTDU) & $1.13 \mathrm{E}+05$ \\
\hline Natural Gas (L/MTDU) & $1.25 \mathrm{E}+00$ \\
\hline Distillate Fuel (Diesel) (L/MTDU) & $5.29 \mathrm{E}-02$ \\
\hline Embodied Energy Inputs & $5.30 \mathrm{E}-04$ \\
\hline Ammonia, NH3 (MT/MTDU) & $1.44 \mathrm{E}-03$ \\
\hline Potassium Hydroxide, KOH (MT/MTDU) & $8.98 \mathrm{E}-03$ \\
\hline Hydrated Lime, CaOH (MT/MTDU) & $8.03 \mathrm{E}-01$ \\
\hline Hydrogen, $\mathrm{H}_{2}$ (MT/MTDU) & $-5.08 \mathrm{E}-01$ \\
\hline Nitrogen, $\mathrm{N}_{2}$ (MT/MTDU) & \\
\hline \multicolumn{2}{|l|}{ Hydrogen Fluoride Acid, HF (MT/MTDU) } \\
\hline $\begin{array}{l}\text { * The embodied energy input associated with HF is shown as negative because HF is a by-product of } \\
\text { this process, thus, embodied energy is recovered in the form of TSP production. }\end{array}$ \\
\hline
\end{tabular}




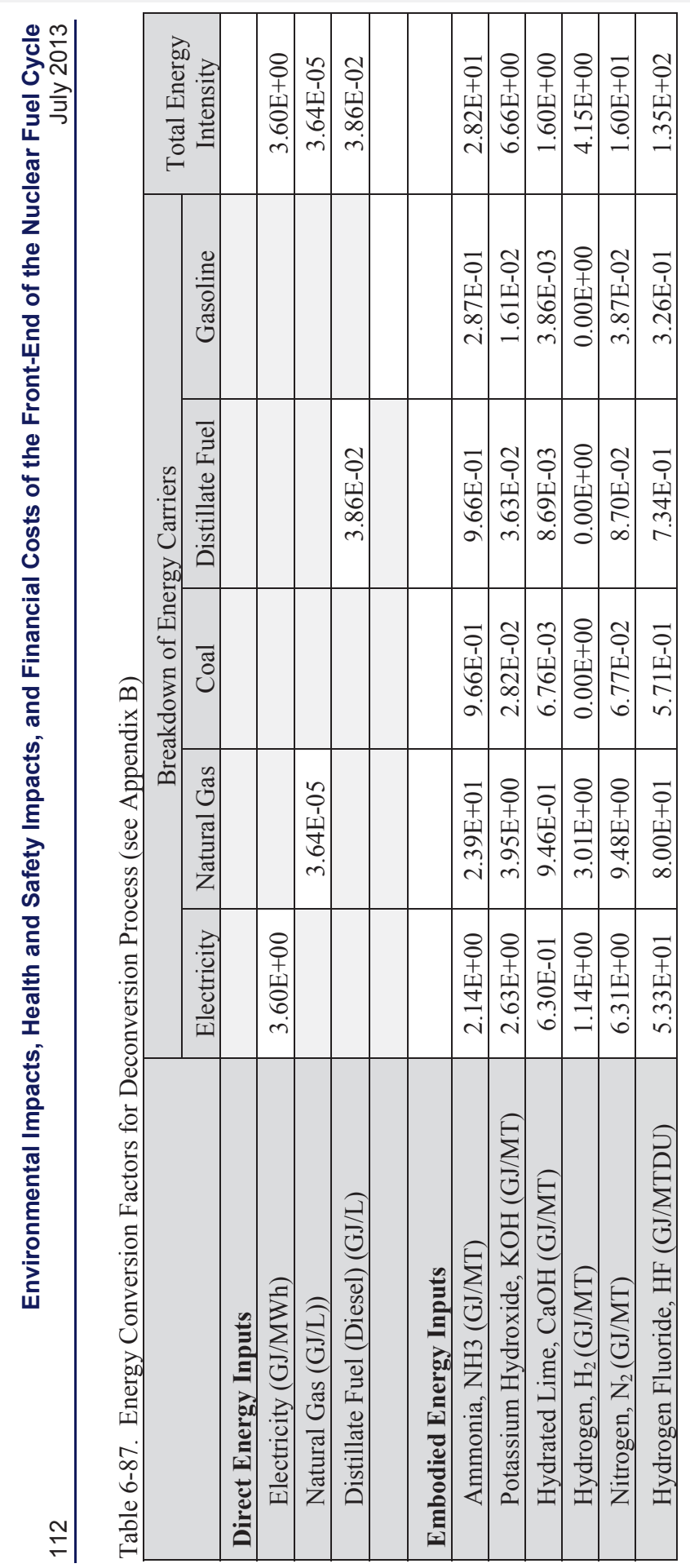




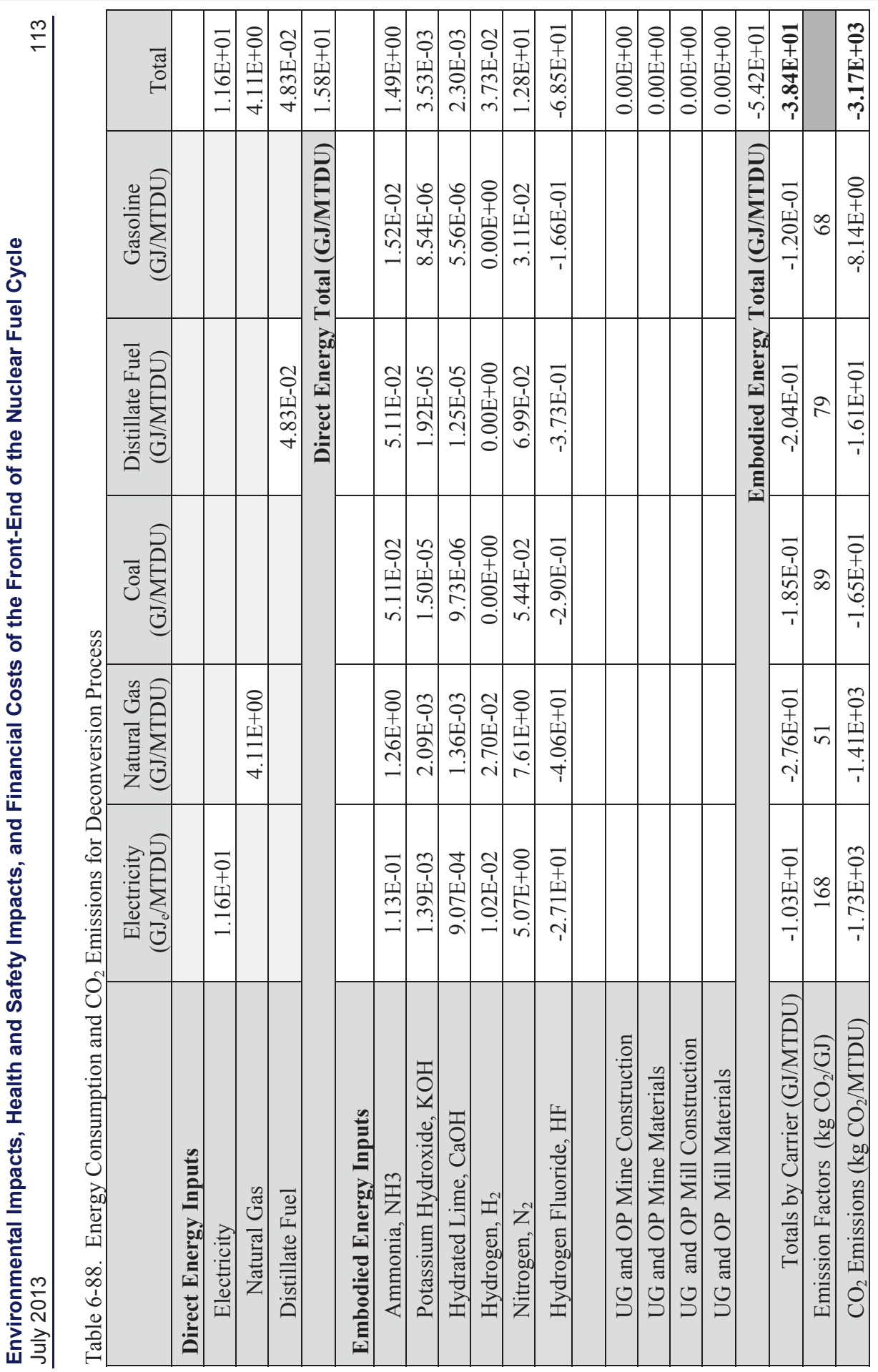




\subsubsection{Health and Safety Impacts - Deconversion}

\section{Occupational Radiological Impacts - Deconversion}

Radiological impacts to workers from deconversion operations are estimated based on information presented in Environmental Impact Statements for proposed facilities in the US, with results given in Table 6-89.

Radiological impacts were taken from the Environmental Impact Statement for the Fluorine Extraction and DU Deconversion Facility in Lea County, New Mexico (NUREG-2113). This EIS was submitted by International Isotopes Fluorine Products, Inc. (IIFP). The Department of Energy has prepared an Environmental Impact Statement for operation of a depleted uranium deconversion facility at the Paducah site (DOE, 2004), in which estimates of occupational exposures were also made, (see Table 6-89). A similar document was prepared for the same type of facility at Portsmouth, $\mathrm{OH}$, using the same basis for estimating impacts.

The two deconversion facilities selected for this analysis employ different processes to convert $\mathrm{DUF}_{6}$ to different endpoints. The IIFP is designed to convert $\mathrm{DUF}_{6}$ to uranium tetrafluoride which will then be used as a feedstock for manufacture of high-purity fluoride products. The Paducah facility will convert $\mathrm{DUF}_{6}$ to $\mathrm{DUO}_{2}$ and $\mathrm{DU}_{3} \mathrm{O}_{8}$, compounds similar to the chemical forms found in nature that are appropriate for long-term storage, transport or final disposal.

Table 6-89. Occupational Radiological Dose Impacts from Deconversion

\begin{tabular}{|c|c|c|c|c|c|c|}
\hline Facility & $\begin{array}{c}\text { Plant } \\
\text { Capacity } \\
\text { (MTDU/yr) }\end{array}$ & Workers & $\begin{array}{c}\text { Avg } \\
\text { Effective } \\
\text { Dose } \\
(\mathrm{mSv} / \mathrm{yr})\end{array}$ & $\begin{array}{c}\text { Max } \\
\text { Effective } \\
\text { Dose } \\
(\mathrm{mSv} / \mathrm{yr})\end{array}$ & $\begin{array}{l}\text { Collective Dose } \\
\text { (Person-mSv/yr) }\end{array}$ & $\begin{array}{c}\text { Collective Impact } \\
\text { (Person-mSv/MTDU) }\end{array}$ \\
\hline IIFP $^{1}$ & 2300 & 140 & 0.75 & 6.9 & 105 & 0.046 \\
\hline Paducah $^{2}$ & 12000 & 150 & 1.01 & 560 & 152 & 0.0126 \\
\hline \multicolumn{6}{|c|}{ Average Collective Impact (Person-mSv/MTDU) } & $\mathbf{0 . 0 2 9}$ \\
\hline \multicolumn{7}{|c|}{$\begin{array}{l}\text { 1. Environmental Impact Statement (EIS) for Fluorine Extraction and DU Deconversion Facility in Lea County, New Mexico } \\
\text { (NUREG-2113). This EIS was submitted by International Isotopes Fluorine Products, Inc. (IIFP). } \\
\text { 2. EIS for Paducah DU deconversion facility (DOE 2004) }\end{array}$} \\
\hline
\end{tabular}

\section{Occupational Chemical Impacts - Deconversion}

Non-radiological chemical impacts to workers from deconversion operations are estimated based on information presented in Environmental Impact Statements for proposed facilities in the US

According the IIFP EIS (NUREG 2113) no worker exposures exceeding the OSHA Standards for Toxic and Hazardous Substances (29 CFR 1910, Subpart Z) are anticipated. Additionally, handling of all chemicals and wastes would be conducted in accordance with the site Environment, Health, and Safety Program which would conform to 29 CFR 1910 OSHA standards and specify the use of appropriate engineered controls, as well as personnel protective equipment, to minimize potential chemical exposures.

The $\mathrm{U}$ to $\mathrm{UF}_{6}$ conversion process may be used as a surrogate for quantifying potential impacts because many of the same chemicals and similar procedures are used. Ambient chemical concentrations from the Port Hope conversion facility (see Table 6-64) are assumed to be representative of those in the IIFP 
Environmental Impacts, Health and Safety Impacts, and Financial Costs of the Front-End of the Nuclear Fuel Cycle

facility and used to derive an estimate for the chemical impacts to workers from deconversion operations as shown in Table 6-90. The average HQ estimated by this method confirms that occupational fluoride exposures would be only $\sim 10 \%$ of the screening level.

Table 6-90. Occupational Chemical Impact data from Deconversion.

\begin{tabular}{|c|c|c|c|c|}
\hline Quarter & $\begin{array}{l}\text { Average Fluoride Levels } \\
\left(\mathrm{mg} / \mathrm{m}^{3}\right)\end{array}$ & $\begin{array}{l}\text { Max Fluoride Levels } \\
\left(\mathrm{mg} / \mathrm{m}^{3}\right)\end{array}$ & $\begin{array}{l}\text { Screening Level } \\
\quad\left(\mathrm{mg} / \mathrm{m}^{3}\right)\end{array}$ & HQ \\
\hline Q1 2010 & 0.3 & 5.6 & 2.5 & 0.12 \\
\hline Q2 2010 & 0.23 & 4.1 & 2.5 & 0.092 \\
\hline Q3 2011 & 0.3 & 9.9 & 2.5 & 0.12 \\
\hline \multirow{2}{*}{\multicolumn{4}{|c|}{$\begin{array}{r}\text { Average HQ } \\
\text { Average Relative Chemical Impact (Hazard Index/MTDU)2 }\end{array}$}} & 0.11 \\
\hline & & & & $1.54 \mathrm{E}-05$ \\
\hline
\end{tabular}

\section{Occupational Accidents and Injuries Impacts - Deconversion}

Non-radiological non-chemical impacts (accidents and injuries) to workers from deconversion operations are assessed using data presented in the IIFP and Paducah EISs, and, by analogy, from the Port Hope conversion facility.

For the IIFP facility EIS, projections of occupational injuries and illnesses were based on the Bureau of Labor Statistics rate of 2.3 per 100 workers in similar industries and the anticipated size of the labor force. However, as noted above, the Port Hope conversion facility performs a very similar operations and hence the conditions leading to occupational accidents and injuries at this facility are similar to those that will be found in a deconversion facility. The workers per MTNU for Port Hope are also very similar to the workers per MTDU at the IIFP (see tables 6-89 and 6-64). The lost time injury rate averaged between 2007 and 2011 at the Port Hope Facility is 0.32 per 100 full time workers (200,000 person-hours) and the severity (average number of days lost per injury) is 7.0 Port Hope (2012). A summary of the data obtained from the reports is presented in Table 6-91.

Table 6-91. Occupational Accident and Injuries Impact data from deconversion ${ }^{1}$.

\begin{tabular}{|c|c|c|c|c|}
\hline $\begin{array}{l}\text { Average Incidence of } \\
\text { Lost Days per 200,000 } \\
\text { Person-hours }\end{array}$ & $\begin{array}{l}\text { Average Person- } \\
\text { hours at IIFP/yr }\end{array}$ & $\begin{array}{l}\text { Average number } \\
\text { of lost time injury } \\
\text { accidents per year }\end{array}$ & $\begin{array}{l}\text { Average Severity } \\
\text { (days lost per } \\
\text { incident) }\end{array}$ & $\begin{array}{c}\text { Days Lost } \\
\text { per year }\end{array}$ \\
\hline 0.32 & 280,000 & 0.45 & 7.0 & 3.1 \\
\hline \multicolumn{4}{|c|}{ Total Average Accident and Injury Impact (days lost/MTDU) } & $1.4 \mathrm{E}-03$ \\
\hline
\end{tabular}




\section{Public Radiological Impacts - Deconversion}

Radiological impacts to the public from deconversion operations are assessed using data from the EIS of two proposed facilities. The EISs employed full pathway analyses.

No liquid effluent discharges are expected to contain radiological waste. Therefore, no significant radiological impact to the public or the environment is expected from liquid effluents (NUREG 2113).A summary of public dose impacts to the critical receptor and the public within an $80 \mathrm{~km}$ radius is presented in Table 6-92. The doses to the critical receptor, a hypothetical person residing at the fence line, for the two facilities differ by orders of magnitude largely due to the design and location of the cylinder storage area at IIFP. For reference, even the higher IIFP dose to a critical receptor is still a factor of five less than the 10 CFR Part 20.1301 dose limit for a member of the public of $1 \mathrm{mSv} /$ year.

Table 6-92. Public Radiological dose impacts from deconversion.

\begin{tabular}{|c|c|c|c|c|c|}
\hline Facility & $\begin{array}{l}\text { Throughput } \\
\text { (MTDU/yr) }\end{array}$ & $\begin{array}{l}\text { Dose to } \\
\text { Critical } \\
\text { Receptor } \\
(\mathrm{mSv} / \mathrm{yr})\end{array}$ & $\begin{array}{l}\text { Collective Dose } \\
\text { (Person-mSv/yr) }\end{array}$ & $\begin{array}{c}\text { Impact to Critical } \\
\text { Receptor } \\
\text { (mSv/MTDU) }\end{array}$ & $\begin{array}{c}\text { Collective Impact } \\
\text { (Person-mSv/MTDU) }\end{array}$ \\
\hline IIFP $^{1}$ & 2300 & $2.1 \mathrm{E}-01$ & $4.34 \mathrm{E}-07$ & $9.13 \mathrm{E}-05$ & $1.9 \mathrm{E}-10$ \\
\hline Paducah $^{2}$ & 12000 & $3.9 \mathrm{E}-07$ & $4.70 \mathrm{E}-04$ & $3.25 \mathrm{E}-11$ & $3.92 \mathrm{E}-08$ \\
\hline \multicolumn{4}{|c|}{ Average Impacts per MTDU } & 4.57E-05 & 1.97E-08 \\
\hline \multicolumn{6}{|c|}{$\begin{array}{l}\text { 1. The highest dose rate at the } 1600 \mathrm{~m} \text { fence line, } 0.21 \mathrm{mSv} / \mathrm{yr} \text {, is primarily associated with direct radiation from DUF6 } \\
\text { cylinders storage pads. } \\
\text { 2. (NRC 2004) }\end{array}$} \\
\hline
\end{tabular}

\section{Public Chemical Impacts - deconversion}

Non-radiological chemical impacts to the public from deconversion operations are using information provided in the EISs

No IIFP liquid effluent discharges are expected to contain chemical waste. Therefore, there is no significant impact from chemical exposures to members of the public or the environment from liquid effluents (NUREG 2113).

The IIFP EIS (NUREG 2113) identifies release of four fluorides - HF, $\mathrm{SiF}_{4}, \mathrm{BF}_{3}$ and $\mathrm{CaF}_{2}$. The fluoride masses of the four fluoride compounds were combined because they have similar OSHA limits, indicating similar degrees of toxicity. The chemical health impact to the public associated with this release is estimated as shown in Table 6-93.

\section{Ecological Radiological Impacts - Deconversion}

Ecological radiological impacts from deconversion operations are assessed using information from the EISs.

Since no effluent releases will be to the aquatic system, this pathway is removed from consideration, and the radiological impacts to humans is shown above to be small. It is generally true that if humans are protected from radiation sources, the ecosystem is also protected. However, there is a much greater likelihood that animals may reside at or near the fence line. Thus, the ecological impact from radiological 
Environmental Impacts, Health and Safety Impacts, and Financial Costs of the Front-End of the Nuclear Fuel Cycle

July 2013

Table 6-93. Public Chemical Fluoride exposure data from deconversion facilities.

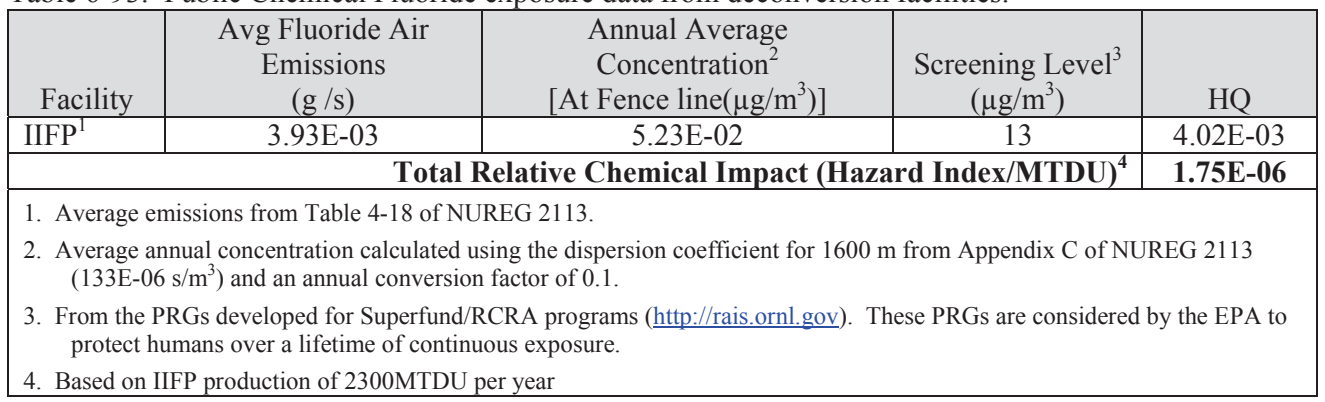

sources is assumed to be equivalent to the direct radiation dose to a critical receptor residing at the IIFP fence line. This is given as .21mSv/yr (NUREG 2113) for an exposure of 2000 hours per year.

Converting $\mathrm{mSv}$ to $\mathrm{mGy}$ (at 1:1) because essentially all of the dose at the fence line is gamma radiation from the cylinder yard and scaling to account for full time residency and converting to mGy yields 0.21 $\mathrm{mGy} / \mathrm{yr} \times 8760 / 2000=0.92 \mathrm{mGy} / \mathrm{yr}$. Considering the IIFP annual production of $2300 \mathrm{MTDU}$ results in an ecological radiological impact estimate of 4E-04 mGY/MTDU.

\section{Ecological Chemical Impacts - Deconversion}

Ecological chemical impacts from deconversion operations are assessed using information from the EISs. No IIFP liquid effluent discharges are expected to contain chemical waste. Therefore, there would be no chemical exposure pathway and no significant impact from chemical exposures to components of the local ecosystem from liquid effluents (NUREG 2113).

The fluoride releases to the atmosphere could be breathed by animals and be deposited onto foliage. Toxicity to animals from fluoride inhalation is not known to be greater than for humans, however there are a few plant species highly sensitive to fluoride deposition. None were identified in NUREG 2113. Therefore concentrations derived for humans (above) are used for estimates of impacts to animals in the ecosystem (see Table 6-93)

\subsubsection{Financial Costs - Deconversion}

Estimates for the price deconversion and disposal services are provided in Table 6-94. Lower and upper bounds are provided to give a sense of the confidence interval associated with the estimate.

Table 6-94. Unit deconversion price estimate ${ }^{1}$.

\begin{tabular}{|c|c|c|}
\hline Reference Value(s) & $\begin{array}{c}\text { Upside } \\
\text { (Low Value) }\end{array}$ & $\begin{array}{c}\text { Downside } \\
\text { (High Value) }\end{array}$ \\
\hline$\$ 6 / \mathrm{kg} \mathrm{DU}$ & $\$ 4 / \mathrm{kg} \mathrm{DU}$ & $\$ 8 / \mathrm{kg} \mathrm{DU}$ \\
\hline $\mathbf{6 E}+\mathbf{3} /$ tDU & $\mathbf{4 E}+\mathbf{3} / \mathbf{t D U}$ & $\mathbf{8 E}+\mathbf{3} / \mathbf{t D U}$ \\
\hline 1. From the 2012 update (INL 2013) to the 2009 AFC CB (Shropshire 2009)
\end{tabular}

This section also provides an illustrative calculation of MTDU production costs associated with the reference Portsmouth deconversion facility identified in Section 5.1.5. Disaggregated capital, operating and decommissioning cost components may be used to estimate the unit deconversion cost by the methodology defined in Section 4.3. [NRC 2007] provides overnight construction, annual operating and 
Environmental Impacts, Health and Safety Impacts, and Financial Costs of the Front-End of the

Nuclear Fuel Cycle

decommissioning costs for Portsmouth as part of the decommissioning funding plan for USEC gaseous diffusion facilities. Given in year 2004 dollars, these costs are inflated to 2012 dollars using the consumer price index. The data and adjusted costs are given in Table 6-95.

Table 6-95. Costs associated with Portsmouth deconversion facility.

\begin{tabular}{|l|l|l|}
\hline \multicolumn{1}{|c|}{ Item } & \multicolumn{1}{|c|}{ Cost (year 2004 \$) } & \multicolumn{1}{c|}{ Cost (year 2012 \$) } \\
\hline Total Overnight Cost $^{1}$ & $\$ 134.0 \mathrm{M}$ & \$164.8 M \\
\hline Operation Cost & & $\$ 29.1 \mathrm{M}$ per year \\
\hline Decommissioning Cost & $\$ 23.8 \mathrm{M}$ per year & \$58.2 M \\
\hline 1. Overnight and operation costs include a 20\% contingency. Operation cost reflects proceeds from HF sale. \\
\hline
\end{tabular}

The construction period identified in [NRC 2007] was 2 years, the operating period was 38 years, and the annual throughput was to be 13,500 tonnes UF6/year, or 9,130 tonnes U/year.

Table 6-96 walks through the calculation of the unit deconversion cost in $\$ / \mathrm{kg} \mathrm{U}$ using the above costs. Values in italics are inputs generic to all technologies. The last six values in the table are calculated according to the procedure defined in Section 4.3.

Although [NRC 2007] utilized a discount rate of 3.5\%, (i.e., $\mathrm{R}=0.035$ ), indicative of government sponsorship of the facility, this will not necessarily pertain to future deconversion facilities. Hence this calculation adopts $\mathrm{R}=0.035$ as well as the upper-bound discount rate recommended by the EMWG, $\mathrm{R}=0.10$, to reflect bounding values for the cost of capital that might be faced by owners and operators of a deconversion facility. Since $\mathrm{R}$ has a substantial impact on the unit cost, the two values appearing in the final row of Table 6-96 may be interpreted as lower and upper bounds. Thus the illustrative deconversion cost at the reference facility is estimated at $\$ 4.18-\$ 5.33 / \mathrm{kg}$ DU.

Table 6-96. Summary of Financial Cost Inputs and Calculation Outcomes.

\begin{tabular}{|c|c|c|c|}
\hline Symbol & Unit & Value $(R=0.05)$ & Value $(R=0.10)$ \\
\hline TOC & $\$$ & \multicolumn{2}{|c|}{$1.64 \mathrm{E}+08$} \\
\hline $\mathrm{OM}$ & $\$ / y r$ & \multicolumn{2}{|c|}{$2.91 \mathrm{E}+07$} \\
\hline $\mathrm{DD}$ & $\$$ & \multicolumn{2}{|c|}{$5.82 \mathrm{E}+07$} \\
\hline$Y_{\text {basis }}$ & - & \multicolumn{2}{|c|}{2012} \\
\hline $\mathrm{T}_{\mathrm{c}}$ & Yr & \multicolumn{2}{|c|}{2} \\
\hline $\mathrm{T}_{\mathrm{o}}$ & $\mathrm{Yr}$ & \multicolumn{2}{|c|}{38} \\
\hline M & $\mathrm{kg} \mathrm{U} / \mathrm{yr}$ & \multicolumn{2}{|c|}{$9.13 \mathrm{E}+06$} \\
\hline$f_{i}$ & - & \multicolumn{2}{|c|}{0.5 for ea. year } \\
\hline$R$ & $1 / y r$ & 0.035 & 0.10 \\
\hline$r_{S F}$ & $1 / y r$ & 0.035 & 0.10 \\
\hline $\mathrm{AF}$ & $1 / \mathrm{yr}$ & 4.80E-02 & $1.03 \mathrm{E}-01$ \\
\hline IDC & $\$$ & $8.71 \mathrm{E}+06$ & $2.54 \mathrm{E}+07$ \\
\hline SFF & $1 / \mathrm{yr}$ & $1.30 \mathrm{E}-02$ & $2.75 \mathrm{E}-03$ \\
\hline $\mathrm{ACC}$ & $\$ / y r$ & $8.28 \mathrm{E}+06$ & $1.95 \mathrm{E}+07$ \\
\hline ADD & $\$ / y r$ & $7.56 \mathrm{E}+05$ & $1.60 \mathrm{E}+05$ \\
\hline $\mathrm{UC}$ & $\$ / \mathrm{kg} \mathrm{U}$ & $4.18 \mathrm{E}+00$ & $5.33 \mathrm{E}+00$ \\
\hline
\end{tabular}


Environmental Impacts, Health and Safety Impacts, and Financial Costs of the Front-End of the Nuclear Fuel Cycle

\subsection{FEFC Impacts - Thorium}

Estimates of environmental, safety and health impacts from extraction and refining of thorium from monazite are summarized in Table 6-97 below. Sufficient data were not identified to estimate impacts from occupational accidents and illnesses or from chemical exposures to either workers or members of the public. However, analogous to uranium, the process for extraction and refining Th could proceed through either caustic or acidic methods. Based on the descriptions of the processes in Appendix B, chemical impacts to workers and the public are not expected to be greater than those estimated for uranium extraction and refinement. The bases for the environmental and health and safety estimates are provided in sections 6.6.1 and 6.6.2.

\subsubsection{Environmental Impacts - Thorium Extraction and Refining}

Land and water use estimates associated with the conversion process are taken directly from Table 5-9 and converted to the units shown above. Estimates for energy consumption and $\mathrm{CO} 2$ emissions from the representative Th extraction and refining process identified in Section 5.6 are developed below using the approach described in Section 4.1.3. The direct and embodied energy inputs from Table 5-9 (reproduced in Table 6-98) are converted to GJ per MTNU in the UF6 product and broken down into their constituent energy carriers using the conversion factors shown in Table 6-99. The result, shown in Table 6-100, provides the total energy intensity of the thorium extraction and refining process broken down by energy carriers. The $\mathrm{CO}_{2}$ emission factors for each energy carrier (Appendix B) are then applied to obtain the total $\mathrm{CO} 2$ emissions for the process.

Table 6-97. Summary of Impacts from Thorium Extraction and Refining

\begin{tabular}{|l|c|}
\hline & Thorium Impacts \\
\hline Normalization Unit & MT Th \\
\hline 4.1 Environmental Impacts & See Section 6.6.1 \\
\hline 4.1 .1 Land Use (km²) & negligible \\
\hline 4.1 .2 Water Use - Net (ML) & $1.1 \mathrm{E}-01$ \\
\hline 4.13 Energy Use and $\mathrm{CO}_{2}$ Emissions & $2.2 \mathrm{E}+02$ \\
\hline Energy Use (GJ) & $2.0+04$ \\
\hline CO2 Emissions kG CO 2 & See Section 6.6 .2 \\
\hline 4.2 Health and Safety Impacts: & $3.8 \mathrm{E}+00$ \\
\hline 4.2 .1 Occupational Radiological (person- mSv) & see note 1 \\
\hline 4.2 .2 Occupational Chemical (Hazard Index) & see note 1 \\
\hline 4.2 .3 Occupational Accident \& Illness (lost days) & $1.3 \mathrm{E}-05$ \\
\hline 4.2 .4 Public Radiological & $5.2 \mathrm{E}-04$ \\
\hline Dose to Critical Receptor (mSv) & \\
\hline Collective Dose (person - mSv) & \\
\hline $\begin{array}{l}\text { 1. Sufficient data not available to support a quantitative estimate. Qualitatively, these impacts are expected to be equal or less } \\
\text { per MTTh than those estimated per MTNU }\end{array}$ \\
\hline
\end{tabular}


Environmental Impacts, Health and Safety Impacts, and Financial Costs of the Front-End of the

Nuclear Fuel Cycle

Table 6-98. Main product and Energy and Material Inputs to Thorium Extraction and Refining

\begin{tabular}{|c|c|}
\hline & Process Inputs per Table 5-6 \\
\hline \multicolumn{2}{|l|}{ Direct Energy Inputs } \\
\hline Electricity (MWh/MTTh) & $8.97 \mathrm{E}+00$ \\
\hline Natural Gas (L/MTTh) & $0.00 \mathrm{E}+00$ \\
\hline Coal (MT/MTTh) & $0.00 \mathrm{E}+00$ \\
\hline Distillate Fuel (Diesel) (MT/MTTh) & $0.00 \mathrm{E}+00$ \\
\hline Gasoline (L/MTTh) & $2.83 \mathrm{E}+03$ \\
\hline \multicolumn{2}{|l|}{ Embodied Energy Inputs } \\
\hline Nitric Acid, HNO3 (MT/MTTh) & $2.61 \mathrm{E}+00$ \\
\hline Hydrochloric Acid, $\mathrm{HCl}$ (MTTh) & $8.42 \mathrm{E}+00$ \\
\hline Tributyl Phosphate, TBP (MT/MTTh) & $7.05 \mathrm{E}-02$ \\
\hline Hexane, C6H14 (MT/MTTh) & $1.59 \mathrm{E}-01$ \\
\hline Hydrogen Peroxide, $\mathrm{H}_{2} \mathrm{O}_{2}$ (MTTh) & $1.14 \mathrm{E}-02$ \\
\hline Sodium Hydroxide, $\mathrm{NaOH}$ (MTTh) & $2.58 \mathrm{E}+01$ \\
\hline Trisodium Phosphate, TSP (MTTh)* & $-8.43 \mathrm{E}+00$ \\
\hline \multicolumn{2}{|c|}{$\begin{array}{l}\text { * The embodied energy input associated with TSP is shown as negative because TSP is a by-product o } \\
\text { this process, thus embodied energy is recovered in the form of TSP production. Other by-products of } \\
\text { the process do not contain significant recoverable energy. }\end{array}$} \\
\hline
\end{tabular}




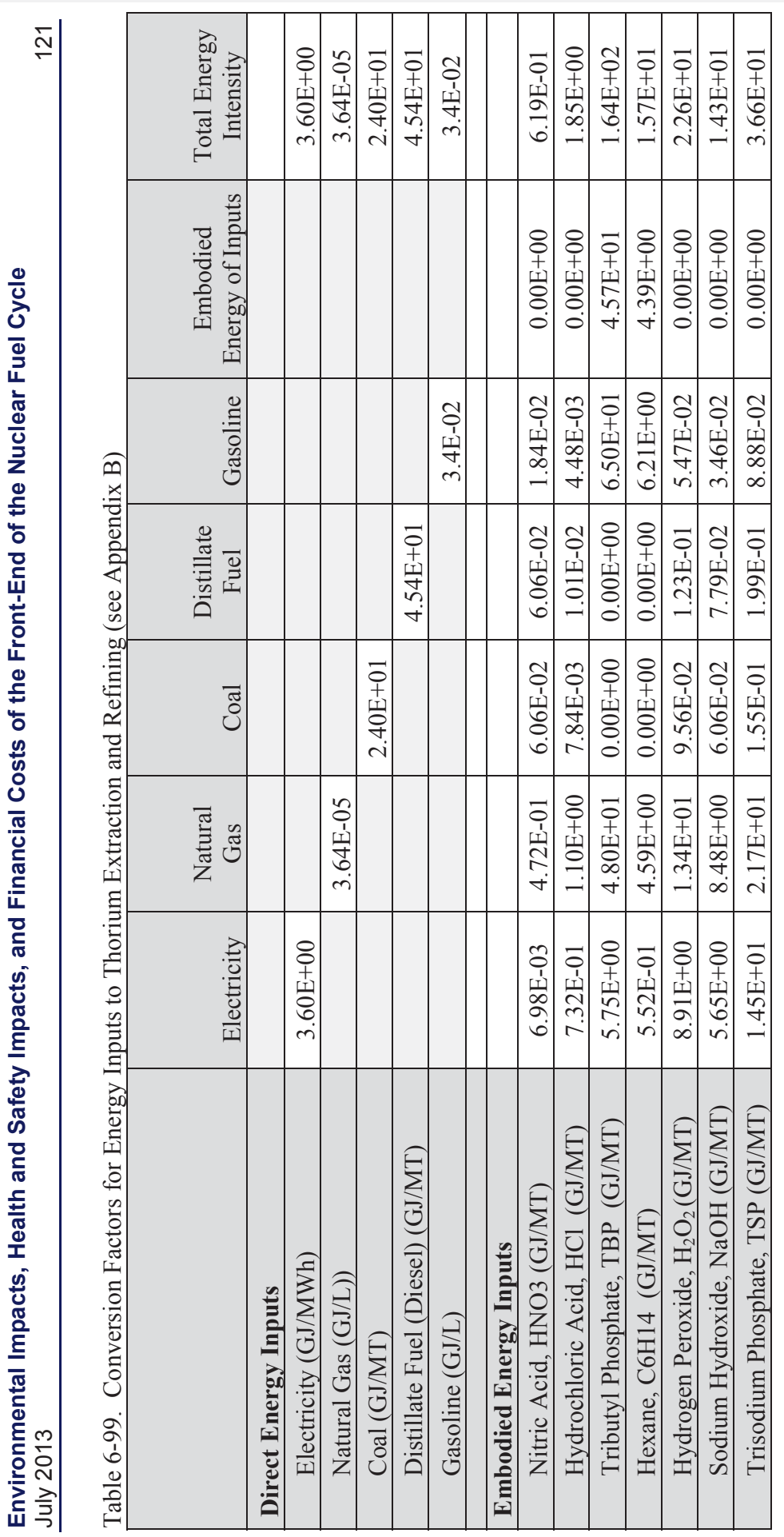




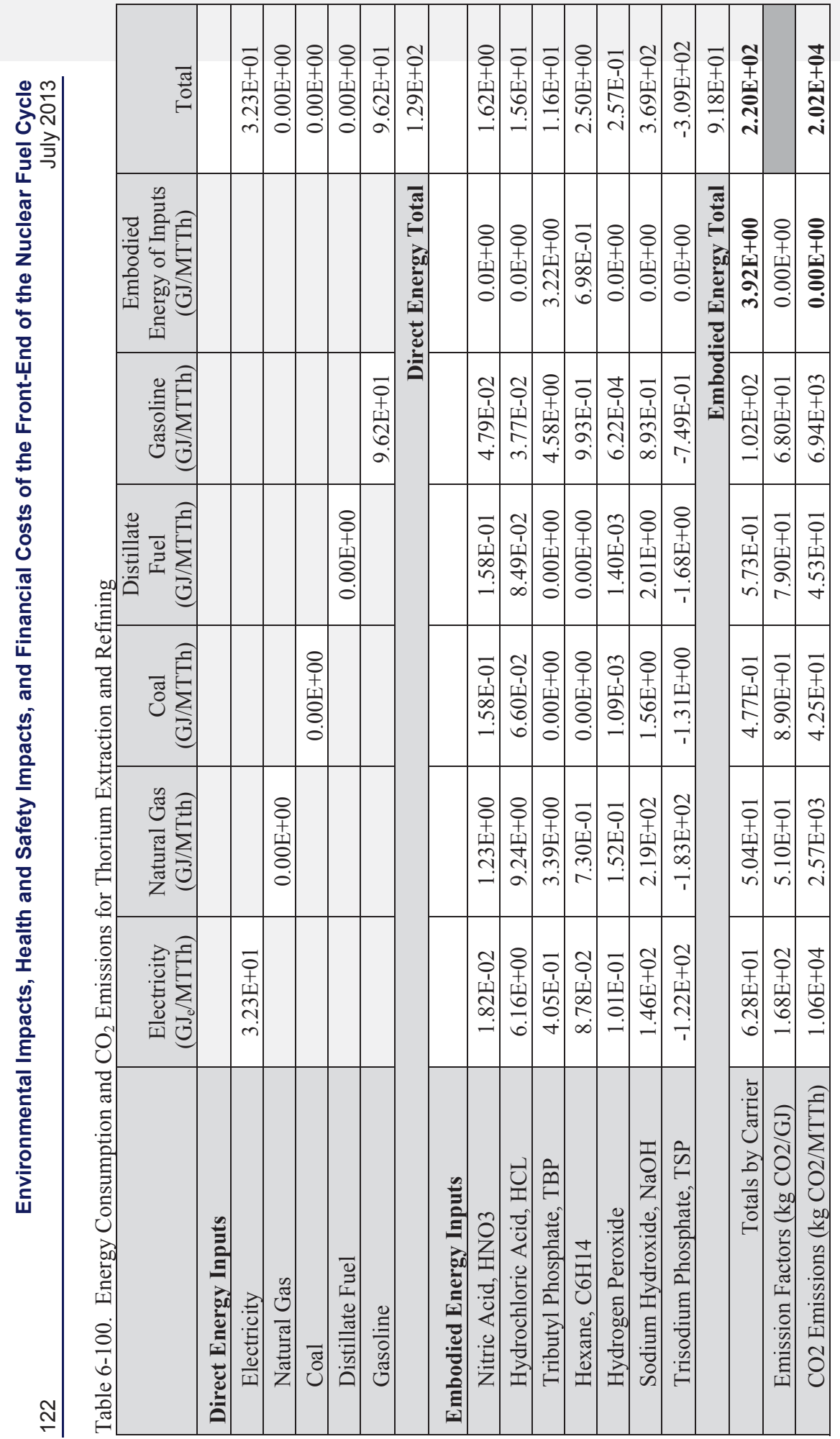


Environmental Impacts, Health and Safety Impacts, and Financial Costs of the Front-End of the Nuclear Fuel Cycle

\subsubsection{Health and Safety Impacts - Thorium Extraction and Refining}

Health and safety issues associated with Th extraction activities are different than for uranium because the half-life of This much longer than U, the half-life of its daughter products are shorter, and the physical form of the Th is much less soluble and mobile. On the other hand, the decay products of thorium come to equilibrium much more quickly than for uranium, and some thorium decay products emit high-energy gamma rays which makes the dose rate from thorium about 100 times that of natural uranium. As a result of these differences, impacts associated with mining and handling of REE-bearing materials may serve as a better analog for estimating impacts than would uranium.

\section{Occupational Radiological Impacts}

Incremental Collective Worker Dose: Although data are scanty, India has continued to recover REEs for the current commercial market and, as a result of their longstanding interest in the thorium fuel cycle, they have also separated and stored thorium and uranium for future use. Haridsan et al $(2008,2010)$ collected data and analyzed workplace radiation exposures at a monazite-based REE plant over a period of approximately two years. The chemical processing of monazite and thorium involves operational radiological safety challenges of varying magnitudes. These parts of the front end of the nuclear fuel cycle involve average per capita occupational exposures in the range of 3.0-7.8 $\mathrm{mSv}$ per year.

Representative exposures for rare earth production were in the range of $0.3-1.0$ person $\cdot \mathrm{mSv}$ with a mean of 0.6 person $\cdot \mathrm{mSv}$ per tonne of rare earth concentrate produced. In terms of thorium hydroxide production, the dose was approximately 6.2 person $\cdot \mathrm{mSv}$ per tonne of thorium hydroxide $(100 \%)$ produced from monazite, given the just under $10 \%$ Th concentration in the original ore. Thus production of thorium hydroxide from monazite results in a collective dose of approximately 6.2 person$\mathrm{mSv} / \mathrm{MTTh}(\mathrm{OH})_{4}(8.0$ person $\mathrm{mSv} / \mathrm{MTTh})$. This collective dose would be attributable to the REE production.

The thorium hydroxide slurry represents an intermediate step if the final goal is thorium oxalate. While the representative refining process used in the document considers thorium nitrate as the final product, both the oxalate and nitrate forms are typical and effective forms for long-term storage. The difference between these two forms is not expected to contribute significantly to the associated occupational dose. [Haridsan 2010] also documents the incremental dose associated with processing thorium hydroxide to generate refined thorium oxalate (and a uranium product), which is 0.9 person $\mathrm{mSv} / \mathrm{MT}$ thorium oxalate. This is equivalent to 1.6 person $\mathrm{mSv} / \mathrm{MTTh}$. In the event that all thorium is produced as a by-product of REE production, only the incremental portion, 1.6 person $\mathrm{mSv} / \mathrm{MTTh}$, would be attributable to thorium production.

In the alternative scenario in which the titanium (ilmenite) processing occurs (assuming the same thorium ore concentration as above in the REE example), monazite would not normally be processed at all and the impacts would be the sum of the two step process: first producing thorium hydroxide from the monazite and then reducing it to thorium oxalate $(8.0$ person $\mathrm{mSv} / \mathrm{MTTh}+1.6$ person $\mathrm{mSv} / \mathrm{MTTh}=9.6$ person $\mathrm{mSv} / \mathrm{MTTh}$ ). If processed however, the monazite would produce both REE and Th. Hence, the associated impacts were allocated equally over these two co-products. As shown in Appendix F, the potential Th supply from by-products worldwide is approximately a 30\%/70\% mix from REE and ilmenite processing. Hence the estimated impact is estimated as

$$
(0.3)(1.6)+(0.7)(9.6 / 2)=3.84 \text { person } \mathrm{mSv} / \mathrm{MTTH}
$$




\section{Public Radiological Impacts - Milling and Refining of Thorium}

Reports of population dose resulting from REE recovery based on methods described in Section 4.2 have not been identified. However, some work was carried out in the past to evaluate public dose as a result of thorium mining and milling in the US. During the late 1970s a number of reports attempted to determine the range of impacts associated with the use of thorium in future nuclear fuel cycles. Among these, [Meyer 1979] reviewed the then current estimates of the extent of thorium resources and estimated the public radiological impact of an operating a thorium mine and mill in the Lemhi Pass district of Idaho and Montana. These authors combined both mining and milling into their single evaluation. Their evaluation is summarized here to provide a contrast with the uranium mining assessments in Sections 6.1 and 6.2., as the work of [Meyer 1979] is contemporaneous with the data derived from the [EPA 1983] document that highlighted reference open pit and underground uranium mines.

The model open pit thorium mine and mill produce and process 1600 metric tons of ore per day having and average $\mathrm{ThO}_{2}$ content of $0.5 \%$. The milling efficiency is $91 \%$ followed by $99.5 \%$ recovery in refining. Thus the daily production of Thorium heavy metal is $6.36 \mathrm{MTTh}$, and with 300 days per year production the annual production is 1910MTTh/y. To support a dose analysis like that portrayed in Section 4.2 for releases to the atmosphere, the facility boundary was taken to be 1600 meters and the population within an $80 \mathrm{~km}$ radius of the Lemhi pass site was estimated to be $\sim 30,000$ people. Impacts estimated for the combined thorium mine and mill are presented in Table 6-101. Data presented in Table 6-101 were calculated with methods contemporary with data obtained from [EPA 1983] for the open pit uranium mine.

Mine operations were not clearly separated from the refining/milling operation in the analysis by Meyer et al (1979), however, the source term for mine operations dominated in the presentation of individual effluents and it is estimated that mine operations contribute approximately $2 \mathrm{x}$ greater dose than mill and refinery operations. Limited data forces this comparison to a less relevant hypothetical thorium mine rather than a more desirable rare earth processing model. This assumption is more speculative than those made in other sections, so there is more uncertainty in this value than the one derived for occupational dose.

Table 6-101. Radiological Dose Impacts to Populations Surrounding Lemhi Pass Thorium Mine and Mill.

\begin{tabular}{|l|c|c|c|c|c|}
\hline & $\begin{array}{c}\text { Annual } \\
\text { Production } \\
\text { (MTTh/year) }\end{array}$ & $\begin{array}{c}\text { Population } \\
\text { (Persons) }\end{array}$ & $\begin{array}{c}\text { Critical } \\
\text { Receptor } \\
\text { TEDE } \\
\text { (mSv/yr) }\end{array}$ & $\begin{array}{c}\text { Average } \\
\text { Annual } \\
\text { TEDE } \\
\text { (mSv/yr) }\end{array}$ & $\begin{array}{c}\text { Average Annual } \\
\text { Collective TEDE } \\
\text { (Person-mSv/yr) }\end{array}$ \\
\hline Th Open Pit Mine and Mill & 1910 & 30,000 & $2.4 E-02$ & $3.4 E-05$ & 1.0 \\
\hline \multicolumn{7}{|c|}{ Portion of dose attributable to milling and refining operations } & 0.33 \\
\hline Total Impact to Critical Receptor (mSv/MTTh) & $\mathbf{1 . 2 6 E - 0 5}$ \\
\hline Total Collective Impact (Person-mSv/MTTh) & $\mathbf{5 . 2 4 E - 0 4}$ \\
\hline Source: Meyer et al 1979
\end{tabular}


Environmental Impacts, Health and Safety Impacts, and Financial Costs of the Front-End of the Nuclear Fuel Cycle

\section{CONCLUSIONS AND RECOMMENDATIONS}

Sufficient and credible data was normally available to reliably estimate land, water, and energy use for existing FEFC processes. Similarly, available data supports credible estimates of industrial and radiological safety impacts to workers. Quantifying public and the ecological impacts proved to be much more problematic. Available data is relatively sparse and the data found typically showed exposures orders of magnitude below any threshold of concern. Further, public and ecological impacts were found to vary considerably from site-to-site due to factors such as proximity of the facility fence, local hydrology and weather patterns, emission stack height, etc. In addition, site-to site variability in the collective dose is strongly influenced due to the local population density. Lastly, design features and other engineering and administrative controls are also site-specific and are typically specified to assure impacts are acceptable. For these reasons, impacts resulting from public and ecological exposure were not found to be a reliable indicator of the implicit hazard associated with FEFC processes.

An upcoming fuel cycle options evaluation and screening will compare a number of proposed fuel cycles. Each proposed fuel cycle will be described by a fuel cycle data package (FCDP) that includes mass flows and other descriptive information for each stage of each fuel cycle. Information from these FCDPs will be used to identify fuel-cycle-specific conversion factors that can be used to scale each of the impact estimates developed in this study (see Table 6-1) to an impact per unit electricity produced by the fuel cycle being evaluated. Each impact can then be summed across all FEFC processes to provide an estimate of the total FEFC impact for the specific fuel cycle.

As an example, the normalized impacts from Table 6-1 are repeated below in Table 7-1 along with fuelcycle-specific conversion factors for a simple once-through PWR system using $4.2 \%$ enriched UOX fuel and $0.25 \%$ DU tails assay. Using the conversion factor shown in the top row, each of the impacts (i.e. rows) in the table is re-normalized to show the total FEFC impacts per $\mathrm{GW}_{\mathrm{e}}{ }^{*} \mathrm{Yr}$ electricity produced from this particular fuel cycle. By inserting fuel-cycle-specific conversion factors, the same procedure can be applied for estimating FEFC impacts from other proposed fuel cycles.

Follow-on work is needed to produce similar impact estimates for the remaining phases of the nuclear fuel cycle in order to enable comparative evaluations of the impacts across the full fuel cycle. 


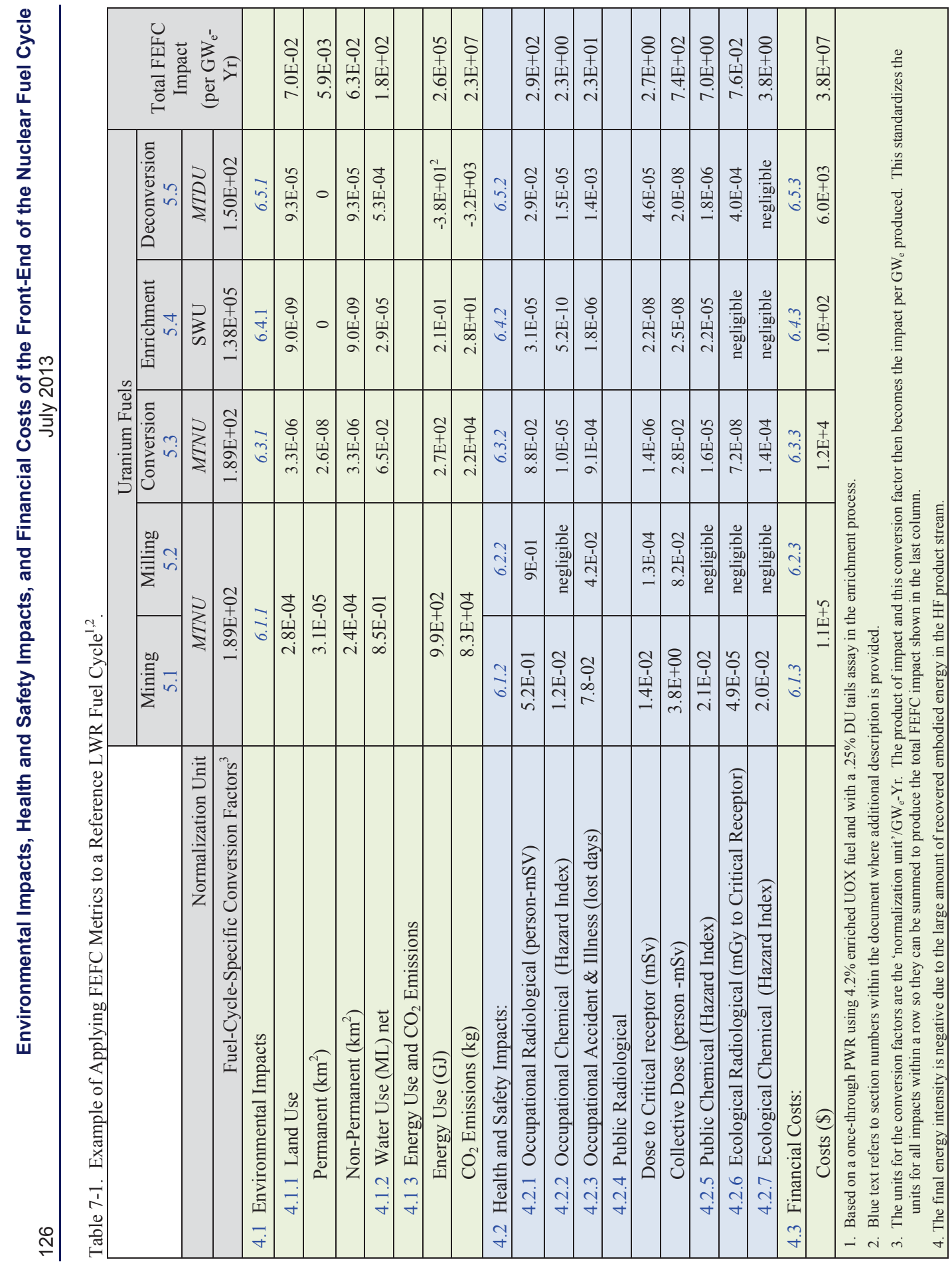


Environmental Impacts, Health and Safety Impacts, and Financial Costs of the Front-End of the Nuclear Fuel Cycle

\section{REFERENCES}

[AEC 1974 (WASH-1248)] US Atomic Energy Commission (AEC) (1974). Environmental Survey of the Uranium Fuel Cycle. Other Information: Orig. Receipt Date: 31-DEC-74, US Department of Energy (US DOE), WASH-1248: Medium: ED; Size: Pages: 277.

[Ahmed 2007] J. U. Ahmed, Occupational Radiological Safety in Uranium Mines and Mills, IAEA Bulletin 23 (2) (September).

[Areva 2007] "Rapport environmental, social, sociétal, de sûreté nucléaire et de radioprotection 2007" Accessed at:http://www.areva-np.com/common/liblocal/docs/Environnement/RAPPORT tricastin-TSN2007\%20bass\%20def.pdf

[Areva (2010)] Données chiffrées et informations sur la sûreté nucléaire et la radioprotection du site AREVA Tricastin: Edition 2010.

http://www.epa.sa.gov.au/xstd_files/Radiation/Other/olympic_annual_2009.pdf).

[Areva 2011] Areva (2011).AREVA and Niger - A Sustainable

Partnership.http://www.areva.com/mediatheque/liblocal/docs/pdf/activites/mines/pdf-

Niger_a\%20Sustainable\%20Partnership-va.pdf.

[Areva 2011a] Données chiffrées et informations sur la sûreté nucléaire et la radioprotection du site AREVA Tricastin, Édition 2011.

http:/www.areva.com/mediatheque/liblocal/docs/pdf/activites/amont/vallee-du-rhone/DonneesChiffreesTSN-Tricastin-2011.pdf

[AREVA, 2011b] “Mise a jour de l”Evaluation des Risques Sanitaires de la plateforme AREVA du Tricastin”, PAR-RAP-10-03797D, 10 fevrier 2011. Accessed at

http://www.areva.com/mediatheque/liblocal/docs/pdf/activites/amont/enrichissement/ERS\%20plateforme $\% 20$ AREVA\%20Tricastin.pdf

[AREVA 2012] AREVA Corporate Website, available: http://www.AREVA.com/EN/operations757/conversion-the-fluorination-of-uranium-in-2-stages.html, web page accessed May 28, 2012.

[Areva 2012] Areva.(2012). "Community Involvement - Areva in Niger."Retrieved August, 2012, from http://www.areva.com/EN/group-1276/commitment-local-economic-and-social-development.html.

[Areva 2012a] Areva corporate website, "Comurhex Expansion: Comurhex II," http://www.areva.com/EN/operations-806/the-comurhex-ii-project-modernization-of-the-industrialconversion-facility.html.

[Areva Website] 'Cominak: Operation of an Unparalleled Mine'. http://www.areva.com/EN/operations602/cominak-operating-the-largest-underground-mine-in-the-world.html Accessed July 10, 2012.

[ARPANSA 2005] "Radiation Protection and Radioactive Waste Management in Mining and Mineral Processing” Australian Radiation Protection and Nuclear Safety Agency, August 2005, from:

http://www.arpansa.gov.au/pubs/rps/rps9.pdf

[Ashbrook 1980] A. W. Ashbrook, B. C. Smart, "A Review and Update of Refining Practice in Canada," in Production of Yellowcake: Proceedings of an Advisory Group Meeting,Paris, June 5-8 1979, IAEA Vienna, 1980.

[ASTM International, 2003], E1943-98 Standard guide for remediation of ground water by natural attenuation at petroleum release sites: ASTM Book of Standards, v. 11.04, 43 p.)

[Bardi 2010] Bardi, U., Extracting Minerals from Seawater: An Energy Analysis,Sustainability2010, 2, 980-992. 
[Barthel, 2005] Fritz H. Barthel, Thorium and Unconventional Uranium Resources, presented at the IAEA Technical Meeting on "Fissile Materials Management Strategies for Sustainable Nuclear Energy", 12-15 September 2005, Vienna, Austria.

[Birch \& Cary 1996] Birch, M. E. and R. A. Cary (1996)."Elemental Carbon-Based Method for Monitoring Occupational Exposures to Particulate Diesel Exhaust."Aerosol Science and Technology25(3): 221-241.

[BHP Billiton 2009] BHP Billiton Ltd. (2009). Annual Radiation Protection Report (1 JULY 2008 - 30 JUNE 2009) at Olympic Dam, Australia.

[Boydell 1980] Boydell, D. W., "Impurities in Uranium Process Solutions," in Production of Yellowcake: Proceedings of an Advisory Group Meeting,Paris, June 5-8 1979, IAEA Vienna, 1980.

[Cameco (2010a)] Quarterly Compliance Report: Port Hope Conversion Facility Operating License FFOL-3631.0/2012 First Quarter 2010.

[Cameco (2010b)] Quarterly Compliance Report: Port Hope Conversion Facility Operating License FFOL-3631.0/2012 Second Quarter 2010.

[Cameco (2011)] Quarterly Compliance Report: Port Hope Conversion Facility Operating License FFOL-3631.0/2012 Third Quarter 2011.

[[Cameco (2012)] 2011 Annual Compliance Monitoring \& Operational Performance Report, Port Hope Conversion Facility. Available at: http:/www.cameco.com/fuel_services/documents/?section=1

[Cameco 2012] "Cameco Resources Smith Ranch Project Technical Report, February 2012, NRC Document ML12163A068.

[Canadian Nuclear Safety Commission 2012] "Proposed Comprehensive Study Report for Cameco Corporation's Proposed Redevelopment of the Port Hope Conversion Facility (Vision 2010), CLEAR 0603-22672, May 2012. Accessed at http://www.ceaa.gc.ca/050/documents/52196/52196E.pdf

[CDC 2012].Centers for Disease Control and Prevention. R. D. Daniels and D. C. Sylvain, Evaluation of Exposure to Radon Progeny During Closure of Inactive Uranium Mines - Colorado, HETA 2011-00903161 (July).

[CNSC 2009] Canadian Nuclear Safety Commission (CNSC) (2009). Occupational Dose Data for Major Canadian Nuclear Facilities 2001-07. INFO-0775 (available at http://nuclearsafety.gc.ca/pubs_catalo gue/uploads/INFO 0775 e.pdf).

[Crow Butte Resources, Inc. 2007], "Environmental Assessment for Amendment to source Materials License SUA-1534 for a Central Processing Plant Upgrade, Adams Assession No. ML07236087.

[Denison 2007] Denison Mines Corporation (2007). “White Mesa Uranium Mill Environmental Report, Denison Mines Corp, Denver Co., 28 February 2007.

[Denison 2007] Denison Mines Corporation (2007). White Mesa Uranium Mill License Renewal Application, State of Utah. License No. UT1900479 (Volumes 1-5).

[Denison 2009] Denison Mines (2009). Request to Provide Information Pursuant to the Clean Air Act Denison Mines (USA) Corp.- White Mesa Uranium Mill, Banding Utah. U. E. P. A. U. EPA). Denver, CO, USA, Denison Mines: 26 pgs.

[Denison 2010] Denison Mines Corporation. (2010, (Last Update Date July 13 2010)). "White Mesa Mill." Retrieved August, 2012, from http://www.denisonmines.com/Document/Details/96.

[Denison 2010a] "Denison Mines Annual Information Form 2010. Web source assessed on 22 January 2013 
Environmental Impacts, Health and Safety Impacts, and Financial Costs of the Front-End of the Nuclear Fuel Cycle

athttp://www.denisonmines.com/s/SiteResources/data/MediaArchive/pdfs/annual_information_forms/fina 1\%20aif\%20-\%20march\%2028,\%202011.pdf

[Denison 2011] Denison Mines (2011).Annual Information Form 2010.March 28 Publication Date.

[Denison 2012] Denison Mines and Energy Fuels Inc. (April 2012). "Energy Fuels Inc. \& Denison Mines (USA) (Investor Presentation)." Retrieved August, 2012 from

http://www.denisonmines.com/s/SiteResources/data/MediaArchive/pdfs/investor_presentations/efrdml\%20investor\%20presentation_final_web.pdf.

[DOE 1999a] DOE, "Record of Decision for Long-Term Management and Use of Depleted Uranium Hexafluoride," Federal Register, Vol. 64, No. 153, page 43358, August 10, 1999. (OR Federal Register Document No. 99-20471)

[DOE 1999b] DOE, "Final Plan for the Conversion of Depleted Uranium Hexafluoride," As Required by Public Law 105-204, 1999.

DOE 2002, A Graded Approach for Evaluating Radiation Doses to Aquatic and Terrestrial Biota. DOESTD-1153-2002

"Estimates of Radiation Doses to Members of the Public from Cotter 2008 Operations," Tetra Tech, Fort Collins, Co., Project 181865, 22 June 2009.

[DOE 2004] Final Environmental Impact Statement for construction and operation of a depleted uranium hexafluoride conversion facility at the Paducah, Kentucky site, DOE/EIS-0359.

[DOE 2004a] DOE, "Record of Decision for Construction and Operation of a Depleted Uranium Hexafluoride Conversion Facility at the Paducah, KY, Site," Federal Register, Vol. 69, No. 143, page 44645, July 27, 2004. (Federal Register Document No. 04-17050)

[DOE 2004b] DOE, "Record of Decision for Construction and Operation of a Depleted Uranium Hexafluoride Conversion Facility at the Portsmouth, OH, Site," Federal Register, Vol. 69, No. 143, page 44649, July 27, 2004. (Federal Register Document No. 04-17048)

[DOE 2005] US Department of Energy, "Nuclear Material Safeguards for Uranium Enrichment Plants," DOE/ORNL Technical Report ORNL ISPO-347/R6, 2005.

[DOE 2012] Department of Energy DUF6 Management Information Network, "DUF6 Management Information Network," http://web.ead.anl.gov/uranium/index.cfm, website accessed June 24, 2012.

[DOE 2013] U.S. Department of Energy (DOE), "Nuclear Fuel Cycle Options Evaluation and Screening - Approach and the Evaluation Metrics - DRAFT" FCRD-FCO-2012-000322, January $11^{\text {th }} 2013$ ).

[Doka 2011] Doka, Gabor. “Life Cycle Inventory of Generic Uranium In-Situ Leaching.” Zurich, November 2011. Paul Scherer Institute.

[Duport 2002] Duport, P. (2002). "Is the Radon Risk Overestimated? Neglected Doses in the Estimation of Risk of Lung Cancer in Uranium Underground Miners."Radiation Protection Dosimetry", Vol 98(3): 329-338

[Eggert 2011] Primary Uranium Supply: An Assessment of the Present (Eggert, Gilmore, Segal, 2011)

[EIA 2011] Energy Information Administration, "Model Documentation Report: Industrial Demand Module of the National Energy Modeling System,” Technical Report DOEEIA-M064(2011), 2011.

[EMWG 2007] Economic Modeling Working Group (EMWG) of the Generation IV International Forum, "Cost Estimating Guidelines for Generation IV Nuclear Energy Systems," OECD Nuclear Energy Agency and Gen-IV International Forum Report, 2007. 
[Enercon 2012] Enercon Federal Services, Inc. "Dry Conversion Process Data," memorandum to DOE Office of Nuclear Energy, July 16, 2012.

[Enercon 2012] Enercon Federal Services, Inc. “Dry Conversion Process Data,” July $16^{\text {th }}, 2012$.

[EPA 1983] US Environmental Protection Agency (US EPA) (1983). Potential Health and Environmental Hazards of Uranium Mine Wastes: Report to the Congress of the United States. Washington, D.C., Office of Radiation Programs, .Volumes 1-3: EPA 520/1-6-83-007

[EPA 1989] U.S. Environmental Protection Agency (US EPA) (1989).Risk Assessment Guidance for Superfund: Volume I - Human Health Evaluation Manual, (Part A) EPA/540/1-89/002.Office of Emergency and Remedial Response, U.S. Environmental Protection Agency, Washington, D.C.

[EPA 1991] U.S. Environmental Protection Agency, Risk Assessment Guidance for Superfund: Volume I - Human Health Evaluation Manual (Part B, Development of Risk-based Preliminary Remediation Goals). OSWER Directive 9285.7-01B.Office of Emergency and Remedial Response, Washington, D.C. 1991.

[EPA 1995] US Environmental Protection Agency (US EPA) (1995). Extraction and Beneficiation of Ores and Minerals: Volume 5: Uranium. Technical Resource Document: EPA-530-R-94-032.

[EPA 1997] US Environmental Protection Agency (US EPA) (1997). Health Effects Assessment Summary Tables (HEAST) FY 1997 Update. (July 1997) EPA-540-R-97-036.

[EPA 2012] U.S. Environmental Protection Agency. "Rare Earth Elements: A Review of Production, Processing, Recycling, and Associated Environmental Issues,” EPA 600/R-12/572 (December).

[EPA 2004] US Environmental Protection Agency (US EPA) (2004).Draft - Aquatic Life Water Quality Criteria for Selenium, EPA-822-D-04-001.

[EPA 2007] US Environmental Protection Agency (US EPA). (2007, Last Updated November 6, 2007). "Nickel Compounds. "Retrieved August, 2012, from http://www.epa.gov/ttn/atw/hlthef/nickel.html.

[EPA 2008] US Environmental Protection Agency (US EPA) (2008). Technologically Enhanced Naturally Occurring Radioactive Materials from Uranium Mining (Volume 1): Mining and Reclamation Background. Washington, D.C., Office of Radiation \& Indoor Air, Radiation Protection Division, EPA402-R-08-005 (Volume 1).

[EPA 2011] US Environmental Protection Agency (US EPA) (2011).An Overview of Methods for EPA's National-Scale Air Toxics Assessment.

[EPA 2012] US Environmental Protection Agency (US EPA). (2012, Last Updated June 5, 2012).

"Water: Drinking Water Contaminants - National Primary Drinking Water Regulations (Primary

Standards) and Secondary Drinking Water Regulations (Secondary Standards)." Retrieved August, 2012, from http://water.epa.gov/drink/contaminants/index.cfm\#List.

[EPA 2012a] US Environmental Protection Agency (US EPA). (2012, (Last Updated August 8, 2012)). "Water: Unregulated Contaminant Monitoring Rule 3: Methods and Contaminants for the Unregulated Contaminant Monitoring Rule 2 (UCMR3). "Retrieved August, 2012, from

http://water.epa.gov/lawsregs/rulesregs/sdwa/ucmr/ucmr3/methods.cfm.

[EPA 2012b] US Environmental Protection Agency (US EPA). (2012, Last Updated July 16, 2012).

"National Ambient Air Quality Standards (NAAQS)."Retrieved August, 2012, from www.epa.gov/air/criteria.html.

[EPA 2012c] US Environmental Protection Agency (US EPA). (2012). "Regional Screening Levels for Chemical Contaminants at Superfund Sites." Retrieved August, 2012, from http://epa-prgs.ornl.gov/cgibin/chemicals/csl_search. 
Environmental Impacts, Health and Safety Impacts, and Financial Costs of the Front-End of the Nuclear Fuel Cycle

July 2013

[EPA 2013] US Environmental Protection Agency (US EPA). (2013, Last Revised 01-23-2012).

"Ecological Risk Assessment: Freshwater Screening Benchmarks." Retrieved January 2013, from http://www.epa.gov/reg3hwmd/risk/eco/btag/sbv/fw/screenbench.htm\#table.

[EPA 2013a] US Environmental Protection Agency (US EPA). (2013, Last revised 01-08-2013).

"National Recommended Water Quality Criteria: Aquatic Life Criteria Table." Retrieved January, 2013, from http://water.epa.gov/scitech/swguidance/standards/criteria/current/index.cfm\#altable.

[ERA 2005] Energy Resources of Australia Ltd. (ERA) (2005).ERA Annual Report 2005 (Ranger Mine). (available at http://www.energyres.com.au/documents/2005_Annual_Report.pdf).

[ERA 2006] Energy Resources of Australia Ltd. (ERA) (2006).ERA Annual Report 2006 (Ranger Mine). (available at http://www.energyres.com.au/documents/2006_Annual_Report.pdf).

[ERA 2007] Energy Resources of Australia Ltd. (ERA) (2007).ERA Annual Report 2007 (Ranger Mine). (available at: http://www.energyres.com.au/documents/2007_Anuual_Report.pdf).

[ERA 2008] Energy Resources of Australia Ltd. (ERA) (2008).ERA Annual Report 2008 (Ranger Mine). (available at: http://www.energyres.com.au/documents/2008_Annual_Report.pdf).

[ERA 2009] Energy Resources of Australia Ltd. (ERA) (2009).ERA Annual Report 2009 (Ranger Mine). (available at http://www.energyres.com.au/documents/ERA_2009_Annual_Report_FINAL1.pdf).

[ERA 2010] Energy Resources of Australia Ltd. (ERA) (2010).ERA Annual Report 2010 (Ranger Mine). (available at http://www.energyres.com.au/documents/ERA_Annual_Report_2010.pdf).

[European Commission 1995] Nuclear Fuel Cycle, Externalities of Fuel Cycles, 'ExternE’ Project,

European Commission, DGXII, Science, Research and Development (JOULE), Brussels, Belgium, 1995.

[Evans 2005] Evans, K. G. et al., eds., “eriss Research Summary,” Technical Report SSR 189, Australia Department of the Environment and Heritage, 2005. (available at http://www.environment.gov.au/ssd/publications/ssr/189.html)

[Fernandes, Franklin et al. 1998] Fernandes, H. M., M. R. Franklin, et al. (1998). "Acid rock drainage and radiological environmental impacts.A study case of the Uranium mining and milling facilities at Poços de Caldas."Waste Management18(3): 169-181.

[Grey 1993] Grey, C. "Uranium: From Ore to Concrete”. The Nuclear Engineer, vol. 34, no. 1, 1993.

Haridasan 2008, P. P. Haridassan, P. M. Pillai, R. M. Tripathi, “Occupational Radiation Exposure Due to NORM in a Rare-Earth Compounds Production Facility", Radiation Protection Dosimetry, Vol. 131, Issue 2, 2008, pp. 217-221

Haridasan 2010. P. P. Haridasan et al., "Operational Radiation Protection Associated with Thorium Processing in India," Naturally Occurring Radioactive Material (NORM VI) Proceedings of a Symposium, Marrakesh, Morocco, p. 119-126 (March 22-26).

[Harlow 1999] Harlow, S.E., "Final Programmatic Environmental Impact Statement for Alternative Strategies for the Long-term Management and Use of Depleted Uranium Hexafluoride,” DOE Technical Report DOE/EIS-0269, 1999.

[Harries 1997] Harries, J., Levins, D., Ring, B. and W. Zuk, "Management of Waste from Uranium Mining and Milling in Australia," Nucl. Eng. Design, 176, 15-21, 1997.

[Hartman 2004a] Hartman, G.S. et al., "Final Environmental Impact Statement for Construction and Operation of a Depleted Uranium Hexafluoride Conversion Facility at the Paducah, Kentucky, Site," DOE Technical Report DOE/EIS-0359, 2004. 
[Hartman 2004b] Hartman, G.S. et al., "Final Environmental Impact Statement for Construction and Operation of a Depleted Uranium Hexafluoride Conversion Facility at the Portsmouth, Ohio, Site," DOE Technical Report DOE/EIS-0360, 2004.

[Hedrick 2002] J. B. Hedrick, "Thorium," chapter in the U.S. Geological Survey Minerals Yearbook 2000.

[HSE 2004] United Kingdom Health and Safety Executive, "Urenco (Capenhurst) Ltd's Strategy for Decommissioning its Nuclear Licensed Site," HM Nuclear Installations Inspectorate technical report, November 2004.

[IAEA 1989] International Atomic Energy Agency, 1989."The Recovery of Uranium from Phosphoric Acid."IAEA-TECDOC-533. Vienna, Austria.

[IAEA 2005] "Thorium fuel cycle - Potential Benefits and Challenges," IAEA-TECDOC-1450,

[IAEA 2005] IAEA (2005) Guidebook on environmental impact assessment for in situ leach mining projects. IAEATECDOC-1428, International Atomic Energy Agency, Vienna, May 2005. http://wwwpub. iaea.org/MTCD/publications/PDF/te_1428_web.pdf(17 April 2010)

IAEA 2011.International Atomic Energy Agency. "Radiation Protection and NORM Residue Management in the Production of Rare Earths from Thorium Containing Minerals," Safety Reports Series No. 68 .

[IARC 2012] International Agency for Research on Cancer (IARC) "Diesel Engine Exhaust Carsinogenic" press release 12 June 2012 (available at: http://press.iarc.fr/pr213 E.pdf, viewed 16 July 2012).

[ICRP 2010] International Commission on Radiation Protection (ICRP).Lung Cancer Risk from Radon and Progeny and Statement on Radon, ICRP Publication 115, Ann. ICRP 40 (1).

[IIFP 2009] Fluorine Extraction Process \& Depleted Uranium De-conversion Plant Environmental Report, International Isotopes Fluorine Products, Inc. ER-IFP-001 Revision A, December 2009.

[INL 2013] Brent Dixon, Kent Williams, Jim Blink, Joe Carter, Ed Danko, Francesco Ganda, T. J. Harrison, Ed Hoffman, Erich Schneider, Steve Sheetz, Tom Wood, "Advanced Fuel Cycle Cost Basis (2012 Addendum)," Idaho National Laboratory technical report INL/EXT-13-28626, February 2013.

[ISO 2006] International Standards Organization, "Environmental management - Life cycle assessment Principles and framework" Report ISO-14040:2006, and "Environmental management — Life cycle assessment — Requirements and guidelines," Report ISO-14044:2006(E), 2006.

[Lacasse, Martin, et al. 2009] Lacasse, Y., S. Martin, et al. (2009). "Dose-response meta-analysis of silica and lung cancer. "Cancer Causes and Control20(6): 925-933.

[LES 2005] Louisiana Energy Services, "Environmental Impact Statement for the Proposed National Enrichment Facility in Lea County, New Mexico," also issued as NRC Technical Report NUREG-1790, 2005.

[Meyer 1979] Meyer, H. R., Till, J. E., Bomar, E. S., Bond, W. D., Morse, L. E., Tennery, V. J. and Yalcintas, M. G. "Radiological Impact of thorium Mining and Milling" Nuclear Safety, 20(3)319-330, 1979.

[Mukherjee 2004] T. K. Mukherjee, "The Role of IREL in the Indian Nuclear Energy Program," in An International Journal of Nuclear Power 18 (2-3) 81-83 published by Nuclear Power Corporation of India Ltd. 
Environmental Impacts, Health and Safety Impacts, and Financial Costs of the Front-End of the Nuclear Fuel Cycle

[MSHA 1981] Miller, H. T. and L. M. Scott (1981).Radiation Exposures Associated with Exploration, Mining, Milling, and Shipping Uranium. Radiation hazards in mining: Control, Measurement, and Medical Aspects: International Conference, Golden, CO, USA, Mine Safety and Health Administration (MSHA).

[MSHA 1995] Mine Safety and Health Administration (MSHA). (1995). "30 CFR § 57.5040 Exposure records." Retrieved July, 2012, from http://www.msha.gov/30cfr/57.5040.htm.

[MSHA 2006] Mine Safety and Health Administration (MSHA) (2006). Metal and Nonmetal Health Inspection Procedures, U.S. Department of Labor.Handbook Series: Number PH06-IV-1(1).

[MSHA 2008] "Injury Experience in Metallic Mineral Mining, 2007U.S. Department of Labor Mine Safety and Health Administration 2008, IR 1337.

http://www.msha.gov/Stats/Part50/Yearly\%20IR\%27s/2007/Metal_Irs_2007.pdf

[MSHA 2009] "Injury Experience in Metallic Mineral Mining, 2008U.S. Department of Labor Mine Safety and Health Administration 2009, IR 1342.

http://www.msha.gov/Stats/Part50/Yearly\%20IR\%27s/2008/Metallic\%20Mineral\%20Publication2008.pdf

[MSHA 2011] Mine Safety and Health Administration (MSHA) (2011).Injury Experience in Metallic Mineral Mining, 2009.IR 1349.

[MSHA 2012] Mine Safety and Health Administration (MSHA). (2012). "Mine Data Retrieval System: Mines by District and then Commodity Mined." Retrieved April, 2012, from http://www.msha.gov/drs/asp/extendedsearch/minesbydistrictcommodity.asp.

[MSHA 2012a] Mine Safety and Health Administration (MSHA). (2012). "Compliance Guide to MSHA's Occupational Noise Exposure Standard APPENDIX B - GLOSSARY OF TERMS" Retrieved August, 2012, from http://www.msha.gov/regs/complian/guides/noise/g3appendixb.htm.

[MSHA 2012b] Mine Safety and Health Administration (MSHA) (2012).Injury Experience in Metallic Mineral Mining, 2010. IR 1355.

[Mudd 2001] Mudd, G. 2001. "Critical review of acid in situ leach uranium mining: 1. USA and Australia." Environmental Geology 41(3): 390-403

[Mudd 2007] Mudd, G.M., M. Diesendorf, "Sustainability Aspects of Uranium Mining: Toward Accurate Accounting?" 2nd International Conference on Sustainability Engineering \& Science, Auckland, New Zealand, February 2007, http://users.monash.edu.au/ gmudd/files/2007-SustEngSci-Sust-v-

Uranium-Mining.pdf

[Mudd 2007a] Mudd, G. M. Compilation of Uranium Production History and Uranium Deposit Data Across Australia; SEA-US Inc, 2007; last updated July 2007.

[NAS 2011] Uranium Mining in Virginia: Scientific, Technical, Environmental, Human Health and Safety, and Regulatory Aspects of Uranium Mining and Processing in Virginia, National Academy of Science (NAS), 2011. Available at http://www.nap.edu/catalog.php?record_id=13266

[NIOSH 1987] National Institute for Occupational Safety and Health (NIOSH) (1987). Criteria For a Recommended Standard: Occupational Exposure to Radon Progeny in Underground Mines, U.S.

Department of Health and Human Services, Public Health Service, Centers for Disease Control. Report No. 88-101.

[NIOSH 2002] NIOSH Hazard Review: Health Effects of Occupational Exposure to Respirable Crystalline Silica NIOSH Publication No. 2002-129 (April 2002) 
[NRC 1976] US Nuclear Regulatory Commission (NRC) (1976). Final Generic Environmental Statement on the Use of Recycle Plutonium in Mixed Oxide Fuel in Light Water Cooled Reactors ("GESMO"). NUREG-0002 (Vol. 2) (available at http://pbadupws.nrc.gov/docs/ML0710/ML071000112.pdf).

[NRC 2007] US Nuclear Regulatory Commission, "Calculation Worksheet: Decommissioning Funding Plan Depleted Uranium Disposition Cost Estimate," NRC Form 383 Docket Numbers 070-7001 and 0707002, February 2007, available: http://pbadupws.nrc.gov/docs/ML0703/ML070370399.pdf, website accessed June 28, 2012.

[NRC 2009] US Nuclear Regulatory Commission (NRC) (2009).Generic Environmental Impact Statement for In-Situ Leach Uranium Milling Facilities. Volumes 1-2: NUREG-1910.

[NRC 2010] US Nuclear Regulatory Commission (NRC) and Office of Federal and State Materials and Environmental Management Programs (2010). Environmental Impact Statement for the Moore Ranch ISL Project in Campbell County, Wyoming (Supplement to the Generic Environmental Impact Statement for the In-Situ Leach Uranium Milling Facilities): Final Report. Supplement 1: NUREG-1910.

[NRC 2011] US Nuclear Regulatory Commission (NRC) (2011). Environmental Impact Statement for the Nichols Ranch ISL Project in Campbell and Johnson Counties, Wyoming (Supplement to the Generic Environmental Impact Statement for the In-Situ Leach Uranium Milling Facilities): Final Report, Office of Federal and State Materials and Environmental Management Programs. Supplement 2: NUREG1910.

[NRC 2011a] US Nuclear Regulatory Commission (NRC), Division of Waste Management and Environmental Protection, et al. (2011). Environmental Impact Statement for the Lost Creek ISL Project in Sweetwater County, Wyoming (Supplement to the Generic Environmental Impact Statement for the InSitu Leach Uranium Milling Facilities): Final Report. Supplement 3: NUREG-1910.

[NRC 2012] US Nuclear Regulatory Commission (NRC).(2012). "10 CFR PART 20-STANDARDS FOR PROTECTION AGAINST RADIATION."Retrieved January, 2012, from http://www.nrc.gov/reading-rm/doc-collections/cfr/part020/full-text.html\#part020-1003.

[NRC 2012a] Occupational Radiation Exposure at Commercial Nuclear Power Reactors and Other Facilities 2010, U.S. Nuclear Regulatory Commission, NUREG 0713, Vol 32, 1012.

[NRC 2012b] US Nuclear Regulatory Commission, "Environmental Impact Statement for the Proposed GE Hitachi Global Laser Enrichment, LLC Facility in Wilmington, North Carolina," Technical Report NUREG-1938, 2012.

[NUREG 2005] NUREG-1970, "Environmental Impact Statement for the Proposed National Enrichment Facility in Lea County, New Mexico, Final Report Vol 1, U.S. Nuclear Regulatory Commission, June 2005.

[NUREG 2006] NUREG-1834, "Environmental Impact Statement for the Proposed American Centrifuge Plant in Piketon, OH, Final Report, Vol 1, U.S. Nuclear Regulatory Commission, April 2006.

[NUREG 2011] NUREG-2113, "Environmental Impact Statement for the Proposed fluorine Extraction Process and Depleted Uranium Deconversion Plant in Lea County, New Mexico, Draft Report, U.S. Nuclear Regulatory Commission, December 2011.

[NUREG 2011] NUREG-1945, “Environmental Impact Statement for the Proposed Eagle Rock Enrichment Facility in Bonneville County, Idaho, Final Report Vol 1, U.S. Nuclear Regulatory Commission, February 2011.

[OECD 2008] "Uranium 2007: Resources, Production and Demand" (also known as the Red Book), Organisation for Economic Co-operation and Development (OECD) Nuclear Energy Agency (NEA), $22^{\text {nd }}$ ed., June 2008. 
Environmental Impacts, Health and Safety Impacts, and Financial Costs of the Front-End of the Nuclear Fuel Cycle

July 2013

[OECD 2010] "Uranium 2009: Resources, Production and Demand" (also known as the Red Book), Organisation for Economic Co-operation and Development (OECD) Nuclear Energy Agency (NEA), $23^{\text {rd }}$ ed., July 2010.

[OECD 2012] "Uranium 2011: Resources, Production and Demand" (also known as the Red Book), Organisation for Economic Co-operation and Development (OECD) Nuclear Energy Agency (NEA), $24^{\text {th }}$ ed., July 2012.

[ORNL 1978] Environmental Assessment of Alternate FBR Fuels: Radiological Assessment of Airborne Releases from Thorium Mining and Milling," by Tennery, et al, ORNL/TM06474"

[ORNL 1981] O'Donnell, F. R. and H. C. Hoy (1981).Occupational Safety Data and Casualty Rates for the Uranium Fuel Cycle.[Glossaries], Oak Ridge National Laboratory (ORNL), Union Carbide

Corporation.ORNL-5797: Pages: 88.

[PNL 1980] Environmental Control Technology for Mining, Milling, and Refining Thorium," by Weakly et al, PNL-3253, February 1980.

[Port Hope 2012], "2011 Annual Compliance Monitoring and Operating Performance Report: Port Hope Conversion Facility”, Cameco Corporation fuel Services, One Eldorado Place, Port Hope Ontario, Canada.

[PPPO 2012] Department of Energy Paducah/Portsmouth Project Office, "PPPO Official Website," http://www.pppo.energy.gov/, website accessed June 24, 2012.

[RAIS 2012] Risk Assessment Information System, Human Health Preliminary Remediation Goals, http://rais.ornl.gov/cgi-bin/prg/PRG_search?select=chem; August, 2012.

[RAIS 2012a] Risk Assessment Information System, Ecological Benchmarks; http://rais.ornl.gov/tools/eco search.php, August, 2012.

[Rao 2011] Rao, L., Recent International R\&D Activities in theExtraction of Uranium from Seawater, Lawrence Berkeley Laboratory, LBNL-4034E, 2011.

[Rössing 2010] Rössing, var., Annual Report to Stakeholders, Rössing Uranium Ltd, Years 1999 to 2009, Swakopmund, Namibia, www.Rössing.com, webpage accessed January 2010.

[Rössing Financial] Rössing Financial Results, Rössing Uranium Ltd, Year 2011, Swakopmund, Namibia, available: www.Rössing.com, webpage accessed July 10, 2012.

[Rössing Uranium Ltd.] Annual Report to Stakeholders, Rössing Uranium Ltd, Year 2011, Swakopmund, Namibia, available: www.Rössing.com, webpage accessed July 10, 2012.

[Rössing U Ltd. 2011] Rössing Uranium Limited (2011). Working for Namibia - 2011 Report to Stakeholders, Rio Tinto.(available at http://www.riotinto.com/documents/2011RULStakeholderReport.pdf).

[Rotty 1975] Rotty, R. M., Perry, A. M. and D. B. Reister, "Net Energy from Nuclear Power," technical report, ORAU-IEA-75-3, Oak Ridge National Laboratory, 1975.

[Sagar 2010] V. B. Sagar et al., "Optimization of Occupational Dose in Thorium Nitrate Processing," Radiation Protection and Environment 33(4) 209-210.

[SCBT 2008] Santa Cruz Biotechnology (SCBT) (2008).Potassium Chloride MSDS.sc-203207.

[SCBT 2010] Santa Cruz Biotechnology (SCBT) (2010).Potassium Sulfate MSDS.sc-203365. 
[Schneider \& Sachde 2011] Schneider, E. A. and D. Sachde, "Cost and Uncertainty Analysis of an Adsorbent Braid System for Uranium Recovery from Seawater," technical report, University of Texas at Austin, August 1, 2011.

[Schneider \& Sachde 2012] Schneider, E. A. and D. Sachde, "The Cost of Recovering Uranium from Seawater by a Braided Polymer Adsorbent System," Science and Global Security, under review, 2012.

[Schneider 2010] Schneider, E. A., Carlsen, B. W. and E. Tavrides, "Measures of the Environmental Footprint of the Front End of the Nuclear Fuel Cycle," INL Technical Report FCRD-SYSA-2010000104, 2010.

[Sears 1982] M. B. Sears, E. L. Etnier, G. S. Hill, B. D. Patton, J. P. Witherspoon, S. N. Yen, "Correlation of Radioactive Waste Treatment Costs and the Environmental Impact of Waste Effluents in the Nuclear Fuel Cycle - Conversion of Yellow Cake to Uranium Hexafluoride," Oak Ridge National Laboratory Technical Report ORNL/TM-8602, 1982.

[Seitz 2005] Seitz, K., “The True Cost of Uranium Production,” World Nuclear Association 2005 Symposium, September 2005, available: http://www.world-nuclear.org/sym/2005/pdf/Seitzppt.pdf, website accessed August 9, 2012.

[SENES 1998] SENES Consultants Limited (1998). Long Term Population Dose Due to Radon (Rn-222) Released from Uranium Mill Tailings: Prepared for the Uranium Institute. Richmond Hill, Ontario, Canada.

[SENES 2009].Risk Assessment for Proposed Uranium and Vanadium mill at the Pinon Ridge Property. SENES Consultants Limited, November 2009.

[Senes 2010] Senes Consultants, Ltd., "Cameco Vision 2010: Environmental Impact Statement, Port Hope Conversion Facility,” December 2010.

[Shropshire 2009] Shropshire, D. et al., “Advanced Fuel Cycle Cost Basis,” Idaho National Laboratory report INL/EXT-07-12107, 2007, revised 2008, 2009.

[Soldat et al. 1974] Soldat, J. K., Robinson, N. M., and Baker, D. A. (1974) Models and Computer Codes for Evaluation Environmental Radiation Doses. BNWL-1754, Pacific Northwest Laboratories, Richland, Washington.

[Spadaro et al. 1998] Spadaro, J.V and A. Rabl External Costs of Energy: Application of the EXTERNE Methodology in France, Centre d'Energetique, Ecole des Mines de Paris,1998.

[Staatz 1972] M. H. Staatz, “Geology and Description of the Thorium-Bearing Veins, Lemhi Pass Quadrangle, Idaho and Montana,” USGS Bulletin 1351,pp. 94, 1972.

[Staatz 1974] M. H. Staatz, “Thorium Veins in the United States,” Economic Geology, 69:494-507, 1974.

[Staatz 1978] M. H. Staatz, "Proceedings of the Uranium Industry Seminar," 1978, GJO-108(78), U.S. Dept. of Energy, Grand Junction, Colorado, pp. 109-115, 1978.

[Steenland, Mannetje et al. 2001] Steenland, K., A. Mannetje, et al. (2001). "Pooled exposure-response analyses and risk assessment for lung cancer in 10 cohorts of silica-exposed workers: an IARC multicentre study." Cancer Causes and Control12(9): 773-784.

[Tamada 2009] Tamada, M., Current status of technology for collection of uranium from seawater,Erice seminar 2009.

[Tamada et al 2006] M. Tamada, M., Seko, N., Kasai, N., and Shimizu, T. Cost estimation of uranium recovery from seawater with system of braid type adsorbent, Transactions of theAtomic Energy Society of Japan, 5 (2006) 358-363. 
[Taylor et al. 2004] Taylor G., Farrington V., Woods P., Ring R. and Molloy R. (2004) Review of Environmental Impacts of the Acid In-situ Leach Uranium Mining Process. Prepared for Pollution Avoidance Division, Environment Protection Authority, Adelaide, Australia by Australia's Commonwealth Scientific and Industrial Research Organisation (CSIRO), Land and Water Client Report, August 2004. http://www.epa.sa.gov.au/pdfs/isl_review.pdf (25 August 2009)

[Tweeton, Peterson 1981] Tweeton D.R., Peterson K.A. 1981. "Selection of lixiviants for in situ leach mining." In: In situ mining research. US Bureau of Mines and Technology Transfer Seminar, Denver, Aug. 5, Information Circular 8852, pp. 17-24.

[Two Lines, Inc., 2009] “Estimates of Radiation Doses to Members of the Public from the Piñon Ridge Mill,” November 2009.

[United Nations 1991] United Nations Statistics Division, "Energy Statistics--A Manual for Developing Countries,” Technical Report Series F, No. 56, 1991.

[UNSCEAR 2008], "Sources and Effects of Ionizing Radiation, Annex B, Exposures of the Public and Workers from Various Sources of Radiation, Vol 1", United Nations Scientific Committee on the Effects of Atomic Radiation, United Nations 2010.

[UNSCEAR 2008], "Sources and Effects of Ionizing Radiation, United Nations Scientific Committee on Effects of Atomic Radiation Report to the General Assembly with Scientific Annexes, volume 1", United Nations 2010

[Uranium Equities Ltd: 2010] Uranium Equities Ltd: 2010 Annual Report. Accessed at http://investor.uel.com.au/IRM/Company/ShowPage.aspx/PDFs/1139-51310136/AnnualReport2010

[USAEC 1962] US Atomic Energy Commission (AEC), "Graphs for Estimating Atmospheric Dispersion, W.F. Hilsmeier and F.A. Gifford, Jr., ORO-545, Unites States Atomic Energy Commission, Division of Technical Information, Oak Ridge, TN, July 1962. http://www.cvmbs.colostate.edu/erhs/ORO_545.pdf

[USBM 1961] S. R. Borrowman and J. B. Rosenbaum, Recovery of Thorium from Ores in Colorado, Idaho, and Montana. USBM-IC-5916, U.S. Bureau of Mines, Denver, CO, 35 pp., 1961.

[USBM 1962] S. R. Borrowman and J. B. Rosenbaum, Recovery of Thorium from a Wyoming Ore. USBM Report Inv. 5917, U.S. Bureau of Mines, Denver, CO, 1962.

[USGS 2003] United States Geological Survey (USGS) (2003). Irrigation-Induced Contamination of Water, Sediment, and Biota in the Western United States - Synthesis of Data from the National Irrigation Water Quality Program, National Irrigation Water Quality Program. Professional Paper 1655.

[USGS 2010] Van Gosen, B.S., Gillerman, V.S., and Armbrustmacher, T.J., 2009, Thorium deposits of the United States - Energy resources for the future?: U.S. Geological Survey Circular 1336, 21 p. [Only available at URL http://pubs.usgs.gov/circ/1336]

[Weakley et al 1980] S. A. Weakley, D. E. Blahnik, J. K. Young, C. H. Bloomster, "Environmental Control Technology for Mining, Milling, and Refining Thorium," PNL-3253, February 1980.

[Weiner 2010] Halsey W., Weiner R., Dixon B. Generic Systems Analysis for Transportation Needs and Impacts for a Fuel Cycle Based on a 800-Tonne Separations Plant. U.S. DOE FCRD Program. January $12,2010$.

[WHO 2004] World Health Organization (WHO) (2004). Uranium in Drinking-Water (Background Document for Development of WHO Guidelines for Drinking-Water Quality).

$\mathrm{WHO} / \mathrm{SDE} / \mathrm{WSH} / 03.04 / 118$. 
Environmental Impacts, Health and Safety Impacts, and Financial Costs of the Front-End of the

Nuclear Fuel Cycle

[WHO 2008] World Health Organization (WHO) (2008).Guidelines for Drinking-water Quality - Third Edition, Incorporating the First and Second Addenda; Geneva Vol. 1 - Recommendations (ISBN: 97892-4-154761-1).

[Wise Uranium 2012] Wise Uranium Project, “Uranium Mine Feasibility Calculator,” http://www.wiseuranium.org/nfcmf.html, website accessed August 12, 2012.

[WNA 2009] World Nuclear Association (2009) In Situ Leach Mining (ISL) of Uranium. WNA Information Paper, June 2009. http://www.world-nuclear.org/info/inf27.html (11 June 2010)

[WNA 2012] World Nuclear Association (WNA). (2012, Last Update Date (July 2012)). "US Uranium Mining and Exploration (US Nuclear Fuel Cycle Appendix 1)."Retrieved August, 2012, from http://world-nuclear.org/info/default.aspx?id=25561\&terms=US\%20nuclear\%20fuel\%20cycle.

[WNA 2013] World Nuclear Association (WNA). (2013, Last revised January 10, 2013). "Uranium in Canada. "Retrieved January, 2013, from http://www.world-nuclear.org/info/inf49.html.

[WNA 2013a] World Nuclear Association (WNA). (2013, Last revised 12-14-2012). "Australia's Uranium. "Retrieved January, 2013, from http://www.world-nuclear.org/info/inf48.html.

[World Nuclear (http://www.world-nuclear.org/info/inf23.html), updated May 2012] The percentages shown here are from active producing mines as of May 2012.

[World Nuclear 2012] 'World Uranium Mining' http://www.world-nuclear.org/info/inf23.html .Updated May 2012.Accessed July 10, 2012.

[Young et al 1980] JK Young, et. al., "Economics of Large-Scale Thorium Oxide Production: Assessment of Domestic Resources", PNL-3150, February 1980. 


\section{Appendix A}

\section{Review of Previous Energy, Water, and Land Use Assessment Methodologies}

\section{WASH 1248 (AEC 1974) - Environmental Survey of the Uranium Fuel Cycle}

Land use, water use and fossil fuel use is normalized to the model LWR annual fuel requirement, based on a 1000 MWe LWR with a 30-year useful lifetime.

Land commitments are described as either "temporary" or "permanent". "Temporary" land commitments encompass the lifetime of the plant, or succeeding plants, and upon abandonment land may be used for any purpose, while "permanent" land commitments represent land that may not be utilized after plant shutdown and decommissioning. Land withdrawn for a power plant by fencing from active use by human habitation is considered as a temporary land commitment, resulting in approximately $70 \%$ of land commitment as temporary.

Water uses have been grouped into three categories based upon the method of return of water to the biosphere, either by (1) evaporation into the air, (2) discharge into water bodies, or (3) return to the ground. Gross water is reported as a more conservative measure, though an estimate is given of water returned to its original state when possible.

Energy use is reported as direct electrical energy consumed, or translated to equivalent coal consumption, assuming that most of the electricity generated in the United States is produced in plants that burn fossil fuels, and assuming coal comprises the bulk of fossil fuel utilization. Additionally, direct natural gas is reported in scf of natural gas consumed for process heat (mainly for use in milling operations).

Special considerations:

1. An open pit mining operation in a western state was selected for the model uranium mining operation, as environmental effects of open pit mining are greater than underground mining in terms of total volume of earth disturbed. The model mill is located adjacent to the model mine operation, and utilizes the acid leach process. The bulk of the total land usage attributable to the model LWR annual fuel requirement is devoted to the permanent disposal of mill tailings (processed product from the mining operation). While it is expected that the tailings pond area will be restored over the life of the plant, land use for the tailings pond is reported as permanent land commitment, due to restrictions by the AEC.

2. The model $\mathrm{UF}_{6}$ production plant is assumed to produce $1 / 2$ of its output by the hydrofluoric process and $1 / 2$ by the wet solvent extraction process in order to represent the average industry effect. The model $\mathrm{UF}_{6}$ plant is built on previous agricultural land to minimize impact on local recreation, historical factors, and adjacent farming activity in the area.

3. The model enrichment operation is taken as the three facilities (GDPs) operating during 1974, with 20 -year life, scaled to the model LWR. None of the land used for the model enrichment facility is considered permanently committed.

4. The model fuel fabrication facility uses the conventional ammonium diuranate process for conversion of $\mathrm{UF}_{6}$ to $\mathrm{UO}_{2}$. 
5. The number of shipments, travel miles, assumed mode and route and gallons of diesel fuel is recorded for transportation.

\section{Rotty 1975 - Net Energy From Nuclear Power}

Reports net energy requirements from the operation of a 1000 MWe nuclear power plant for 30 years with a capacity factor of 0.75 . An evaluation of both electrical and thermal energy requirements, both direct and indirect, of each process in the NFC is made. Thermal energy requirements are essentially all obtained from the combustion of fossil fuels and do not include fuel used to generate electricity. The electrical requirements calculated make no distinction as to the primary fuel source used to generate the electricity. The timing of energy inputs and outputs is also noted since a fuel inventory of several years of operation must be on hand before the station starts to deliver electricity.

Four net energy ratios are calculated in this study:

1. Electrical output divided by the total thermal (fossil) energy subsidy required to produce that output.

a. Electrical requirements of the system are assumed to be the output of fossil fueled power plants $\rightarrow$ electrical requirements are multiplied by 3.34 to obtain the fossil energy requirements.

2. Electrical output divided by the equivalent electrical input subsidy.

a. Thermal requirements of the system are assumed to be produced in fossil fueled power plants $\rightarrow$ thermal requirements are divided by 3.34 to estimate the amount of electrical energy that could be produced by this thermal energy.

3. Ratio of the energy output of the total energy subsidy required.

a. Thermal energy requirements are expressed in $\mathrm{MWH}\left(1 \mathrm{MWH}=3.41310^{6} \mathrm{BTU}\right)$

4. Net electrical output, (i.e., the electrical energy output of the power plant minus the electrical energy input requirements, divided by the thermal energy requirements in $\mathrm{MWH}$ )

Three distinct categories of energy are considered:

1. Direct energy input to a process

a. Includes both fossil fuels and electricity purchased and used in the performance of the process (but not fossil fuels used to generate the electricity)

2. Energy content of the materials required in each process

a. Includes energy requirements for the production of the raw materials (e.g., cladding materials in the fabrication of fuel elements)

3. Energy used in construction of capital facilities, buildings, and major equipment

a. Includes energy content of materials that go into the building and the direct energy expenditures in the erection of the building ${ }^{28}$ evaluated as completely as possible, but did not consider energy in the construction of the plant required to manufacture said machinery

Direct energy inputs were evaluated by searching for direct fuel and electricity purchases, while the energy content of process materials were estimated through conversion of dollar value of the purchases to energy content through the IEA TOTEN Program (developed for Rotty 1975 study).

\section{Sovacool 2008 - Valuing the greenhouse gas emissions from nuclear power: A critical survey}

Assesses total carbon dioxide-equivalent emissions over the enter nuclear fuel cycle by reviewing 103 studies, narrowed down according to a three-phase selection process; (1) excludes studies more than 10 years old, (2) excludes analyses that were not in the public domain, cost money to access, or were not published in English, (3) excludes studies whose methodology were not reliable (relied on "unpublished data", utilized "secondary sources", etc.).

28. Study is not transparent in its methodology, deemed not useful. 
Environmental Impacts, Health and Safety Impacts, and Financial Costs of the Front-End of the Nuclear Fuel Cycle

Rashad 2000 - Nuclear power and the environment: comparative assessment of environmental and health impacts of electricity-generating systems

Land use is based solely on final occupied land area of nuclear power plant. Net energy analysis includes fossil fuel consumption associated with both direct and indirect energy consumption for generating electricity, but does not clearly define scope of study. Emission estimates are based on previous studies.

Dones 2005 - Life Cycle Inventories for the Nuclear and Natural Gas Energy Systems, and Examples of Uncertainty Analysis

Averages two units of LWRs currently operating in Switzerland to assessed, modeled, and extrapolated to Western Europe. Constructs LCI from considering front-end, power plant, and back-end stages of the nuclear fuel cycle, as well as stages that "contribute meaningfully to cumulative burdens".

Occupied land estimates for mill tailing ponds are taken from previous studies.

Energy use is reported in electricity-equivalent units, assuming a reference efficiency of conversion thermal energy to electricity of $35 \%$. Energy use estimates are from primary data when possible - main assumptions are (1) electricity supply of $2400 \mathrm{kWh} / \mathrm{kg}$ SWU to diffusion Eurodif plant in France is directly from nuclear power plants on site and facility is water-cooled, (2) electricity supply to USEC diffusion plant (Paducah, USA) is directly from coal power plants, assumed electricity intensity is 2600 $\mathrm{kWh} / \mathrm{kg}$ SWU and facility is cooled with CFC-114, leaking at an assumed rate of about $0.02 \mathrm{~kg} / \mathrm{kg} \mathrm{SWU}$, (3) electricity intensity for all centrifuge Urenco plants is $40 \mathrm{kWh} / \mathrm{kg} \mathrm{SWU}$, assuming supply from the UCTE grid and facility is cooled using R134a, leaking at a rate of $2.610^{-4} \mathrm{~kg} / \mathrm{kg} \mathrm{SWU}$.

\section{Fthenakis 2009 - Land use and electricity generation: A life-cycle analysis}

Direct and indirect land transformation is analyzed for the US nuclear fuel cycle. Energy and material inputs are adapted from DOE reports, and converted into land-transformation equivalents based on Ecoinvent database. Land occupation, typically measured as product of land area $\left(\mathrm{m}^{2}\right)$ and time (year), involves the duration over which the area of the transformed land returns to its original state. Estimates for the time needed to recover the full productivity of land must be made, and considerations are made for differing ecosystems disrupted.

\section{Kommonen 2006 - Use of Environmental Life Cycle Impact Assessment for Power Generation Systems: Canadian Electricity Association Case Study}

Uses the Life Cycle Stressor-Effects Assessment (LCSEA) model for LCIA modeling, designed to conform to ISO-14040, ISO-14041, and ISO-14042.

"Life Cycle Stressor-Effects Assessment (LCSEA): A Framework for Integrating Life-Cycle Impact Assessment with Environmental Assessment Techniques, Practitioners' Manual"

Unable to find exact citation, summary of "LCSEA FRAMEWORK: Procedures for Calculating Specific Category Indicators" follows.

A stressor-effect network is constructed for each identified impact. Example below: 
Environmental Impacts, Health and Safety Impacts, and Financial Costs of the Front-End of the

Nuclear Fuel Cycle

Example Stressor-Effect

Figure 1. Regional Acidification.

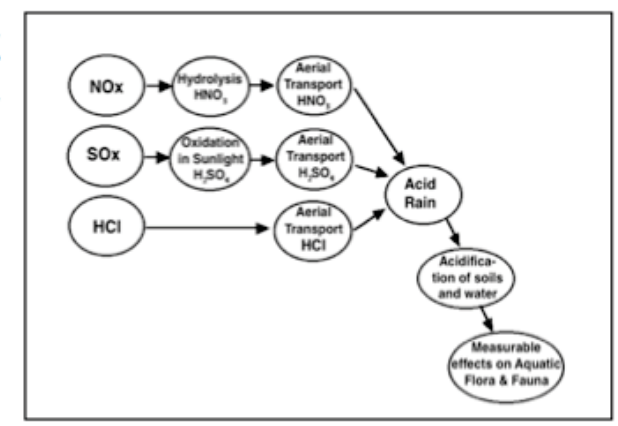

The node with the strongest link to both the stressor (proposed stressor: mining operation) and the impact endpoint (proposed impact endpoint: land transformed) shall be identified as category indicator for the network. The identified impact is normalized to a function unit (proposed functional unit: $\mathrm{kg} \mathrm{NU}$ ).

Proposed impact endpoints are given (as listed in Table 1: Life Cycle Impact Indicators from Kommonen 2006) as well as proposed units of measure. Proposed node for category indicator is also given. 


\section{Appendix B}

\section{Data Tables and Sources for Energy and $\mathrm{CO}_{2}$ Calculations}

This appendix contains data tables used to implement the energy use calculation described in Section 4.1.3. Since it is not possible to identify all commodities that may be input to the NFC technologies in advance, the appendix also provides instructions for obtaining additional data for those commodities. The emphasis of the instructions is to ensure that a consistent methodology and data set is employed to across all NFC technologies.

Table B-1 provides energy density conversion factors for selected common energy carriers. The data are taken from http://en.wikipedia.org/wiki/Energy density. This site provides factors for several dozen other energy carriers and should be consulted if an unlisted energy carrier is encountered. Table B-2 provides the energy densities for materials used in FEFC processes. Table B-3 provides carbon intensity conversion factors employed in this document. The data for fossil fuel and domestic electricity generators are taken from (EIA, 2010) and from (CARMA, 2010) for foreign and world-average electricity generation. In some cases the energy carriers specified by the references were not specific. Table B-4 identifies assumptions with respect to selecting the $\mathrm{CO} 2$ intensities to specific carriers.

Table B-1. Energy density and conversion factors for final energy carriers

\begin{tabular}{|l|c|l|l|}
\hline \multicolumn{1}{|c|}{ Carrier } & Energy Density & \multicolumn{1}{c|}{ Unit } & \multicolumn{1}{c|}{ Comments } \\
\hline Electricity & $3.60 \mathrm{E}+00$ & $\mathrm{GJ} / \mathrm{MWh}$ & (unit conversion only - electrical GJ per electrical $\mathrm{MWh}$ ) \\
\hline Gasoline & $4.72 \mathrm{E}+01$ & $\mathrm{GJ} / \mathrm{MT}$ & $34.0 \mathrm{MJ} / \mathrm{L}$ \\
\hline Diesel & $4.54 \mathrm{E}+01$ & $\mathrm{GJ} / \mathrm{MT}$ & $38.6 \mathrm{MJ} / \mathrm{L}$ \\
\hline Coal & $2.40 \mathrm{E}+01$ & $\mathrm{GJ} / \mathrm{MT}$ & $\mathrm{US}$ average heating value \\
\hline Hydrogen & $1.42 \mathrm{E}+02$ & $\mathrm{GJ} / \mathrm{MT}$ & $4.5 \mathrm{MJ} / \mathrm{L}$ if compressed to $690 \mathrm{bar}$ and $15^{\circ} \mathrm{C}$ \\
\hline Ethanol & $3.00 \mathrm{E}+01$ & $\mathrm{GJ} / \mathrm{MT}$ & \\
\hline Propane & $4.96 \mathrm{E}+01$ & $\mathrm{GJ} / \mathrm{MT}$ & \\
\hline Natural Gas & $5.36 \mathrm{E}+01$ & $\mathrm{GJ} / \mathrm{MT}$ & $0.0364 \mathrm{MJ} / \mathrm{L}$ at $\mathrm{STP}, 22.2 \mathrm{MJ} / \mathrm{L}$ if LNG at $-160^{\circ} \mathrm{C}$ \\
\hline
\end{tabular}

The remainder of this appendix describes the methodology employed to generate the above table of energy densities for common FEFC materials. Table B-5 shows a table row depicting the energy embodied in a material input to an NFC process (nitric acid in this example). Note that each table row represents an energy use assessment that accounts for materials and energy carriers crossing a system boundary, akin to that of the NFC technology itself. Figure 4-1 in Section 4.1.3, for example, includes a system boundary (dashed rectangle) enclosing a chemical production plant. The methodology described below will direct readers to data sources where the energy inputs to industrial processes including chemicals, metals and other commodities are collected. Since the data reported in these sources varies in form and reporting method, the methodology will also describe how to translate the data into entries in Table B-5. 


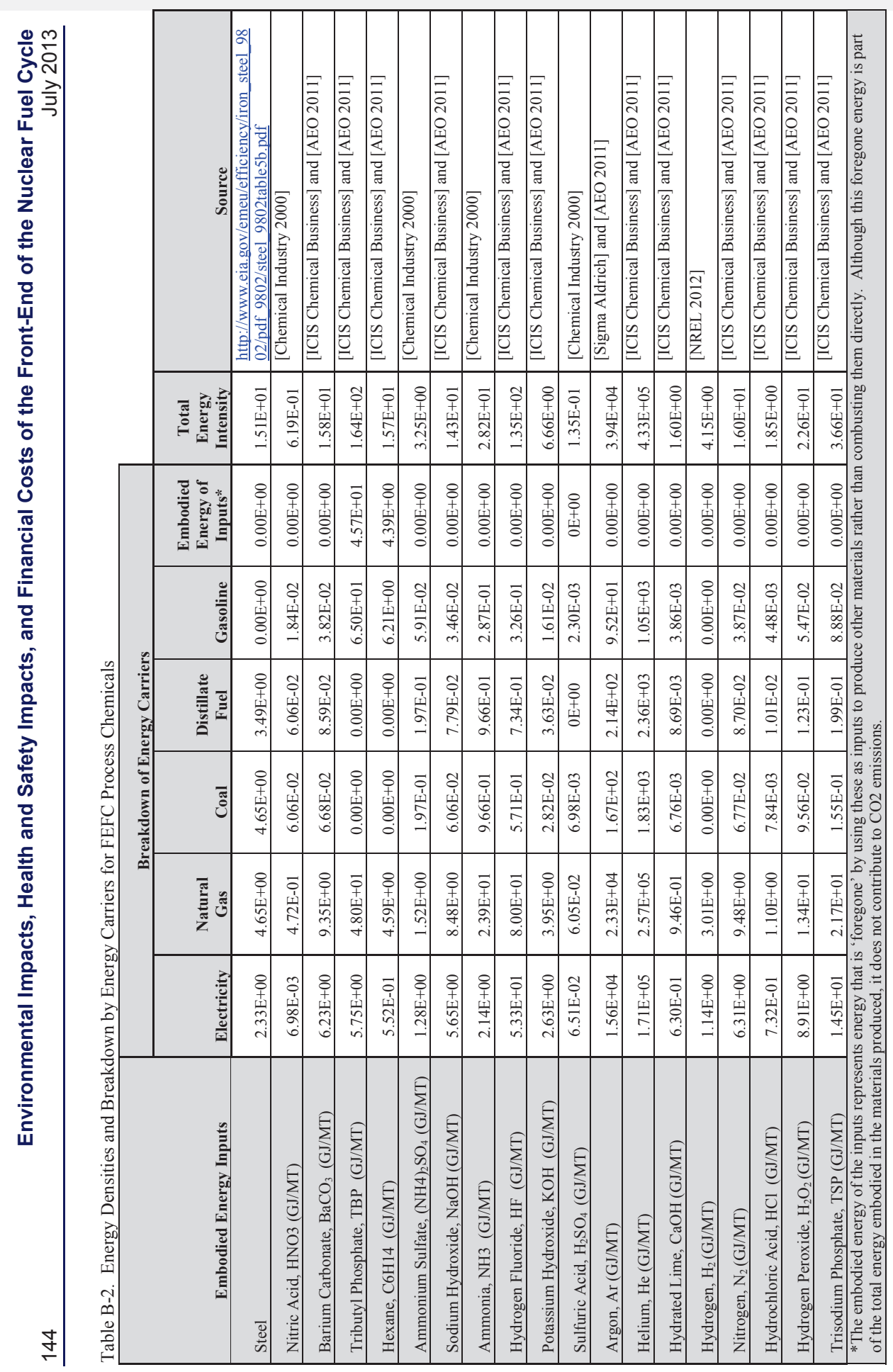


Environmental Impacts, Health and Safety Impacts, and Financial Costs of the Front-End of the Nuclear Fuel Cycle

July 2013

Table B-3. Carbon intensity conversion factors for final energy carriers

\begin{tabular}{|l|c|c|}
\hline \multicolumn{1}{|c|}{ Carrier } & Factor & Unit \\
\hline Gasoline & 68 & $\mathrm{~kg} \mathrm{CO}_{2} / \mathrm{GJ}(\mathrm{t})$ \\
\hline Distillate Fuel & 79 & $\mathrm{~kg} \mathrm{CO}_{2} / \mathrm{GJ}(\mathrm{t})$ \\
\hline Coal - Industrial Coking & 89 & $\mathrm{~kg} \mathrm{CO}_{2} / \mathrm{GJ}(\mathrm{t})$ \\
\hline Natural Gas & 51 & $\mathrm{~kg} \mathrm{CO}_{2} / \mathrm{GJ}(\mathrm{t})$ \\
\hline & & \\
\hline Coal - fired electricity (US avg) & 272 & $\mathrm{~kg} \mathrm{CO}_{2} / \mathrm{GJ}(\mathrm{e})$ \\
\hline Natural Gas fired elec. (US avg) & 114 & $\mathrm{~kg} \mathrm{CO}_{2} / \mathrm{GJ}(\mathrm{e})$ \\
\hline Electricity - US Grid Average & 168 & $\mathrm{~kg} \mathrm{CO}_{2} / \mathrm{GJ}(\mathrm{e})$ \\
\hline Electricity - Canada Grid Average & 59 & $\mathrm{~kg} \mathrm{CO}_{2} / \mathrm{GJ}(\mathrm{e})$ \\
\hline Electricity - Australia Grid Avg & 248 & $\mathrm{~kg} \mathrm{CO}_{2} / \mathrm{GJ}(\mathrm{e})$ \\
\hline Electricity - World Average & 153 & $\mathrm{~kg} \mathrm{CO}_{2} / \mathrm{GJ}(\mathrm{e})$ \\
\hline
\end{tabular}

Table B-4. Assumptions used for mapping energy carriers to those specified in previous table.

\begin{tabular}{|c|c|}
\hline Specified Carrier & CO2 intensity factor used \\
\hline Fuel Oil & Gasoline \\
\hline Liquid Propane Gas & Gasoline \\
\hline Residual & Gasoline \\
\hline Coal and Coke & Coal \\
\hline Steam & Natural Gas \\
\hline Other & Distillate Fuel \\
\hline
\end{tabular}

Table B-5. One entry (row) in an energy embodied in materials table.

\begin{tabular}{|c|c|c|c|c|c|c|c|}
\hline $\mathbf{A}$ & B & $\mathrm{C}$ & D & $\mathbf{E}$ & $\mathbf{F}$ & G & H \\
\hline Commodity & $\begin{array}{l}\text { Electrical } \\
(\text { GJ/MT) }\end{array}$ & $\begin{array}{c}\text { Direct } \\
(\mathrm{GJ} / \mathrm{MT})\end{array}$ & $\begin{array}{l}\text { Breakdown of } \\
\text { Direct Energy }\end{array}$ & $\begin{array}{c}\text { Feedstock } \\
\text { Energy } \\
\text { (GJ/MT) }\end{array}$ & $\begin{array}{c}\text { Embodied } \\
\text { Energy of Inputs } \\
\text { (GJ/MT) }\end{array}$ & $\begin{array}{c}\text { Total Energy } \\
\text { Embodied } \\
\text { (GJ/MT) }\end{array}$ & Source \\
\hline HNO3 & $6.98 \mathrm{E}-03$ & $6.12 \mathrm{E}-01$ & $\begin{array}{l}3 \%, 77.2 \% \\
9.9 \%, 9.9 \%{ }^{1}\end{array}$ & $0.00 \mathrm{E}+00$ & $0.00 \mathrm{E}+00$ & $6.19 \mathrm{E}-01$ & Chemical Industry 2000 \\
\hline
\end{tabular}

The explanation presented below will use chemical production processes as examples since these constitute a large share of the embodied energetic inputs to NFC processes. It will also direct readers to analogous data for other industrial processes. Regardless of industry, the table is structured as follows. Electrical energy (GJ per material basis unit, assumed MT in the example entry) input to the process is in Column B and the sum of all other energy carrier inputs (GJ/material basis unit), the direct energy, is in Column C. A variety of energy carriers may contribute to this total, and their breakdown (when available from the data source) is given in Column D. Column E provides the feedstock energy; this entry will be zero for most materials with organic chemicals being a notable exception. The process represented by this row entry may itself have material inputs that carry embodied energy. When a data 
Environmental Impacts, Health and Safety Impacts, and Financial Costs of the Front-End of the

Nuclear Fuel Cycle

source reports this item, it is to be reported in Column F. Finally, Column G, the total energy embodied in the material, is the sum of the Column B, C, E and F entries and Column $\mathbf{H}$ is the reference(s) for the data.

If the input in question is a chemical, the reader should first check "Energy and Environmental Profile of the US Chemical Industry" [Chemical Industry 2000] to ascertain whether the chemical is covered in that document. See Section Y.1. If the chemical is not covered in [Chemical Industry 2000], or if the material is not a chemical, the reader should refer to "Industrial Demand Module of the National Energy Modeling System" [EIA 2011] and skip to Section Y.2.

The 8-volume document [Chemical Industry 2000] provides a thorough picture of the energy intensities associated with six chemical chains that comprise over half of the energy consumption in the U.S. chemical industry. The chemical chains are ethylene, propylene, BTX (benzene-toluene-xylene), butadiene, agricultural chemicals, and caustics; each chain includes numerous chemicals derived from the chain parent.

The report is available for download from DOE at http://www1.eere.energy.gov/manufacturing/industries technologies/chemicals.html. ${ }^{29}$ Figure B-1 provides an example table from [Chemical Industry 2000] which describes the energy consumed in the production of polyethylene. This figure will be used to illustrate how to populate the entries in Table 2 .

\begin{tabular}{|c|c|c|c|}
\hline Energy & $\begin{array}{c}\text { Specific Energy }{ }^{\prime} \\
\text { (Btu/lb) }\end{array}$ & $\begin{array}{c}\text { Average Specific } \\
\text { Energy (Btu/lb) }\end{array}$ & $\begin{array}{l}\text { Chemical Industry } \\
\text { Energy Use } 1\left(10^{12} \text { Btu }\right)\end{array}$ \\
\hline Electricity" & $473-1,278$ & 876 & 23.6 \\
\hline \multicolumn{4}{|l|}{ Energy for Steam/Process Heat ' } \\
\hline Fuel $O$ OII and $L P G^{\circ}$ & $5 \cdot 13$ & 9 & 0.3 \\
\hline Natural Gas & $127-339$ & 233 & 6.3 \\
\hline Coal and Coke & $17 \cdot 44$ & 30 & 0.8 \\
\hline Other & $17 \cdot 44$ & 30 & 0.8 \\
\hline NET PROCESS ENERGY & $638-1,718$ & 1,178 & 31.8 \\
\hline Electricity Losses & $982-2,654$ & 1,818 & 49.1 \\
\hline Energy Export & 0 & 0 & 0.0 \\
\hline TOTAL PROCESS ENERGY & 1,620 & 2,996 & 80.9 \\
\hline Heat of Feedstock $(\mathrm{\Delta HC})^{\circ}$ & 21,625 & 21,625 & 583.9 \\
\hline TOTAL PRIMARY ENERGY & $23,245 \cdot 25,997$ & 24,621 & 664.8 \\
\hline Feedstock Process Energy & 8,649 & 8,649 & 233.5 \\
\hline $\begin{array}{l}\text { TOTAL ENERGY EMBODIED IN } \\
\text { POLYETHYLNE MFG }\end{array}$ & $31,894 \cdot 34,646$ & 33,270 & 898.3 \\
\hline
\end{tabular}

Electricity directly input

Energy directly input (broken down by carrier)

Feedstock energy

Primary energy input for feed material fabrication

Figure B-1. Example table from [Chemical Industry 2000].Describes the energy consumed in the production of $1 \mathrm{lb}$. polyethylene $\left(1 \mathrm{BTU} / \mathrm{lb} .=2.329 \times 10^{-3} \mathrm{GJ} / \mathrm{MT}\right)$.

Table B-6 shows an example row of Table B-5 obtained from the energy intensity data provided in Figure $\mathrm{B}-2$. The values for column $\mathrm{B}$ are outlined in purple, $\mathrm{C}$ in blue, $\mathrm{E}$ in green, and $\mathrm{F}$ in red. The column $\mathrm{F}$

29. Click on the 'Documents for Historical Reference' tab at the bottom of the page. The link to the report is the second item in the list. 
Environmental Impacts, Health and Safety Impacts, and Financial Costs of the Front-End of the Nuclear Fuel Cycle

entry is the energy embodied in material inputs to the production of the chemical. The values outlined in blue must be added to obtain entry $\mathrm{C}$, but the breakdown of energy carriers by percentage should be recorded in entry D and the categories footnoted at the bottom of the table. The values of columns $\mathrm{B}, \mathrm{C}$, and $\mathrm{E}$ are then added to obtain the entry for column $\mathrm{G}$.

Table B-6. Example table for polyethylene, containing energy intensities given in Figure B-1.

\begin{tabular}{|c|c|c|c|c|c|c|c|}
\hline $\mathbf{A}$ & $\mathbf{B}$ & $\mathrm{C}$ & D & $\mathbf{E}$ & $\mathbf{F}$ & $\mathbf{G}$ & $\mathbf{H}$ \\
\hline Commodity & $\begin{array}{l}\text { Electrical } \\
\text { (GJ/MT) }\end{array}$ & $\begin{array}{c}\text { Direct } \\
(\mathrm{GJ} / \mathrm{MT})\end{array}$ & $\begin{array}{l}\text { Breakdown of } \\
\text { Direct Energy }\end{array}$ & $\begin{array}{l}\text { Feedstock } \\
\text { Energy } \\
(\mathrm{GJ} / \mathrm{MT})\end{array}$ & $\begin{array}{c}\text { Embodied } \\
\text { Energy of Inputs } \\
\text { (GJ/MT) }\end{array}$ & $\begin{array}{l}\text { Total Energy } \\
\text { Embodied } \\
\text { (GJ/MT) }\end{array}$ & Source \\
\hline Polyethylene & $2.04 \mathrm{E}+00$ & $7.03 \mathrm{E}-01$ & $\begin{array}{c}3 \%, 77 \% \\
10 \%, 10 \%{ }^{1}\end{array}$ & $5.04 \mathrm{E}+01$ & $2.01 \mathrm{E}+01$ & $7.65 \mathrm{E}+01$ & Chemical Industry 2000 \\
\hline
\end{tabular}

Built and maintained by the US Energy Information Administration, the National Energy Modeling System (NEMS) is a partial equilibrium linear programming model of the United States energy sector. Since the NEMS model matches energy supply and demand by solving the energy balance for the United States economy, it incorporates an extensive database of material, commodity and other industrial process energy intensities. These intensities are found in the Industrial Demand Module documentation [EIA 2011], available online at ftp://ftp.eia.doe.gov/modeldoc/m064(2011).pdf.

Given the breadth of the NEMS model, though, its energy intensity data are often highly aggregated. For example, the energy intensities of passenger car, truck, and train manufacturing are consolidated into a single sector entitled transportation equipment. When data are aggregated in this way, NEMS usually reports energy intensities in units of thousand BTU/dollar of shipments. This approach employs the assumption that the energy intensity per dollar of value shipped is broadly similar across the industries within the sector. Sectors are chosen by grouping similar industries where this assumption yields reasonable results.

A handful of specific industrial commodities constitute such a significant share of energy consumption that they are awarded a category of their own. Their energy intensities are reported in more conventional units of million BTU/short ton of production. Cement, iron and steel, and aluminum fall into this category. In both cases, the energy consumption is broken down by energy carrier. Table B-7 summarizes commodities and sectors covered in [EIA 2011] and possibly relevant to the NFC along with the tables where the data may be found and the units in which the data are given.

The use of the [EIA 2011] data to obtain the energy embodied in a generic inorganic chemical will be shown. If the energy intensity coefficients for the sector are given in units of thousand BTU/year $2005 \$$, as is the case for chemicals, this entails a two-step process: first, the energy intensity coefficients must be obtained from the relevant table in [EIA 2011]. Second, the price of the bulk chemical must be obtained and, if necessary, adjusted to year 2005 dollars. If the coefficients are in units of million BTU/short ton, the second step is unnecessary and only a conversion to the appropriate SI units, for instance $G J / M T$, is needed. Since the general format of the tables in [EIA 2011] is the same regardless of the reporting unit, the single example of an inorganic chemical should suffice to illustrate both cases.

Figure B-2 shows the portion of Table B-8 from [AEO 2011]relevant to production of inorganic chemicals (Note: $3412 \mathrm{BTU}=1 \mathrm{kWh}$ ). Information given in Figure 2is used to populate a row of Table 2as follows. If the intensity data are in units of thousand BTU/2005 \$, a table row carrying the same column definitions as Table B-5 but with entries carrying units of $G J / 2005 \$$ is created. Table B-8 shows a row prepared in this way using energy intensity data provided in Figure B-2. The values summed to 


\section{Environmental Impacts, Health and Safety Impacts, and Financial Costs of the Front-End of the \\ Nuclear Fuel Cycle

Table B-7. Partial list of commodity and sector energy intensities reported in [EIA 2011]

\begin{tabular}{|l|l|l|}
\hline Commodity/Sector & Table in [EIA 2011] & Units of Data \\
\hline Organic Chemicals & B-5 & Thousand BTU/year 2005 \$ of shipments \\
\hline Inorganic Chemicals & B-5 & Thousand BTU/year 2005 \$ of shipments \\
\hline Resins & B-5 & Thousand BTU/year 2005 \$ of shipments \\
\hline Glass & B-6 & Million BTU/short ton of product \\
\hline Cement & B-7 & Million BTU/short ton of product \\
\hline Iron \& Steel & B-8 & Million BTU/short ton of product \\
\hline Aluminum & B-9 & Million BTU/short ton of product \\
\hline Fabricated Metals & B-10 & Thousand BTU/year 2005 \$ of shipments \\
\hline Machinery & B-10 & Thousand BTU/year 2005 \$ of shipments \\
\hline Computers \& Electronics & B-10 & Thousand BTU/year 2005 \$ of shipments \\
\hline Electrical Equipment & B-10 & Thousand BTU/year 2005 \$ of shipments \\
\hline Transportation Equipment & B-10 & Thousand BTU/year 2005 \$ of shipments \\
\hline Construction & B-12 & Thousand BTU/year 2005 \$ of shipments \\
\hline
\end{tabular}

\begin{tabular}{|c|c|c|c|c|c|c|c|c|c|}
\hline \multicolumn{5}{|c|}{ electricity input } & \multicolumn{4}{|c|}{$\begin{array}{l}\text { energy input, } \\
\text { broken down by carrier }\end{array}$} & \\
\hline \multicolumn{10}{|c|}{ (Thousand Btu/2005\$ of Shipments, Unless Otherwise Indicated) } \\
\hline & $\begin{array}{c}\text { Shipments } \\
\text { (Billion } \\
2005 \$ \text { ) }\end{array}$ & Electricity & $\begin{array}{c}\text { Natural } \\
\text { Gas }\end{array}$ & Residual & Distillate & LPG & Coal & Steam & $\begin{array}{c}\text { Petrochemical } \\
\text { Feedstocks }\end{array}$ \\
\hline \multicolumn{10}{|l|}{ Inorganic } \\
\hline End Use & & 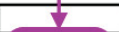 & & & & & 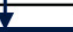 & & \\
\hline \begin{tabular}{|l|} 
Direct Heat \\
\end{tabular} & 37.3 & 0.097 & 1.695 & 0.045 & 0.093 & 0.002 & 0.088 & 1.826 & 0.000 \\
\hline Refrigeration & 37.3 & 0.000 & 0.000 & 0.000 & 0.000 & 0.000 & 0.000 & 0.000 & 0.000 \\
\hline $\begin{array}{l}\text { Machine } \\
\text { Drive }\end{array}$ & 37.3 & 6.553 & 0.000 & 0.000 & 0.013 & 0.002 & 0.000 & 0.000 & 0.000 \\
\hline Electrolytic & 37.3 & 1.397 & 0.000 & 0.000 & 0.000 & 0.000 & 0.000 & 0.000 & 0.000 \\
\hline Other & 37.3 & 0.000 & 0.000 & 0.000 & 0,000 & 0.000 & 0.000 & 0.000 & 0000 \\
\hline Feedstocks & 37.3 & 0.000 & 8.561 & 0.000 & 0.000 & 0.000 & 0.000 & 0.000 & 0.000 \\
\hline
\end{tabular}

Figure B-2. Energy consumed in the production of an inorganic bulk chemical.

obtain column B are outlined in purple, column C in blue, and column E in green. All values outlined in blue must be added to obtain the column $\mathrm{C}$ entry, but the columns must be summed individually to obtain the percentage breakdown of energy carriers for column D.

In the case illustrated in Figure B-2, it would be possible to also obtain the energy embodied in the process inputs (column F) by summing the values outlined in red and redefining the electricity and energy input ranges to avoid double counting. But since this 'feedstocks' row is not uniformly present in the EIA 
Environmental Impacts, Health and Safety Impacts, and Financial Costs of the Front-End of the Nuclear Fuel Cycle

tables, for standardization of reporting it is recommended that column $\mathrm{F}$ of entries in Table 2/Table 5 be left at 0 for all rows derived from the EIA data.

The values in columns B, C, and $\mathrm{E}$ are then added to obtain the entry for column $\mathrm{G}$. For convenience, energy intensity data are provided in Table B- 8 for both inorganic and organic chemicals. If the intensity data was given in [EIA 2011] in million BTU/short ton, the table row just computed should, following unit conversions, carry units of $G J / M T$ (or more generally $G J /$ material basis unit) and be ready for insertion as a row in Table B-5. Otherwise, the row just created will have units of GJ/year $2005 \$$, and price data for the material in question (\$/material basis unit) must be obtained and adjusted to year 2005 dollars. A discussion of the procedure for adjusting the price basis year as well as the recommended data source for chemical prices follows.

\begin{tabular}{|c|c|c|c|c|c|c|c|}
\hline $\mathbf{A}$ & B & $\mathrm{C}$ & D & $\mathbf{E}$ & $\mathbf{F}$ & G & $\mathbf{H}$ \\
\hline Commodity & $\begin{array}{c}\text { Electrical } \\
(\mathrm{GJ} / \mathrm{MT})\end{array}$ & $\begin{array}{c}\text { Direct } \\
(\mathrm{GJ} / \mathrm{MT})\end{array}$ & $\begin{array}{l}\text { Breakdown of } \\
\text { Direct Energy }\end{array}$ & $\begin{array}{c}\text { Feedstock } \\
\text { Energy } \\
(\mathrm{GJ} / \mathrm{MT})\end{array}$ & $\begin{array}{c}\text { Embodied } \\
\text { Energy of } \\
\text { Inputs (GJ/MT) }\end{array}$ & $\begin{array}{c}\text { Total Energy } \\
\text { Embodied } \\
\text { (GJ/MT) }\end{array}$ & Source \\
\hline Industrial Inorganics & $8.49 \mathrm{E}-03$ & $1.30 \mathrm{E}-02$ & $\begin{array}{l}83.2 \%, 0.4 \%, 0.9 \% \\
0 \%, 0.7 \%, 14.8 \%{ }^{1}\end{array}$ & $0.00 \mathrm{E}+00$ & $0.00 \mathrm{E}+00$ & $2.15 \mathrm{E}-02$ & [AEO 2011] \\
\hline Industrial Organics & $1.22 \mathrm{E}-03$ & $2.39 \mathrm{E}-02$ & $\begin{array}{l}14.6 \%, \quad 0.9 \%, \quad 0 \%, \\
57.2 \%, 0 \%, 27.0 \%{ }^{1}\end{array}$ & $9.69 \mathrm{E}-03$ & $0.00 \mathrm{E}+00$ & $3.48 \mathrm{E}-02$ & [AEO 2011] \\
\hline
\end{tabular}

Dollar values should be adjusted to year 2005 dollars using Consumer Price Index (CPI) data, available at $\mathrm{ftp}$ ://ftp.bls.gov/pub/special.requests/cpi/cpiai.txt. For a snapshot of the webpage, see Figure B-3. The decision to adjusted to the 2005-dollar is made to be consistent with [AEO 2011]. For consistency, use January average inflation rates to convert to the 2011 reference year value. In Figure 4, \$9.8 in the year 1913 buys $\$ 10.1$ in the year 1915 .

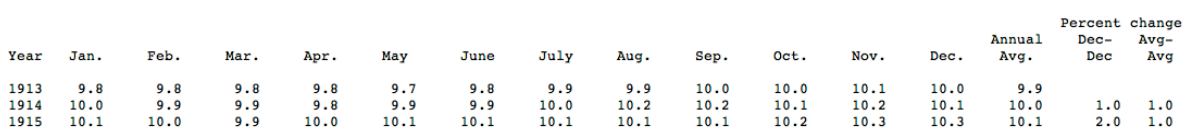

Figure B-3. Snapshot of table from CPI webpage.

Chemical price data may be found at the ICIS Chemical Market Reporter, [ICIS 2006], available at http://www.icis.com/chemicals/channel-info-chemicals-a-z/.[ICIS 2006] contains frozen price data on chemicals from the year 2006, with some 2007 and 2008 updates; see Figure B-4 for a snapshot of the webpage. Prices given in [ICIS 2006] are in 2006 dollars, unless indicated by an asterisk (*) for 2008 dollars, or a plus sign $(+)$ for 2007 dollars.

Given that the energy intensities in [EIA 2011] are specified in year 2005 dollars, it is desirable to obtain price data from as close to 2005 as possible. Although the above-described CPI adjustment can be used to account for inflation, a host of other factors affect chemical prices. Thus, price data from distant years, even if adjusted for inflation via the CPI, may yield incorrect material energy intensities if used in conjunction with the 2005 energy per dollar of product value data of [EIA 2011].

When chemical price data are unavailable at [ICIS 2006], [ICIS Chemical Business], http://www.icis.com/v2/magazine/home.aspx, provides free access to articles older than 12 months. In 
Environmental Impacts, Health and Safety Impacts, and Financial Costs of the Front-End of the

Nuclear Fuel Cycle

the Advanced Search option of [ICIS Chemical Business], enter the information shown in Figure B-5, outlined in green, with the chemical input in the 'With exact phrase' blank, outlined in purple. Figures B5 thru B-7 from (ICIS Chemical Business)

\begin{tabular}{|c|c|c|c|c|c|c|c|c|c|}
\hline \multirow{2}{*}{$\frac{\text { A-L }}{a}$} & \multicolumn{9}{|c|}{ M-Z } \\
\hline & b & c & d & f & g & 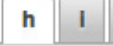 & \begin{tabular}{|l||l||l|l|} 
& $\mathbf{k}$ & $\mathbf{I}$ \\
\end{tabular} & 1 & \\
\hline \multicolumn{4}{|c|}{ Chemical } & \multicolumn{4}{|c|}{ Description } & Weight & Price, US\$ \\
\hline \multicolumn{4}{|c|}{ Heptane } & \multicolumn{4}{|c|}{ indust. tanks, f.o.b. Beaumont, Tex. } & gal & $1.21-1.64$ \\
\hline \multicolumn{4}{|c|}{ Heptane } & \multicolumn{4}{|c|}{ indust. tanks, works } & gal & $1.21-1.64$ \\
\hline \multicolumn{4}{|c|}{ Hexanei } & \multicolumn{4}{|c|}{ indust. tanks, works } & gal & $1.15-1.19$ \\
\hline \multicolumn{4}{|c|}{ Hexane } & \multicolumn{4}{|c|}{ 95\% tanks, f.o.b. Houston, Tex. } & gal & $1.15-1.19$ \\
\hline \multicolumn{4}{|c|}{ 1-Hexanol } & \multicolumn{4}{|c|}{ syn. tanks, f.o.b. } & $\mathrm{Ib}$ & 0.88 \\
\hline \multicolumn{4}{|c|}{ +Hydrochloric acid } & \multicolumn{4}{|c|}{$\begin{array}{l}22 \text { deg. Be, US Gulf dom. ex-works US } \\
\text { NE }\end{array}$} & tonne & 85.43 \\
\hline \multicolumn{4}{|c|}{ +Hydrochloric acid } & \multicolumn{4}{|c|}{22 deg. Be, US Gulf dom. ex-works USG } & tonne & 93.7 \\
\hline \multicolumn{4}{|c|}{$\begin{array}{l}\text { Hydrogen } \\
\text { peroxide }\end{array}$} & \multicolumn{4}{|c|}{$\begin{array}{l}35 \%, \text { tech., tankcars, works, frt. } \\
\text { equald. }\end{array}$} & Ib & $0.245-0.270$ \\
\hline \multicolumn{4}{|c|}{$\begin{array}{l}\text { Hydrogen } \\
\text { peroxide }\end{array}$} & \multicolumn{4}{|c|}{$50 \%$, as is basis, tankcars, frt. equald. } & Ib & $0.3425-0.3700$ \\
\hline \multicolumn{4}{|c|}{$\begin{array}{l}\text { Hydrogen } \\
\text { peroxide }\end{array}$} & \multicolumn{4}{|c|}{$70 \%$, as is basis, tankcars, frt. equald. } & Ib & $0.475-0.480$ \\
\hline \multicolumn{4}{|c|}{$\begin{array}{l}\text { Hydrogen } \\
\text { peroxide }\end{array}$} & \multicolumn{4}{|c|}{$\begin{array}{l}50 \% \text {, as is basis, } 15 \text {-gal. dms., frt. } \\
\text { equald. }\end{array}$} & Ib & 0.53 \\
\hline \multicolumn{4}{|c|}{$\begin{array}{l}\text { Hydrogen } \\
\text { peroxide }\end{array}$} & \multicolumn{4}{|c|}{$\begin{array}{l}50 \% \text {, as is basis, } 55 \text {-gal dms., frt. } \\
\text { equald. }\end{array}$} & Ib & 0.495 \\
\hline
\end{tabular}

Figure B-4. Example snapshot [ICIS 2006]. 
Environmental Impacts, Health and Safety Impacts, and Financial Costs of the Front-End of the Nuclear Fuel Cycle

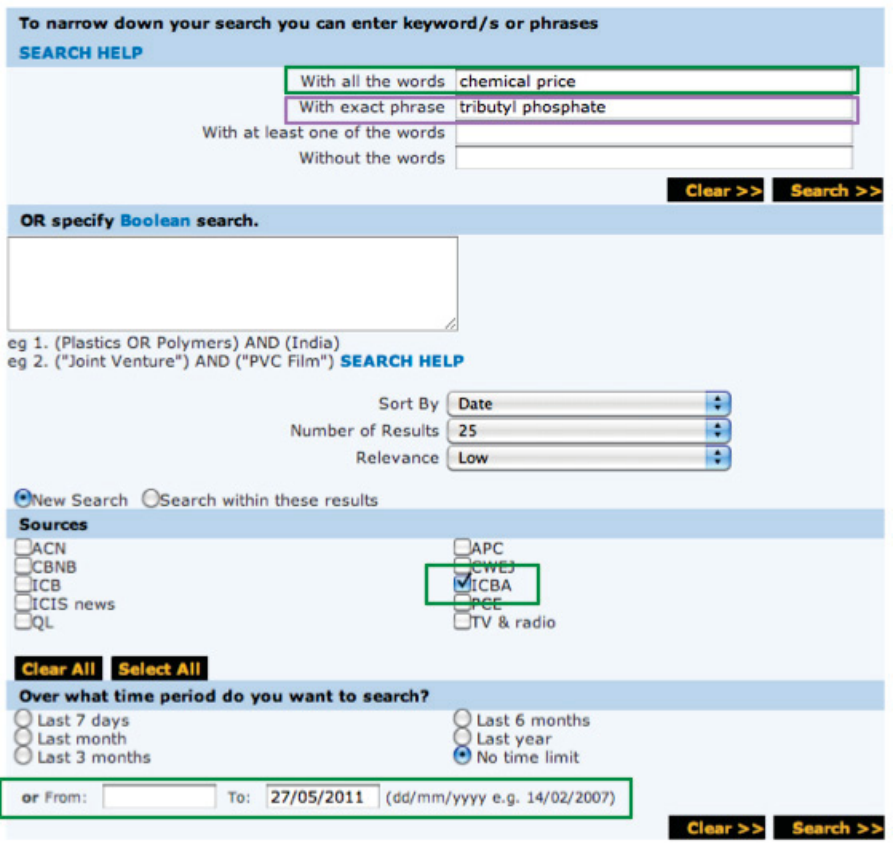

Figure B-5. Example ‘Advanced Search’ options for chemical price search.

Entries in green should be entered as shown, with the date entered as a year prior to the current date, and entry in purple should contain chemical of interest. Many search options will appear with similar titles to those shown in Figure B-6, with prices shown as in Figure B-7 (price reads as 1.8-2.36 2004\$ per 1b. of tributyl phosphate).

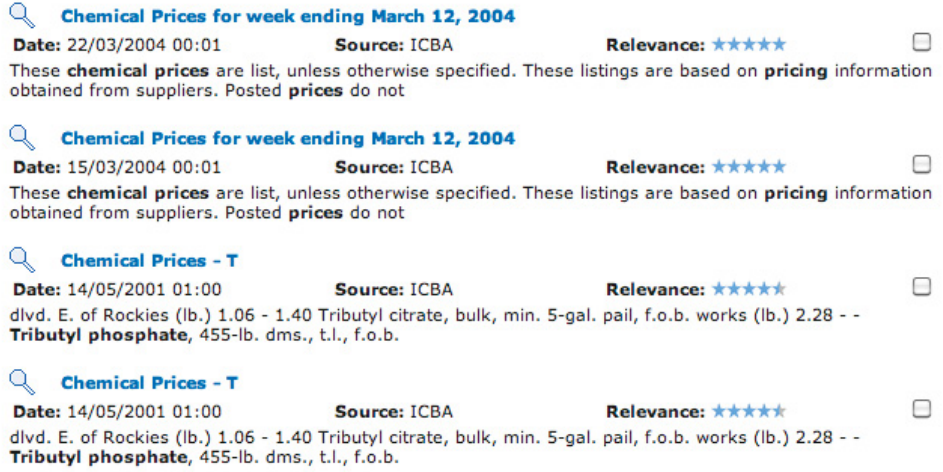

Figure B-6. Example search results from. 
Environmental Impacts, Health and Safety Impacts, and Financial Costs of the Front-End of the

Nuclear Fuel Cycle

\begin{tabular}{|c|c|c|c|}
\hline & $y$ 吅. & 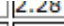 & 45 \\
\hline Tributyl phosphate 455-lb. dms., t.l., f.o.b. Charleston, N.C. & lb. & 1.80 & 2.36 \\
\hline |Trichloroethvlene. drums. dlvd. & $7 \longdiv { l b . }$ & 7.65 & F \\
\hline
\end{tabular}

Figure B-7. Example chemical price listing from search results.

Once the price in year $2005 \$$ per material basis unit is obtained, it is multiplied by the entries in columns B, C, E and G of Table B-8 (GJ per year 2005 \$) to obtain the Table B-5 row (GJ per material basis unit) for that material. The procedure for commodities other than organic and inorganic chemicals is the same, except that a table analogous to Table B- 8 must be created for that commodity from the appropriate EIA data table. Price data sources for other commodities, and their conversion to year 2005 dollars, should be clearly documented.

\section{References for Appendix B}

[Chemical Industry 2000]U.S. Department of Energy Office of Industrial Technologies, "Energy and Environmental Profile of the U.S. Chemical Industry," 2000,

http://www1.eere.energy.gov/manufacturing/industries technologies/chemicals.html.

[NREL] National Renewable Energy Laboratory, "U.S. Life Cycle Inventory Database."

[CPI]Bureau of Labor Statistics, "Consumer Price Index History

Table,"ftp://ftp.bls.gov/pub/special.requests/cpi/cpiai.txt.

[ICIS 2006]ICIS Chemical Market Reporter, "Indicative Chemical Prices A-Z," http://www.icis.com/chemicals/channel-info-chemicals-a-z/.

[ICIS Chemical Business] ICIS Chemical Business, http://www.icis.com/v2/magazine/home.aspx.

[AEO 2011]U.S. Department of Energy Office of Energy Analysis, "Model Documentation Report: Industrial Demand Module of the National Energy Modeling System," 2011,

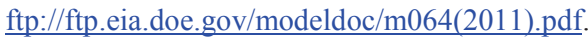




\section{Appendix C}

\section{Uranium Recovery from Seawater and from Phosphates}

\section{Recovery from Phosphates}

Figure C-1 shows the significant inputs and outputs of the uranium recovery from phosphates process. Uranium is recoverable as a by-product of phosphate rock that is commonly used to produce fertilizer by using solvent extractants and other chemicals, including DEPA-TOPO (di(2-ethylhexyl) phosphoric acidtrioctyl phosphine oxide), OPAP (octyl phenyl acid phosphate extractant), and OPPA (octyl pyro phosphoric acid extractant)(IAEA 1989). The IAEA considers uranium in phosphate an unconventional resource, and the 2009 Red Book (OECD, 2010) indicates that few countries report phosphate uranium resources - which impedes the compilation of a summary of data (Eggert, 2011). Although the recovery of uranium from phosphates has been used since the late 1950's, most production took place between 1978 and 1983. During this time uranium recovery from phosphoric acid represented nearly 5\% of world production (1500-2000 tonnes of uranium). However, there is potential for significant uranium production from phosphates in the future, although the amount is difficult to predict. The Urtek PhosEnergy process has passed a pilot scale demonstration in the U.S. and hopes to commence production sometime in 2013 with an estimated potential annual recovery of 4,500 to 9,000 tonnes U3O8 (Uranium Equities Limited, 2009).

The milling processes for mined phosphate rock can be divided into three main categories: thermal, wet, and rock crushing and calcining. Metallurgical reasons restrict uranium recovery to the wet processes, and the recovery of uranium from wet-process phosphoric acid is a proven technology that has been used commercially, although on a limited scale. As quoted from (IAEA 1989), "It is well known that the phosphate ion in the fluorapatite structure $\left[3 \mathrm{Ca}_{3}\left(\mathrm{PO}_{4}\right)_{2}{ }^{*} \mathrm{CaF}_{2}\right]$ can be partly replaced by vanadate, silicate, sulfate or carbonate ions. Rare earths, chromium, iron and uranium are other common impurities. Average concentrations of this last metal can be 50 to $200 \mathrm{ppm}$ U." Currently during the process of producing fertilizer, most of the uranium is dissolved in the phosphoric acid and shipped out with the fertilizer In the past, commercial processes have used conventional techniques to recover uranium from phosphoric acid that include: solvent extraction, ion exchange, and precipitation (IAEA 1989).

The Red Book indicates that prices greater than $\$ 100 / \mathrm{lb}_{3} \mathrm{O}_{8}$ would be necessary for phosphate processing facilities to become economically viable once again, however, recent developments in uranium by-product recovery technology have the potential to make uranium recovery from wet-process phosphoric acid to produce a significant share of world uranium production in the future. Urtek LLC, a USA registered company with owners that include Cameco and Uranium Energies Limited, has patented an ion exchanged based process called the PhosEnergy Process. This new method of recovery is expected to have operating costs in the range of $\$ 20-30 / 1 b \mathrm{U}_{3} \mathrm{O}_{8}$, which is well below the current market price of uranium. PhosEnergy implementation has passed pilot scale at a USA based phosphoric acid facility with promising results, and production could proceed as early as 2013 (Eggert, 2011).

Data was unable to be obtained on the necessary inputs and the waste streams associated with uranium recovery from phosphate production. The inputs necessary for older technology were decided as irrelevant as they are neither economical nor likely to be used in the future, and data for the newer PosEnergy Process was unavailable as it is still in the pilot stage of development. 
Environmental Impacts, Health and Safety Impacts, and Financial Costs of the Front-End of the

Direct Energy Inputs
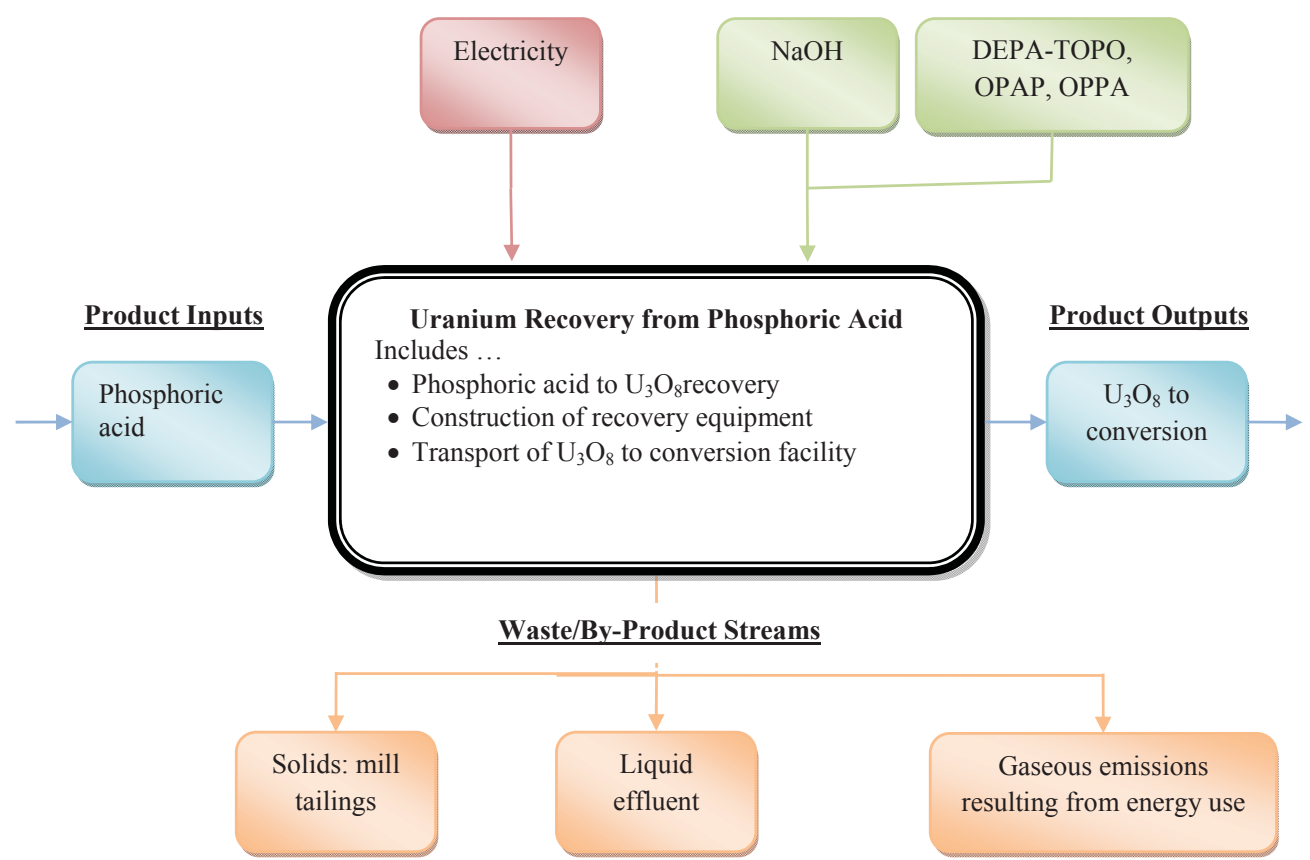

Figure C-1.Inputs and Outputs for uranium recovery from phosphates

\section{Uranium Extraction from Seawater}

Extraction of uranium from seawater is an evolving set of technologies. A current vision of seawater extraction would involve placing an array of adsorbent material in the sea, periodically retrieving the adsorbent, extracting the uranium from the array material and producing yellow cake. Each of these steps contains a host of technologies to be optimized subject to constraints such as seawater uranium concentrations of about $3 \mathrm{ppb}$, water temperature, cost of adsorbent production, durability of adsorbent, sorption capacity, sorption durability, sorption rate, and release characteristics of adsorbent material. Like all real world systems, each of the developing technologies is interconnected with all others. Imagine an interconnected system that involved a factory to produce an adsorbent material, deployment of hundreds of thousands of tons of this material in the sea, periodic (e.g., bimonthly) recovery (getting it out of the sea onto a boat for delivery to a processing facility or processing at sea) of the adsorbent, extraction of uranium from the adsorbent, processing to yield yellowcake. Thus, uranium extraction from seawater involves both mining and milling. Several authors have summarized the previous development work, mostly in Japan, which has provided a focus where major efficiency improvements are needed (Tamada, 2009), (Schneider \& Sachde, 2011), (Bardi, 2010), and (Rao, 2011). Given the developing technologies in seawater extraction of uranium (Schneider \& Sachde, 2012), (have performed an economic analysis on this subject. Many of the details on quantities that follow are based on this work 
Environmental Impacts, Health and Safety Impacts, and Financial Costs of the Front-End of the Nuclear Fuel Cycle

that also quantified a number of parameters needed for the present report. Due to the economic focus of this work, attention was not paid to impacts related to occupational personnel, the public and the marine environment. However, it may be possible to set the stage for a partial analysis of these impacts.

In (Schneider \& Sachde, 2012), the focus was an economic analysis based on the most recent Japanese developments with an examination of individual cost elements and an evaluation of the role of improvements in key cost areas. The current concept is to have a polyethylene based braided rope-like structure that has a buoyant inner core and an outer layer of sorbent material treated to enhance sorption properties for uranium (Tamada, 2009). These structures are to be anchored to the seabed using chains. There, the fibrous adsorbent can utilize the ocean currents and the wave motion. After sufficient time for uranium loading, the braid is recovered to the surface. The material is then brought to a facility for processing. First the uranium is eluted from the adsorbent then extracted to eventually produce yellow cake. Elution is achieved using a dilute hydrochloric acid to dissolve alkaline and alkaline earth metals that are also adsorbed on to the fabric from the sea, followed by nitric acid to precipitate uranium followed by aqueous ammonia to produce a high purity ammonium diuranate which is calcined to produce yellow cake (Tamada et al, 2006). If the adsorbent is still functional (useable given sorbent properties, elution fraction or mechanical) it is deployed undersea again, otherwise it is replaced.

For the purpose of the current analysis, it is assumed that a polyethylene spinning company is contracted to produce the necessary volume of adsorbent material to the correct specifications. Therefore, the adsorbent will be considered a material input to the seawater extraction process. The same holds true for all mooring related materials.

The variables most readily subject to technical improvements are found to be characteristics of the adsorbent such as adsorbent capacity, number of reuses, and cost of replacement adsorbent.

Improvements in the first two of these variables were shown by (Schneider \& Sachde, 2012) to be critical to reduce to cost structure for uranium production from seawater.

Table C-1 contains the requirements for production of 1,200 metric tons per year uranium metal. The JAEA estimate of annual costs resulted in a uranium production cost of approximately 87,700 yen (in 2005) per kg U extracted (Tamada 2009). Depending on the specific method of inflation and changes in exchange rate, the JAEA estimate reflects a production cost of between $\$ 900$ to $\$ 1000$ per kg U (2010 US\$). Reanalysis (Schneider and Sachde 2012) of the cost based on the original JAEA parameters plus a $5 \%$ decrease in adsorption efficiency per reuse would be $\$ 1230 / \mathrm{kg}$ U. By looking at potential improvements in adsorbent, (see below table) and including a 5\% efficiency loss per reuse, they have estimated the cost to be $\$ 450 / \mathrm{kg} U$ if these improvements are in fact attained.

The Department of Energy has an on-going effort to evaluate potential improvements in the overall seawater extraction process. According to a presentation by Dr. Sheng Dai (ORNL) on 8 Mar 2012, laboratory results have improved on the Japanese adsorbent capacity with an increase of about $5 \mathrm{X}$ the sorption capacity for uranium. A major issue is still the durability of the adsorption fabric; a testing program is underway to determine the extent of reuse of current fabric.

Energy and other resource inputs to the seawater extraction process are depicted in Figure C-2. Details of quantities of specific resources and other pertinent data are given in Table C-2. 
Environmental Impacts, Health and Safety Impacts, and Financial Costs of the Front-End of the

Nuclear Fuel Cycle

Table C-1. Example process data for seawater extraction

\begin{tabular}{|l|c|c|l|l|}
\hline \multicolumn{1}{|c|}{ Item } & $\begin{array}{c}\text { Value Based } \\
\text { on Original } \\
\text { JAEA Work }\end{array}$ & $\begin{array}{c}\text { Partially Optimized } \\
\text { Schneider \& Sachde } \\
2012\end{array}$ & \multicolumn{1}{|c|}{ Units } & \multicolumn{1}{|c|}{ Comments } \\
\hline Uranium Production & 1,200 & 1,200 & Metric tons per year & Metallic U basis \\
\hline Adsorbent Capacity & 2 & 6 & Kg-U/t-adsorbent & $\begin{array}{l}\text { Mooring for } 60 \text { days } \\
\text { in a region of } 25^{\circ} \mathrm{C} \\
\text { ocean current }\end{array}$ \\
\hline $\begin{array}{l}\text { Length of Campaign } \\
\text { (Recovery time period) }\end{array}$ & 60 & 60 & Days per use & $\begin{array}{l}\text { Time period moored } \\
\text { in seawater }\end{array}$ \\
\hline Adsorbent reuse & 6 & 18 & Recycles & Lifetime of adsorbent \\
\hline Adsorbent Required & 100,000 & 33,333 & Metric tons per year & Calculated \\
\hline Adsorbent Replaced & 100,000 & 11,111 & Metric tons per year & Calculated \\
\hline
\end{tabular}

Direct Energy Inputs

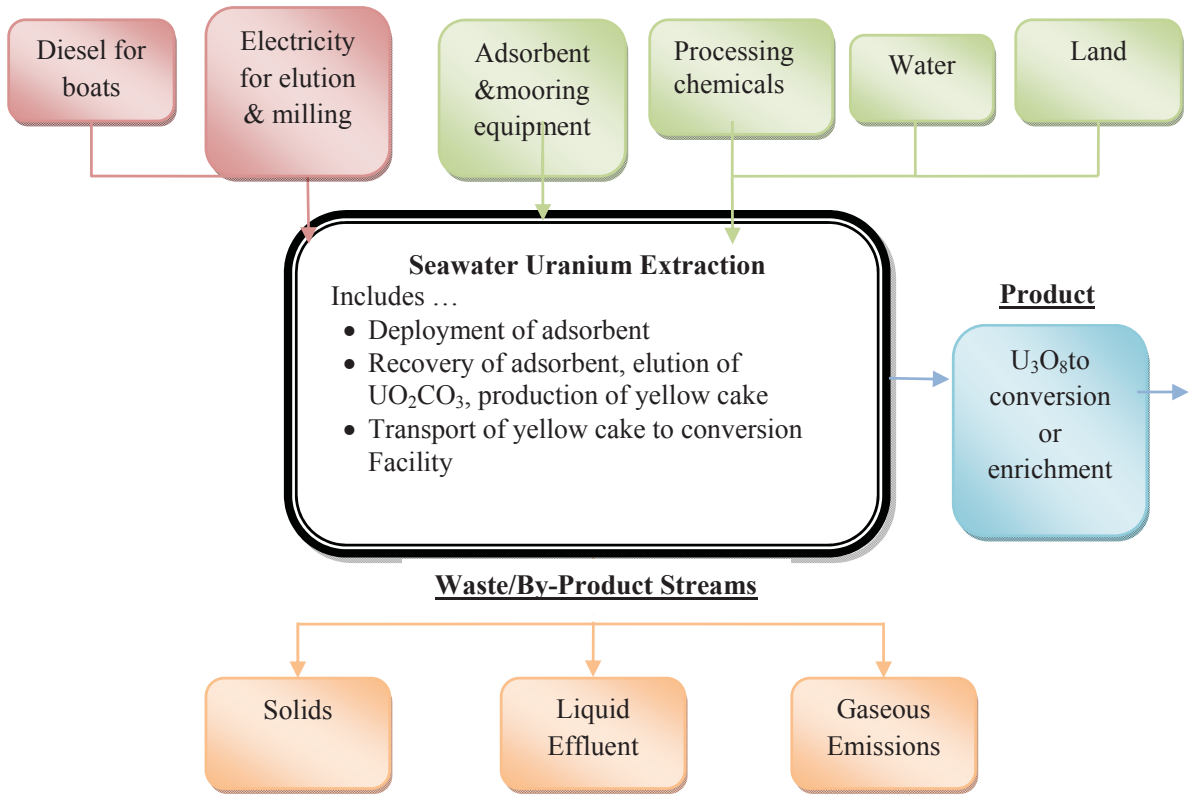

Figure C-2. Inputs and Outputs for Seawater Uranium Extraction. 
Environmental Impacts, Health and Safety Impacts, and Financial Costs of the Front-End of the Nuclear Fuel Cycle

July 2013

Table C-2. Seawater uranium extraction operations data*.

\begin{tabular}{|c|c|c|}
\hline & Units & Value based on Japanese Data \\
\hline \multicolumn{3}{|l|}{ Main Product } \\
\hline Inflow & MTNU & 0 \\
\hline Outflow (U3O8) & MTNU & 1200 \\
\hline \multicolumn{3}{|l|}{ Direct Energy Inputs } \\
\hline Diesel fuel (Boats) & Gal & $12 \mathrm{M}$ \\
\hline U Elution \& Refining & GJ & 2.84 \\
\hline \multicolumn{3}{|l|}{ Material Inputs } \\
\hline Braided Adsorbent & MT & 100,000 \\
\hline Mooring Chain & $\mathrm{km}$ & 14,789 \\
\hline \multicolumn{3}{|l|}{ Chemical Inputs } \\
\hline Nitric Acid $67 \%$ & MT & 5,180 \\
\hline Hydrochloric Acid 36\% & MT & 383 \\
\hline Sulfuric Acid $66^{\circ} \mathrm{Be}$ & MT & 73 \\
\hline Magnesium Oxide & MT & 61 \\
\hline Calcium Oxide & MT & 27 \\
\hline Kerosene & MT & 11 \\
\hline Sodium Carbonate & MT & 7 \\
\hline TBP & MT & 4 \\
\hline Ammonia & MT & 0.45 \\
\hline Filter Aid & MT & 0.07 \\
\hline \multicolumn{3}{|l|}{ Water Use } \\
\hline Combined Process Water & MT & 489,630 \\
\hline Cooling Water & MT & 741 \\
\hline \multicolumn{3}{|l|}{ Land Use } \\
\hline Seabed Temporary & $\mathrm{km}^{2}$ & 118 \\
\hline Elution \& Milling Temp & $\mathrm{km}^{2}$ & \\
\hline \multicolumn{3}{|l|}{ Workforce Size } \\
\hline Chemical Processing & FTE & 31 \\
\hline Mooring \& Recovery & FTE & 1972 \\
\hline
\end{tabular}




\section{Appendix D}

\section{Comparison of Mining Technology Estimates based on Three Data Sources}

A comparison is provided between the mining technology mix estimated based on the World Nuclear website, the 2009 version of the Red Book (OECD, 2010), and a 2011 uranium resources database created by Colorado School of Mines (Eggert, 2011). The following section contains summary data on uranium production and resources/reserves in terms of production method. In a general sense, reserves refer to quantities of uranium that are known to exist with a high degree of certainty, and that can be mined in a manner that is both commercially and technically feasible. Resources, in contrast, are additional quantities of uranium that are known to exist with moderate to high degrees of certainty; they either cannot presently be mined in a manner that is both commercially and technically feasible, or they have not been studied in sufficient detail to make this determination.

\section{Observations:}

The percentage breakdown of uranium production by process type varies between all three sources. The reason for the significant difference between the CSM paper and both the Red Book and World Nuclear numbers is that the CSM production percentages (see TableD-1) are calculated based upon the type of mining method needed to produce from resources, including both mines that are currently producing and expected to produce in the future. The World Nuclear numbers shown in Table 5-1 come from data collected from active producing mines as of May 2012 and the Red Book (OECD, 2012) data (see Table D-2) is an estimate of the type of distribution of active producing mines as of 2011. Some discrepancies between all three data sources can be attributed to differences in the source of the data that was used to estimate the percentages of each mining method used throughout the industry.

\section{Profile of Current Uranium Resources (CSM Database):}

The percentage distributions shown in Table D-1 are for the mining method used or likely to be used on existing resources that include currently operating mines, and those expected to likely come into operation in the future. This data could be used to project how the primary supply of uranium might evolve. However, there are assumptions made in these figures and any forecast into the future involves significant uncertainty. Most of the resources in the Open Pit/Underground category are from the Olympic Dam Mine. Currently, Olympic Dam is an underground operation; however, there is a proposed open pit expansion. Therefore the percentage distribution of the mining methods depends greatly upon whether the proposed mine expansion takes place.

Table D-1. Profile of current uranium resources. (Eggert, 2011)

\begin{tabular}{|l|c|c|c|}
\hline \multicolumn{1}{|c|}{ Mining Method } & $\mathrm{t} \mathrm{U}$ & Percentage of Total & Count \\
\hline Open Pit/Underground & $2,402,659$ & 32.2 & 15 \\
\hline Open Pit & $1,917,276$ & 25.7 & 44 \\
\hline Underground & $1,179,163$ & 15.8 & 189 \\
\hline Unspecified & $1,030,860$ & 13.8 & 80 \\
\hline In-Situ Recovery & 925,360 & 12.4 & 359 \\
\hline Total & $7,455,318$ & 100.0 & \\
\hline
\end{tabular}


Environmental Impacts, Health and Safety Impacts, and Financial Costs of the Front-End of the Nuclear Fuel Cycle

July 2013

Table D-2. Percentage distribution of world production, by production method. (2011 Red Book, OECD, 2012)

\begin{tabular}{|l|c|c|c|c|c|}
\hline \multicolumn{1}{|c|}{ Production Method } & 2007 & 2008 & 2009 & 2010 & 2011 (est.) \\
\hline Open-pit & 24.4 & 27.3 & 25.60 & 22.92 & 17.98 \\
\hline Underground & 36.5 & 32 & 32.61 & 31.75 & 29.26 \\
\hline In situ Leaching & 27.2 & 29.5 & 33.81 & 39.34 & 42.30 \\
\hline In place leaching (stope or block leaching) & $<0.1$ & $<0.1$ & 0.00 & 0.00 & 0.00 \\
\hline Co-product/By-product & 9.5 & 8.9 & 7.25 & 5.66 & 8.22 \\
\hline Heap Leaching (sub set of OP) & 2.3 & 2.3 & 0.71 & 0.29 & 2.06 \\
\hline $\begin{array}{l}\text { Other Methods (includes mine water treatment and } \\
\text { environmental restoration) }\end{array}$ & 0.1 & $<0.1$ & 0.02 & 0.04 & 0.18 \\
\hline
\end{tabular}




\section{Appendix E}

\section{Comparison of Impacts from Wet vs Dry Conversion Process}

The wet conversion process was selected as the representative process and used as the basis for estimating the impacts in section 6 of this report. This appendix provides additional information on the dry conversion process as well as a comparison between the two.

Table E-1 provides key inputs, outputs, and other information relative to the dry conversion process. Table E-2 and Figure E-1 depict selected impacts of the dry conversion process in relation amount to those of the wet conversion process as given in Section $6^{30}$. The discrepancy in the permanently committed land (PL) in the two processes likely arises from data provenance; data was available of the dry conversion process from (Enercon, 2012) and reflects MTW, whereas the wet conversion process was sized using data taken from (AEC, 1974), which considers a generic facility. The basis for the values given in Table 5-6 is provided in Appendix H, Table H-2.

\footnotetext{
${ }^{30}$ Details of the dry conversion metric calculations are not shown, but followed the same procedure (defined in Section 4) as was taken for the wet process.
} 
Environmental Impacts, Health and Safety Impacts, and Financial Costs of the Front-End of the Nuclear Fuel Cycle

Table E-1. Material and Energy Balance, Dry Process $\mathrm{UF}_{6}$ Conversion

\begin{tabular}{|c|c|c|c|c|}
\hline & Value & Units & Source & Assumptions \\
\hline \multicolumn{5}{|l|}{ Main Product } \\
\hline Inflow & $1.0010 \mathrm{E}+00$ & MT U & ORNL 1983 & $\begin{array}{l}\text { Assumes } 99.9 \% \text { uranium recovery. } \\
\text { Average UF6 outflow over the vears }\end{array}$ \\
\hline Outflow (DU3O8) & $1.00 \mathrm{E}+00$ & MT U & Enercon 2012 & 2007 to 2010 . \\
\hline \multicolumn{5}{|l|}{ Direct Energy Inputs } \\
\hline Electricity & $6.77 \mathrm{E}+00$ & $\mathrm{MWh}$ & Enercon 2012 & \\
\hline Natural Gas & $4.57 \mathrm{E}+06$ & $\mathrm{~L}$ & Enercon 2012 & \\
\hline \multicolumn{5}{|l|}{ Natural Resource Use } \\
\hline \multicolumn{5}{|l|}{ Water } \\
\hline Gross & $1.10 \mathrm{E}+06$ & $\mathrm{~L}$ & Enercon 2012 & \\
\hline Net & $5.05 \mathrm{E}+05$ & $\mathrm{~L}$ & Enercon 2012 & \\
\hline \multicolumn{5}{|l|}{ Land } \\
\hline Temporarily Committed & $8.18 \mathrm{E}+00$ & $\mathrm{~m} 2$ & Enercon 2012 & $\begin{array}{l}\text { Model facility has } 54 \text { year } \\
\text { operational lifetime. }\end{array}$ \\
\hline Permanently Committed & $4.83 \mathrm{E}-01$ & $\mathrm{~m} 2$ & Enercon 2012 & \\
\hline \multicolumn{5}{|l|}{ Material Inputs } \\
\hline & & & & $\begin{array}{l}\text { Site inventory scaled by ratio of HF } \\
\text { annual consumption in wet process }\end{array}$ \\
\hline Ammonia (NH3) & $1.35 \mathrm{E}-02$ & MT & Enercon 2012 & $\begin{array}{l}\text { to inventory. } \\
\text { Site inventory scaled by ratio of } \mathrm{HF} \\
\text { annual consumption in wet process }\end{array}$ \\
\hline Hydrogen Fluoride (HF) & $2.81 \mathrm{E}-01$ & MT & Enercon 2012 & $\begin{array}{l}\text { to inventory. } \\
\text { Site inventory scaled by ratio of } \mathrm{HF} \\
\text { annual consumption in wet process }\end{array}$ \\
\hline Potassium Hydroxide $(\mathrm{KOH})$ & 4.93E-02 & MT & Enercon 2012 & $\begin{array}{l}\text { to inventory. } \\
\text { Site inventory scaled by ratio of } \mathrm{HF} \\
\text { annual consumption in wet process }\end{array}$ \\
\hline Sulfuric Acid (H2SO4) & $1.23 \mathrm{E}-01$ & MT & Enercon 2012 & $\begin{array}{l}\text { to inventory. } \\
\text { Site inventory scaled by ratio of } \mathrm{HF}\end{array}$ \\
\hline Potassium Bifluoride (KHF2) & $3.95 \mathrm{E}-01$ & MT & Enercon 2012 & $\begin{array}{l}\text { annual consumption in wet process } \\
\text { to inventory. }\end{array}$ \\
\hline
\end{tabular}


Environmental Impacts, Health and Safety Impacts, and Financial Costs of the Front-End of the

Nuclear Fuel Cycle

Table E-2. Comparison of Dry Conversion and Wet Conversion Process Environmental Impacts.

\begin{tabular}{|c|c|c|c|c|c|c|}
\hline & \multicolumn{2}{|c|}{ Dry Conversion Process } & \multicolumn{2}{|c|}{ Wet Conversion Process } & \multicolumn{2}{|c|}{ Ratio } \\
\hline & \multicolumn{4}{|c|}{ Impact per MT U Output } & Dry : Wet & Wet : Dry \\
\hline \multicolumn{7}{|l|}{ Energy Use } \\
\hline Direct & $1.91 \mathrm{E}+02$ & GJ & $1.73 E+02$ & GJ & $1.10 \mathrm{E}+00$ & $9.09 \mathrm{E}-01$ \\
\hline Embodied & $7.33 \mathrm{E}+01$ & GJ & $9.60 \mathrm{E}+01$ & GJ & 7.63E-01 & $1.31 \mathrm{E}+00$ \\
\hline Energy (Total) & $2.64 \mathrm{E}+02$ & GJ & $2.69 \mathrm{E}+02$ & GJ & $9.80 \mathrm{E}-01$ & $1.02 \mathrm{E}+00$ \\
\hline \multicolumn{7}{|l|}{ Natural Resource Use } \\
\hline \multicolumn{7}{|l|}{ Water } \\
\hline Gross & $1.10 \mathrm{E}+06$ & $\mathrm{~L}$ & $6.46 \mathrm{E}+05$ & $\mathrm{~L}$ & $1.70 \mathrm{E}+00$ & $5.88 \mathrm{E}-01$ \\
\hline Net & $5.05 \mathrm{E}+05$ & $\mathrm{~L}$ & $6.46 \mathrm{E}+04$ & $\mathrm{~L}$ & $7.82 \mathrm{E}+00$ & $1.28 \mathrm{E}-01$ \\
\hline \multicolumn{7}{|l|}{ Land } \\
\hline Temporarily Committed & $8.18 \mathrm{E}+00$ & $\mathrm{~m} 2$ & $3.28 \mathrm{E}+00$ & $\mathrm{~m} 2$ & $2.50 \mathrm{E}+00$ & $4.00 \mathrm{E}-01$ \\
\hline Permanently Committed & $4.83 \mathrm{E}-01$ & $\mathrm{~m} 2$ & $2.62 \mathrm{E}-02$ & $\mathrm{~m} 2$ & $1.84 \mathrm{E}+01$ & $5.43 \mathrm{E}-02$ \\
\hline Total Land Usage & $8.67 \mathrm{E}+00$ & $\mathrm{~m} 2$ & $3.30 \mathrm{E}+00$ & $\mathrm{~m} 2$ & $2.62 \mathrm{E}+00$ & 3.81E-01 \\
\hline
\end{tabular}

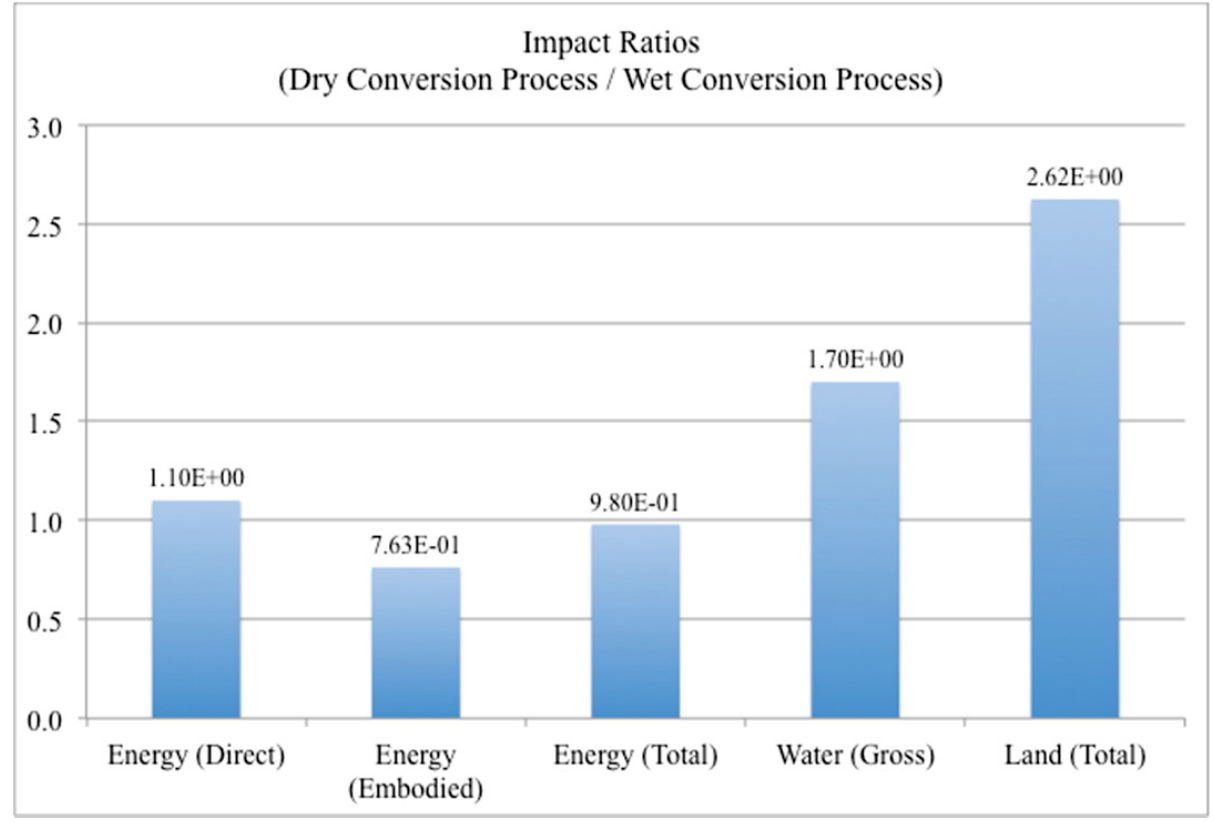

Figure E-1. Impact ratios of dry conversion process to wet conversion process. 


\section{Appendix F}

\section{Thorium Extraction and Refining from By-Products of REE and IImenite Mining}

This appendix includes two estimates of the thorium supply that could be available from by-product streams as well as a detailed discussion of the process for extracting and refining thorium from byproducts of rare earth and ilmenite mining. Section I provides a conservative Th supply estimate based on global mining of REE and ilmenite. Section II gives a more focused estimate based on specific mining operations in the U.S. Section III provides an overview of the process for extracting and refining Th from these by-product streams.

Sections I and II were prepared by Rod Eggert and Brett Jordan of the Colorado School of Mines. Section III was prepared by Raymond Wymer, Allen Croff, Timothy Ault, Steven Krahn of Vanderbilt University.

\section{Potential Global Production of Thorium as a Byproduct}

Should a demand for thorium arise, it could be produced globally as a byproduct of currently operating rare-earth and titanium-sand mines. Table F-1 summarizes estimates of potential annual thorium production from these sources by country. These figures are based on actual main-product production levels in 2011.

Table F-1. Potential Global Thorium Byproduct Production by Country ${ }^{1}$

\begin{tabular}{|c|c|}
\hline Country & $\begin{array}{c}\text { Total Potential Thorium } \\
\text { (Metric Tonnes per Year) }\end{array}$ \\
\hline Australia & 138 \\
\hline Brazil & 6 \\
\hline Canada & 100 \\
\hline China & 428 \\
\hline India & 44 \\
\hline Madagascar & 37 \\
\hline Malaysia & N/A \\
\hline Mozambique & 51 \\
\hline Norway & 48 \\
\hline South Africa & 148 \\
\hline Sri Lanka & 4 \\
\hline Ukraine & 40 \\
\hline United States & 40 \\
\hline Vietnam & 73 \\
\hline Other countries & 5 \\
\hline Total & 1,162 Tonnes \\
\hline 1. Note that these estimates are conservative and represent a lower bound of production rather than an expected total. \\
\hline
\end{tabular}




\section{Thorium as a Byproduct of Rare-earth Mining}

Estimates of thorium as a byproduct of rare-earth mining are based on actual rare-earth oxide produced in 2011. Since 2011, two major rare earth projects have begun to ramp-up production, the Mt. Weld mine in Australia and the Mountain Pass mine in California. Combined these mines are projected to produce nearly 40,000 tonnes per year at capacity (Lynas; Molycorp 2013). With this in mind, 2011 quantities are intended to give an idea of what thorium production could look like, and should not be interpreted as a forecast for future production.

In China, quantities from each province are capped by the state. Rare-earth production for the individual provinces is based on these quotas. Recently however, these quotas have always been exceeded (though in 2011 enforcement cut back on much of this excess supply). To account for this difference, each province's quota was multiplied by the country's total quota violation, a factor of about 1.03. An average REO-to-thorium ratio was computed based on their relative concentration in the average ore body of each country or province. This ratio can be used to assess potential byproduct thorium, assuming a similar metallurgical recovery of thorium as the main product. Table F-2 provides a summary of Th available as a byproduct of existing REO production.

Table F-2. Thorium as a Rare-earth By-product by Country

\begin{tabular}{|c|c|c|c|}
\hline Country & $\begin{array}{l}2011 \text { REO Production } \\
\text { (metric tonnes per year) }\end{array}$ & REO to Th ratio & Potential Thorium \\
\hline Australia & $2,200^{1}$ & $227: 1^{3}$ & 10 \\
\hline China & 96,900 & - & 340 \\
\hline Inner Mongolia & $51,652^{2}$ & $286: 1^{4}$ & 180 \\
\hline Sichuan & $25,206^{2}$ & $219: 1^{4}$ & 115 \\
\hline Shandong & $1,550^{2}$ & $219: 2^{4}$ & 7 \\
\hline Rest of China & $18,492^{2}$ & $500: 1^{5}$ & 37 \\
\hline Total & 98,896 & - & 350 \\
\hline \multicolumn{4}{|c|}{$\begin{array}{l}\text { 1. Gambogi, Joseph. Rare Earths Mineral Commodity Summary. Issue brief. N.p., 2013. Web. Mar. } 2013 . \\
\text { <http://minerals.usgs.gov/minerals/pubs/commodity/rare_earths/mcs-2013-raree.pdf>. } \\
\text { 2. "Rare-Earth Supply." Innovation Metals Corp. N.p., n.d. Web. } 22 \\
\text { 3. Rare Earths \& Yttrium: Market Outlook to 2015. 14th ed. Roskill, 2011. } \\
\text { 4. Bi, Yanfeng. "Separation of Thorium from Rare Earth Elements." YouTube. N.p., } 12 \text { Dec. 2012. Web. } 22 \text { Mar. } \\
\text { 2013. <http://www.youtube.com/watch?v=813kBhBgBGU>. } \\
\text { 5. Kremers, Howard E. 1958. Commercial Thorium Ores. Society of Mining Engineers }\end{array}$} \\
\hline
\end{tabular}

\section{Thorium as a Byproduct of Titanium Sand Mining}

According to the World Nuclear Association, thorium's occurrence in heavy mineral sand concentrate ranges from $80-800 \mathrm{ppm}$, or $0.008-0.08 \%$ (Mineral Sands). To find the potential production of thorium from these heavy mineral sands, this concentration was compared to the concentration of one of the most important minerals in these deposits, ilmenite. Ilmenite's grade in heavy sand concentrate can vary as widely as thorium's. Because of this variation, a more conservative estimate will be calculated. It is based on a higher grade of ilmenite (here assumed to be $60 \%$ of the heavy mineral sand concentrate), and a lower grade of thorium $(0.008 \%)$. These figures imply that every 7,500 tonnes of ilmenite produced will yield 1 tonne of thorium (if their metallurgical recovery rate is the same). This ratio is used to calculate the potential production of each country in Table F-3. 
Environmental Impacts, Health and Safety Impacts, and Financial Costs of the Front-End of the Nuclear Fuel Cycle

Table F-3. Thorium as a Titanium Sand Byproduct - Annual Production by Country ${ }^{1}$

\begin{tabular}{|l|c|c|}
\hline \multicolumn{1}{|c|}{ Country } & $\begin{array}{c}\text { 2011 Ilmenite Produced } \\
\text { ('000 tonnes) }\end{array}$ & $\begin{array}{c}\text { Potential Thorium } \\
\text { (tonnes) }\end{array}$ \\
\hline Australia & 960 & 128 \\
\hline Brazil & 45 & 6 \\
\hline Canada & 750 & 100 \\
\hline China & 660 & 88 \\
\hline India & 330 & 44 \\
\hline Madagascar & 280 & 37 \\
\hline Malyasia & N/A & 51 \\
\hline Mozambique & 380 & 48 \\
\hline Norway & 360 & 148 \\
\hline South Africa & 1,110 & 4 \\
\hline Sri Lanka & 31 & 40 \\
\hline Ukraine & 300 & 40 \\
\hline United States & 300 & 73 \\
\hline Vietnam & 550 & 5 \\
\hline Other countries & 40 & 813 \\
\hline Total & 6,096 & \\
\hline 1. (WNA 2010) and (Bedinger 2013) & & \\
2. Malaysian data unavailable, but is a potential source & & \\
\hline \multicolumn{2}{|l}{} \\
\hline
\end{tabular}

\section{Potential U.S. Thorium as By-product}

The following estimates potential thorium (Th) production in the United States as a byproduct of rareearth and titanium-sand production. Table F-4 summarizes the estimates, which represent potential production from three rare-earth mines that either are in production now (Mountain Pass) or may come into production in the next decade (Bokan Mountain, Bear Lodge) as well as a titanium sand mine currently operated by Iluka Resources. As such, they are lower-bound estimates, as long as these mines actually become or remain commercially viable because of the value of their main products, rare earths and titanium. Various estimates are provided. Summing the low estimates indicates a minimum annual Th production of 249 MTTh is achievable with potential for annual production as high as 976 MTTh.

Details for the estimates shown in Table F-4 are provided in Tables F-5 through F-8. All of these estimates use the same metallurgical recovery rate for thorium as the associated main products.

Table F-4. Potential U.S. Thorium Production as a Byproduct of Rare-Earth and Titanium-Sand Mining

\begin{tabular}{|l|l|c|c|c|}
\hline \multirow{2}{*}{$\begin{array}{c}\text { Mine } \\
\text { Thorium Concentration / Source }\end{array}$} & $\begin{array}{c}\text { Mine } \\
\text { Life } \\
\text { (yrs) }\end{array}$ & $\begin{array}{c}\text { MT of Elemental Thorium } \\
\text { Annual } \\
\text { Production }\end{array}$ & $\begin{array}{c}\text { Life-of-Mine } \\
\text { Production* }\end{array}$ \\
\hline \multirow{2}{*}{$\begin{array}{l}\text { Bokan Mountain, } \\
\text { Alaska (in advanced } \\
\text { exploration) }\end{array}$} & $84.28(\mathrm{PPM})($ TetraTech 2013) & 11 & 27 & 297 \\
\cline { 2 - 5 } & $1520(\mathrm{PPM})$ (Van Gosen 2013) & 11 & 517 & 5687 \\
\hline \multirow{2}{*}{$\begin{array}{l}\text { Bear Lodge, Wyoming } \\
\text { (in advanced } \\
\text { exploration) }\end{array}$} & $0.23 \%($ Roche Engineering 2012) & 19 & 119 & 2261 \\
\cline { 2 - 5 } & $312(\mathrm{PPM})$ (Roche Engineering 2012) & 19 & 82 & 1558 \\
\cline { 2 - 5 } & $1160(\mathrm{PPM})$ (Van Gosen 2013) & 19 & 307 & 5833 \\
\cline { 2 - 5 } & $562(\mathrm{PPM})$, no outlier (Van Gosen & 19 & 149 & 2831 \\
\hline
\end{tabular}


Environmental Impacts, Health and Safety Impacts, and Financial Costs of the Front-End of the

Nuclear Fuel Cycle

\begin{tabular}{|c|c|c|c|c|}
\hline & 2013) & & & \\
\hline \multirow{2}{*}{$\begin{array}{l}\text { Mountain Pass, } \\
\text { California (in } \\
\text { production) }\end{array}$} & $0.026 \%$ Grade / Staatz* & 30 & 58 & 1740 \\
\hline & $0.032 \%$ Grade (Van Gosen 2013$)^{*}$ & 30 & 70 & 2100 \\
\hline $\begin{array}{l}\text { Virginia (Iluka) } \\
\text { (various resources, } \\
\text { some in production) }\end{array}$ & $0.002 \%$ Grade (Van Gosen 2013 ) & $\begin{array}{l}\text { Indefi } \\
\text { nite }\end{array}$ & 82 & \\
\hline \multirow{2}{*}{$\begin{array}{l}\text { Total Annual } \\
\text { Byproduct Supply }\end{array}$} & Low & & 249 & \\
\hline & High & & 976 & \\
\hline
\end{tabular}

Tables F-5 through F-8 show more detail on how the figures in Table F-4 are calculated. Every mine starts with at least one estimate of average thorium concentration in-situ represented by a column. This concentration is multiplied by tonnage of ore mined annually to find "Thorium in raw ore." The thorium then proceeds through the same stages of processing as the rare earth materials, with the recovery fraction showing the quantity of material that moves to that stage; the remainder is treaded as waste. The recovery fractions are a combination of given and calculated information. Public documents outlining these processes either report directly or imply (through the concentration of rare earths in total material) a tonnage of total rare earth oxides (TREO) at each stage. The ratio of TREO advancing from a given stage to the next is the recovery fraction.

The Bokan Mountain preliminary economic assessment reports an average thorium concentration of $84.28 \mathrm{ppm}$ at a cut-off grade of $0.4 \%$ total rare earth oxide. Samples taken by Van Gosen averaged 1520 ppm thorium. The proposed Bokan mine is expected to produce 540 thousand tonnes of ore per year. As shown in Table F-5, the resulting range of annual Th production is from $\sim 27$ to $517 \mathrm{MT}$ Th.

Table F-5. Potential Thorium as By-product from Bokan Mountain, Alaska

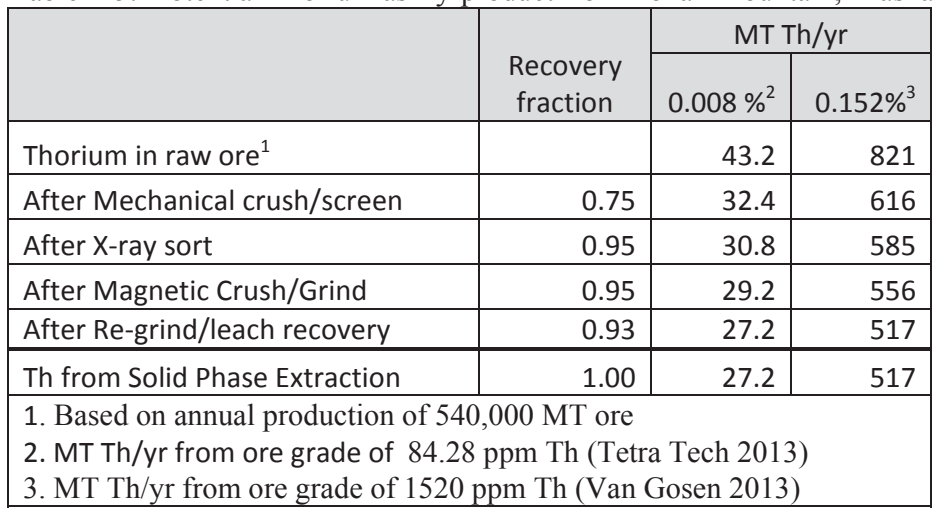

The Bear Lodge technical report includes two thorium estimates, one as an in-situ concentration (312 $\mathrm{ppm}$ ) and one as a grade of $0.23 \%$ thorium in the $61,533 \mathrm{MT}$ of pre-produced concentrate . Samples taken by Van Gosen at the site averaged $1160 \mathrm{ppm}$. One of these samples had a concentration that was approximately three times larger than the next highest. With this sample removed, thorium concentration averages approximately 562 ppm (labeled 'No Outlier' in Table F4). As shown in Table F-6, the resulting range of annual Th production is from $\sim 82$ to $307 \mathrm{MT}$ Th. 
Environmental Impacts, Health and Safety Impacts, and Financial Costs of the Front-End of the Nuclear Fuel Cycle

July 2013

Table F-6. Potential Thorium as By-product from Bear Lodge, Wyoming

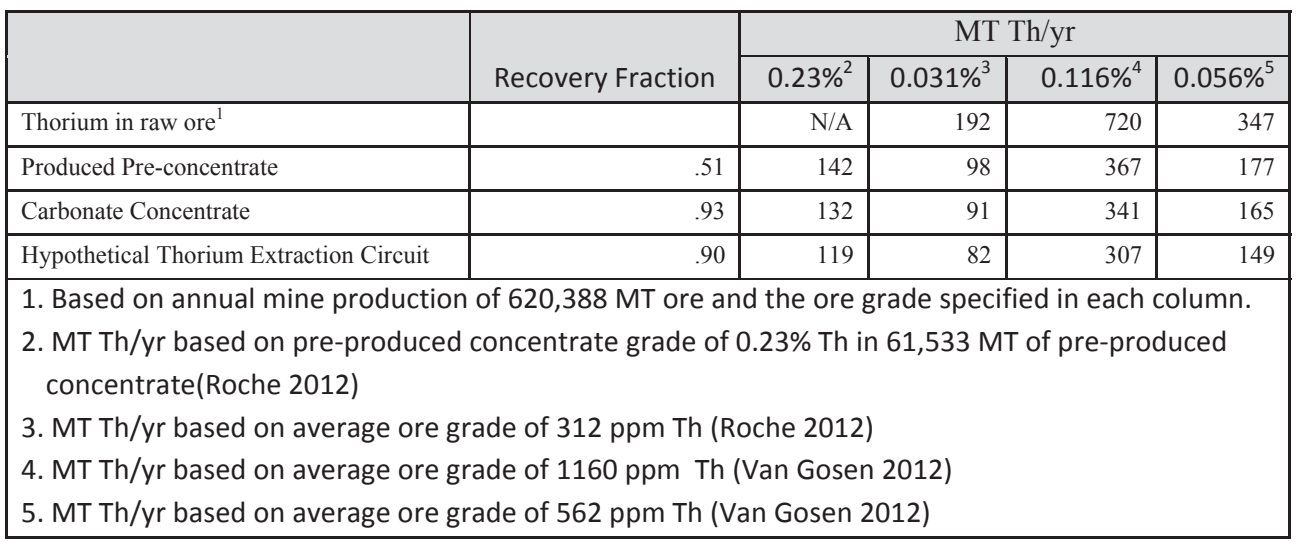

The Mountain Pass mine does not report an average concentration of thorium in its technical report. Thorium concentration estimates for this mine come from Staatz (1979) and Van Gosen (personal communication). The Mountain Pass mine is expected to produce 414,039 metric tonnes of ore per year. The estimates of ore grade range from $.023 \%$ to $.028 \%$ thorium, based on an oxide to element ratio of $1.1379: 1$. The estimates assume that the recovery of thorium is the same as for REOs, as the rare earths and thorium are contained in the same mineral, bastnäsite. As shown in Table F-7, the resulting range of annual Th production from by-products of this mining operation at is $\sim 58$ to $70 \mathrm{MT}$ Th

Table F-7. Potential Thorium as By-product from Mountain Pass (California)

\begin{tabular}{|c|c|c|c|}
\hline & \multirow{2}{*}{ Recovery Fraction } & \multicolumn{2}{|c|}{ MT Th/yr } \\
\hline & & $0.00023^{2}$ & $0.00028^{3}$ \\
\hline Thorium in raw ore $^{1}$ & & 95 & 116 \\
\hline Bastnäsite concentrate to Chemical Plant & 0.65 & 62 & 75 \\
\hline Total Recovered REO/ Th & 0.93 & 58 & 70 \\
\hline $\begin{array}{l}\text { 1. Based on annual production of } 414,039 \\
\text { 2. MT Th/yr based on mill feed at } .023 \% \mathrm{~T} \\
\text { 3. MT Th/yr based on mill feed at } .028 \% \mathrm{~T}\end{array}$ & $\begin{array}{l}1 \mathrm{~T} \text { ore (SRK 2011) } \\
\text { (.026\% Th Oxide (St } \\
.032 \% \text { Th oxide Van }\end{array}$ & $\begin{array}{l}\text { et al 1979)) } \\
\text { en 2013)) }\end{array}$ & \\
\hline
\end{tabular}

The Iluka titanium-sand mine in Virginia also does not have publically available estimates of thorium concentrations. Other monazite data (supplied by Van Gosen, personal communication) are the basis for the in Table F-8 which provide the range of annual Th that could result from by-products of titanium sand-mining.

Monazite is contained within the heavy mineral group, but not the subset of this group known as the valuable heavy minerals (VHM). Unlike the mines above, thorium is removed in the first concentrating 
Environmental Impacts, Health and Safety Impacts, and Financial Costs of the Front-End of the

Nuclear Fuel Cycle

step. However for consistency, the assumption that thorium is recovered at the same rate as the VHM is maintained.

Table F-8. Potential Thorium as By-product from Virginia (Iluka)

\begin{tabular}{|c|c|c|c|}
\hline & D & & \\
\hline & Recovery Fraction & Monazite $^{*}$ & $\mathrm{Th}^{*}$ \\
\hline & & $0.45 \%$ & $5.01 \%$ \\
\hline Heavy mineral in mined sand & & 1806 & 90 \\
\hline after concentrating & 0.94 & 1698 & 85 \\
\hline Process Loss & 1.00 & 1698 & 85 \\
\hline Additional Process Loss & 0.97 & 1647 & 82 \\
\hline $\begin{array}{l}\text { * 4,560,510 tonnes of sand a } \\
\text { (Iluka 2011) in-turn contair } \\
\text { (Van Gosen 2013). }\end{array}$ & $\begin{array}{l}\text { I annually containing } \\
\% \text { monazite. Monaz }\end{array}$ & $\begin{array}{l}325 \text { tonnes } \\
\text { pically conta }\end{array}$ & $\begin{array}{l}y \text { mineral } \\
1 \% \text { Th }\end{array}$ \\
\hline
\end{tabular}

\section{Summary of the Thorium Refining Process}

There are more than 100 thorium-bearing minerals, with about 60 having $>1 \%$ thorium in association with uranium and rare earths. Monazite alluvial deposits contain about $40 \%$ of the thorium reserves and can average $3-10 \%$ thorium. Therefore, flowsheets based on thorium recovery from monazite can be a useful surrogate for evaluating thorium recovery flowsheets in general. Monazite is a very refractory orthophosphate of cerium and light rare earths containing thorium and uranium.

This appendix is primarily concerned with the refining of monazite ores to produce thorium. Monazite may be a byproduct or co-product of iron ore mining, rare earth ore mining, or ilmenite (titanium source) beach sand mining. Beach sand mining requires less crushing and sizing energy than the other options, but the chemical processes used to isolate thorium are not expected to vary significantly between cases. Even once monazite is separated, the present value of its thorium content may be less than that of its rare earth content. Thus, thorium is often not recovered, though thorium compounds are sometimes stockpiled for future recovery (for example, U.S. in the past, India at present). Though most prior work related to isolating thorium has examined monazite, a few sources have considered another rare earth mineral, bastnasite, which can also contain high thorium concentrations; this will be also discussed to a lesser extent.

To obtain a reactor-grade thorium product, monazite or bastnasite must be isolated from other geologic materials, at high purity, and then chemically attacked to solubilize its components from a tightly bound mineral structure. After separating some undesirable contaminants and/or byproduct streams, solvent (liquid-liquid) extraction is generally employed to obtain high grade thorium with very low levels of contamination.

The Thorium recovery process described follows the block flow diagram given below in Figure F-1. 


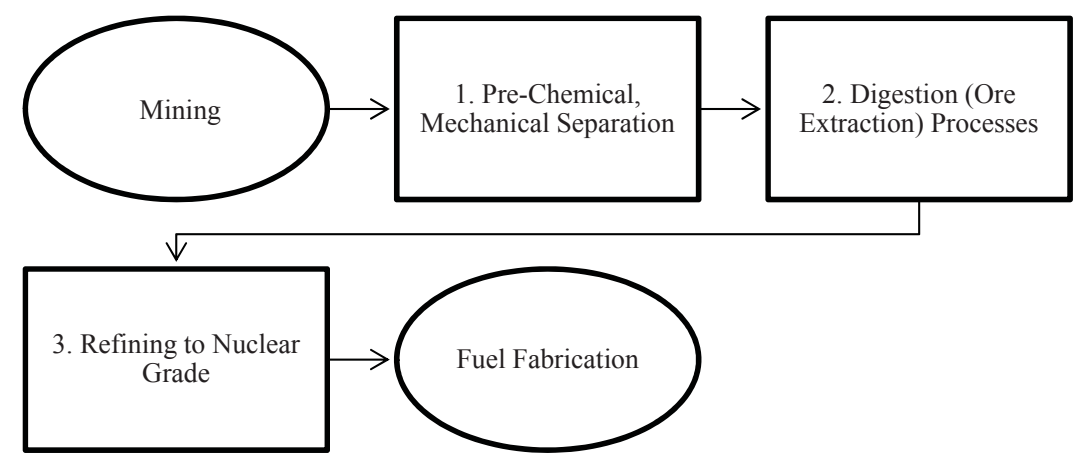

Figure F-1. Overview of Thorium Recovery Process.

\section{Pre-Chemical Stage (see Figure F-2)}

Monazite is almost always obtained in conjunction with other, more abundant minerals and must be separated before it can be processed further. Monazite is beneficiated from minerals where it is often present at $<1 \%$ in alluvial deposits. These minerals (include monazite) are crushed for processing. After some initial crushing, monazite may be concentrated to about $98 \%$ by gravity, electromagnetic and/or electrostatic methods or a combination of them. The exact sequence depends on the mix of minerals encountered and the products and co-products/by-products desired. Once the monazite is isolated, the particle size must be further reduced for the subsequent acidic or caustic attack to be most effective.

\subsection{Initial Crushing of Minerals}

The minerals are crushed/grinded to a reasonably small size to facilitate the separation of different mineral types.

\subsection{Beneficiation of Monazite from other Minerals}

Monazite would most likely be produced as a byproduct of another commodity. In the case of beach sand mining in Virginia, ilmenite is the primary product, followed by zircon and perhaps rutile. Processes already exist to isolate these components; the difference is that the monazite, currently considered a waste stream, would become a product stream.

\subsubsection{Gravitational Separation}

With a specific gravity often in excess of 5, monazite is usually among the densest, if not the densest, mineral obtained during mining operations. Correspondingly, gravity-based separations are typically used to isolate monazite.

\subsubsection{Magnetic Separation}

Ilmenite is highly magnetic and can be readily removed from the monazite. Monazite has a rather middling susceptibility to magnetism and remains with the less magnetic minerals. 
Environmental Impacts, Health and Safety Impacts, and Financial Costs of the Front-End of the

\subsubsection{Electrostatic Separation}

Unlike most of its accompanying minerals, monazite has a very low electrostatic attraction. Thus, most remaining minerals are removed by this means, and very pure monazite is obtained. The order of the monazite separation steps may vary by facility; for instance, [Kaya 2003] describes a process flow where the electrostatic separations preceding the magnetic separations.

\subsection{Further Sizing of Particles}

The mesh size must be brought down to the order of a hundred microns by grinding and/or crushing for subsequent chemical processing to be effective. In some cases, the initial crushing may have been sufficient, and the step would subsequently be unnecessary

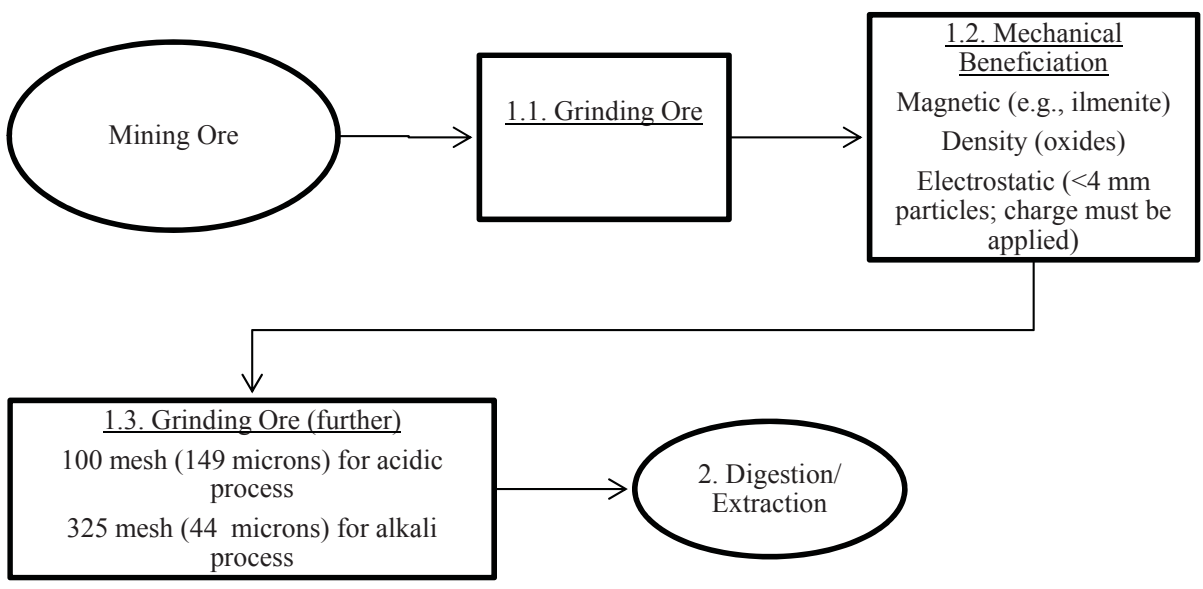

Figure F-2. Pre-Chemical Processes to Separate Monazite-Bearing Ore

\section{Digestion (Ore Extraction) Processes}

Once the purified monazite has been sized to an appropriate range, it must be solubilized for separation to be reasonably achieved. Monazite has a very refractory crystal structure ([Keni 1990]) which requires a highly concentrated, potent chemical agent to open the lattice and extract its thorium, uranium, and rare earths content. A strong acid or base can be used, and variations exist within both routes. Neither the acid nor the alkali digestion process is selective for thorium extraction, so further separation is necessary. Potentially valuable phosphoric acid is produced in the acid process; in the alkali process sodium phosphate is recovered as a by-product.

An important alternative to thorium isolation by precipitation in the acid/caustic digestion process is recovery of thorium, rare earths and uranium by two cycles of solvent extraction of the sulfate solution obtained by digestion. In the first cycle uranium is preferentially extracted using a tertiary 
Environmental Impacts, Health and Safety Impacts, and Financial Costs of the Front-End of the Nuclear Fuel Cycle

amine; in the second cycle thorium is recovered from the first cycle raffinate by primary amine extraction. Rare earths are recovered by primary amine extraction of the second cycle raffinate. However, the acid and caustic digestion processes will be the primary ones considered herein.

Some publications refer to these processes as the final steps of milling rather than the early stages of refining. This potential confusion can be resolved by distinguishing between milling, extracting, and refining, rather than merely milling and refining.

\subsection{Acid Digestion Processes (see Figure F-3).}

\subsubsection{Filtration of Non-Extracted Components}

The purpose of this step is to eliminate undissolved monazite constituents and other solid components such as silica and zircon. This is a physical, rather than a chemical, stage. The digested solution is typically diluted and allowed sufficient time to permit the solids from the aqueous monazite to settle. Some sources ([ORNL 1978] \& others) indicate that a flocculating agent may be added in this step to speed settling of the solids.

\subsubsection{Dilution}

The thorium-containing sulfate-phosphate solution must be diluted with water by a factor of 6-7 in preparation for subsequent steps.

\subsubsection{Precipitation of Monazite Components}

Depending on the process, more than one precipitation reaction could be usedto form a thorium-rich precipitate. The Indian process described by [Keni 1990] uses ammonium hydroxide to lower the $\mathrm{pH}$ and shift the phosphoric acid solution back to phosphate ions, resulting in a thorium phosphate precipitate.

\subsubsection{Precipitation of Monazite Components}

Depending on the process, more than one precipitation reaction could be used. The goal here is to add an agent that results in the formation of a thorium-rich precipitate. The Indian process described by [Keni 1990] uses ammonium hydroxide to lower the $\mathrm{pH}$ and shift the phosphoric acid solution back to phosphate ions, resulting in a thorium phosphate precipitate.

\subsubsection{Filtration of Rare Earth, Uranium, and Thorium Phases}

Once the thorium is in a distinct phase from the rare earths and uranium, physical processes can again be applied to separate the aqueous and solid phases. This is a not a perfect separation, and rare earths may constitute up to $30 \%$ of the precipitate phase, but this is sufficient enough to be a useful starting point for nuclear-grade refining. 
Environmental Impacts, Health and Safety Impacts, and Financial Costs of the Front-End of the

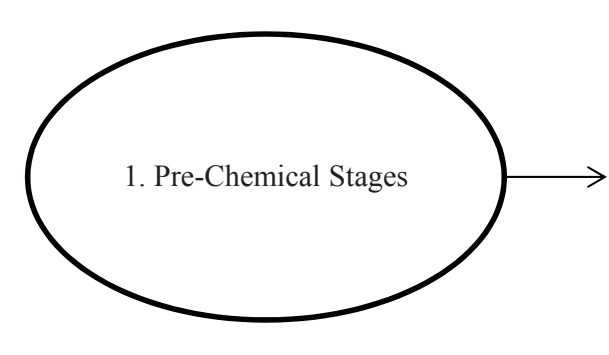

\subsubsection{Ore Digestion}

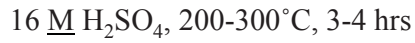

$\mathrm{H}_{2} \mathrm{SO}_{4} /$ monazite $=1.6-2.5$

95\% thorium extraction

soluble thorium sulfate/pyrophosphate

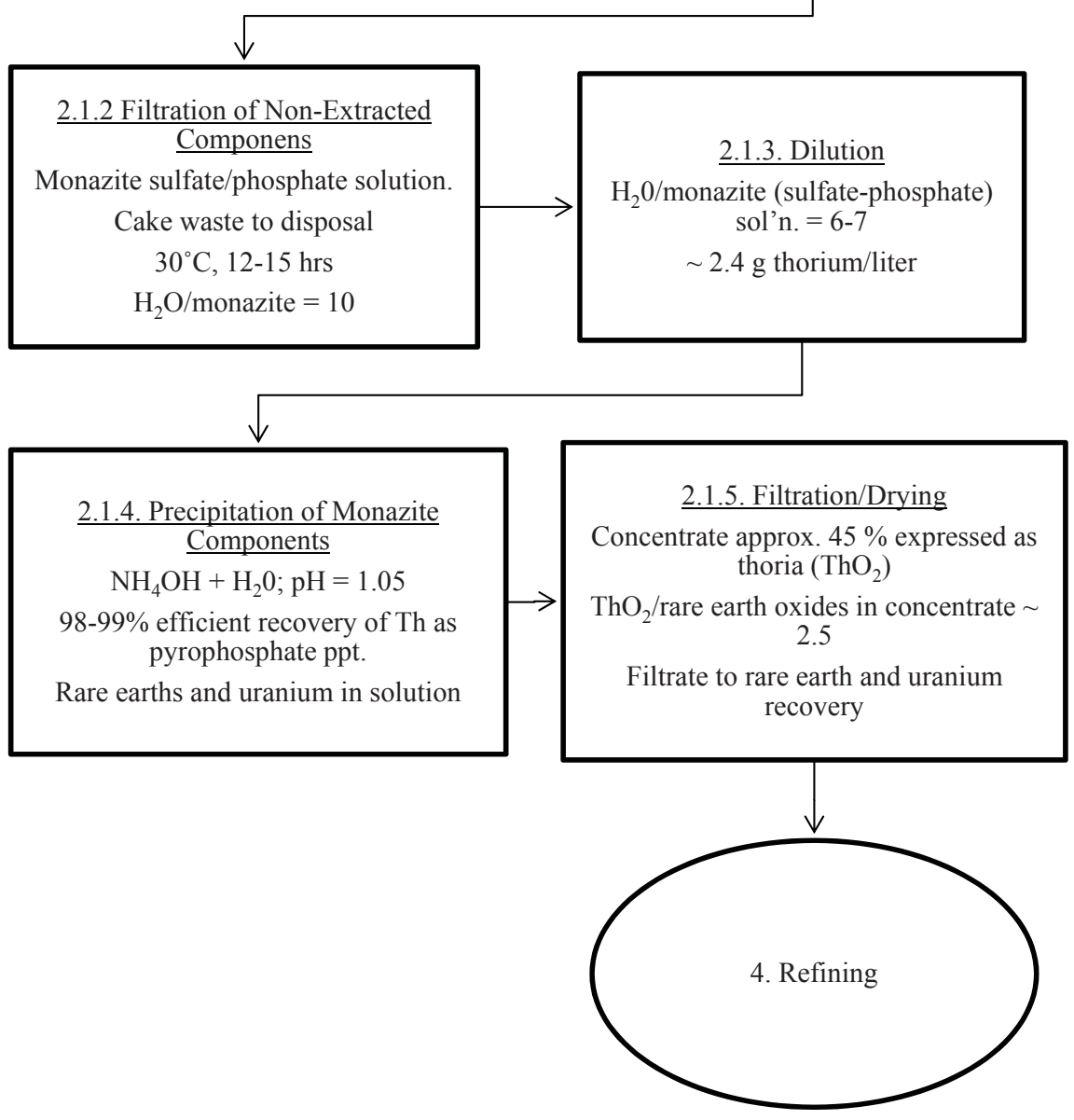

Figure F-3. Sulfuric Acid Digestion Process for Extraction of Thorium. 
Environmental Impacts, Health and Safety Impacts, and Financial Costs of the Front-End of the Nuclear Fuel Cycle

2.2. Caustic Digestion Processes (see Figure F- 4).

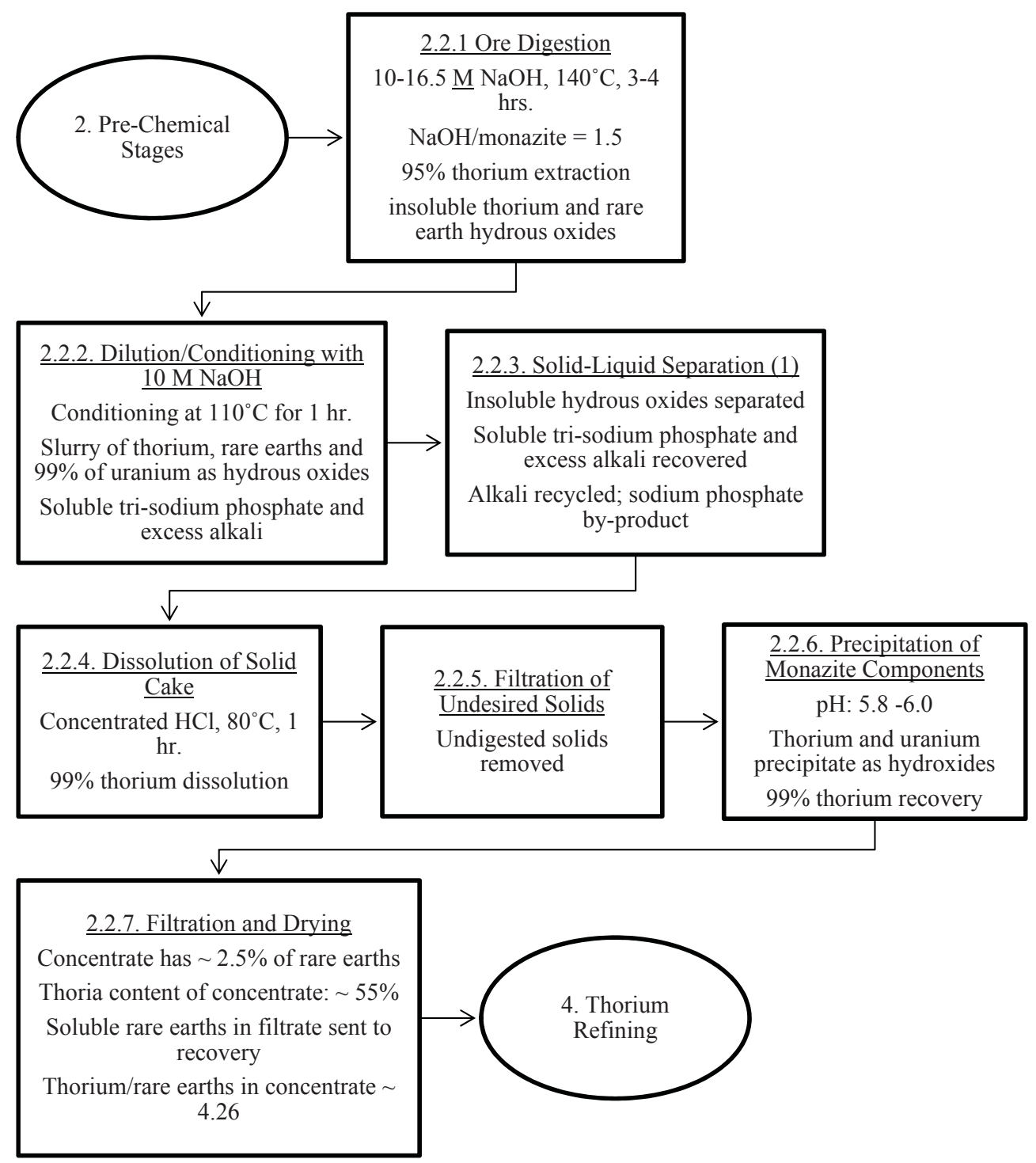

Figure F-4. Caustic (Alkali) Digestion Process for Extraction of Thorium. 


\subsubsection{Ore Digestion}

Like in the acidic version, a strong chemical attack is used to break monazite's mineral structure and dissolve desired (and some undesired) components to an aqueous phase. Monazite particles are added to a solution of concentrated strong base, usually sodium or potassium hydroxide. [Keni 1990] describes using monazite particles at $325 \mathrm{mesh}(44 \mu \mathrm{m})$ with $45 \%$ sodium hydroxide, which with sufficient digestion time can extract $95 \%$ of monazite's thorium content, (i.e., roughly the same as the acidic process). In contrast to the acidic process, this version results in the thorium, uranium, and rare earths being present in the solid phase as hydroxides and oxides, while the phosphates from the monazite end up in the aqueous phase as sodium or potassium phosphate. Separating the phosphates at this early stage is one of the major advantages of the caustic process ([Hughes 1980]).

\subsubsection{Dilution/Conditioning}

The dissolved mixture is diluted to lower the sodium hydroxide concentration to about $30 \%$. Sufficient time (about 1 hour) at 110 degrees Celsius allows the hydroxides (which contain thorium) to form a slurry that is conducive for the subsequent solid liquid separation [Keni 1990].

\subsubsection{Solid-Liquid Separation}

Physical processes are used to separate the aqueous phosphate solution from the solid thorium/uranium/rare earth hydrous oxides. The phosphate solution can be collected as a byproduct.

\subsubsection{Dissolution of Solid Cake}

The thorium-bearing solid phase is dissolved by the addition of a strong acid. The process described by [Keni 1990] involves the addition of concentrated hydrochloric acid, while [Hughes 1980] uses sulfuric acid. Sufficient time is allowed to dissolve at least $99 \%$ of the thorium.

\subsubsection{Filtration of Undesired Solids}

Physical processes are applied to separate the thorium/uranium/rare earth solution from undesired solids. This step is analogous to step 3.1.2 for the acid process.

\subsubsection{Precipitation of Monazite Components}

This step is analogous to 3.1 .3 of the acid separation process. Depending on the process, more than one precipitation reaction could occur. The goal here is to add some agent that results in the formation of a thorium-rich precipitate phase. [Keni 1990] shows the addition of sodium hydroxide to precipitate thorium and uranium hydroxides. This method has the limitation that extra measures must be taken to remove the uranium later in the refining process. However, [Ali 2007] mentions that rinsing with a mixture of sodium carbonate, sodium hydroxide, and hydrogen peroxide can remove as much as $80 \%$ of this uranium. 
Environmental Impacts, Health and Safety Impacts, and Financial Costs of the Front-End of the Nuclear Fuel Cycle

\subsubsection{Filtration and Drying}

Filtration separates the thorium-rich solid phase from the aqueous phase. The aqueous phase is rich in rare earths and is a valuable by-product. The solid phase, containing mostly thorium and uranium hydroxides, is dried and prepared for the refining process. This solid "cake" will still contain a fair amount of rare earth material; this will be removed in subsequent refining steps.

2.3. Summary of Predicted Health and Safety Impacts of Digestion Process

\subsubsection{Impacts of Acid Digestion Process}

Ore Digestion: Significant potential health issues associated with handling concentrated $\mathrm{H} 2 \mathrm{SO} 4$ and $\mathrm{H} 3 \mathrm{PO} 4$

Filtration: Disposal of cake waste is a potential environmental issue

Dilution with Water: No apparent significant issues

Thorium Precipitation: Potential health issue associated with handling $\mathrm{NH} 4 \mathrm{OH}$

Filtration/Drying: Concentrated thorium solid: potential health inhalation radiation hazard from $220 \mathrm{Rn}$

2.3.2. Impacts of Caustic Digestion Process

Ore Digestion: Significant potential health issues associated with handling concentrated $\mathrm{NaOH}$ and $\mathrm{Na} 3 \mathrm{PO} 4$

Dilution/Conditioning: Significant potential health issues associated with handling concentrated $\mathrm{NaOH}$

Solid-Liquid Separation (1): Some potential health hazards associated with handling $\mathrm{NaOH}$ and $\mathrm{Na} 3 \mathrm{PO} 4$

Dissolution of Solid Cake: Significant health hazard associated with handling and vapors from concentrated $\mathrm{HCl}$

Solid-Liquid Separation (2): Potential radon release

Precipitation with $\mathrm{NaOH}$ : Potential health issue associated with handling $\mathrm{NaOH}$

Filtration/Drying: Concentrated thorium solid: small potential inhalation radiation hazard from $220 \mathrm{Rn}$

3. Refining Thorium Concentrates to Nuclear-Grade Material (Figure F-5).

With the starting point of a precipitated thorium "cake" containing perhaps $50 \%$ thorium, additional steps are applied to reduce impurities to the parts-per-million level. There are a number of options that have been researched, though the most experience appears to be in solvent extraction methods.

\subsection{Solvent Extraction}

3.1.1.Dissolution of Thorium Concentrates \& Cerium Reduction 
Environmental Impacts, Health and Safety Impacts, and Financial Costs of the Front-End of the

Nuclear Fuel Cycle

This step achieves two objectives simultaneously. The first is to dissolve the thorium concentrate via a strong acid. As thorium nitrate has historically been the preferred compound for storage and use, nitric acid is the most likely candidate. Furthermore, cerium, a prominent rare earth, has much of the same chemical behavior as thorium in the tetravalent state ([Keni 1990]). Since the only other available charge states for cerium are less than four, a reducing agent must be used. [Keni 1990] shows hydrogen peroxide being used for this purpose.

\subsubsection{Extraction/Scrubbing/Stripping for Uranium}

Uranium mostly follows thorium up until this point and must be separated from the final thorium product. The extent and nature of this step depends on two factors. First, the extraction method used directly impacts how much uranium is present in the refining steps. According to [Keni 1990], the acidic digestion process removes considerably more uranium than the thorium process, so feed from the caustic process might require a greater number of uranium extraction stages. Second, the solvent choice could potentially eliminate the need for this step entirely. The solvent with the most nuclear-related experience is tributyl phosphate (TBP). Its familiarity and availability are strong advantages, but it is more selective for uranium than thorium, thus necessitating a set of stages that keeps most of the thorium in the raffinate. Research is going on with other solvent choices like esters and amines, and should a viable solvent be found that is selective for thorium, the need for these stages could be eliminated entirely. Recent experiments suggest that some amines are capable of this ([Ali 2007]). However, [Mukherjee 2004] suggests that is still standard practice to incorporate a dual extraction scheme even when amines are used. An upside to this is that uranium can be collected as a separate product stream.

A typical stage would probably consist of a mixer-settler system in which entering aqueous and organic phases are pumped and stirred together for a sufficient period of time and then allowed to be separate again by gravity in a calm pool downstream. These stages can be linked in series to produce better separations. A countercurrent layout produces the most efficient separations. 
Environmental Impacts, Health and Safety Impacts, and Financial Costs of the Front-End of the Nuclear Fuel Cycle

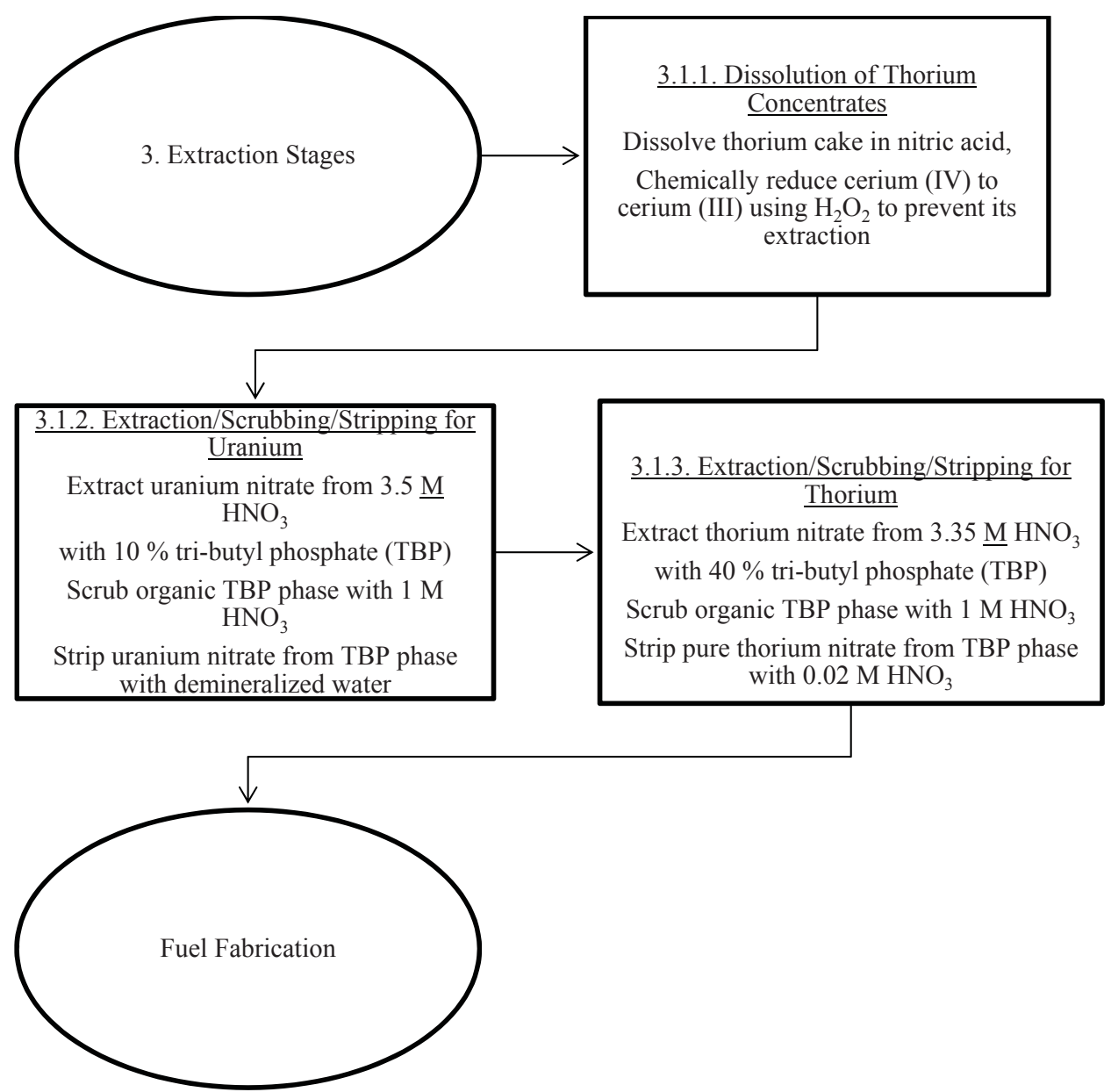

Figure F-5. Refining Thorium to Nuclear Grade.

\subsubsection{Extraction/Scrubbing/Stripping for Thorium}

Once uranium has been separated from thorium, a series of solvent extraction and scrubbing stages should be set up with the intent of obtaining a thorium-rich product stream containing only trace amounts of other elements. The choice of solvent should be selective for thorium versus rare earths and other elements. A number of solvents have been proposed for this objective. [Ali 2007] explored the use of Aliquat 336, a long-chain amine, in kerosene. This species achieved 96\% extraction for thorium, 93\% for cerium (this experiment didn't pre-reduce the cerium), 53\% for uranium, and much less for rare earths in a single stage. Other promising amines include Primene JM-T and Primene 81-R, which were shown by [Amaral 2010] to achieve over $90 \%$ extraction for thorium while less than 
10\% for uranium. [Hughes 1980] identifies Adogen 283. Of course, if uranium levels are already very low, TBP is an option. The extraction steps are used in conjunction with scrubbers that return rare earth impurities to the aqueous phase [PNL 1980b].

This process would also consist of a series of mixer-settlers, most likely laid out in a counter-current configuration. The number of stages could range from 3 to 12 (amalgamation of multiple sources).

Once purified, the thorium in the product stream must be removed from the organic phase. A strong acid is usually used for this purpose. If thorium nitrate is the desired product, nitric acid is certainly the ideal choice here. However, [Mukherjee 2004] indicates that in recent times, thorium oxalate may be a more desirable product since it is safer to store and transport. For other end products, hydrochloric acid ([Ali 2007]) is also an option. [Hughes 1980] instead recommends a base, specifically sodium carbonate or ammonium carbonate.

To recover most of the thorium, multiple stages are used.

\subsection{Other Refining Methods}

\subsubsection{Ion Chromatography}

[Borai 2002] describes the use of ion chromatography columns to separate rare earths, thorium, and uranium. However, scaling up such a process to industrial levels would likely be infeasible.

\section{A Summary of Bastnasite Separation}

Bastnasite is probably the main mineral alternative to monazite as a thorium source. It is already mined in China as a source of rare earths. Bastnasite and monazite are sometimes also found together, as in some portions of the vast Chinese deposits. Based on an article by [Li 2004], the process of isolating thorium from this ore is somewhat similar to the monazite processing, involving a series of physical and chemical separation processes. Bastnasite physical processing employs flotation in early stages and documented processes appear to favor acid digestion and the use of much higher processing temperatures than monazite during chemical processing steps [Gupta 2005]. The ore is digested by a strong acid, and the thorium is separated from the rare earths by solvent extraction using an amine.

\section{Extraction and Refining Process Flowsheet Case Studies}

Given the various options for refining thorium, many potential flowsheets could be envisioned. This detailed analysis considers one particular case, the extraction of thorium from Indian beach sand monazite using the caustic digestion process followed by two-part solvent extraction with TBP. This uses process details given by [Keni 1990] supplanted by mineral information from [USGS 1958] where relevant.

The flowsheets are divided into two parts, one for caustic digestion/extraction (Figure F-6) and another for refining to nuclear grade (Figure F-7). The primary exit stream first part directly feeds the second part. The materials used in these processes are given in Tables F-9 and F-10, respectively. The flowsheet is normalized per metric ton of thorium oxide product. Thorium, rare earths, and uranium are, unless otherwise stated, given as oxide equivalents. For instance, even though thorium is present as thorium hydroxide throughout much of the extraction process, its mass will still be represented as equivalents of thorium oxide. 
Environmental Impacts, Health and Safety Impacts, and Financial Costs of the Front-End of the Nuclear Fuel Cycle

In the event of thorium being produced as byproduct of rare earths, most of the extraction steps would already be accounted for in the effort to isolate the rare earths content. The processes unique to the thorium stream begin with the collection of the solid precipitate stream of thorium and uranium. The processes used to isolate thorium would result in a secondary rare earth stream which could be added to the primary rare earth product stream. Though this report focuses on the production of thorium as a by-product or co-product of rare earths, it is worth noting that this particular refining process also produces two smaller product streams: one with trisodium phosphate (TSP) and one with uranium.

The ratios of monazite components are based on [Keni 1990] and, where needed, [USGS 1958]. Note that there are potential modifications that could be made to this process, for instance, the use of an amine as an extraction reagent rather than tributyl phosphate (TBP). In some instances, [Keni 1990] does not thoroughly specify a stream's contents, and assumptions are made when necessary. This is the case for the hydrochloric acid supply, the hydrogen peroxide supply, and the largest nitric acid supply. In these instances, feed amounts are estimated based on the minimum chemical demand to react with approximately all thorium, uranium, and rare earths (or with all cerium in the case of hydrogen peroxide).

In addition to the steps shown, one additional component would need to be provided at this process' exit stream. Though thorium is shown in terms of thorium oxide equivalents in this flowsheet, the final product of the refinery is actually thorium nitrate tetrahydrate. This material would need undergo calcination (heating in the presence of air) in order to be converted to thorium oxide, the desired form for fuel fabrication. This heating would contribute to the energy demand of the process; however, it is expected that this treatment would result in negligible loss of thorium, and thus the thorium oxide equivalent balance would remain unchanged.

For reference, a blue box represents a feed stream, a purple box represents a recycled stream, a red box represents a waste stream, and a green box represents a product stream. Purple arrows represent recycled streams.

Table F-9. Chemical Requirements for Indian Monazite Refining Process

\begin{tabular}{|c|c|c|}
\hline Material & Amount used & per \\
\hline Monazite & $15,000 \mathrm{~kg}$ & MT ThO2 \\
\hline Water & $190,000 \mathrm{~kg}$ & MT ThO2 \\
\hline Sodium Hydroxide & $23,000 \mathrm{~kg}$ & MT ThO2 \\
\hline Hydrochloric Acid & $7,400 \mathrm{~kg}$ (plus excess) & MT ThO2 \\
\hline Nitric Acid & $2,500 \mathrm{~kg}$ (plus excess) & MT ThO2 \\
\hline Hydrogen Peroxide & $10 \mathrm{~kg}$ (plus excess) & MT ThO2 \\
\hline Kerosene & $14,000 \mathrm{~kg}$ & Facility (recycled) \\
\hline TBP & $6,200 \mathrm{~kg}$ & Facility (recycled) \\
\hline
\end{tabular}


Environmental Impacts, Health and Safety Impacts, and Financial Costs of the Front-End of the

Nuclear Fuel Cycle

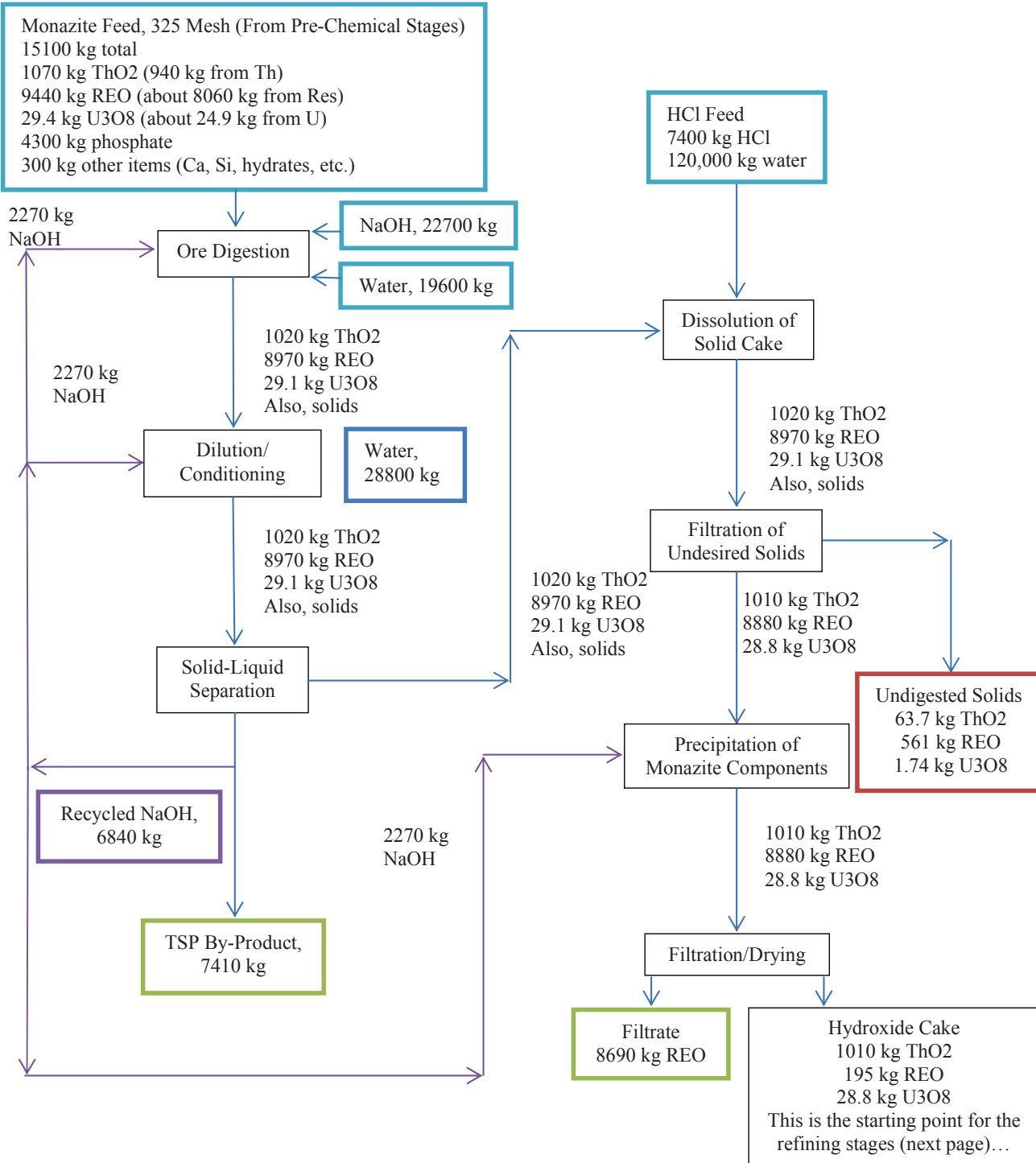

Figure F-6. Flowsheet for Caustic Digestion and Extraction of Indian Monazite 
Environmental Impacts, Health and Safety Impacts, and Financial Costs of the Front-End of the Nuclear Fuel Cycle

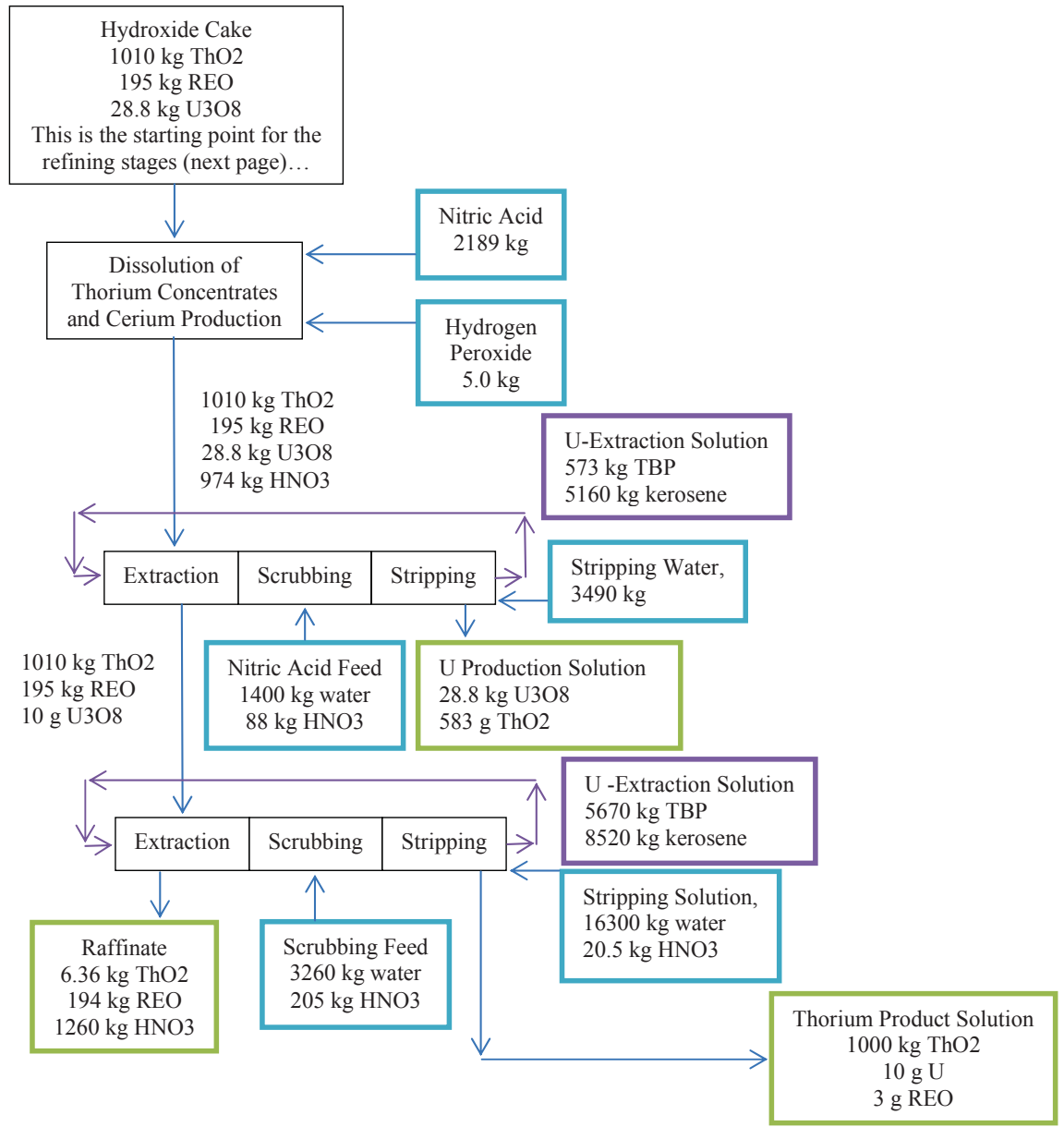

Figure F-7. Flowsheet for Refining following Caustic Digestion and Extraction of Indian Monazite

Table F-10. Products Generated by Indian Monazite Refining Process

\begin{tabular}{|c|c|c|}
\hline Material & Amount made & per \\
\hline Thorium Oxide & $1,000 \mathrm{~kg}$ & MT ThO2 \\
\hline Uranium Oxide & $29 \mathrm{~kg}$ & MT ThO2 \\
\hline Trisodium phosphate (TSP) & $7,400 \mathrm{~kg}$ & MT ThO2 \\
\hline Rare Earth Oxides & $\begin{array}{c}8,700 \mathrm{~kg} \text { (and possibly another } 200 \mathrm{~kg} \text { if raffinate } \\
\text { recovery is viable) }\end{array}$ & MT ThO2 \\
\hline
\end{tabular}


6. References.

[Ali 2007] Ali, A. M. I. et al. "Recovery of Thorium (IV) from Leached Monazite Solutions Using Counter-Current Extraction”. International Journal of Mineral Processing, Vol. 81, 2007, pp. 217 223

[Amaral 2010] Amaral, Janubia C. B. S. and Morais, Carlos A. "Thorium and Uranium Extraction from Rare Earth Elements in Monazite Sulfuric Acid Liquor Through Solvent Extraction", Minerals Engineering, Vol. 23, 2010, pp. 498-503

[Bedinger 2013] Bedinger, George M. Titanium Mineral Concentrates Mineral Commodity Summary. Issue brief. USGS, 2013. Web. Mar. 2013.

$<$ http://minerals.usgs.gov/minerals/pubs/commodity/titanium/mcs-2013-timin.pdf>.

[Borai 2002] Borai, E. H. and Mady, A. S. "Separation and Quantification of U-238, Th-232, and Rare Earths in Monazite Samples by Ion Chromatography Coupled with On-Line Flow Scintillation Detector", Applied Radiation and Isotopes, Vol. 57, Issue 4, pp. 463-469

[Gupta 2005] Gupta, C. K. and Krishnamurthy, Nagaiyar. Metallurgy of Rare Earths. CRC Press, 2005.

[Hughes 1980] Hughes, K.C . and Singh, R. "The Isolation of Thorium from Monazite by Solvent Extraction, Part I". Hydrometallurgy, Vol. 6, Issues 1-2, Sep. 1980, pp. 25-33

[Iluka 2011] Iluka Resources. Iluka Review. 2011. http://www.iluka.com/docs/annual-reports/ilukareview 2011AF399505AA89.pdf?sfvrsn=4

[Kaya 2003] Kaya, M. and Bozkurt, V. Thorium as a Nuclear Fuel, International Mining Congress and Exhibition of Turkey 2003, ISBN 975-395-605-3.

[Keni 1990]. Keni, V.S. "Extraction and Refining of Thorium". Thorium Utilization: Proceedings of the Indo-Japan Seminar on Thorium Utilization, Dec. 10-13, 1990.

[Li 2004] Li, Deqian et al. "Separation of Thorium (IV) and Extracting Rare Earths from Sulfuric and Phosphoric Acid Solutions by Solvent Extraction Method". Journal of Alloys and Compounds, Vol. 374, Issues 1-2, July 2004, pp. 431-433

[Lynas Corporation] Lynas Advanced MaterialsPlant.

http://www.lynascorp.com/SiteCollectionDocuments/Fact\%20Sheets/Lynas_Advanced_Material_Pla $\underline{\text { nt.pdf }}$

[Molycorp 2013], “Molycorp Announces New Rare Earth Complex Is Operational and Ramping Up Toward Full-Scale Production”. 10 Jan. 2013.

[Mukherjee 2004] Mukherjee, T. K. "Processing of Indian Monazite for the Recovery of Thorium and Uranium Values". Chapter of C. Ganguly's Characterisation and Quality Control of Nuclear Fuels (A collection of papers at the International Conference on Characterisation and Quality)

[ORNL 1978] Tennery, V. J. et al. "Environmental Assessment of Alternative FBR Fuels: Radiological Assessment of Airborne Releases from Thorium Mining and Milling”, ORNL/TM-6474, Oct. 1978

[PNL 1980a] Young, J. K. et al. "Economics of Large-Scale Thorium Oxide Production: Assessment of Domestic Resources", PNL-3150, Feb. 1980

[PNL 1980b] Weakley, S. A. et al. "Environmental Control Technology for Mining, Milling, and Refining Thorium”. PNL-3253, Feb. 1980 
Environmental Impacts, Health and Safety Impacts, and Financial Costs of the Front-End of the Nuclear Fuel Cycle

[Roche Engineering 2012] "Technical Report on the Mineral Reserves and Development of the Bull Hill Mine”. Roche Engineering. April 2012

[SRK 2010]. SRK Consulting. "Engineering Study for Re-Start of the Mountain Pass Rare Earth Element Mine and Processing Facility Mountain Pass, California”. April 28, 2010.

http://www.sec.gov/Archives/edgar/data/1489137/000095012310065239/d74323fwfwp.htm\#tocpage

[Staatz et al 1979] Staatz, M.H., Armbrustmacher, T.J., Olson, J.C., Brownfield, I.K., Brock, M.R., Lemons, J.F., Jr., Coppa, L.V., Clingan, B.V., 1979, Principal thorium resources in the United States: U.S. Geological Survey Circular 805, $42 \mathrm{p}$

[TetraTech 2013], "Preliminary Economic Assessment on the Bokan Mountain Rare Earth Element Project, Near Ketchikan Alaska”. Tetra Tech. January 2013.

[USGS 1958] USGS, Systematic Mineralogy of Uranium and Thorium, Geological Survey Bulletin 1064, 1958

[Van Gosen 2013] Van Gosen, Brad, U.S. Geological Survey. Personal Communication, February 2013.

[World Nuclear Association 2010] "Mineral Sands." World-nuclear.org. World Nuclear Association, Dec. 2010. <http://www.world-nuclear.org/info/inf30a.html>. 


\section{Appendix G}

\section{Review of Impacts from Laser Enrichment Technologies}

The NRC issued a construction and operation license for the General Electric (GE)-Hitachi Global Laser Enrichment LLC (GLE) facility in late September 2012. The license grants GEH permission to construct, operate, and eventually, decommission a laser-based uranium enrichment facility, capable of enriching uranium up to $8 \mathrm{wt} \%{ }^{235} \mathrm{U}$. The proposed GLE facility, located near Wilmington, North Carolina, is expected to employ the Separation of Isotopes by Laser Excitation (SILEX) process. The concept for Molecular Laser Isotope Separation (MLIS), which preceded SILEX, was originally conceived in the 1960s. The technology is based on the principle of photo-ionization; uranium in the gaseous $\mathrm{UF}_{6}$ form is bombarded with tuned laser radiation, which breaks the molecular bond holding on one of the six fluorine atoms to a ${ }^{235} \mathrm{U}$ atom. Solid ${ }^{235} \mathrm{UF}_{5}$ is then disassociated from the unaffected gaseous ${ }^{238} \mathrm{UF}_{6}$ molecules.

Apart from the actual step in the enrichment process that involves the use of lasers, the processes used for the receipt and handling of feedstock $\mathrm{UF}_{6}$ and the enriched and depleted $\mathrm{UF}_{6}$ streams are very similar to those used at other enrichment facilities. Annual mass flows and general information regarding the GLE facility is given in Table G-1. The GLE facility is expected to have a 40 year operation lifetime, with an initial planned maximum target production capacity of 6,000 kSWU per year. Approximately ninehundred Type $48 \mathrm{Y}$ cylinders are expected to be processed annually. Depleted $\mathrm{UF}_{6}$ tails are expected to be stored onsite.

In February 2012, NRC staff issued the Final EIS (NRC 2012b) for the GLE facility. Environmental impacts that could be determined from the EIS are available in Table G-2; Table G-3 displays the calculations leading from the raw data in Table G-1 to the final value appearing in Table G-2. Land and water use metrics are calculated following the procedures outlined in Section 4.1.1 and Section 4.1.2, respectively. Estimates of the energy consumption and costs associated with the SILEX enrichment process were unable to be made from (NRC 2012b). Facility construction was expected to begin in 2012, and continue through 2020. Initial production would commence in 2014 with full capacity attained in 2020. Prior to license expiration in 2052, GLE will decide whether or not to renew its operating license, or decontaminate and decommission the facility.

Even among plants implementing the same technology, land and water use impacts can vary greatly from site to site as they are affected by the amount and value of land and water immediately available. The proposed GLE Facility is located in an unincorporated portion of New Hanover County, which has zoning jurisdiction over the facility. The largest municipality in the county is Wilmington, which has a population of approximately 100,000 . At the Wilmington site, groundwater is extracted from the Peedee sand aquifer, and must undergo treatment prior to use at Wilmington facilities.

Land and water use impacts for the GLE facility do not differ markedly from those of the reference NEF centrifuge enrichment facility identified in Section 5.4. Expected land and water usage are 4.44 $\mathrm{m}^{2} / \mathrm{kSWU}$ and $1.98 \times 10^{4} \mathrm{~L} / \mathrm{kSWU}$, respectively, at the GLE facility, compared with land and water usage of $8.99 \mathrm{~m}^{2} / \mathrm{kSWU}$ and $2.92 \times 10^{4} \mathrm{~L} / \mathrm{kSWU}$, respectively, at the NEF facility. In general, these natural resources are scarcer near the GLE facility than near the NEF facility. The nearest permanent resident to the NEF site is 4.3 kilometers ( 2.6 miles) west of the facility, but several residential developments are proposed in the directly adjacent to the GLE site. The GLE facility withdraws water from the Peedee Aquifer, which has a hydraulic conductivity near $12 \mathrm{~m} / \mathrm{d}$, while the NEF facility utilizes the Ogallala 
Environmental Impacts, Health and Safety Impacts, and Financial Costs of the Front-End of the Nuclear Fuel Cycle

Aquifer, which has a hydraulic conductivity near $70 \mathrm{~m} / \mathrm{d}$. It should be noted that while land and water use impacts are similar for the two enrichment technologies, there may be significant differences in energy use and financial costs; however, data was unavailable for these two metrics.

Table G-1. GLE Facility information.

\begin{tabular}{|c|c|c|c|}
\hline & Value & Units & Source \\
\hline \multicolumn{4}{|c|}{ A. Annual mass flows and general information for GLE facility } \\
\hline Facility lifetime & $4.00 \mathrm{E}+01$ & $\mathrm{a}$ & [NRC 2012b] \\
\hline Maximum production & $6.00 \mathrm{E}+03$ & kSWU/a & [NRC 2012b] \\
\hline Type $48 \mathrm{Y}$ cylinders processed & $9.00 \mathrm{E}+02$ & cylinders/a & [NRC 2012b] \\
\hline \multicolumn{4}{|l|}{ B. Raw data for Table 2 entries } \\
\hline Land & $2.63 \mathrm{E}+02$ & acres & [NRC 2012b] \\
\hline Water & $8.60 \mathrm{E}+04$ & $\mathrm{gal} / \mathrm{d}$ & [NRC 2012b] \\
\hline
\end{tabular}

Table G-2. Environmental Impacts associated with GLE SILEX Enrichment Facility.

\begin{tabular}{|c|c|c|c|}
\hline & Value & Units & Source \\
\hline \multicolumn{4}{|l|}{ Main Product } \\
\hline Outflow & $1.00 \mathrm{E}+00$ & $\mathrm{kSWU}^{1}$ & \\
\hline \multicolumn{4}{|l|}{ Feed } \\
\hline Inflow (NU) & $1.37 \mathrm{E}+00$ & $\mathrm{MT} \mathrm{U}^{1}$ & \\
\hline \multicolumn{4}{|l|}{ Product } \\
\hline Outflow (Enriched U) & $1.60 \mathrm{E}-01$ & $\mathrm{MT} \mathrm{U}^{1}$ & \\
\hline Outflow (Depleted U) & $1.21 \mathrm{E}+00$ & $\mathrm{MT} \mathrm{U}^{1}$ & \\
\hline \multicolumn{4}{|l|}{ Natural Resource Use } \\
\hline Land & $4.44 \mathrm{E}+00$ & $\mathrm{~m}^{2}$ & [NRC 2012b] \\
\hline Water & $1.98 \mathrm{E}+04$ & $\mathrm{~L}$ & [NRC 2012b] \\
\hline
\end{tabular}




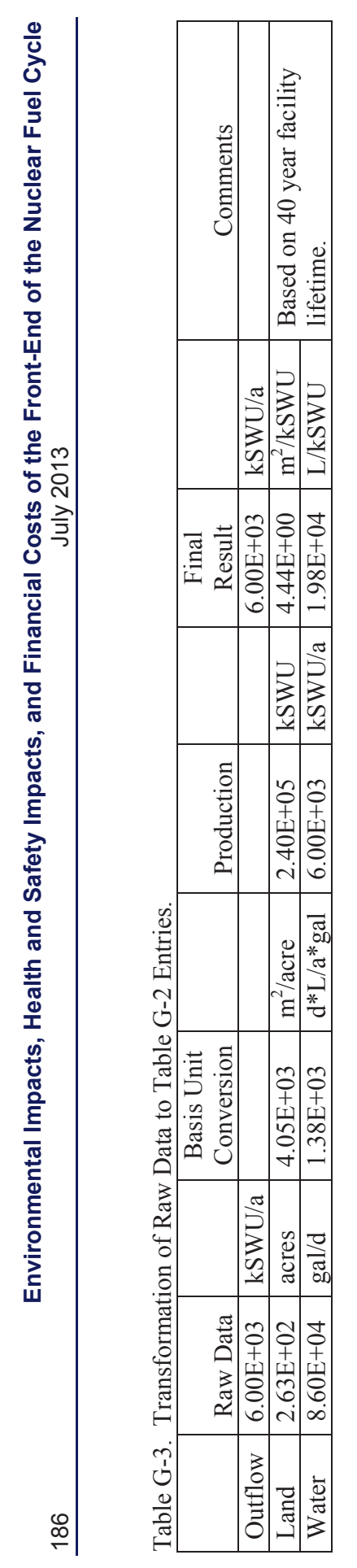


Environmental Impacts, Health and Safety Impacts, and Financial Costs of the Front-End of the

Nuclear Fuel Cycle

July 2013

\section{Appendix $\mathrm{H}$}

\section{Calculation of FEFC Process Inputs and Outputs}


Environmental Impacts, Health and Safety Impacts, and Financial Costs of the Front-End of the Nuclear Fuel Cycle July 2013 


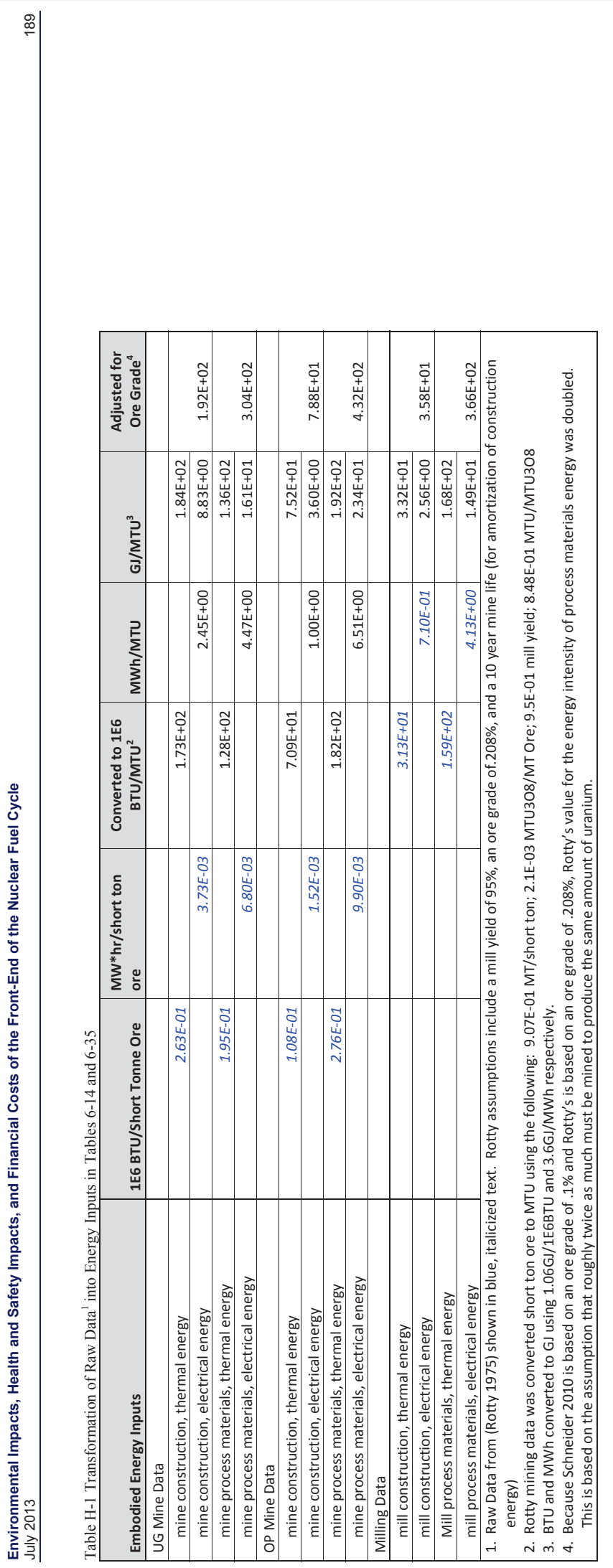




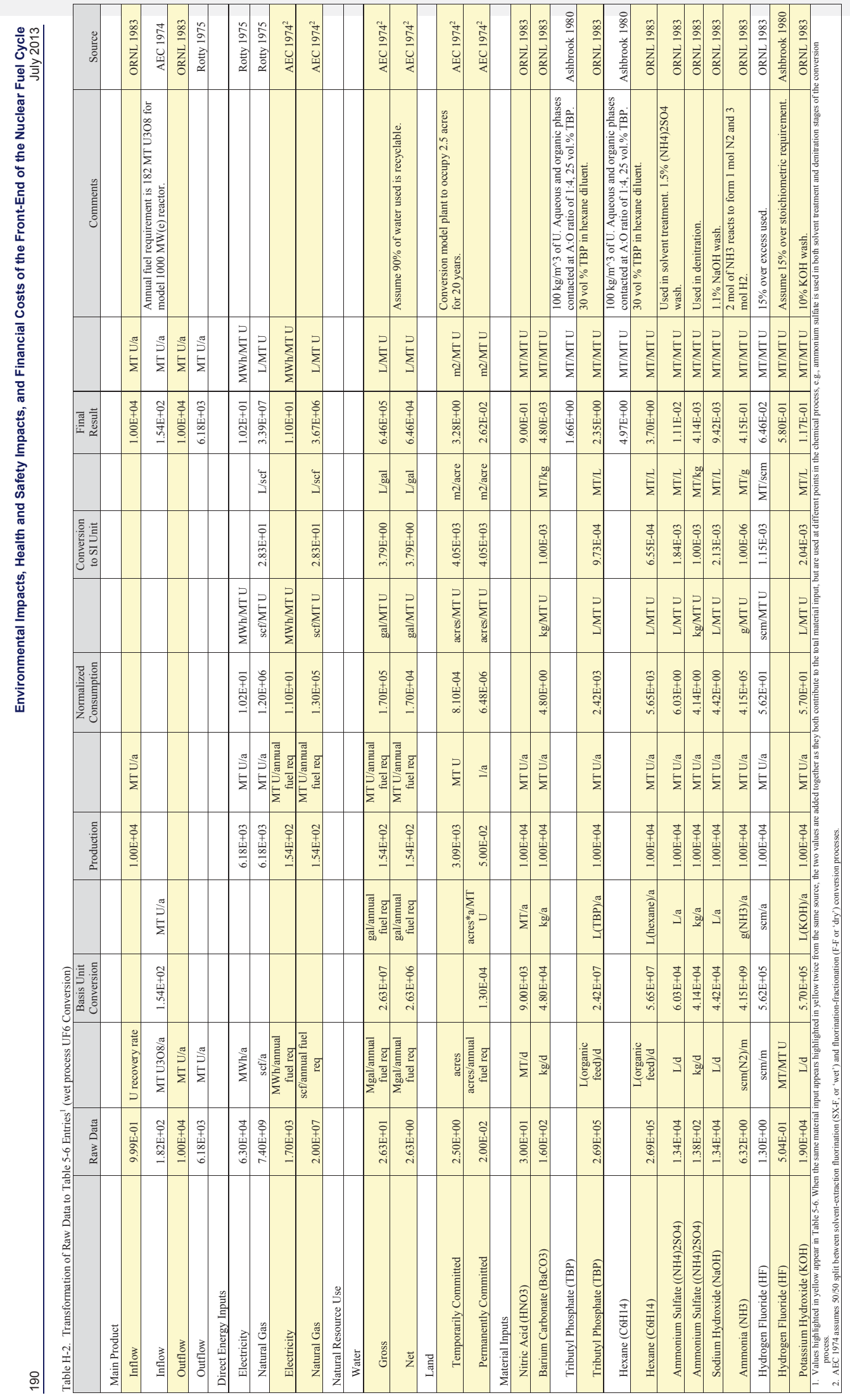




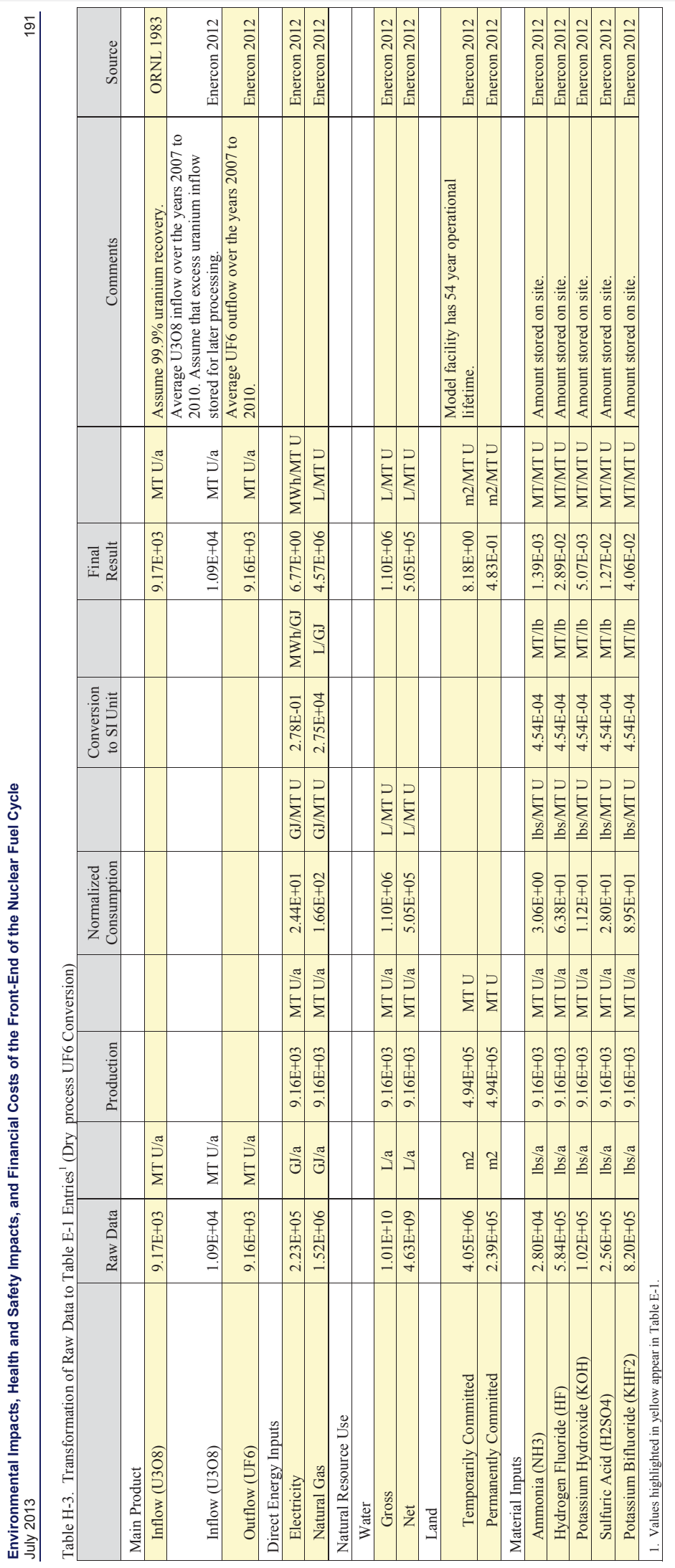




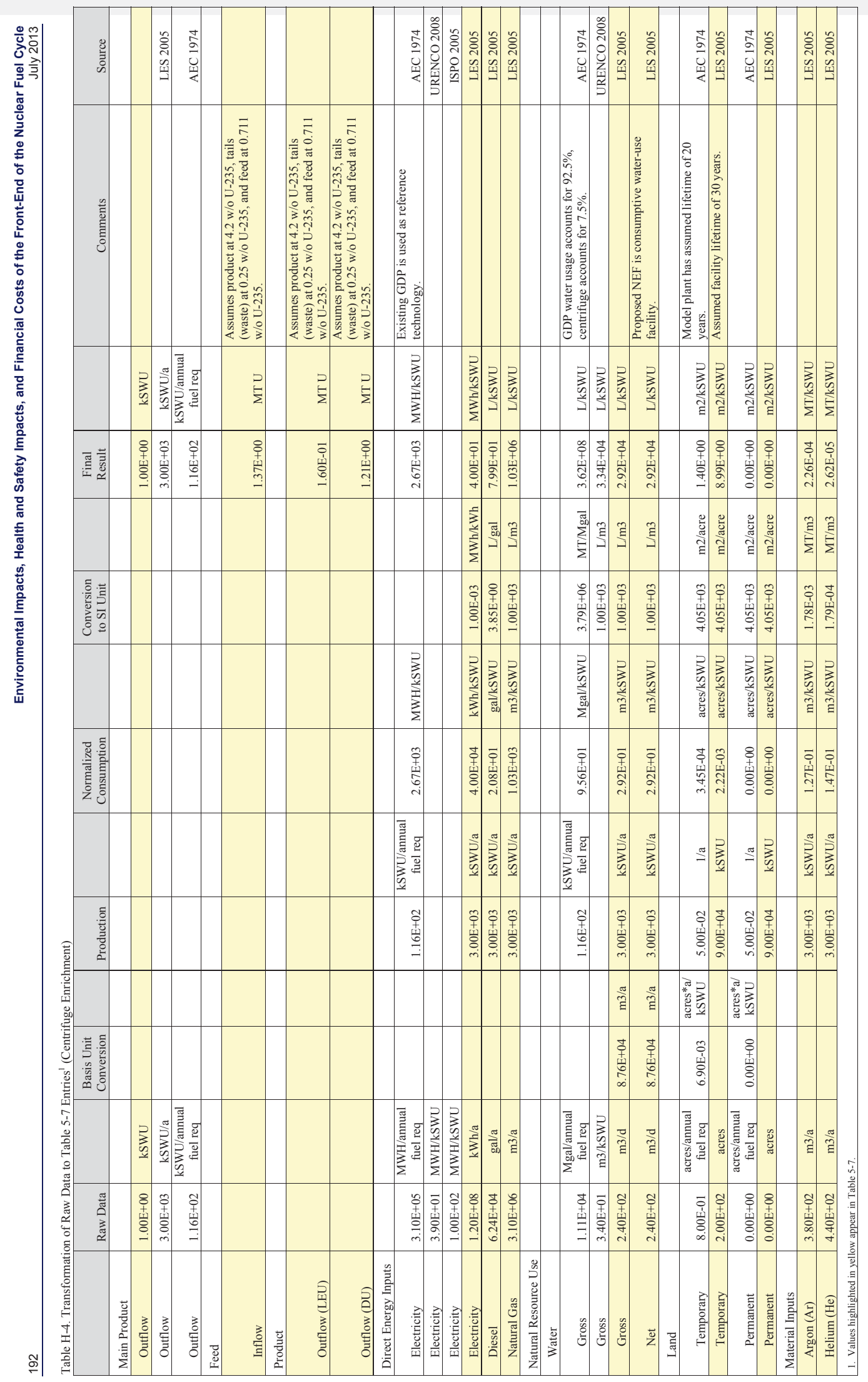




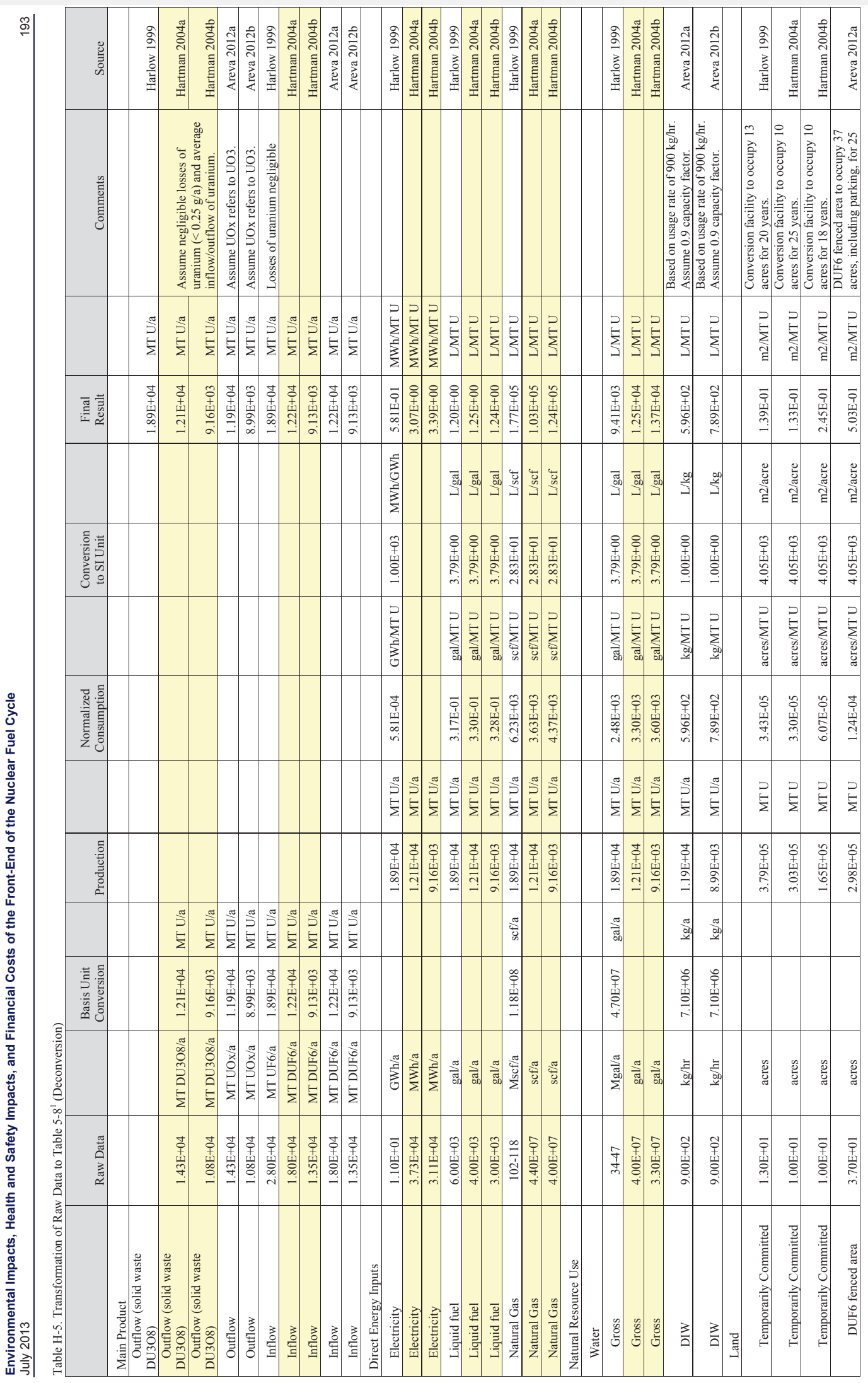




\begin{tabular}{|c|c|c|c|c|c|c|c|c|c|c|c|c|c|c|c|c|c|c|c|c|}
\hline 总 & 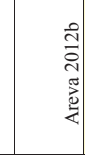 & 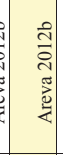 & 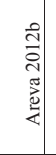 & 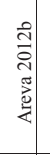 & 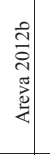 & 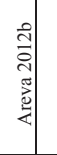 & 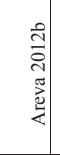 & 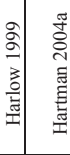 & 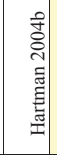 & | & | & 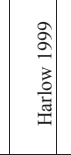 & 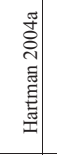 & 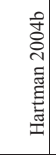 & 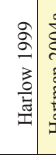 & 榇 & 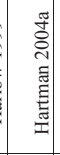 & 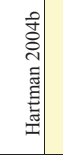 & | & $\stackrel{8}{\pi}$ \\
\hline 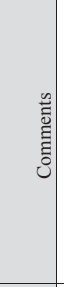 & 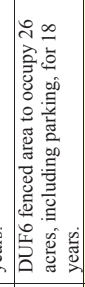 & 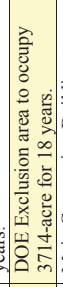 & 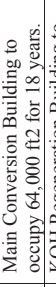 & \begin{tabular}{c|c} 
\\
0 \\
0 \\
0
\end{tabular} & 象 & 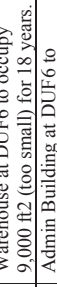 & 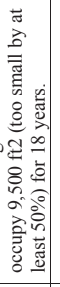 & 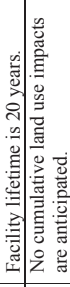 & 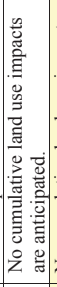 & 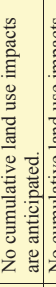 & 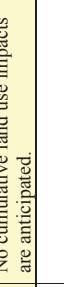 & 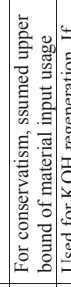 & 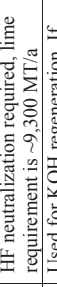 & 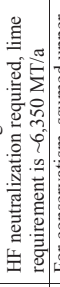 & 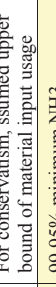 & 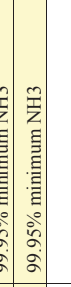 & 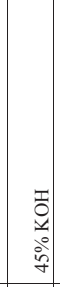 & 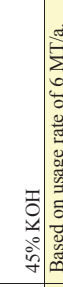 & 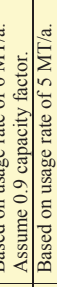 & 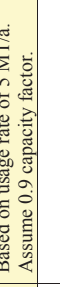 \\
\hline & 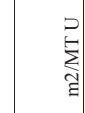 & 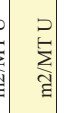 & 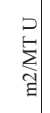 & 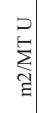 & 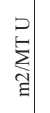 & $\begin{array}{l}\vec{D} \\
\stackrel{\vec{t}}{\mid} \\
\stackrel{\Xi}{\Xi}\end{array}$ & : & 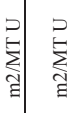 & 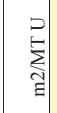 & : & 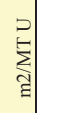 & 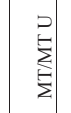 & 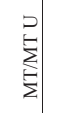 & $\begin{array}{l}\text { D. } \\
\stackrel{t}{\mid} \\
\frac{1}{2}\end{array}$ & 包 & $=$ & 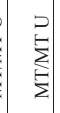 & 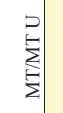 & 主 & \\
\hline 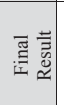 & $\begin{array}{l} \\
\overline{0} \\
\dot{0} \\
0 \\
0 \\
0\end{array}$ & \begin{tabular}{|c|c|} 
\\
$\vdots$ \\
$\vdots$ \\
$\vdots$ \\
$\vdots$
\end{tabular} & 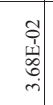 & 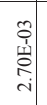 & 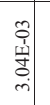 & 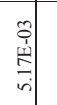 & 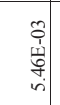 & 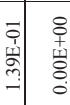 & \begin{tabular}{|c|} 
\\
\\
$\mathbf{1}$ \\
$\vdots$ \\
0
\end{tabular} & $\begin{array}{l} \\
\\
\vdots \\
\vdots \\
\vdots \\
\end{array}$ & \begin{tabular}{l|l} 
\\
$\vdots$ \\
$\vdots$ \\
0 \\
0
\end{tabular} & 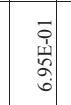 & 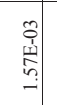 & | & 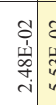 & 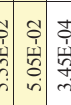 & 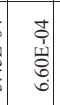 & 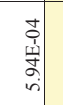 & 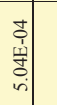 & \\
\hline & & $\frac{2}{0}$ & 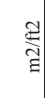 & ฐี & ฐ & $\begin{array}{l}\mathfrak{a} \\
\stackrel{\Xi}{\Xi}\end{array}$ & $\begin{array}{l}\text { ज्ञ } \\
\text { ․․ }\end{array}$ & 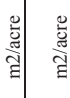 & 总 & : & : & $\stackrel{\overrightarrow{\hat{E}}}{\mathrm{\Sigma}}$ & & 亭 & $\stackrel{े}{\frac{\hat{t}}{2}}$ & 妾言 & & $\frac{\mathrm{s}}{\mathrm{s}}$ & & \\
\hline 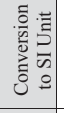 & 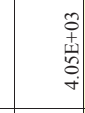 & 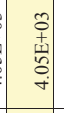 & 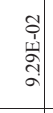 & \begin{tabular}{l} 
: \\
\multirow{3}{\vdots}{} \\
$\vdots$
\end{tabular} & 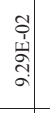 & 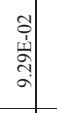 & 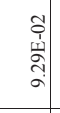 & 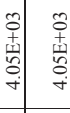 & 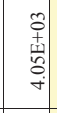 & 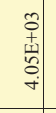 & 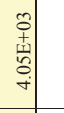 & 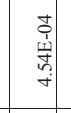 & & 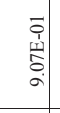 & 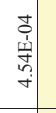 & 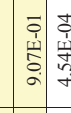 & & 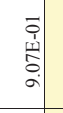 & & \\
\hline & 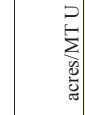 & 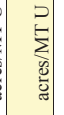 & 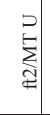 & D્a & 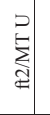 & 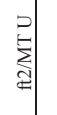 & 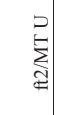 & 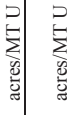 & 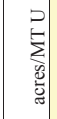 & 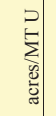 & | & 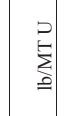 & & 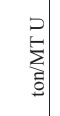 & $\begin{array}{l}\vec{t} \\
\stackrel{D}{=}\end{array}$ & : & & 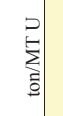 & & \\
\hline 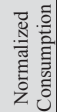 & | & 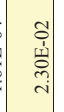 & $\begin{array}{r}\overrightarrow{0} \\
\overrightarrow{0} \\
\dot{3} \\
\dot{m}\end{array}$ & 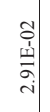 & 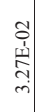 & 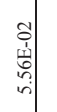 & 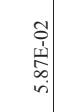 & 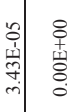 & $\mid \begin{array}{l}0 \\
\vdots \\
\vdots \\
\vdots \\
0 \\
0\end{array}$ & $\begin{array}{l}\stackrel{8}{0} \\
\vdots \\
\vdots \\
: \\
0\end{array}$ & $\begin{array}{l}\text { o } \\
\vdots \\
\vdots \\
\vdots \\
:\end{array}$ & 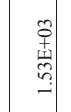 & & | & $\begin{array}{c}\overrightarrow{0} \\
\text { 索 } \\
\dot{f} \\
i\end{array}$ & 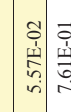 & & 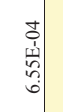 & & \\
\hline & $\vec{\xi}$ & $\vec{b}$ & $\overrightarrow{\mathrm{E}}$ & $\overrightarrow{\mathrm{z}}$ & $\overrightarrow{5}$ & $\vec{E}$ & $\vec{b}$ & $\vec{\Sigma}$ & $\overrightarrow{5}$ & $\vec{E}$ & $\vec{y}$ & 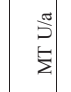 & $\stackrel{s}{5}$ & 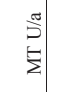 & $\stackrel{m}{5}$ & $\frac{5}{5}$ & 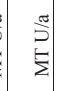 & 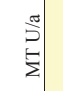 & $\stackrel{n}{5}$ & \\
\hline 部 & 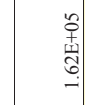 & 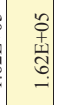 & 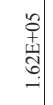 & 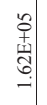 & 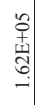 & 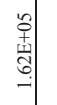 & 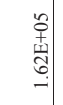 & 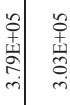 & 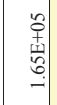 & 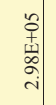 & 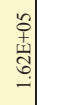 & 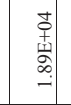 & 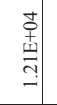 & $\begin{array}{c}0 \\
\stackrel{0}{0} \\
\stackrel{4}{0} \\
\vdots \\
0\end{array}$ & 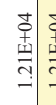 & 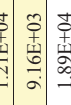 & 怘 & 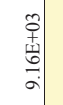 & 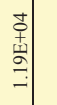 & $\begin{array}{cc}0 \\
\vdots \\
\mathbf{1} \\
\vdots \\
\infty \\
\infty\end{array}$ \\
\hline & & & & & & & & & & & & $\stackrel{0}{=}$ & & & $\stackrel{\frac{\pi}{g}}{=}$ & $\stackrel{\pi}{\stackrel{2}{g}}$ & & & & \\
\hline 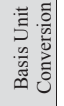 & & & & & & & & & & & & 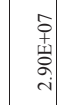 & & & |ct & 。韋龺 & & & & \\
\hline & | & 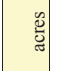 & $\nsubseteq$ & $\nsubseteq$ & $\nsubseteq$ & $q$ & $\nsubseteq$ & 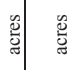 & |ֶّ & 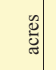 & : & 总 & $\overline{\mathrm{E}}$ & పूّ & $\stackrel{m}{\bar{z}}$ & $\stackrel{5}{2}$ & 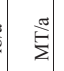 & $\tilde{\Xi}$ & 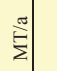 & $\sum$ \\
\hline 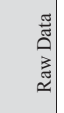 & 产 & 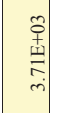 & 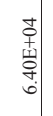 & 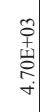 & 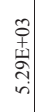 & 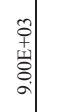 & & 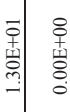 & \begin{tabular}{|c|c}
0 \\
0 \\
$\mathbf{1}$ \\
0 \\
0
\end{tabular} & 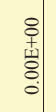 & $\begin{array}{l}\text { : } \\
\vdots \\
\vdots \\
\vdots\end{array}$ & ิે & 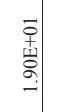 & 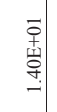 & 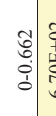 & 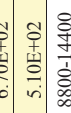 & $\begin{array}{c}0 \\
0 \\
\mathbf{1} \\
\vdots \\
\infty \\
\infty\end{array}$ & 章 & 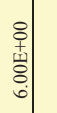 & 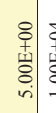 \\
\hline & 壭 & 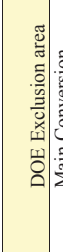 & 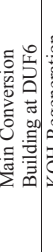 & & 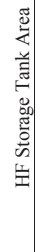 & 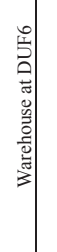 & 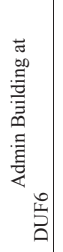 & 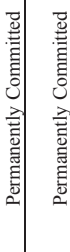 & 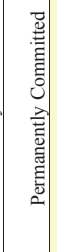 & 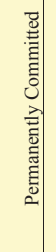 & 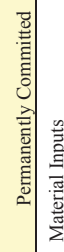 & 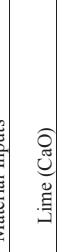 & 离 & 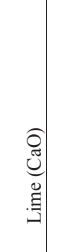 & 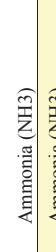 & : & 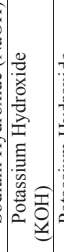 & 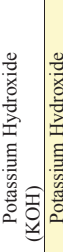 & 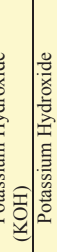 & 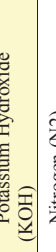 \\
\hline
\end{tabular}




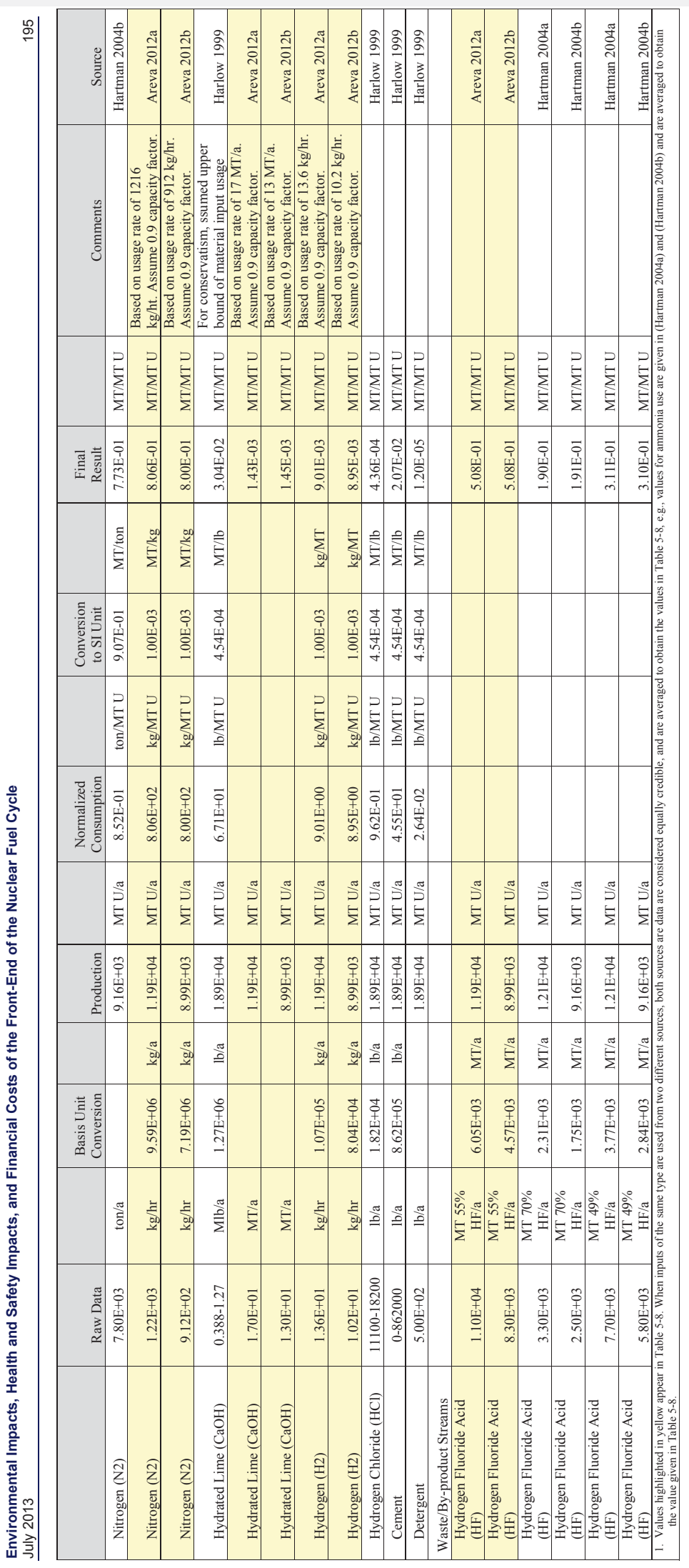




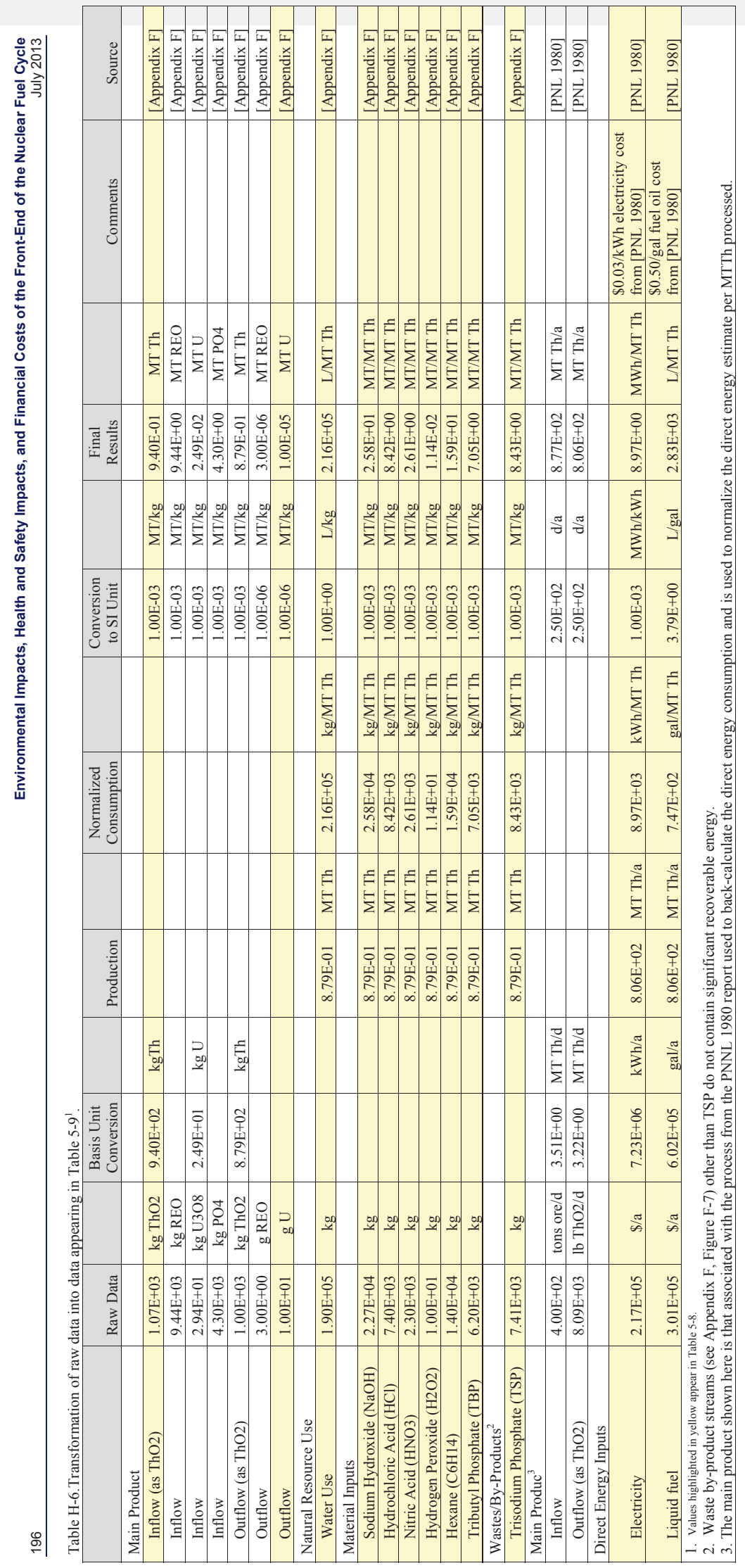

